\title{
Rb-Promoted Molybdenum Carbide Nano-Catalysts for Higher Alcohol Synthesis from Syngas
}

\author{
A Dissertation \\ Presented to \\ the faculty of the School of Engineering and Applied Science \\ University of Virginia \\ In Partial Fulfillment \\ of the requirements for the Degree \\ Doctor of Philosophy (Chemical Engineering) \\ by \\ Heng Shou
}

May 2013 


\section{APPROVAL SHEET}

The dissertation is submitted in partial fulfillment of the

requirements for the degree of

Doctor of Philosophy (Chemical Engineering)

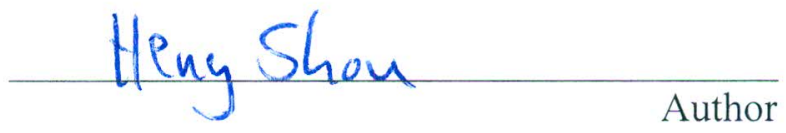

This dissertation has been read and approved by the examining committee
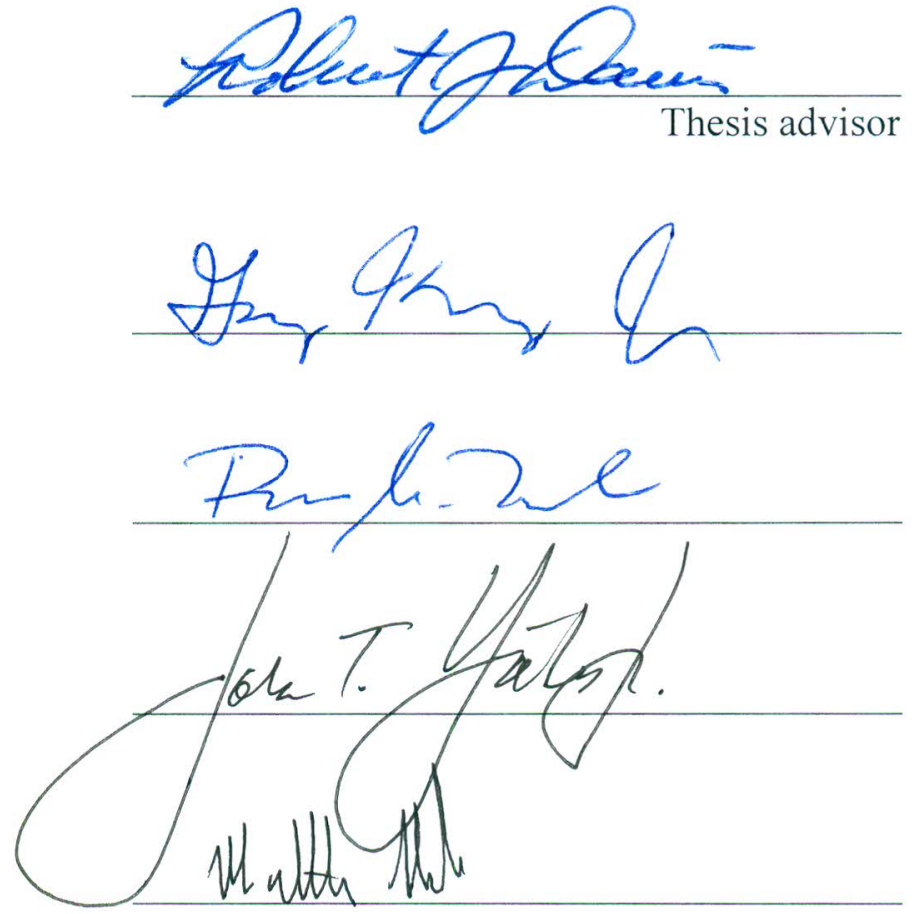

Accepted for the School of Engineering and Applied Science

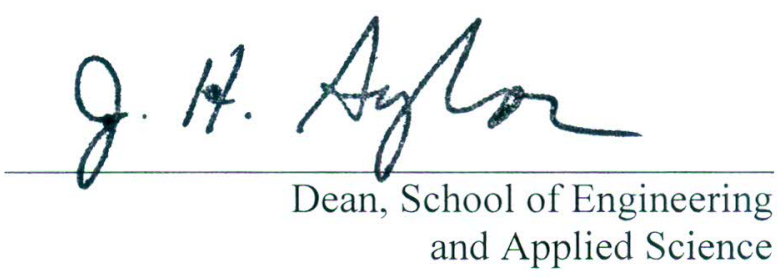

May 2013 


\section{Abstract}

The catalytic conversion of synthesis gas derived from coal, natural gas or renewable biomass is among the most promising routes to produce alternative energy carriers and chemical feedstocks. Although production of diesel fuel and methanol from syngas has been well-developed on a world scale, there is still a growing need for the direct synthesis of higher $(\mathrm{C} 2+)$ alcohols for use as fuel additives or chemical precursors. When properly promoted by alkali metals, molybdenum carbide is considered to be a promising catalyst for this process. In this study, molybdenum carbide nanoclusters (1-3 $\mathrm{nm}$ ) were synthesized on various supports using wet impregnation. The selectivity of catalytic syngas conversion toward $\mathrm{C} 2+$ alcohols was enhanced with added $\mathrm{Rb}_{2} \mathrm{CO}_{3}$ promoter. Although the alcohol selectivity decreased with CO conversion, the loss can be partially recovered with addition of a cobalt promoter. In situ X-ray absorption spectroscopy (XAS) was conducted in a self-built high-pressure reactor cell operating at syngas reaction conditions ( $573 \mathrm{~K}, 30$ bar syngas), which revealed the existence of surface oxygen on $\mathrm{Mo}_{2} \mathrm{C}$ and the structural modification of $\mathrm{Rb}_{2} \mathrm{CO}_{3}$ promoter in $\mathrm{CO}$ hydrogenation. An air-free sample preparation method was developed for ex situ XAS analysis, which allowed direct evidence of surface oxidation of $\mathrm{Mo}_{2} \mathrm{C}$ caused by passivation to be observed. The reduction of highly dispersed cobalt domains $(<2 \mathrm{~nm})$ in co-existence with $\mathrm{Mo}_{2} \mathrm{C}$ was also observed by XAS.

Diffuse reflectance Fourier-transform infrared spectroscopy (DRIFTS) was used to characterize the surface of $\mathrm{Mo}_{2} \mathrm{C}$ nanoclusters at working conditions. With $\mathrm{CO}$ as a probe, DRIFTS unveiled the structure-function relationship between the Rb promoter and the catalyst for the first time. A strong correlation between the red-shifted band of 
adsorbed CO and the elevated alcohol selectivity was observed. More importantly, experimental results from probe reactions and IR spectroscopy, combined with the firstprinciple theoretical calculations (performed in collaboration with Georgia institute of Technology), suggested that the basic $\mathrm{Rb}_{2} \mathrm{CO}_{3}$ promoter likely interacted with the $\mathrm{Mo}_{2} \mathrm{C}$ catalyst by neutralizing the acidic hydroxyl groups on the catalyst surface.

Finally, an advanced multi-component system for steady-state isotopic transient kinetic analysis (SSITKA) was constructed to allow the measurement of fundamental kinetic parameters. The multi-product SSITKA revealed that the intrinsic turnover frequency (TOF) on the "slow" $\mathrm{Mo}_{2} \mathrm{C}$ catalysts was in fact comparable to other active catalysts for CO hydrogenation such as those based on Fe and Rh. Consequently, the very small coverage of the reactive intermediates on $\mathrm{Mo}_{2} \mathrm{C}$ surface was discovered to be the reason for its low apparent activity in CO hydrogenation. 


\section{Acknowledgements}

I would like to express my sincerest gratitude to my advisor, Prof. Robert Davis, for providing invaluable guidance, support, encouragement and help throughout my study, research and career development. Heartiest thanks go to the financial support from The Dow Chemical Company, the collaboration with the Georgia Institute of Technology, and all the precious discussions with Dr. Daniela Ferrari, Prof. Christopher Jones, Prof. David Sholl, Dr. David Barton, Dr. Billy Bardin, Prof. Pradeep Agrawal, Dr. Gerolamo Budroni, Mr. Liwei Li, Mr. Michael Morrill, Dr. Thao Tien Nguyen and Ms. Hiroko Okatsu.

I would like to thank Dr. Mitsuhiro Murayama and Mr. Richard White for their precious help and efforts with the electron microscopy analysis, and Prof. Gary Koenig, Prof. David Green and Prof. Brent Gunnoe for letting me use their gloveboxes for sample preparation. Best regards go to the supportive staff members in the department, Ms. Vickie Falconer, Ms. Kim Doerr, Ms. Teresa Morris, Mr. Rick Buchanan and Ms. Margaret Taylor. Many thanks to all the fellow students in Davis group, particularly Dr. Yuanzhou Xi (the big brother to maintain the Tsinghua-Peking rivalry), Dr. Bhushan Zope (the rival fan of Manchester United), Dr. Ali Haider (the syngas predecessor), Dr. Joseph Kozlowski (the Rocky Mountain), Mr. Oliver Daniel (the artist), Dr. Sara Davis (the lab female, for the most of the time), Mr. Kehua Yin (the little brother from Peking) and Mr. Derek Felcone (the dumb-throat office mate), for sharing a productive and delightful time.

The use of the NSLS was supported by the U.S. Department of Energy, Office of Science, Office of Basic Energy Sciences, under Contract No. DE-AC02-98CH10886. Beamline X18B at the NSLS is supported in part by the Synchrotron Catalysis 
Consortium, U. S. Department of Energy Grant No. DE-FG02-05ER15688. I appreciate the priceless assistance received from the beamline scientists, Dr. Nebojsa Marinkovic and Dr. Syed Khalid at X-18B, and Dr. Bruce Ravel at X-23A2.

I also want to express my sincere gratitude to my dear friends from Peking University and University of Virginia, Na Liu , Jing He, Isabel Green, Nianyun Chen, Danqing Zhu, Yige Wu, Jianbin Wang, Yichi Zhang, Yixuan Lü, Zhiyuan Tao, Xuhui Feng, Jiajun Mei, Xiaopu Wang, Kerui Xu and many others. Despite of being the only child in my family, I am thankful to have you all as my sisters and brothers to share the joy and to overcome the toughness.

Last but not least, I thank my family, my mother Jianhui Li (李建辉), my father Jinbao Shou (寿金宝) and my grandmother Zhuhua Wu (吴祝华), for giving me everlasting love and support. Your love makes me who I am, and I devote my heart and soul to make you proud. 


\section{Table of Contents}

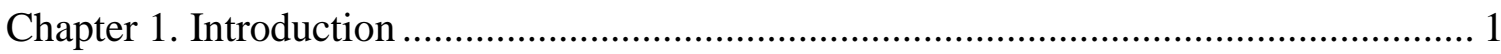

1.1 Higher alcohol synthesis: A potential way to selectively convert syngas ................. 1

1.2 Catalyst candidates for higher alcohol synthesis: The choice of molybdenum carbide...................................................................................................... 3

1.3 Summary of research topics of interest................................................................... 7

1.3.1 Influence of oxygen ................................................................................. 7

1.3.2 CO adsorption on molybdenum carbide ........................................................... 8

1.3.3 The interaction between the alkali metal species and the molybdenum carbide

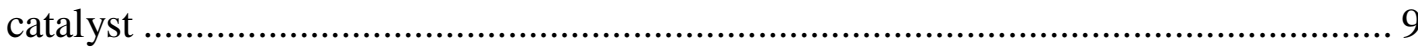

1.3.4 Cobalt as a secondary promoter ......................................................................... 10

1.3.5 Nature of active sites on molybdenum carbide................................................. 11

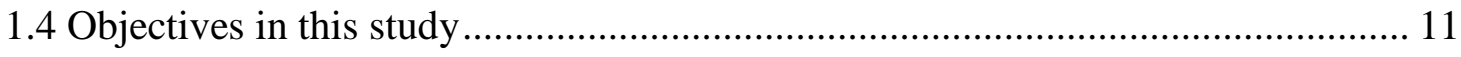

References of Chapter 1.................................................................................... 13

Chapter 2. Reactivity and in situ X-ray absorption spectroscopy of Rb-promoted $\mathrm{Mo}_{2} \mathrm{C} / \mathrm{MgO}$ catalysts for higher alcohol synthesis .......................................................... 21

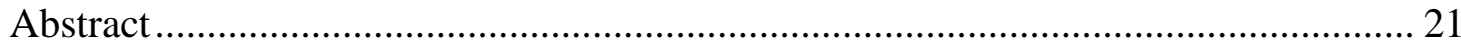

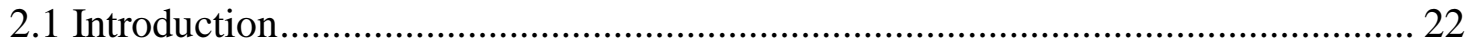

2.2 Experimental methods ......................................................................................... 24

2.2.1 Catalyst synthesis ........................................................................................... 24

2.2.2 Catalyst characterization .................................................................................. 25

2.2.3 Hydrogenation of carbon monoxide .............................................................. 25

2.2.4 X-ray absorption spectroscopy....................................................................... 27

2.3 Results and discussion ................................................................................... 29

2.3.1 Characterization by $\mathrm{X}$-ray diffraction, elemental analysis, $\mathrm{N}_{2}$ adsorption, and electron microscopy ……………………....................................................... 29

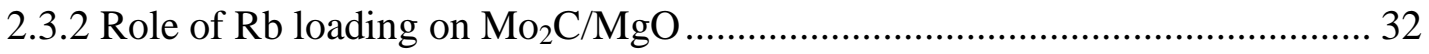


2.3.3 Influence of process variables: gas flow rate, temperature, pressure, and $\mathrm{H}_{2} / \mathrm{CO}$ ratio 37

2.3.4 X-ray absorption spectroscopy...................................................................... 41

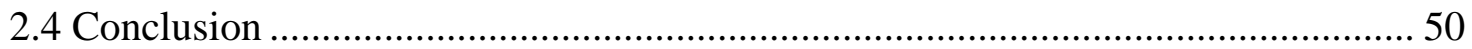

References of Chapter 2 2........................................................................................ 51

Chapter 3. Influence of passivation on the reactivity of unpromoted and Rb-promoted $\mathrm{Mo}_{2} \mathrm{C}$ nanoparticles for $\mathrm{CO}$ hydrogenation ..................................................................... 55

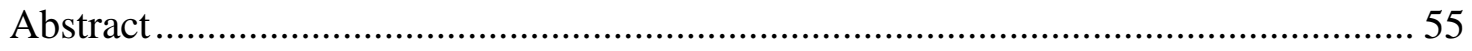

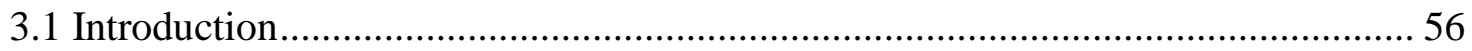

3.2 Experimental methods ........................................................................................ 58

3.2.1 Catalyst synthesis ........................................................................................... 58

3.2.2 Hydrogenation of carbon monoxide .............................................................. 59

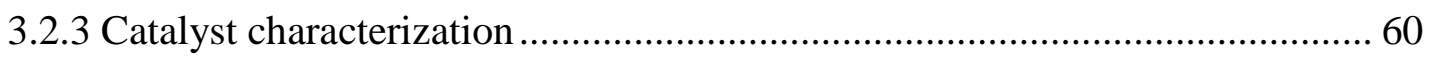

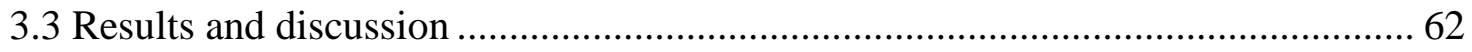

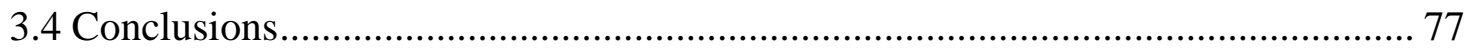

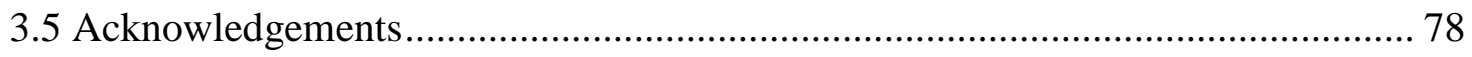

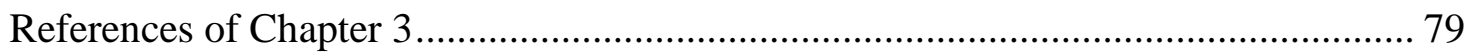

Chapter 4. Use of infrared spectroscopy and density functional theory to study the influence of rubidium on alumina-supported molybdenum carbide catalyst for higher alcohol synthesis from syngas ....................................................................................... 82

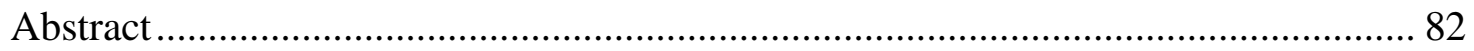

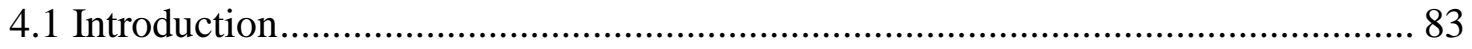

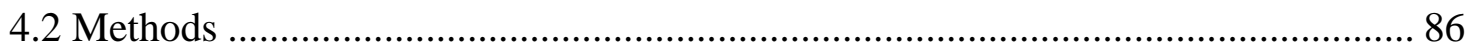

4.2.1 Catalyst synthesis .......................................................................................... 86

4.2.2 Hydrogenation of carbon monoxide ................................................................ 87

4.2.3 Catalyst characterization ............................................................................... 87

4.2.4 Diffuse reflectance infrared Fourier transform spectroscopy ……………….... 89 


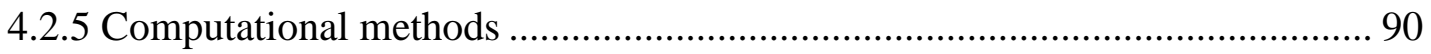

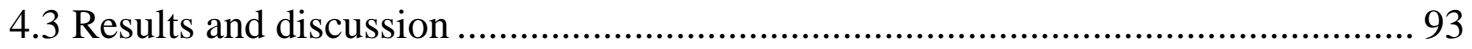

4.3.1 Characterization by X-ray diffraction and X-ray absorption spectroscopy ..... 93

4.3.2 $\mathrm{CO}$ adsorption on $\mathrm{Mo}_{2} \mathrm{C}$ and $\mathrm{Rb}$-promoted $\mathrm{Mo}_{2} \mathrm{C}$....................................... 99

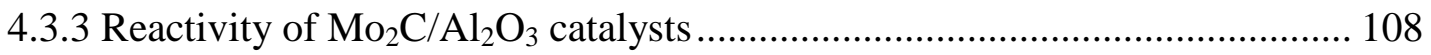

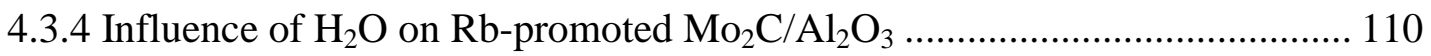

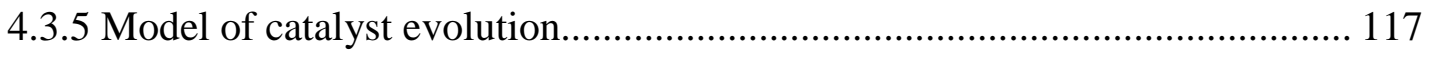

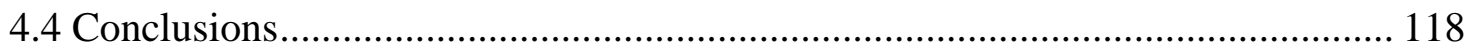

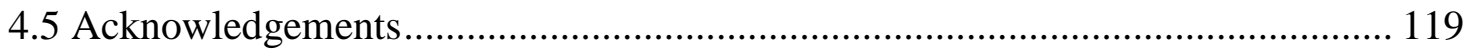

References of Chapter 4........................................................................... 119

Chapter 5. Influence of Cobalt on Rubidium-Promoted Alumina-Supported Molybdenum Carbide Catalysts for Higher Alcohol Synthesis from Syngas ...................................... 127

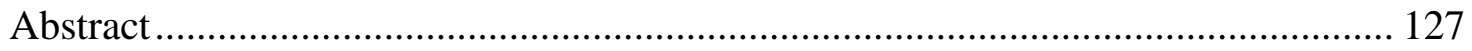

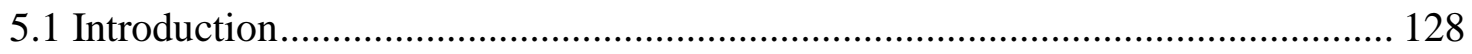

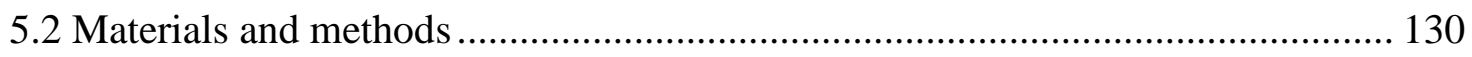

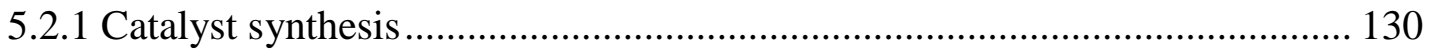

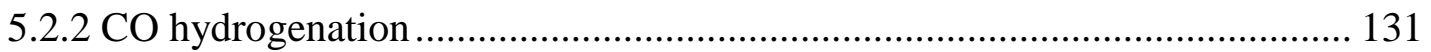

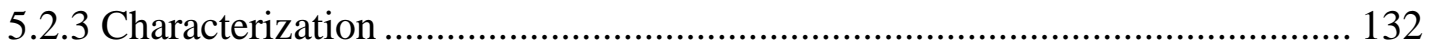

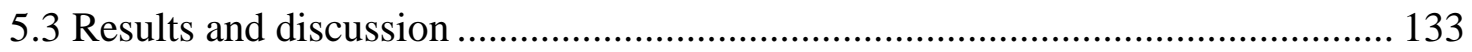

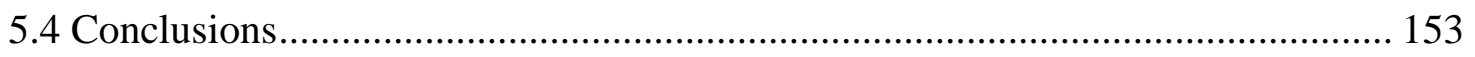

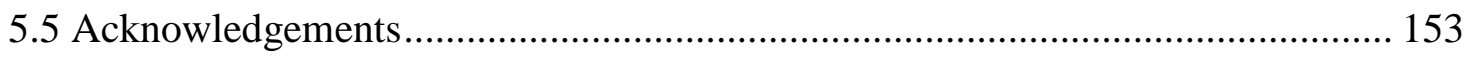

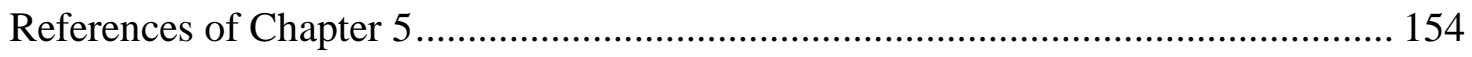

Chapter 6. Multi-product steady-state isotopic transient kinetic analysis of CO hydrogenation over supported molybdenum carbide............................................... 159

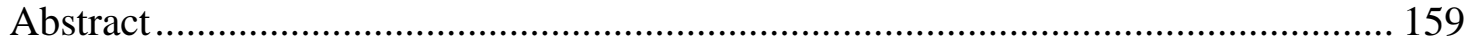

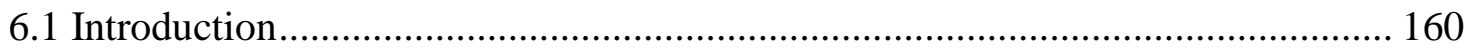




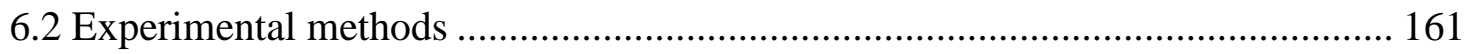

6.2.1 Catalyst synthesis ........................................................................................ 161

6.2.2 Hydrogenation of carbon monoxide ................................................................. 162

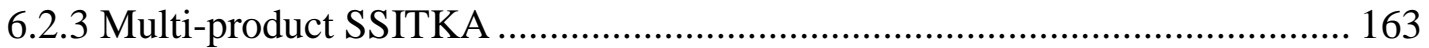

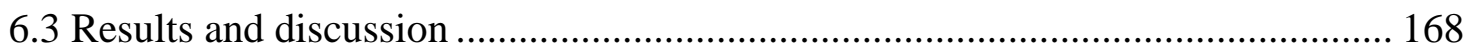

6.3.1 Transient analysis of $\mathrm{CO}$ hydrogenation over $\mathrm{Mo}_{2} \mathrm{C} / \alpha-\mathrm{Al}_{2} \mathrm{O}_{3} \ldots \ldots \ldots \ldots \ldots \ldots \ldots . . . . . .169$

6.3.2 Transient analysis of $\mathrm{CO}$ hydrogenation over Rb-promoted $\mathrm{Mo}_{2} \mathrm{C} / \alpha-\mathrm{Al}_{2} \mathrm{O}_{3} .180$

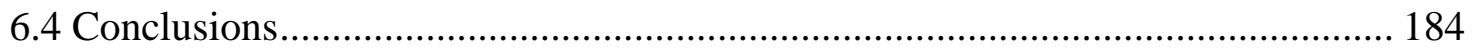

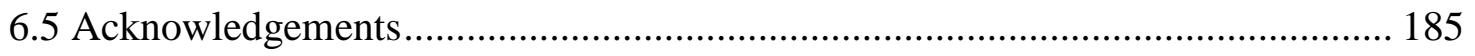

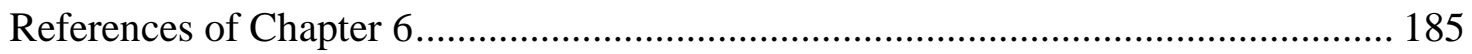

Chapter 7. Conclusions and future work....................................................................... 192

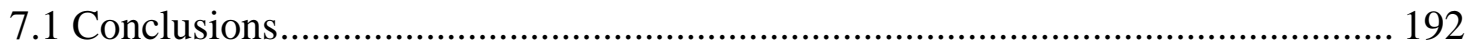

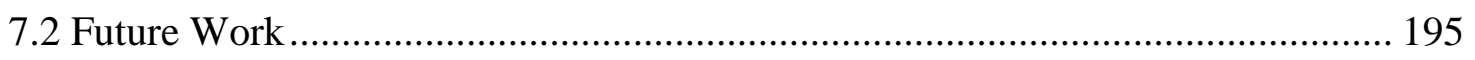

7.2.1 Single-phase molybdenum-based bimetallic carbide catalysts for CO hydrogenation ......................................................................................................... 196

7.2.2 Direct conversion of syngas to C2-C4 olefins ................................................ 197

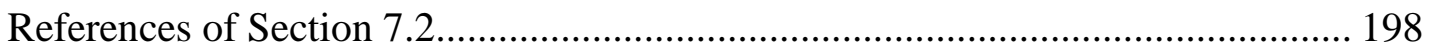

Appendix A. Upgrade of steady-state isotopic transient kinetic analysis system for the multi-product purpose .................................................................................................... 199

Appendix B. List of Publications at University of Virginia........................................... 200 


\section{List of Tables}

Table 2.1 Results from elemental analysis .................................................................... 30

Table 2.2 Results from $\mathrm{N}_{2}$ Adsorption........................................................................ 31

Table 2.3 Conversion of synthesis gas over Rb-promoted $5 \mathrm{wt} . \% \mathrm{Mo}_{2} \mathrm{C} / \mathrm{MgO}$ catalysts 33

Table 2.4 Comparison of catalyst activity at similar CO conversion level by varying temperature and gas flow rate......................................................................................... 38

Table 2.5 Impact of partial pressure on production distribution of CO hydrogenation over 5 wt.\% Rb-5 wt.\% $\mathrm{Mo}_{2} \mathrm{C} / \mathrm{MgO}$ catalyst...................................................................... 40

Table 2.6 Effect of pressure on reactivity of CO hydrogenation over a 5 wt.\% Rb-5 wt.\%

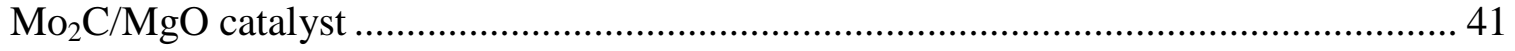

Table 2.7 Results from the analysis of Mo EXAFS.......................................................... 46

Table 3.1 Reactivity of non-passivated 5 wt. $\% \mathrm{Mo}_{2} \mathrm{C} / \mathrm{Al}_{2} \mathrm{O}_{3}$ catalysts in syngas reaction 63

Table 3.2 Influence of passivation on the reactivity of unpromoted and Rb-promoted 5 wt. $\% \mathrm{Mo}_{2} \mathrm{C} / \mathrm{Al}_{2} \mathrm{O}_{3}$ catalysts at similar $\mathrm{CO}$ conversion levels. 67

Table 3.3 Chain growth probability of hydrocarbons (paraffins and olefins combined).. 70

Table 3.4 Shift of the Mo K Edge Energy from Mo foil. 73

Table 3.5 Results from the analysis of Mo EXAFS from carbide catalyst........................ 75

Table 4.1 Shift of the Mo K Edge Energy from Mo foil.................................................... 95

Table 4.2 Results from the analysis of Mo EXAFS from molybdenum carbide samples 96

Table 4.3 DFT-simulated CO adsorption on reconstructed $\mathrm{Mo}_{2} \mathrm{C}$ (001) surface 102

Table 4.4 DFT-simulated CO adsorption on modified re-constructed $\mathrm{Mo}_{2} \mathrm{C}(001)$ surface 107

Table 4.5 Reactivity of 2 wt.\% $\mathrm{Mo}_{2} \mathrm{C} / \mathrm{Al}_{2} \mathrm{O}_{3}$ catalysts in syngas reaction 110

Table 5.1 Reactivity of $\mathrm{Co}-\mathrm{Mo}_{2} \mathrm{C} / \alpha-\mathrm{Al}_{2} \mathrm{O}_{3}$ and Rb-promoted $\mathrm{Co}-\mathrm{Mo}_{2} \mathrm{C} / \alpha-\mathrm{Al}_{2} \mathrm{O}_{3}$ catalysts in $\mathrm{CO}$ hydrogenation .......................................................................................... 134

Table 5.2 Chain growth probability $(\alpha)$ and $R^{2}$ derived from linear fits........................ 139 
Table 5.3 Influence of $\mathrm{Rb}$ loading on the reactivity of $\mathrm{Co}-\mathrm{Mo}_{2} \mathrm{C} / \alpha-\mathrm{Al}_{2} \mathrm{O}_{3}$ (molar ratio of $\mathrm{Co} / \mathrm{Mo}=1$ ) in $\mathrm{CO}$ hydrogenation 140

Table 5.4 Results from the Analysis of Mo K edge EXAFS 146

Table 5.5 Results from the Analysis of Co K edge EXAFS 150

Table 6.1 Reactivity of 5 wt.\% $\mathrm{Mo}_{2} \mathrm{C} / \alpha-\mathrm{Al}_{2} \mathrm{O}_{3}$ catalysts in $\mathrm{CO}$ hydrogenation at ambient pressure 168

Table 6.2 Fractional contribution of different sites on $\mathrm{Mo}_{2} \mathrm{C}$ catalyst 173

Table 6.3 Comparison of the fraction of transient $\left(X_{\mathrm{A}}\right)$ associated with Pool A on 5 wt.\% $\mathrm{Mo}_{2} \mathrm{C} / \alpha-\mathrm{Al}_{2} \mathrm{O}_{3}$ : fit of exponential decay vs. absolute changes in transient responses ... 173

Table 6.4 Surface reaction parameters of CO hydrogenation on Pool A over 5 wt.\% $\mathrm{Mo}_{2} \mathrm{C} / \alpha-\mathrm{Al}_{2} \mathrm{O}_{3}$ and 1.5 wt.\% Rb-5 wt. $\% \mathrm{Mo}_{2} \mathrm{C} / \alpha-\mathrm{Al}_{2} \mathrm{O}_{3}$ catalysts estimated by SSITKA 176

Table 6.5 Time constants and surface coverages during CO hydrogenation over 5 wt.\% $\mathrm{Mo}_{2} \mathrm{C} / \alpha-\mathrm{Al}_{2} \mathrm{O}_{3}$ catalysts estimated by SSITKA (transient response measured up to $1 \mathrm{~h}$, corresponding to Figure 6.4)..... 179

Table 6.6 Concentrations of reaction intermediates and surface coverages in $\mathrm{CO}$ hydrogenation over 5 wt.\% $\mathrm{Mo}_{2} \mathrm{C} / \alpha-\mathrm{Al}_{2} \mathrm{O}_{3}$ and 1.5 wt.\% Rb-5 wt.\% $\mathrm{Mo}_{2} \mathrm{C} / \alpha-\mathrm{Al}_{2} \mathrm{O}_{3}$ catalysts estimated by the decays of desorption rates (see Figure 6.7)..... 182

Table A.1 Upgrades of conventional SSITKA for multi-product purposes 199 


\section{List of Figures}

Figure 1.1 Pathways for syngas utilization adapted from Spath and Dayton [5] ............... 2

Figure 1.2 Reaction pathway for CO hydrogenation adapted from Lee et al. [13] ............ 4

Figure 2.1 High pressure, borosilicate tubular reactor/X-ray cell. ............................... 29

Figure 2.2 X-ray diffraction patterns of (a) $\mathrm{MgO}$, (b) $\mathrm{Mo}_{2} \mathrm{C} / \mathrm{MgO}$, (c) $\mathrm{Mo}_{2} \mathrm{C}$, and (d) hydrated MgO. Patterns are offset for clarity. ........................................................... 30

Figure 2.3 HAADF images of (a) $5 \% \mathrm{Mo}_{2} \mathrm{C} / \mathrm{MgO}$, (b) $5 \% \mathrm{Rb}-5 \% \mathrm{Mo}_{2} \mathrm{C} / \mathrm{MgO}$. Catalysts had been used for $48 \mathrm{~h}$ in $\mathrm{CO}$ hydrogenation before TEM analysis.............................. 31

Figure 2.4 Change of catalytic performance of 5 wt.\% $\mathrm{Rb}-5$ wt.\% $\mathrm{Mo}_{2} \mathrm{C}$ during $\mathrm{CO}$ hydrogenation at $573 \mathrm{~K}$ and 30 bar: (a) $\mathrm{CO}$ conversion; (b) selectivity to $\mathrm{CO}_{2}$; (c) selectivity to hydrocarbons; (d) selectivity to alcohols............................................. 34

Figure 2.5 Reaction pathway for CO hydrogenation adapted from [18] ........................ 35

Figure 2.6 Influence of gas flow rate on $\mathrm{CO}$ conversion (including $\mathrm{CO}_{2}$ ) over 5 wt.\% Rb5 wt. $\% \mathrm{Mo}_{2} \mathrm{C} / \mathrm{MgO}\left(30 \mathrm{bar}, \mathrm{H}_{2} / \mathrm{CO}=1\right.$ ).

Figure 2.7 Influence of CO conversion on product distribution during HAS over 5 wt.\% $\mathrm{Rb}-5$ wt.\% $\mathrm{Mo}_{2} \mathrm{C} / \mathrm{MgO}$ : (a) selectivity of total hydrocarbons and total alcohols; (b) selectivity of $\mathrm{CO}_{2}$; (c) selectivity of individual alcohols; (d) ratio of alkenes and alkanes.

* HC refers to hydrocarbon. 39

Figure 2.8 X-ray absorption near edge structure (XANES) at the Mo $K$ edge of: (a) Mo reference standards, (b) $\mathrm{Mo}_{2} \mathrm{C} / \mathrm{MgO}$, (c) $\mathrm{Rb}-\mathrm{Mo}_{2} \mathrm{C} / \mathrm{MgO}$. $\mathrm{MoO}_{3} / \mathrm{MgO}$ is the catalyst precursor before carburization. 43

Figure 2.9 Correlation of the Mo $K$ edge energy ( $E_{0}$ defined as energy at half step) to the oxidation state of reference compounds (triangles) and supported catalyst (circles)....... 44

Figure 2.10 Magnitude of the Fourier transform of the $k^{3}$-weighted Mo $K$ edge EXAFS of Mo standards compared to MgO-supported Mo species: (a) $\mathrm{Mo}_{2} \mathrm{C}$, (b) $\mathrm{Rb}-\mathrm{Mo}_{2} \mathrm{C} / \mathrm{MgO}$ RT after rxn, (c) $\mathrm{Mo}_{2} \mathrm{C} / \mathrm{MgO}$ RT after rxn, (d) Mo foil, (e) $\mathrm{MoO}_{3} / \mathrm{MgO}$, (f) $\mathrm{Rb}_{2} \mathrm{MoO}_{4}$. Spectra are offset for clarity..... 45

Figure 2.11 Comparison of curve fit to experimental Mo $K$ edge EXAFS of the 5 wt.\% $\mathrm{Rb}-5$ wt. $\% \mathrm{Mo}_{2} \mathrm{C} / \mathrm{MgO}$ catalyst in 30 bar syngas at $573 \mathrm{~K}$ (a) Magnitude (solid line) and the imaginary part (dash line) of the Fourier transform of EXAFS compared to the result from the curve fit (circle); (b) $k^{3}$-weighted Mo $K$ edge EXAFS (solid line) and the result from curve fit (circle). 48 
Figure 2.12 XANES at the Rb $K$ edge. Solid lines are spectra recorded at RT without any pretreatment. Dashed lines are spectra recorded at RT after various treatments: (a) $\mathrm{Rb}_{2} \mathrm{CO}_{3}-\mathrm{Mo}_{2} \mathrm{C} / \mathrm{MgO}$ (before and after exposure to 30 bar syngas at $573 \mathrm{~K}$ for $4 \mathrm{~h}$ ), (b) $\mathrm{Rb}_{2} \mathrm{CO}_{3}-\mathrm{Mo}_{2} \mathrm{C} / \mathrm{MgO}$ (before and after heating in Ar at $573 \mathrm{~K}$ for $4 \mathrm{~h}$ ), (c) $\mathrm{Rb}_{2} \mathrm{CO}_{3} / \mathrm{MgO}$ (before and after heating in Ar at $573 \mathrm{~K}$ for $4 \mathrm{~h}$ ), (d.1) $\mathrm{Rb}_{2} \mathrm{CO}_{3} / \mathrm{H}_{2} \mathrm{O}$ paste at $\mathrm{RT}$, (d.2) $\mathrm{Rb}_{2} \mathrm{CO}_{3}$ as received. Spectra are offset for clarity.

Figure 3.1 (a) Reactor for carburization and CO hydrogenation, and (b) XAS sample tube. Both were used for air-free handling. 59

Figure 3.2 Change in catalytic performance of non-passivated 1.5 wt.\% Rb-5 wt.\% $\mathrm{Mo}_{2} \mathrm{C} / \mathrm{Al}_{2} \mathrm{O}_{3}$ during $\mathrm{CO}$ hydrogenation at $573 \mathrm{~K}$ and 30 bar over time: (a) CO conversion; (b) selectivity of $\mathrm{CO}_{2}$; (c) selectivity of total hydrocarbons and of total alcohols; (c) selectivity of C1-C5 linear alcohols. 64

Figure 3.3 Change in production rates of hydrocarbons (square) and alcohols (circle) during $\mathrm{CO}$ hydrogenation at $573 \mathrm{~K}$ and 30 bar over: (a) 1.5 wt.\% Rb-5 wt.\% $\mathrm{Mo}_{2} \mathrm{C} / \mathrm{Al}_{2} \mathrm{O}_{3}$, non-passivated, dry impregnation (DI) of $\mathrm{Rb}_{2} \mathrm{CO}_{3}$ before carburization; (b) 5 wt.\% Rb-5 wt.\% $\mathrm{Mo}_{2} \mathrm{C} / \mathrm{Al}_{2} \mathrm{O}_{3}$, non-passivated, DI of $\mathrm{Rb}_{2} \mathrm{CO}_{3}$ after carburization.

Figure 3.4 Evaluation of chain growth probability of linear hydrocarbons (paraffins and olefins combined) 69

Figure 3.5 X-ray absorption near edge structure (XANES) at the Mo $K$ edge of: (a) Mo reference standards, (b) alumina-supported Mo species, $\mathrm{MoO}_{3} / \mathrm{Al}_{2} \mathrm{O}_{3}$ (calcined), $\mathrm{MoO}_{2} / \mathrm{Al}_{2} \mathrm{O}_{3}$ (reduced) and $\mathrm{Mo}_{2} \mathrm{C} / \mathrm{Al}_{2} \mathrm{O}_{3}$ (carburized), (c) a comparison between freshly prepared and passivated $\mathrm{Mo}_{2} \mathrm{C} / \mathrm{Al}_{2} \mathrm{O}_{3}$. 72

Figure 3.6 Fourier transform (not corrected for phase shifts) of $k^{3}$-weighted Mo EXAFS: (a) $5 \% \mathrm{Mo} / \mathrm{Al}_{2} \mathrm{O}_{3}$, calcined; (b) bulk $\mathrm{MoO}_{3}$; (c) 5 wt.\% $\mathrm{Mo} / \mathrm{Al}_{2} \mathrm{O}_{3}$, reduced; (d) 1.5 wt. $\%$ $\mathrm{Rb}-5$ wt.\% Mo/ $/ \mathrm{Al}_{2} \mathrm{O}_{3}$, reduced; (e) bulk $\mathrm{MoO}_{2}$; (f) 5 wt.\% Mo, carburized; (g) 1.5 wt.\% $\mathrm{Rb}-5$ wt.\% Mo, carburized; (h) bulk $\mathrm{Mo}_{2} \mathrm{C}$. Spectra are offset for clarity. 74

Figure 3.7 Comparison of the curve fit to experimental Mo $K$ edge EXAFS of the 1.5 wt.\% $\mathrm{Rb}-5$ wt.\% $\mathrm{Mo}_{2} \mathrm{C} / \mathrm{Al}_{2} \mathrm{O}_{3}$ catalyst without passivation, before reaction. (a) $k^{3}$-weighted Mo $K$ edge EXAFS (solid line) and the result from curve fit (circles); (b) Magnitude (solid line) and the imaginary part (dashed line) of the Fourier transform of EXAFS compared to the result from the curve fit (circles). 76

Figure 3.8 Electron micrographs of (a) 5 wt.\% $\mathrm{Mo}_{2} \mathrm{C} / \mathrm{Al}_{2} \mathrm{O}_{3}$ with passivation after reaction, (b) 1.5 wt.\% $\mathrm{Rb}-5$ wt. $\% \mathrm{Mo}_{2} \mathrm{C} / \mathrm{Al}_{2} \mathrm{O}_{3}$ with passivation and after reaction. Catalysts were used for $48 \mathrm{~h}$ in CO hydrogenation before TEM analysis. The scale bars are $5 \mathrm{~nm}$. 77

Figure 4.1 Reconstructed bare hexagonal $\mathrm{Mo}_{2} \mathrm{C}(001)$ surface. Mo atoms are shown as green spheres and $\mathrm{C}$ atoms as cyan spheres. 
Figure 4.2 X-ray diffraction patterns of (a) 2 wt. $\% \mathrm{Mo}_{2} \mathrm{C} / \mathrm{Al}_{2} \mathrm{O}_{3}$, (b) $\mathrm{Al}_{2} \mathrm{O}_{3}$ (Mager Scientific) used to support $\mathrm{Mo}_{2} \mathrm{C}$, (c) $\gamma-\mathrm{Al}_{2} \mathrm{O}_{3}$ reference (Alfa-Aesar), (d) $\alpha-\mathrm{Al}_{2} \mathrm{O}_{3}$ (Mager Scientific) and (e) bulk $\mathrm{Mo}_{2} \mathrm{C}$. Patterns are offset for clarity. 93

Figure 4.3 Mo K edge XANES of: (a) Mo standards; (b) alumina-supported Mo samples. 94

Figure 4.4 Fourier transform (not corrected for phase shifts) of $k^{3}$-weighted EXAFS of: (a) 2 wt.\% $\mathrm{Mo}_{2} \mathrm{C} / \mathrm{Al}_{2} \mathrm{O}_{3}$, non-passivated (purged in He after carburization, air-free handling for sample preparation); (b) 2 wt. $\% \mathrm{Mo}_{2} \mathrm{C} / \mathrm{Al}_{2} \mathrm{O}_{3}$, passivated; (c) $10 \mathrm{wt} . \% \mathrm{Rb}-2 \mathrm{wt} . \%$ $\mathrm{Mo}_{2} \mathrm{C} / \mathrm{Al}_{2} \mathrm{O}_{3}$, passivated and after $72 \mathrm{~h}$ reaction (purged in $\mathrm{N}_{2}$ after syngas reaction, airfree handling for sample preparation); (d) $\mathrm{Mo}_{2} \mathrm{C}$ standard. Spectra are offset for clarity.95

Figure 4.5 Comparison of curve fit to experimental Mo $K$ edge EXAFS of the nonpassivated 2 wt.\% $\mathrm{Mo}_{2} \mathrm{C} / \mathrm{Al}_{2} \mathrm{O}_{3}$ (air-free): (a) magnitude (solid line) and the imaginary part (dash line) of the FT of EXAFS compared with the result from the curve fit (circle); (b) $k^{3}$-weighted Mo $K$ edge EXAFS (solid line) and the result from curve fit (circle).... 98

Figure 4.6 IR spectroscopy of gaseous species in CO hydrogenation at $573 \mathrm{~K}, 30$ bar syngas over 5 wt.\% Rb-2 wt. $\% \mathrm{Mo}_{2} \mathrm{C} / \mathrm{Al}_{2} \mathrm{O}_{3}$ 99

Figure 4.7 Diffuse reflectance Fourier transform spectra of adsorbed CO on 2 wt.\% $\mathrm{Mo}_{2} \mathrm{C} / \mathrm{Al}_{2} \mathrm{O}_{3}$ at room temperature after being pretreated at $573 \mathrm{~K}$, in 30 bar syngas $\left(\mathrm{H}_{2} / \mathrm{CO}=1\right)$ for $12 \mathrm{~h}$ and in 1 bar $\mathrm{H}_{2}$ for $1 \mathrm{~h}$. 100

Figure 4.8 Top and side view of $\mathrm{CO}$ adsorption on reconstructed hexagonal $\mathrm{Mo}_{2} \mathrm{C}(001)$ surface: (a) CO-free, (b) CO adsorbed on C-top sites, (c) CO adsorbed on Mo-top sites. $\mathrm{Mo}, \mathrm{C}$, and $\mathrm{O}$ atoms are shown as green, cyan, and red spheres, respectively..... 101

Figure 4.9 Diffuse reflectance Fourier transform spectra of adsorbed CO on samples at room temperature after being pretreated at $573 \mathrm{~K}$, in 30 bar syngas $\left(\mathrm{H}_{2} / \mathrm{CO}=1\right)$ for $12 \mathrm{~h}$ and in 1 bar $\mathrm{H}_{2}$ for $1 \mathrm{~h}$ (a) 2 wt.\% $\mathrm{Mo}_{2} \mathrm{C} / \mathrm{Al}_{2} \mathrm{O}_{3}$, (b) 2 wt.\% Rb-2 wt.\% $\mathrm{Mo}_{2} \mathrm{C} / \mathrm{Al}_{2} \mathrm{O}_{3}$, (c) 5 wt.\% Rb-2 wt.\% $\mathrm{Mo}_{2} \mathrm{C} / \mathrm{Al}_{2} \mathrm{O}_{3}$, (d) 7.5 wt.\% Rb-2 wt.\% $\mathrm{Mo}_{2} \mathrm{C} / \mathrm{Al}_{2} \mathrm{O}_{3}$, (e) 10 wt.\% Rb-2 wt. $\% \mathrm{Mo}_{2} \mathrm{C} / \mathrm{Al}_{2} \mathrm{O}_{3}$. Spectra are offset for clarity. 104

Figure 4.10 Top and side view of $\mathrm{CO}$ adsorption on Rb-modified reconstructed hexagonal $\mathrm{Mo}_{2} \mathrm{C}(001)$ surface: (a) no adsorbed $\mathrm{CO}$, (b) $\mathrm{CO}$ adsorbed on C-top sites, (c) $\mathrm{CO}$ adsorbed on Mo-top sites; and $\mathrm{CO}$ adsorption on Rb-modified reconstructed hexagonal $\mathrm{Mo}_{2} \mathrm{C}(001)$ surface: (d) no adsorbed $\mathrm{CO}$, (e) $\mathrm{CO}$ adsorbed on C-top sites, (f) $\mathrm{CO}$-adsorbed on Mo-top sites. Mo, C, O and Rb atoms are shown as green, cyan, red and purple spheres, respectively. 106

Figure 4.11 Influence of pretreatment conditions on the IR bands of adsorbed CO on 2 wt. $\% \mathrm{Mo}_{2} \mathrm{C} / \mathrm{Al}_{2} \mathrm{O}_{3}$ with various pretreatment conditions, with (b) - (e) sequentially performed on a separate sample from (a): (a) 1 bar $\mathrm{H}_{2}$ at $573 \mathrm{~K}$ for $12 \mathrm{~h}$; (b) 1 bar $\mathrm{H}_{2} \mathrm{O} / \mathrm{He}$ at $300 \mathrm{~K}$ for $2 \mathrm{~h}$ and 1 bar He at $423 \mathrm{~K}$ for $1 \mathrm{~h}$; (c) 1 bar $\mathrm{H}_{2}$ at $573 \mathrm{~K}$ for $12 \mathrm{~h}$; (d) 30 bar syngas $\left(\mathrm{H}_{2} / \mathrm{CO}=1\right)$ for $12 \mathrm{~h}$ and in 1 bar $\mathrm{H}_{2}$ for $1 \mathrm{~h}$; (e) 1 bar $\mathrm{H}_{2}$ at $573 \mathrm{~K}$ for $12 \mathrm{~h}$. Spectra are offset for clarity. 111 
Figure 4.12 Influence of pretreatment conditions on the IR bands of adsorbed CO on 7.5 wt.\% Rb-2 wt.\% $\mathrm{Mo}_{2} \mathrm{C} / \mathrm{Al}_{2} \mathrm{O}_{3}$ with various pretreatment conditions, with (b) - (e) sequentially performed on a separate sample from (a): (a) 1 bar $\mathrm{H}_{2}$ at $573 \mathrm{~K}$ for $12 \mathrm{~h}$; (b) 1 bar $\mathrm{H}_{2} \mathrm{O} / \mathrm{He}$ at $300 \mathrm{~K}$ for $2 \mathrm{~h}$ and 1 bar He at $423 \mathrm{~K}$ for $1 \mathrm{~h}$; (c) 1 bar $\mathrm{H}_{2}$ at $573 \mathrm{~K}$ for 12 h; (d) 30 bar syngas $\left(\mathrm{H}_{2} / \mathrm{CO}=1\right.$ ) for $12 \mathrm{~h}$ and in 1 bar $\mathrm{H}_{2}$ for $1 \mathrm{~h}$; (e) $1 \mathrm{bar}_{2}$ at $573 \mathrm{~K}$ for $12 \mathrm{~h}$. Spectra are offset for clarity. 112

Figure 4.13 Change in the production rates of hydrocarbons (solid squares), ethers (open circles), alcohols (solid up triangles) and total oxygenates (open down triangles, alcohols and esters combined) over 7.5 wt.\% Rb-2 wt.\% $\mathrm{Mo}_{2} \mathrm{C} / \mathrm{Al}_{2} \mathrm{O}_{3}$ pretreated with: (a) 1 bar $\mathrm{H}_{2}$ at $573 \mathrm{~K}$ for $12 \mathrm{~h}$; (b) 1 bar $\mathrm{H}_{2} \mathrm{O} / \mathrm{N}_{2}$ at $300 \mathrm{~K}$ for $2 \mathrm{~h}$, followed with 1 bar $\mathrm{H}_{2}$ at $573 \mathrm{~K}$ for $12 \mathrm{~h}$.

Figure 4.14 Schematic illustration of (a) $\mathrm{H}_{2} \mathrm{O}$ molecules absorbed on $\mathrm{Mo}_{2} \mathrm{C}$ surface; (b) $\mathrm{OH}$ groups and $\mathrm{H}$ atoms adsorbed on $\mathrm{Mo}_{2} \mathrm{C}$ surface after the dissociation of adsorbed $\mathrm{H}_{2} \mathrm{O}$; (c) the energy profile of $\mathrm{H}_{2} \mathrm{O}$ dissociation. Mo, C, $\mathrm{H}$ and $\mathrm{O}$ atoms are shown as green, cyan, white and red spheres, respectively. The energy of the initial state $\left(\mathrm{H}_{2} \mathrm{O}^{*}\right)$ is defined as zero. 115

Figure 4.15 Working model of the modified $\mathrm{Mo}_{2} \mathrm{C}$ surfaces for $\mathrm{CO}$ hydrogenation ..... 118

Figure 5.1 Changes in the rate of production of hydrocarbons, methanol and higher alcohols with $\mathrm{Co} / \mathrm{Mo}$ ratio over $2.5 \mathrm{wt}$ \% Rb-promoted $\mathrm{Co}-\mathrm{Mo}_{2} \mathrm{C} / \alpha-\mathrm{Al}_{2} \mathrm{O}_{3}$ catalysts in $\mathrm{CO}$ hydrogenation at $573 \mathrm{~K}$ and 30 bar. 136

Figure 5.2 Evaluation of chain growth probability of linear hydrocarbons (paraffins and olefins combined, filled squares) and linear alcohols (open circles) over $\mathrm{Co}-\mathrm{Mo}_{2} \mathrm{C}$ catalysts with various Co/Mo ratios, without Rb promoter (a-e) and with Rb promoter (fj). 138

Figure 5.3 Change of alcohol selectivity with $\mathrm{CO}$ conversion over Rb-promoted $\mathrm{Mo}_{2} \mathrm{C} / \alpha$ $\mathrm{Al}_{2} \mathrm{O}_{3}(\mathrm{Co} / \mathrm{Mo}=0)$ and Rb-promoted $\mathrm{Co}-\mathrm{Mo}_{2} \mathrm{C} / \alpha-\mathrm{Al}_{2} \mathrm{O}_{3}(\mathrm{Co} / \mathrm{Mo}=1)$ catalysts. The loading of $\mathrm{Mo}$ is $5 \mathrm{wt}$ \%. The loading of $\mathrm{Rb}$ is $2.5 \mathrm{wt} . \%$. Reaction conditions: $573 \mathrm{~K}, 30$ bar syngas, $\mathrm{H}_{2} / \mathrm{CO}=1$. 141

Figure 5.4 X-ray diffraction patterns of (a) $\alpha-\mathrm{Al}_{2} \mathrm{O}_{3}$ (Mager Scientific); (b) $\mathrm{Mo}_{2} \mathrm{C} / \alpha-\mathrm{Al}_{2} \mathrm{O}_{3}$; (c) $\mathrm{Co}-\mathrm{Mo}_{2} \mathrm{C} / \alpha-\mathrm{Al}_{2} \mathrm{O}_{3}, \mathrm{Co} / \mathrm{Mo}=0.2$; (d) $\mathrm{Co}-\mathrm{Mo}_{2} \mathrm{C} / \alpha-\mathrm{Al}_{2} \mathrm{O}_{3}, \mathrm{Co} / \mathrm{Mo}=0.4$; (e) $\mathrm{Co}-$ $\mathrm{Mo}_{2} \mathrm{C} / \alpha-\mathrm{Al}_{2} \mathrm{O}_{3}, \mathrm{Co} / \mathrm{Mo}=1$; (f) $\mathrm{Co} / \alpha-\mathrm{Al}_{2} \mathrm{O}_{3}$. Patterns are offset for clarity. 142

Figure 5.5 Mo $\mathrm{K}$ edge XANES of (a) bulk $\mathrm{Mo}_{2} \mathrm{C}$ and alumina-supported $\mathrm{Co}-\mathrm{Mo}_{2} \mathrm{C}$ species with various molar ratios of $\mathrm{Co} / \mathrm{Mo}$; (b) a comparison between $\mathrm{Co}-\mathrm{Mo}_{2} \mathrm{C} / \alpha-$ $\mathrm{Al}_{2} \mathrm{O}_{3}(\mathrm{Co} / \mathrm{Mo}=1.0)$ and Rb-promoted $\mathrm{Co}-\mathrm{Mo}_{2} \mathrm{C} / \alpha-\mathrm{Al}_{2} \mathrm{O}_{3}(\mathrm{Co} / \mathrm{Mo}=1.0)$ after $120 \mathrm{~h}$ syngas reaction. 143

Figure 5.6 Fourier transform (not corrected for phase shifts) of $k^{3}$-weighted Mo $K$ edge EXAFS: (a) $\mathrm{Mo}_{2} \mathrm{C} / \alpha-\mathrm{Al}_{2} \mathrm{O}_{3}$; (b) $\mathrm{Co}-\mathrm{Mo}_{2} \mathrm{C} / \alpha-\mathrm{Al}_{2} \mathrm{O}_{3}, \mathrm{Co} / \mathrm{Mo}=0.4$; (c) $\mathrm{Co}-\mathrm{Mo}_{2} \mathrm{C} / \alpha-\mathrm{Al}_{2} \mathrm{O}_{3}$, $\mathrm{Co} / \mathrm{Mo}=1.0$; (d) bulk $\mathrm{Mo}_{2} \mathrm{C}$. Spectra are offset for clarity. 146 
Figure 5.7 Comparison of the curve fit to experimental Mo $K$ edge EXAFS of Co$\mathrm{Mo}_{2} \mathrm{C} / \alpha-\mathrm{Al}_{2} \mathrm{O}_{3}(\mathrm{Co} / \mathrm{Mo}=1.0)$ : (a) $k^{3}$-Weighted Mo $K$ edge EXAFS (solid line) and the result from curve fit (circles); (b) magnitude (solid line) and the imaginary part (dashed line) of the Fourier transform of EXAFS compared with the result from the curve fit (circles).

Figure 5.8 Co $K$ edge XANES of (a) Co reference standards; (b) Co- $\mathrm{Mo}_{2} \mathrm{C} / \alpha-\mathrm{Al}_{2} \mathrm{O}_{3}$ catalysts with various molar ratios of $\mathrm{Co} / \mathrm{Mo}$. The loading of Mo is $5 \mathrm{wt} \%$. The molar loading of $\mathrm{Co}$ in the sample "Co/Mo $=\infty$ " (Co supported on $\left.\alpha-\mathrm{Al}_{2} \mathrm{O}_{3}\right)$ is equivalent to that of Mo in a 5 wt.\% Mo sample. 149

Figure 5.9 FT (not phase-shift-corrected) of $k^{3}$-weighted Co K edge EXAFS: (a) 3.1 wt.\% $\mathrm{Co} / \alpha-\mathrm{Al}_{2} \mathrm{O}_{3}$; (b) $\mathrm{Co}_{3} \mathrm{O}_{4}$; (c) $\mathrm{CoO}$; (d) $\mathrm{Co}-\mathrm{Mo}_{2} \mathrm{C} / \alpha-\mathrm{Al}_{2} \mathrm{O}_{3}, \mathrm{Co} / \mathrm{Mo}=0.4$; (e) $\mathrm{Co}-\mathrm{Mo}_{2} \mathrm{C} / \alpha-$ $\mathrm{Al}_{2} \mathrm{O}_{3}, \mathrm{Co} / \mathrm{Mo}=1.0$; (f) Co foil. Spectra are offset for clarity. The loading of Mo is 5 wt.\%. The Co/Mo ratio is mole-based. The molar loading of Co corresponding to $3.1 \mathrm{wt} \%$ Co is equivalent to that of Mo in a 5 wt.\% Mo sample. 150

Figure 5.10 Comparison of the curve fit to experimental Co $K$ edge EXAFS of Co$\mathrm{Mo}_{2} \mathrm{C} / \alpha-\mathrm{Al}_{2} \mathrm{O}_{3}(\mathrm{Co} / \mathrm{Mo}=1.0)$ : (a) $k^{3}$-Weighted Mo $K$ edge EXAFS (solid line) and the result from curve fit (circles); (b) magnitude (solid line) and the imaginary part (dashed line) of the Fourier transform of EXAFS compared with the result from the curve fit (circles). 151

Figure 6.1 The reaction system for multi-product SSITKA 165

Figure 6.2 Example normalized transient responses for $\mathrm{Ar},{ }^{12} \mathrm{CH}_{4}$ and ${ }^{13} \mathrm{CH}_{4}$ following a ${ }^{12} \mathrm{CO} /{ }^{13} \mathrm{CO}$ switch during steady state $\mathrm{CO}$ hydrogenation. The shaded area represents the surface mean residence time of $\mathrm{CH}_{4}\left(\tau_{\text {methane }}\right)$. 166

Figure 6.3 Differential CO conversions (excluding $\mathrm{CO}_{2}$ ) over $\mathrm{Mo}_{2} \mathrm{C} / \alpha-\mathrm{Al}_{2} \mathrm{O}_{3}$ catalysts at steady state. Reaction conditions: $573 \mathrm{~K}, 1.2 \mathrm{bar}, \mathrm{H}_{2} / \mathrm{CO}=1$. 169

Figure 6.4 Normalized transient responses up to $1 \mathrm{~h}$ of (a) ${ }^{12} \mathrm{CO}_{2}$, (b) ${ }^{12} \mathrm{CH}_{4}$, and the ${ }^{12} \mathrm{C}$ portion in (c) $\mathrm{C}_{2} \mathrm{H}_{4}$ and (d) $\mathrm{C}_{2} \mathrm{H}_{6}$, over a $5 \mathrm{wt} \% \mathrm{Mo}_{2} \mathrm{C} / \alpha-\mathrm{Al}_{2} \mathrm{O}_{3}$ catalyst in $\mathrm{CO}$ hydrogenation, along with corresponding exponential fits of $F(\mathrm{t})=X_{\mathrm{A}} \exp \left[-\left(t-t_{0}\right) T_{\mathrm{A}}\right]+$ $X_{\mathrm{B}} \exp \left[-\left(t-t_{0}\right) T_{\mathrm{B}}\right]+X_{\mathrm{bkg}}$ (see Table 6.2). Data were further normalized by the corresponding initial response. Experimental conditions: $\mathrm{T}=573 \mathrm{~K}, \mathrm{P}=1.2 \mathrm{bar}, \mathrm{H}_{2} / \mathrm{CO}=$

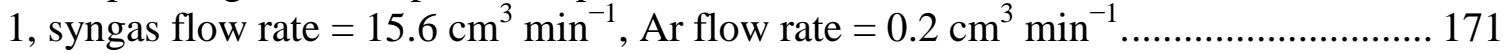

Figure 6.5 Typical normalized transient responses associated with Pool A: (a) $\mathrm{Ar},{ }^{12} \mathrm{CH}_{4}$ and ${ }^{12} \mathrm{CO}_{2}$ and ${ }^{13} \mathrm{CH}_{4}$ over 5 wt. $\% \mathrm{Mo}_{2} \mathrm{C} / \alpha-\mathrm{Al}_{2} \mathrm{O}_{3}$; (b) $\mathrm{Ar},{ }^{12} \mathrm{C}$ (in $\mathrm{CO}, \mathrm{C}_{2} \mathrm{H}_{4}, \mathrm{C}_{2} \mathrm{H}_{6}$ and $\mathrm{C}_{3} \mathrm{H}_{6}$ ) and ${ }^{13} \mathrm{C}$ (in $\mathrm{C}_{2} \mathrm{H}_{6}$ ) over 5 wt.\% $\mathrm{Mo}_{2} \mathrm{C} / \alpha-\mathrm{Al}_{2} \mathrm{O}_{3}$; (c) $\mathrm{Ar},{ }^{12} \mathrm{CH}_{4}$ and ${ }^{13} \mathrm{CH}_{4}$ over 1.5 wt.\% Rb-5 wt.\% $\mathrm{Mo}_{2} \mathrm{C} / \alpha-\mathrm{Al}_{2} \mathrm{O}_{3}$; (d) $\mathrm{Ar},{ }^{12} \mathrm{C}$ (in $\mathrm{CO}, \mathrm{C}_{2} \mathrm{H}_{4}, \mathrm{C}_{2} \mathrm{H}_{6}$ and $\mathrm{C}_{3} \mathrm{H}_{6}$ ) and ${ }^{13} \mathrm{C}$ (in $\mathrm{C}_{2} \mathrm{H}_{4}$ ) over 1.5 wt.\% Rb-5 wt.\% $\mathrm{Mo}_{2} \mathrm{C} / \alpha-\mathrm{Al}_{2} \mathrm{O}_{3}$. $T=573 \mathrm{~K}, p=1.2$ bar, $\mathrm{H}_{2} / \mathrm{CO}=1$, Syngas flow rate $=13.2 \mathrm{~cm}^{3} \mathrm{~min}^{-1}$, Ar flow rate $=0.2 \mathrm{~cm}^{3} \mathrm{~min}^{-1}$. Data were normalized by initial and final transient responses. 174 
Figure 6.6 Mean surface residence time $(\tau)$ of $\mathrm{CO}$ (square), and intermediates leading to $\mathrm{CO}_{2}$ (up triangle), $\mathrm{CH}_{4}$ (circle), $\mathrm{C}_{2} \mathrm{H}_{4}$ (down triangle), $\mathrm{C}_{2} \mathrm{H}_{6}$ (diamond) and $\mathrm{C}_{3} \mathrm{H}_{6}$ (left triangle) vs. the reciprocal of gas flow rate during steady state of $\mathrm{CO}$ hydrogenation over (a) 5 wt.\% $\mathrm{Mo}_{2} \mathrm{C} / \alpha-\mathrm{Al}_{2} \mathrm{O}_{3}$ and (b) 1.5 wt.\% Rb-5 wt.\% $\mathrm{Mo}_{2} \mathrm{C} / \alpha-\mathrm{Al}_{2} \mathrm{O}_{3} \ldots \ldots \ldots \ldots \ldots \ldots \ldots . . . . . . . . . . .175$

Figure 6.7 Normalized desorption rates of carbon in various reaction intermediates (leading to different products) on (a) 5 wt. $\% \mathrm{Mo}_{2} \mathrm{C} / \alpha-\mathrm{Al}_{2} \mathrm{O}_{3}$, and (b) $1.5 \mathrm{wt} . \% \mathrm{Rb}-5 \mathrm{wt} . \%$ $\mathrm{Mo}_{2} \mathrm{C} / \alpha-\mathrm{Al}_{2} \mathrm{O}_{3}$ in steady-state $\mathrm{CO}$ hydrogenation. Data were normalized by the initial and

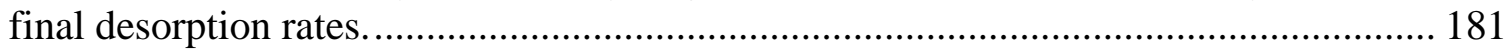

Figure 7.1 Syngas conversion (via methanol) towards C2-C4 olefins and ethanol........ 195

Figure 7.2 Product distribution predicted by the Anderson-Schulz-Flory model [11].. 197 


\section{Chapter 1. \\ Introduction}

\subsection{Higher alcohol synthesis: A potential way to selectively convert syngas}

Limited crude oil reserves and competition with the food industry associated with fermentation-based biofuel production inspire new research efforts on effective catalytic transformations of alternative carbon sources to produce energy carriers and chemical feedstocks. Syngas $\left(\mathrm{CO}+\mathrm{H}_{2}\right)$ can be derived from gasification of coal [1], steam reforming of natural gas [2] and gasification [3] or aqueous-phase reforming [4] of renewable biomass, and is a platform for the synthesis of fuels and chemicals. Given the abundant reserves of coal and natural gas, especially the newly discovered shale gas, North America possesses vast potential resources of syngas, which provides a platform for producing of alternative fuels and chemicals and attracts new efforts in research and development.

Fuels and chemicals produced from syngas are shown in Figure 1.1, which include hydrogen, methanol, diesel, isobutanol, ethanol, etc. [5] Fischer-Tropsch synthesis (FTS) of hydrocarbons has received growing attention as a source of low-sulfur diesel fuel because of the uncertainty of crude oil prices. Fischer-Tropsch synthesis has been applied on a large scale in some industrial sectors in Qatar (29,000 barrels per day (bpd)), Malaysia (15,000 bpd), and South Africa (150,000 bpd), and a 140,000 bpd liquid petroleum product capacity is under construction in Qatar (Shell's Pearl GTL project) [1]. However, the popularity of FTS is hampered by high capital costs as well as high operation and maintenance costs [6]. Higher alcohol (C2+ alcohols) synthesis from 
synthesis gas, as a source of chemical feedstocks, however, might be more commercially attractive. For example, Celanese Corporation reported an expected ethanol price of \$1.4/gallon with their new coal-to-ethanol technology via acetic acid [7,8], and E. I. du Pont de Nemours and Company and BP have a stated goal for a butanol price of \$1/gallon with their bio-based process currently under development [9]. Considering that methanol is produced from syngas over $\mathrm{Cu}-\mathrm{ZnO}$ catalysts, which possesses huge global demand of approximately 40 million tonnes annually [10], it is reasonable to expect a comparably low price for higher alcohols produced by a similar catalytic process, assuming production and selectivity achievements are realized.

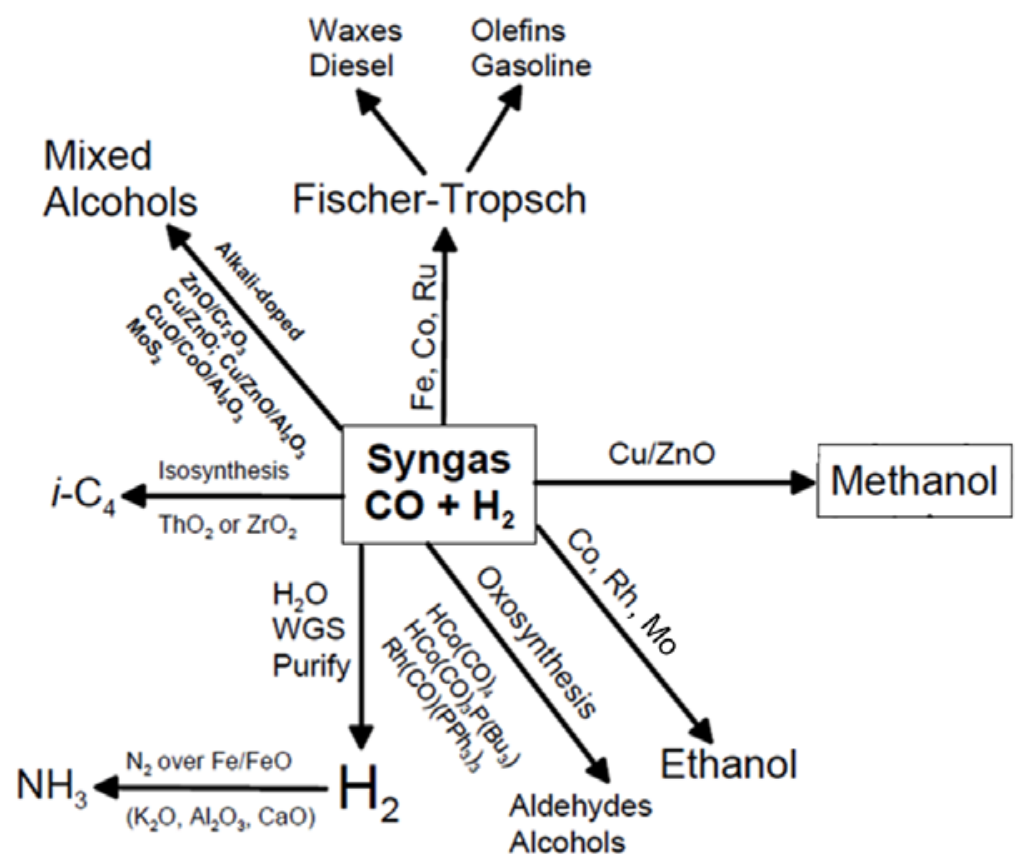

Figure 1.1 Pathways for syngas utilization, depicted on the base of Spath and Dayton [5] Because of methanol's low solubility in gasoline, it needs to be further converted to another molecule such as methyl tert-butyl ether (MTBE) before blended into gasoline. However, MTBE is being phased out as a fuel additive because of environmental concerns. Higher alcohols, on the other hand, have mutual solubility with gasoline and 
ethanol has been widely used in the US as a gasoline additive. Since almost all the ethanol used for fuel is produced from fermentation, there is still a need for a more efficient catalytic process for the production of ethanol (and other higher alcohols).

In higher alcohol synthesis from syngas, the major reaction is higher alcohol formation, while methanol synthesis, Fischer-Tropsch synthesis, water-gas shift reaction and the Boudouard reaction comprise the side reactions:

$\begin{array}{ll}\begin{array}{l}\text { Higher alcohol synthesis } \\ \text { Methanol synthesis }\end{array} & n \mathrm{CO}+2 n \mathrm{H}_{2} \rightarrow \mathrm{C}_{n} \mathrm{H}_{2 n+1} \mathrm{OH}+(n-1) \mathrm{H}_{2} \mathrm{O} \quad(n>1) \\ \text { Fischer-Tropsch synthesis } & \begin{array}{l}\mathrm{CO}+2 \mathrm{H}_{2} \rightarrow \mathrm{CH}_{3} \mathrm{OH} \\ \\ \end{array} \\ \begin{array}{l}\text { Water-gas shift } \\ \text { Boudouard reaction }\end{array} & \mathrm{CO}+(2 n+1) \mathrm{H}_{2} \mathrm{O} \rightarrow \mathrm{C}_{n} \mathrm{H}_{2 n+2}+n \mathrm{CO}_{2}+\mathrm{C}_{n} \mathrm{H}_{2 n}+n \mathrm{H}_{2} \mathrm{O} \\ & 2 \mathrm{CO} \rightarrow \mathrm{C}+\mathrm{CO}_{2}\end{array}$

\subsection{Catalyst candidates for higher alcohol synthesis: The choice of molybdenum carbide}

An effective catalyst for the production of higher alcohols from syngas needs to incorporate multiple functionalities, such as CO activation, hydrogenation, carbon chain growth, alcohol coupling, etc., with $\mathrm{C}-\mathrm{O}$ bonds being partially preserved. Lee et al. [11] depicted the simplified scheme (Figure 1.2) of CO conversion based on the ideas discussed by Ponec and co-workers [12,13]. According to this scheme, all the products can be derived from an adsorbed intermediate ${ }^{*} \mathrm{C}_{\mathrm{m}} \mathrm{H}_{\mathrm{n}}$, (where $*$ denotes a surface site). This intermediate can undergo four different transformations to products namely: (1) hydrogenation to alkanes, (2) carbonylation to alcohol precursors, (3) desorption as olefins, and (4) further chain growth by inserting ${ }^{*} \mathrm{CH}_{\mathrm{x}}$. In this competitive process, hydrogenation activity of a catalyst needs to be partially suppressed to enhance 
production of alcohols (as well as alkenes). Thus, no single-component transition metal catalyst has been discovered to effectively catalyze higher alcohol synthesis.

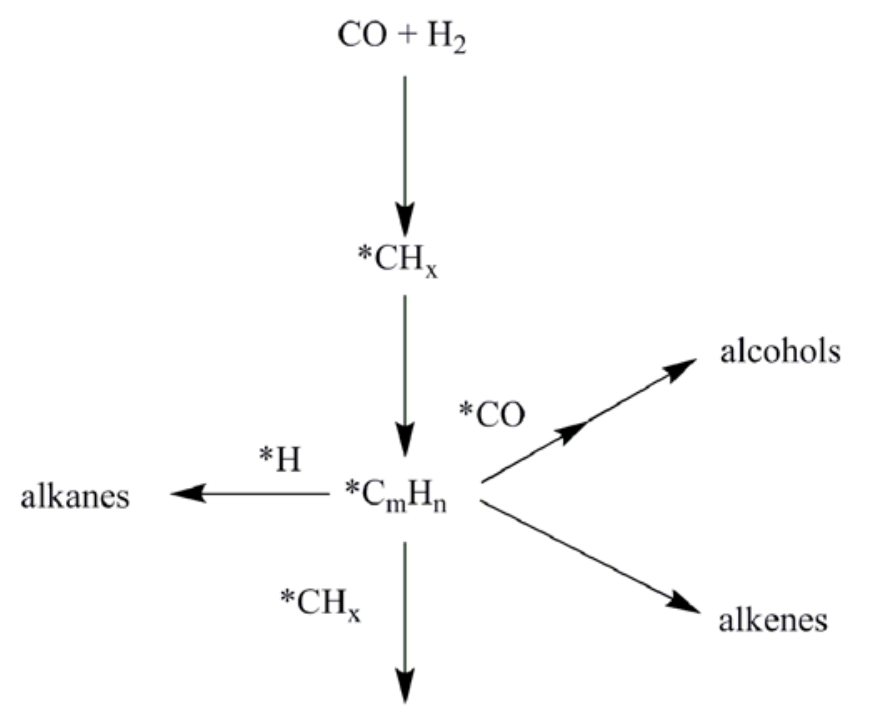

Figure 1.2 Reaction pathway for CO hydrogenation adapted from Lee et al. [11]

Exploratory research on higher alcohol synthesis from syngas has discovered some promising candidates [13-17]. Rhodium-based catalysts are effective for the formation of ethanol and other C2-oxygenates from syngas [3,18-20]. Although Rhbased catalysts possess the best ethanol selectivity among the various catalysts for syngas conversion investigated [21-24], the high selectivity towards hydrocarbons, especially $\mathrm{CH}_{4}$, likely prohibits its large-scale utilization. Furthermore, the very high cost of Rh motivates substantial research interests in the non-precious metal alternatives to Rh.

Several non-precious metal catalysts for higher alcohol synthesis from syngas have thus been evaluated and include, for example, $\mathrm{Cu}$ catalysts $\left(\mathrm{Cu} / \mathrm{ZnO}\right.$ and $\mathrm{Cu} / \mathrm{Cr}_{2} \mathrm{O}_{3}$, primarily for isobutanol [14]), Cu-Co catalysts [25], Zn-Cr-K [15], and promoted Fischer-Tropsch catalysts [3,19], but improvements in the overall catalytic activity, alcohol selectivity, and long-term stability of these catalytic materials for higher alcohol synthesis are still needed. 
Methanol synthesis catalysts $\mathrm{ZnO} / \mathrm{Cr}_{2} \mathrm{O}_{3}$ (relatively high temperature) and $\mathrm{Cu} / \mathrm{ZnO}$ (relatively low temperature), if promoted with alkali metal oxides, produce C1C6 linear and branched alcohols, especially isobutanol [14,26], primarily via aldol condensation or methanol homologation [27]. However, their ethanol selectivity is rather poor because of the fast chain growth of the C2 surface intermediate [28,29]. Alkalimetal-doped Fischer-Tropsch catalysts, although promoting the selectivity of C2+ alcohols over methanol, produce mostly hydrocarbons (> 50\%) from synthesis gas [19]. The performance of $\mathrm{Cu}-\mathrm{Co}$-based catalysts is also poor from the practical point of view, because of their long-term instability and their low alcohol selectivity [30-34].

Metallic Mo adsorbs CO too strongly for CO dissociation, and hence inhibits the reaction of CO. In the presence of the structurally incorporated $\mathrm{C}$, P, or S, however, the interaction between Mo and CO is weakened, which facilitates CO dissociation, either directly on $\mathrm{Mo}_{2} \mathrm{C}$, or assisted by hydrogen on $\mathrm{MoS}_{2}, \mathrm{Mo}_{2} \mathrm{C}$, and $\mathrm{MoP}$ [17]. When promoted by alkali metals, Mo-based catalysts also show encouraging properties for higher alcohol synthesis from CO hydrogenation [17]. It has also been reported that Mo sulfide, phosphide, nitride, and carbide resist sulfur poisoning to some extent [35]. Additional advantages of Mo-based catalysts for practical applications include: less severe catalyst deactivation due to coke deposition (even with a syngas containing a low $\mathrm{H}_{2}$ /CO ratio of less than 2), higher selectivity to linear alcohols (especially ethanol), and low sensitivity to $\mathrm{CO}_{2}$ in the syngas [18]. Both supported and unsupported $\mathrm{MoS}_{2}$-based catalysts have been heavily investigated for higher alcohol synthesis [36-42] since The Dow Chemical Company first developed it in the 1980’s [43-47]. Molybdenum sulfide catalysts effectively produce alcohol from syngas, with alcohol selectivity higher than 75\% 
(on a $\mathrm{CO}_{2}$-free basis) and total alcohol yield as high as $400 \mathrm{mg} \mathrm{g}_{\text {cat }}^{-1} \mathrm{~h}^{-1}$. However, trace amounts of $\mathrm{H}_{2} \mathrm{~S}$ in the feed were required to sustain the performance of the $\mathrm{MoS}_{2}$-based catalysts [44]. Moreover, small amounts of sulfur may enter the carbon skeleton of the products, which is problematic as the world moves toward the use of very-low-sulfur fuels [39]. Thus, there is a need for a non-sulfided alternative for $\mathrm{MoS}_{2}$-based catalyst in this process, among which molybdenum carbide has demonstrated some promise when properly promoted.

After the landmark discovery by Levy and Boudart fourty years ago [48], early transition metal carbides are recognized as potential substitutes to Pt-group metal catalysts because of their similar surface electronic properties [49,50]. Using a temperature-programmed carburization with reductive carburizing gas (such as a mixture of $\mathrm{CH}_{4}$ and $\mathrm{H}_{2}$ ), these materials can be synthesized from the corresponding oxide precursors [51]. The carburization temperature is programmed to increase at a constant rate until certain maximum temperature is reached. This method directly converts the oxide precursor into carbide without forming the metallic state that is more prone to sinter and hence to result in low specific surface area or low dispersion [52].

Early transition metal carbides (e.g., molybdenum carbide, $\mathrm{Mo}_{2} \mathrm{C}$ ) have been demonstrated to be catalytically active for a variety of reactions, such as hydrogenolysis [51], isomerization [54,55], dehydrogenation [56,57], condensation [57,58], water-gas shift [59], CO hydrogenation [11,60-63], etc. When properly promoted, molybdenum carbide has demonstrated modest selectivity to higher alcohols from syngas at appropriate conditions [62,63]. 
The product distribution observed with Mo-based catalysts in CO hydrogenation followed the classic Anderson-Schulz-Flory distribution for hydrocarbons and C2+ alcohols [63-65]. A CO insertion mechanism was speculated for the carbon chain growth in the formation of both hydrocarbons and alcohols [36], which has yet been experimentally proved.

Besides the unclear carbon chain growth mechanism, the fundamentals of the catalysts have yet been well interpreted in many other aspects, including the in situ metal speciation, interaction between the promoters and the catalyst, reaction kinetics, etc. Moreover, improvement on the catalyst performance is still needed.

\subsection{Summary of research topics of interest}

\subsubsection{Influence of oxygen}

It is known that the highly reactive carbide surface is very oxophilic and therefore needs to be passivated before exposure to air. Prior works have described the various behaviors of oxygen-modified carbide surfaces in different reactions. For example, Boudart and co-workers claimed that surface oxygen inhibits the very high reactivity of fresh tungsten carbide for hydrogenolysis of hydrocarbons but forms acid sites that catalyze hydrocarbon isomerization reactions through coupled dehydrogenation and carbenium ion reactions [66-70]. A similar phenomenon was also observed on $\mathrm{Mo}_{2} \mathrm{C}$ catalysts [54]. The presence of acid sites on the catalyst formed by passivation would likely be detrimental to the desired product distribution in higher alcohol synthesis from syngas. In other work, Liu et al. reported that a carbide-modified W(111) surface was highly selective for the dehydrogenation of cyclohexane to benzene after exposure to $\mathrm{O}_{2}$

at $900 \mathrm{~K}$, but was inactive to cyclohexane after exposure to $\mathrm{O}_{2}$ at $<600 \mathrm{~K}$ [71]. Similarly, 
Hwu et al. found that a carbide-modified $\mathrm{Mo}(110)$ surface exposed to $\mathrm{O}_{2}$ at $900 \mathrm{~K}$ exhibited decomposition activity for cyclohexene, ethylene and methanol, whereas the carbide surface was relatively unreactive toward those substrates after $\mathrm{O}_{2}$ exposure at 600 $\mathrm{K}$ [72]. Nagai et al. also show that passivation of molybdenum carbide with dilute $\mathrm{O}_{2}$ at room temperature reduced its activity in $\mathrm{CO}_{2}$ hydrogenation to form $\mathrm{CO}$ and $\mathrm{CH}_{4}$ [73]. Using FT-IR spectroscopy, $\mathrm{Li}$ and co-workers revealed that a surface passivation procedure with dilute $\mathrm{O}_{2}$ at room temperature irreversibly modified a fresh molybdenum carbide surface, hence significantly reducing the number of sites for CO adsorption [74,75]. Evidently, carbidic carbon atoms and/or metal atoms react with the $\mathrm{O}_{2}$ used in passivation, which can significantly modify the observed reactivity of carbide catalysts. Evidently, carbidic carbon atoms and/or metal atoms react with the $\mathrm{O}_{2}$ used in passivation, which can significantly modify the observed reactivity of carbide catalysts. Therefore, the influence of $\mathrm{O}_{2}$ passivation on reactivity must be examined as part of any comprehensive study of carbidic materials for catalysis.

\subsubsection{CO adsorption on molybdenum carbide}

Aegerter et al. attributed a feature of $2178 \mathrm{~cm}^{-1}$ to $\mathrm{CO}$ adsorption on coordinatively-unsaturated $\mathrm{Mo}(\mathrm{IV})$ on a passivated $\mathrm{Mo}_{2} \mathrm{C} / \gamma-\mathrm{Al}_{2} \mathrm{O}_{3}$ catalyst after activation in $\mathrm{H}_{2}$ [76]. The features in the range of 2071-2054 $\mathrm{cm}^{-1}$ have been assigned to linearly adsorbed $\mathrm{CO}$ on a clean hexagonal $\mathrm{Mo}_{2} \mathrm{C}$ foil [77], on carbidic Mo sites present on $\mathrm{Mo}_{2} \mathrm{C} / \gamma-\mathrm{Al}_{2} \mathrm{O}_{3}$ catalysts [74-76], and on modeled surfaces of hexagonal $\mathrm{Mo}_{2} \mathrm{C}$ described by DFT [78,79]. A shoulder CO band at $2125 \mathrm{~cm}^{-1}$ has also been reported when $\mathrm{Mo}_{2} \mathrm{C}$ foil was pre-exposed to $\mathrm{O}_{2}$ [77]. Bands for linearly adsorbed $\mathrm{CO}\left(2015 \mathrm{~cm}^{-1}\right)$ and bridge-bonded CO $\left(1850 \mathrm{~cm}^{-1}\right)$ were also seen by high-resolution electron energy 
loss spectroscopy (HREELS) on a Mo (110) single crystal with a surface carbide layer [80]. Moreover, ketenylidene species have been proven to be the most stable configuration of adsorbed $\mathrm{CO}$ on a C-terminated $\mathrm{Mo}_{2} \mathrm{C}$ surface by DFT [81]. Ketenylidene also formed when $\mathrm{CO}$ was adsorbed on a $\mathrm{W}_{2} \mathrm{C}$ surface that possessed a similar structure to $\mathrm{Mo}_{2} \mathrm{C}$, giving $\mathrm{C}-\mathrm{O}$ stretching frequencies ranging from $1954 \mathrm{~cm}^{-1}$ to $2041 \mathrm{~cm}^{-1}$ with increasing CO coverage [82].

However, previous works had not demonstrated whether the adsorption modes of $\mathrm{CO}$ on $\mathrm{Mo}_{2} \mathrm{C}$ mentioned above were catalytically relevant in $\mathrm{CO}$ hydrogenation. The $\mathrm{CO}$ adsorption experiments on the working catalysts are necessary for a better understanding of the catalyst surface.

\subsubsection{The interaction between the alkali metal species and the molybdenum carbide catalyst}

The addition of alkali metal species to Mo-based catalysts shifts the product selectivity in syngas conversion from hydrocarbons to alcohols. By using Auger electron spectroscopy, Lee et al. observed better dispersion of $\mathrm{K}$ promoter on $\mathrm{MoS}_{2}$ [38] and $\mathrm{Mo}_{2} \mathrm{C}$ [11] catalysts for alcohol synthesis after being exposed to syngas reaction conditions, and hence speculated that the promotional effect of alkali metal species was mostly the result of the surface sites being blocked from adsorbing reactants. By using diffuse reflectance infrared Fourier-transform spectroscopy (DRIFTS), Koizumi et al. claimed that syngas adsorption on a $\mathrm{MoS}_{2} / \gamma-\mathrm{Al}_{2} \mathrm{O}_{3}$ catalyst for $\mathrm{CO}$ hydrogenation was significantly suppressed by K species and the K-promoted Mo species were likely more oxidized than those on K-free $\mathrm{MoS}_{2}$ [63]. Muramatsu et al. also studied the role of a K promoter on a Mo oxide catalyst for alcohol production from syngas and concluded that 
$\mathrm{K}$ inhibits both dehydration of alcohols (to alkenes) and the hydrogenation of alkenes (to alkanes) [84]. For supported $\mathrm{MoS}_{2}$-based catalysts, interactions between $\mathrm{K}$ promoters and Mo begins with the oxidized catalyst precursors [37,85-87] and that some K-Mo-S and/or K-Mo-S-O species are formed after sulfidation. However, it is still unclear whether the promoters enhance the activity of the catalysts for higher alcohol synthesis. Although CO adsorption has been used to probe the surfaces of $\mathrm{MoS}_{2}$-based [88-93] and $\mathrm{Mo}_{2} \mathrm{C}$-based [74-77,94] catalysts, few of these studies addressed the promotional influence of the alkali metals on higher alcohol synthesis.

Han et al. [95] reported an optimized hexagonal $\mathrm{Mo}_{2} \mathrm{C}$ structure for the adsorption of $\mathrm{K}$ and $\mathrm{Rb}$ atoms and found that they tended to be adsorbed on the C-terminated reconstructed hexagonal $\mathrm{Mo}_{2} \mathrm{C}(001)$ surface, where the adsorbed $\mathrm{K}$ or $\mathrm{Rb}$ atom was coordinated with three $\mathrm{C}$ atoms and three Mo atoms. However, it was unclear whether this configuration was catalytically relevant to the actual catalyst surface during reaction.

Therefore, a better interpretation is needed on the interaction between the alkali metal promoter and the $\mathrm{Mo}_{2} \mathrm{C}$ catalyst that affects the product distribution in $\mathrm{CO}$ hydrogenation, i.e., the structure-function relationship.

\subsubsection{Cobalt as a secondary promoter}

Since addition of cobalt to alkali-metal-promoted $\mathrm{MoS}_{2}$ catalysts enhanced their activity in higher alcohol synthesis from syngas [96], and the $\mathrm{Mo}_{2} \mathrm{C}$ - and $\mathrm{MoS}_{2}$-based catalysts behave very similarly in syngas conversion, it is logical to explore the influence of Co on alkali-metal-promoted $\mathrm{Mo}_{2} \mathrm{C}$ catalysts in the reaction. In fact, Sun and coworkers studied the influence of CO-hydrogenation-active components (Fe, Co and $\mathrm{Ni}$ ) on unsupported $\mathrm{Mo}_{2} \mathrm{C}$ for conversion of syngas and reported that the alcohol production 
rate over $\mathrm{Mo}_{2} \mathrm{C}$ catalysts was promoted by added $\mathrm{Co}$ and $\mathrm{Fe}$, but not $\mathrm{Ni}$, and $\mathrm{Co}$ was best promoter among the three [13,97]. Lucero et al. reported that $\mathrm{Ni}$ enhanced the productivity and ratio of ethanol to methanol over Na-promoted bulk $\mathrm{Mo}_{2} \mathrm{C}$ catalysts [98]. However, the synergetic effects between $\mathrm{Mo}_{2} \mathrm{C}$ and the transition metal promoter, especially the atomic interaction, have yet to be well explained. Moreover, optimization of the alcohol selectivity on this type of catalyst is still needed.

\subsubsection{Nature of active sites on molybdenum carbide}

The apparent reactivity of the $\mathrm{Mo}_{2} \mathrm{C}$-based catalysts was low compared to other elements that are active in CO hydrogenation. For example, the apparent turnover frequencies (TOFs) of CO (normalized by the amount of surface metal atoms) on $\mathrm{Mo}_{2} \mathrm{C} / \alpha-\mathrm{Al}_{2} \mathrm{O}_{3}$ catalysts [99] were approximately two orders of magnitude lower than that on a $\mathrm{Fe}-\mathrm{Rh} / \mathrm{TiO}_{2}$ catalyst under similar conditions [20]. The very low apparent activity can be attributed to either the intrinsic slow turnover of the catalytic cycle or the small concentration of the active sites. Due to the high oxophilicity of $\mathrm{Mo}_{2} \mathrm{C}$, it needs an appropriate in situ pretreatment is needed to count the active sites on the surface of $\mathrm{Mo}_{2} \mathrm{C}$, which may not be achieved by a conventional methodology (like CO chemisorption). Therefore, a powerful in situ technique is needed to unveil the kinetic information on $\mathrm{Mo}_{2} \mathrm{C}$ catalysts in $\mathrm{CO}$ hydrogenation.

\subsection{Objectives in this study}

This study explored the roles of structure, reaction conditions and catalyst passivation on catalyst performance in selective syngas conversion. The research efforts aim to understand: 
1. The in situ metal speciation, including molybdenum carbide catalysts and the rubidium and cobalt promoters;

2. The nature of the promotional effect on molybdenum carbide, especially from the alkali metals;

3. The intrinsic kinetic parameters of CO hydrogenation on molybdenum carbide.

A variety of in situ techniques were used to study the catalysts at syngas working conditions, including X-ray absorption spectroscopy (XAS), diffuse reflectance infrared Fourier transform spectroscopy (DRIFTS) and steady-state isotopic transient kinetic analysis (SSTIKA). Catalysts were also characterized by transmission electron microscopy, elemental analysis, X-ray powder diffraction and surface area analysis.

Hydrogenation of $\mathrm{CO}$ was conducted in a fixed-bed stainless steel reactor at typical conditions of $573 \mathrm{~K}, 30$ bar syngas and $\mathrm{H}_{2} / \mathrm{CO}=1$. Rubidium was chosen to be the alkali metal promoter rather than the conventional potassium for a spectroscopic reason, since it has the appropriate edge energy for in situ transmission-mode XAS with high-pressure syngas. All the XAS experiments were conducted at beamlines X18B and X23A2 at National Synchrotron Light Source, Brookhaven National Laboratory. An airfree sample preparation method was also developed for ex situ XAS to simplify the operation on the beamline, which involved the use of glovebox. Infrared spectroscopy was performed in diffuse-reflectance-mode with loose-powder samples to simplify the sample preparation (transmission-mode IR needs the sample to be pelletized), and the DRIFTS reactor/cell also allowed sample pretreatment at syngas reaction conditions. The SSITKA method was used to study the intrinsic kinetics of $\mathrm{CO}$ hydrogenation on $\mathrm{Mo}_{2} \mathrm{C}$ catalysts. The conventional SSITKA system in the lab was substantially upgraded for 
multi-product analyses, which avoided problematic fragmentation and overlapping peaks in the mass spectrometer.

\section{References of Chapter 1}

[1] D. Leckel, "Diesel Production from Fischer-Tropsch: The Past, the Present, and New Concepts,” Energy \& Fuels 23 (2009) 2342-2358.

[2] J. Rostrup-Nielsen, "Fuels and Energy for the Future: The Role of Catalysis," Catalysis Reviews: Science and Engineering 46 (2004) 247-270.

[3] J.J. Spivey, A. Egbebi, "Heterogeneous catalytic synthesis of ethanol from biomassderived syngas," Chemical Society Reviews 36 (2007) 1514-1528.

[4] J.N. Chheda, G.W. Huber, J.A. Dumesic, "Liquid-phase catalytic processing of biomass-derived oxygenated hydrocarbons to fuels and chemicals," Angewandte Chemie International Edition 46 (2007) 7164-7183.

[5] P.L. Spath, D.C. Dayton, "Preliminary Screening - Technical and economic assessment of synthesis gas to fuels and chemicals with emphasis on the potential for biomass-derived syngas," U.S. Department of Energy Report, Oak Ridge, TN, 2003.

[6] G.W. Huber, S. Iborra, A. Corma, "Synthesis of Transportation Fuels from Biomass: Chemistry, Catalysts, and Engineering,” Chemical Reviews 106 (2006) 4044-4098.

[7] V.J. Johnston, L. Chen, B.F. Kimmich, J.T. Chapman, J.H. Zink, "Direct and selective production of ethanol from acetic acid utilizing a platinum/tin catalyst," U.S. Patent 7863489, 2011, to Celanese Corporation.

[8] V.J. Johnston, L. Chen, B.F. Kimmich, J.T. Chapman, J.H. Zink, "Direct and selective production of ethanol from acetic acid utilizing a platinum/tin catalyst," U.S. Patent 8071821, 2011, to Celanese Corporation.

[9] G. Hess, "BP and DuPont plan 'biobutanol'," Chemical Engineering News 84 (2006) 9.

[10] G.A. Olah, A. Goeppert, G.K.S. Prakash, "Beyond Oil and Gas: The Methanol Economy,” John Wiley \& Sons, 2006.

[11] J.S. Lee, S. Kim, Y.G. Kim, "Electronic and geometric effects of alkali promoters in CO hydrogenation over $\mathrm{K} / \mathrm{Mo}_{2} \mathrm{C}$ catalysts," Topics in Catalysis 2 (1995) 127140 .

[12] V. Ponec, “Active centres for synthesis gas reactions," Catalysis Today 12 (1992) 227-254. 
[13] K. Fang, D. Li, M. Lin, M. Xiang, W. Wei, Y. Sun, "A short review of heterogeneous catalytic process for mixed alcohols synthesis via syngas," Catalysis Today 147 (2009) 133-138.

[14] P. Forzatti, E. Tronconi, I. Pasquon, "Higher alcohol synthesis,” Catalysis Reviews: Science and Engineering 33 (1991) 109-168.

[15] I. Wender, “Reactions of synthesis gas,” Fuel Processing Technology 48 (1996) 189-297.

[16] R.G. Herman, “Advances in catalytic synthesis and utilization of higher alcohols," Catalysis Today 55 (2000) 233-245.

[17] S. Zaman, K.J. Smith, "A review of molybdenum catalysts for synthesis gas conversion to alcohols: catalysts, mechanisms and kinetics," Catalysis Reviews: Science and Engineering 54 (2012) 41-132.

[18] M.M. Bhasin, G.L. O’Connor, “Procede de preparation selective de derives hydrocarbones oxygenes a deux atomes de carbone,” Belgian Patent 824822, 1975.

[19] V. Subramani, S.K. Gangwal, "A review of recent literature to search for an efficient catalytic process for the conversion of syngas to ethanol," Energy \& Fuels 22 (2008) 814-839.

[20] M.A. Haider, M.R. Gogate, R.J. Davis, "Fe-promotion of supported Rh catalysts for direct conversion of syngas to ethanol,” Journal of Catalysis 261 (2009) 9-16.

[21] S.S.C. Chuang, R.W. Stevens, R. Khatri, "Mechanism of C2+ oxygenate synthesis on Rh catalysts,” Topics in Catalysis 32 (2005) 225-232.

[22] J. Hu, Y. Wang, C. Cao, D.C. Elliott, D.J. Stevens, J.F. White, “Conversion of biomass-derived syngas to alcohols and C2 oxygenates using supported Rh catalysts in a microchannel reactor,” Catalysis Today 120 (2007) 90-95.

[23] Z. Fan, W. Chen, X. Pan, X. Bao, "Catalytic conversion of syngas into C2 oxygenates over Rh-based catalysts - Effect of carbon supports,” Catalysis Today 147 (2009) 86-93.

[24] D. Mei, R. Rousseau, S.M. Kathmann, V.-A. Glezakou, M.H. Engelhard, W. Jiang, C. Wang, M.A. Gerber, J.F. White, D.J. Stevens, "Ethanol synthesis from syngas over Rh-based $/ \mathrm{SiO}_{2}$ catalysts: A combined experimental and theoretical modeling study,” Journal of Catalysis 271 (2010) 325-342.

[25] P. Chaumette, P. Courty, A. Kiennemann, R. Kieffer, S. Boujana, G.A. Martin, J.A. Dalmon, P. Meriaudeau, C. Mirodatos, "Evolution of alcohol synthesis catalysts under syngas,” Industrial \& Engineering Chemistry Research 33 (1994) 1460-1467. 
[26] A. Beretta, Q. Sun, R.G. Herman, K. Klier, "Production of methanol and isobutyl alcohol mixtures over double-bed cesium-promoted $\mathrm{Cu} / \mathrm{ZnO} / \mathrm{Cr}_{2} \mathrm{O}_{3}$ and $\mathrm{ZnO} / \mathrm{Cr}_{2} \mathrm{O}_{3}$ catalysts,” Industrial \& Engineering Chemistry Research 35 (1996) 1534-1542.

[27] J.G. Nunan, C.E. Bogdan, K. Klier, K.J. Smith, C.-W. Young, R.G. Herman, "Methanol and $\mathrm{C} 2$ oxygenate synthesis over cesium doped $\mathrm{CuZnO}$ and $\mathrm{Cu} / \mathrm{ZnO} / \mathrm{Al}_{2} \mathrm{O}_{3}$ catalysts: A study of selectivity and ${ }^{13} \mathrm{C}$ incorporation patterns," Journal of Catalysis 113 (1988) 410-433.

[28] K.J. Smith, R.B. Anderson, "A chain growth scheme for the higher alcohols synthesis,” Journal of Catalysis 85 (1984) 428-436.

[29] K.J. Smith, C.W. Young, R.G. Herman, K. Klier, "Development of a kinetic model for alcohol synthesis over a cesium-promoted copper/zinc oxide catalyst," Industrial \& Engineering Chemistry Research 30 (1991) 61-71.

[30] V. Mahdavi, M.H. Peyrovi, M. Islami, J.Y. Mehr, "Synthesis of higher alcohols from syngas over $\mathrm{Cu}-\mathrm{Co}_{2} \mathrm{O}_{3} / \mathrm{ZnO}, \mathrm{Al}_{2} \mathrm{O}_{3}$ catalyst," Applied Catalysis A: General 281 (2005) 259-265.

[31] V. Mahdavi, M.H. Peyrovi, "Synthesis of C1-C6 alcohols over copper/cobalt catalysts: Investigation of the influence of preparative procedures on the activity and selectivity of $\mathrm{Cu}-\mathrm{Co}_{2} \mathrm{O}_{3} / \mathrm{ZnO}, \mathrm{Al}_{2} \mathrm{O}_{3}$ catalyst," Catalysis Communications 7 (2006) 542-549.

[32] N. Tien-Thao, H. Alamdari, M.H. Zahedi-Niaki, S. Kaliaguine, " $\mathrm{LaCo}_{1-x} \mathrm{Cu}_{\mathrm{x}} \mathrm{O}_{3-\delta}$ perovskite catalysts for higher alcohol synthesis," Applied Catalysis A: General. 311 (2006) 204-212.

[33] N. Tien-Thao, M.H. Zahedi-Niaki, H. Alamdari, S. Kaliaguine, "Conversion of syngas to higher alcohols over nanosized $\mathrm{LaCo}_{0.7} \mathrm{Cu}_{0.3} \mathrm{O}_{3}$ perovskite precursors," Applied Catalysis A: General 326 (2007) 152-163.

[34] N. Tien-Thao, M. Hassan Zahedi-Niaki, H. Alamdari, S. Kaliaguine, "Effect of alkali additives over nanocrystalline Co-Cu-based perovskites as catalysts for higher-alcohol synthesis,” Journal of Catalysis 245 (2007) 348-357.

[35] S.T. Oyama, "Novel catalysts for advanced hydroprocessing: transition metal phosphides," Journal of Catalysis 216 (2003) 343-352.

[36] J.M. Christensen, P.A. Jensen, N.C. Schiødt, A.D. Jensen, "Coupling of Alcohols over Alkali-Promoted Cobalt-Molybdenum Sulfide,” ChemCatChem 2 (2010) 523526.

[37] Y. Avila, C. Kappenstein, S. Pronier, J. Barrault, "Alcohol synthesis from syngas over supported molybdenum catalysts," Applied Catalysis A: General 132 (1995) 97-109. 
[38] J.S. Lee, S. Kim, K.H. Lee, I.-S. Nam, J.S. Chung, Y.G. Kim, H.C. Woo, "Role of alkali promoters in $\mathrm{K} / \mathrm{MoS}_{2}$ catalysts for $\mathrm{CO}-\mathrm{H}_{2}$ reactions," Applied Catalysis A: General 110 (1994) 11-25.

[39] J.M. Christensen, P.M. Mortensen, R. Trane, P.A. Jensen, A.D. Jensen, "Effects of $\mathrm{H}_{2} \mathrm{~S}$ and process conditions in the synthesis of mixed alcohols from syngas over alkali promoted cobalt-molybdenum sulfide,” Applied Catalysis A: General 366 (2009) 29-43.

[40] V.R. Surisetty, A. Tavasoli, A.K. Dalai, "Synthesis of higher alcohols from syngas over alkali promoted $\mathrm{MoS}_{2}$ catalysts supported on multi-walled carbon nanotubes," Applied Catalysis A: General 365 (2009) 243-251.

[41] G. Budroni, R. Bruening, D. Ferrari, D. Nieskens, N. Rane, "Conversion of syngas to mixed alcohols on supported $\mathrm{CoMoS}_{\mathrm{x}}$ catalysts," Patent Application (2012) WO 2012078276 A1 20120614, to The Dow Chemical Company.

[42] G. Budroni, R. Bruening, D. Ferrari, D. Nieskens, N. Rane, "Conversion of syngas to mixed alcohols on chromium-promoted, supported $\mathrm{CoMoS}_{\mathrm{x}}$ catalysts," Patent application (2012) WO 2011-US59512 A1 20120614, to The Dow Chemical Company.

[43] G.J. Quarderer, G.A. Cochran, "Catalytic process for producing mixed alcohols from hydrogen and carbon monoxide," European Patent EP0119609, 1984, to The Dow Chemical Company.

[44] M.M. Conway, C.B. Murchison, R.R. Stevens, "Method for adjusting methanol to higher alcohol ratios,” U.S. Patent 4675344, 1987, to The Dow Chemical Company.

[45] G.J. Quarderer, G.A. Cochran, "Process for producing alcohols from synthesis gas," U.S. Patent 4749724, 1988, to The Dow Chemical Company.

[46] R.R. Stevens, "Process for producing alcohols from synthesis gas," U.S. Patent 4752622, 1988, to The Dow Chemical Company.

[47] R.R. Stevens, "Process for producing alcohols from synthesis gas," U.S. Patent 4882360, 1989, to The Dow Chemical Company.

[48] R.B. Levy, M. Boudart, "Platinum-like behavior of tungsten carbide in surface catalysis,” Science 181 (1973) 547-549.

[49] H.H. Hwu, J.G. Chen, "Surface chemistry of transition metal carbides," Chemical Reviews 105 (2005) 185-212.

[50] J.G. Chen, "Carbide and nitride overlayers on early transition metal surfaces: preparation, characterization, and reactivities," Chemical Reviews 96 (1996) 14771498. 
[51] J.S. Lee, S.T. Oyama, M. Boudart, "Molybdenum carbide catalysts: I. Synthesis of unsupported powders,” Journal of Catalysis 106 (1987) 125-133.

[52] S. T. Oyama, "Preparation and Catalytic Properties of Transition Metal Carbides and Nitrides,” Catalysis Today 15 (1992) 179-200.

[53] J.S. Lee, S. Locatelli, S.T. Oyama, M. Boudart, "Molybdenum carbide catalysts 3. Turnover rates for the hydrogenolysis of n-butane,” Journal of Catalysis 125 (1990) 157-170.

[54] E.A. Blekkan, C. Pham-Huu, M.J. Ledoux, J. Guille, "Isomerization of $n$-heptane on an oxygen-modified molybdenum carbide catalyst," Industrial \& Engineering Chemistry Research 33 (1994) 1657-1664.

[55] M.J. Ledoux, C. Pham-Huu, R.R. Chianelli, “Catalysis with carbides,” Current Opinion in Solid State and Materials Science 1 (1996) 96-100.

[56] T. Hyeon, M. Fang, K.S. Suslick, "Nanostructured molybdenum carbide: sonochemical synthesis and catalytic properties," Journal of the American Chemical Society 118 (1996) 5492-5493.

[57] S.K. Bej, C.A. Bennett, L.T. Thompson, "Acid and base characteristics of molybdenum carbide catalysts,” Applied Catalysis A.: General 250 (2003) 197-208.

[58] S.K. Bej, L.T. Thompson, “Acetone condensation over molybdenum nitride and carbide catalysts,” Applied Catalysis A: General 264 (2004) 141-150.

[59] J. Patt, D.J. Moon, C. Phillips, L. Thompson, "Molybdenum carbide catalysts for water-gas shift,” Catalysis Letter 65 (2000) 193-195.

[60] I. Kojima, E. Miyazaki, I. Yasumori, "Synthesis of hydrocarbons from $\mathrm{CO}$ and $\mathrm{H}_{2}$ over metal carbide catalysts," Journal of the Chemical Society, Chemical Communications (1980) 573-574.

[61] I. Kojima, E. Miyazaki, "Catalysis by transition metal carbides: V. Kinetic measurements of hydrogenation of $\mathrm{CO}$ over $\mathrm{TaC}$, $\mathrm{TiC}$, and $\mathrm{Mo}_{2} \mathrm{C}$ catalysts," Journal of Catalysis 89 (1984) 168-171.

[62] H.C. Woo, K.Y. Park, Y.G. Kim, I.S. Nam, J.S. Chung, J.S. Lee, "Mixed alcohol synthesis from carbon monoxide and dihydrogen over potassium-promoted molybdenum carbide catalysts,” Applied Catalysis 75 (1991) 267-280.

[63] M. Xiang, D. Li, W. Li, B. Zhong, Y. Sun, "Performances of mixed alcohols synthesis over potassium promoted molybdenum carbides,” Fuel 85 (2006) 26622665. 
[64] A.K. Gunturu, E.L. Kugler, J.B. Cropley, D.B. Dadyburjor, “A kinetic model for the synthesis of high-molecular-weight alcohols over a sulfided Co-K-Mo/C Catalyst,” Industrial \& Engineering Chemistry Research 37 (1998) 2107-2115.

[65] K.J. Smith, R.G. Herman, K. Klier, "Kinetic modelling of higher alcohol synthesis over alkali-promoted $\mathrm{Cu} / \mathrm{ZnO}$ and $\mathrm{MoS}_{2}$ catalysts”. Chemical Engineering Science 45 (1990) 2639-2646.

[66] F.H. Ribeiro, R.A. Dalla Betta, M. Boudart, J. Baumgartner, E. Iglesia, "Reactions of neopentane, methylcyclohexane, and 3,3-dimethylpentane on tungsten carbides: The effect of surface oxygen on reaction pathways,” Journal of Catalysis 130 (1991) 86-105.

[67] F.H. Ribeiro, M. Boudart, R.A. Dalla Betta, E. Iglesia, "Catalytic reactions of nalkanes on $\beta-\mathrm{W}_{2} \mathrm{C}$ and $\mathrm{WC}$ : The effect of surface oxygen on reaction pathways," Journal of Catalysis 130 (1991) 498-513.

[68] E. Iglesia, J.E. Baumgartner, F.H. Ribeiro, M. Boudart, "Bifunctional reactions of alkanes on tungsten carbides modified by chemisorbed oxygen," Journal of Catalysis 131 (1991) 523-544.

[69] E. Iglesia, F.H. Ribeiro, M. Boudart, J.E. Baumgartner, "Synthesis, characterization, and catalytic properties of clean and oxygen-modified tungsten carbides," Catalysis Today 15 (1992) 307-337.

[70] E. Iglesia, F.H. Ribeiro, M. Boudart, J.E. Baumgartner, "Tungsten carbides modified by chemisorbed oxygen. A new class of bifunctional catalysts," Catalysis Today 15 (1992) 455-458.

[71] N. Liu, S.A. Rykov, J.G. Chen, “A comparative surface science study of carbide and oxycarbide: the effect of oxygen modification on the surface reactivity of C/W(1 1 1),” Surface Science 487 (2001) 107-117.

[72] H.H. Hwu, M.B. Zellner, J.G. Chen, "The chemical and electronic properties of oxygen-modified C/Mo(110): a model system for molybdenum oxycarbides,” Journal of Catalysis 229 (2005) 30-44.

[73] M. Nagai, T. Kurakami, S. Omi, “Activity of carbided molybdena-alumina for $\mathrm{CO}_{2}$ hydrogenation,” Catalysis Today 45 (1998) 235-239.

[74] W. Wu, Z. Wu, C. Liang, X. Chen, P. Ying, C. Li, "In situ FT-IR spectroscopic studies of $\mathrm{CO}$ adsorption on fresh $\mathrm{Mo}_{2} \mathrm{C} / \mathrm{Al}_{2} \mathrm{O}_{3}$ catalyst," The Journal of Physical Chemistry B 107 (2003) 7088-7094.

[75] W. Wu, Z. Wu, C. Liang, P. Ying, Z. Feng, C. Li, “An IR study on the surface passivation of $\mathrm{Mo}_{2} \mathrm{C} / \mathrm{Al}_{2} \mathrm{O}_{3}$ catalyst with $\mathrm{O}_{2}, \mathrm{H}_{2} \mathrm{O}$ and $\mathrm{CO}_{2}$," Physical Chemistry Chemical Physics 6 (2004) 5603-5608. 
[76] P.A. Aegerter, W.W.C. Quigley, G.J. Simpson, D.D. Ziegler, J.W. Logan, K.R. McCrea, S. Glazier, M.E. Bussell, "Thiophene Hydrodesulfurization over AluminaSupported Molybdenum Carbide and Nitride Catalysts: Adsorption Sites, Catalytic Activities, and Nature of the Active Surface,” Journal of Catalysis 164 (1996) 109121.

[77] J. Wang, M. Castonguay, P.H. McBreen, S. Ramanathan, S.T. Oyama, "Chemisorption of CO and NO molybdenum carbide foils," in: S.T. Oyama (Ed.), The Chemistry of Transition Metal Carbides and Nitrides, Springer, 1996: pp. 426438.

[78] H. Tominaga, M. Nagai, "Density functional theory of water-gas shift reaction on molybdenum carbide,” The Journal Physical Chemistry B 109 (2005) 20415-20423.

[79] X.-R. Shi, J. Wang, K. Hermann, "CO and NO adsorption and dissociation at the $\beta$ $\mathrm{Mo}_{2} \mathrm{C}(0001)$ surface: A density functional theory study," The Journal Physical Chemistry C 114 (2010) 13630-13641.

[80] B. Frühberger, J.G. Chen, "Modification of the surface reactivity of Mo(110) upon carbide formation," Surface Science 342 (1995) 38-46.

[81] J. Ren, C.-F. Huo, J. Wang, Y.-W. Li, H. Jiao, "Surface structure and energetics of oxygen and CO adsorption on $\alpha-\mathrm{Mo}_{2} \mathrm{C}(000$ 1)," Surface Science 596 (2005) 212221.

[82] T. Aizawa, S. Otani, "Adsorption of $\mathrm{CO}$ and $\mathrm{O}_{2}$ on $\mathrm{W}_{2} \mathrm{C}(0001)$," The Journal of Chemical Physics 135 (2011) 144704.

[83] N. Koizumi, G. Bian, K. Murai, T. Ozaki, M. Yamada, "In situ DRIFT studies of sulfided $\mathrm{K}-\mathrm{Mo} / \gamma-\mathrm{Al}_{2} \mathrm{O}_{3}$ catalysts," Journal of Molecular Catalysis A: Chemical 207 (2004) 173-182.

[84] A. Muramatsu, T. Tatsumi, H. Tominaga, "Mixed alcohol synthesis from $\mathrm{CO}-\mathrm{H}_{2}$ by use of KCl-promoted $\mathrm{Mo} / \mathrm{SiO}_{2}$ catalysts," Bulletin of the Chemical Society of Japan 60 (1987) 3157-3161.

[85] M. Jiang, G.-Z. Bian, Y.-L. Fu, "Effect of the $\mathrm{K}-\mathrm{Mo}$ interaction in $\mathrm{K}-\mathrm{MoO}_{3} / \gamma$ $\mathrm{Al}_{2} \mathrm{O}_{3}$ catalysts on the properties for alcohol synthesis from syngas," Journal of Catalysis 146 (1994) 144-154.

[86] N.F.D. Verbruggen, G. Mestl, L.M.J. von Hippel, B. Lengeler, H. Knoezinger, "Structure of K-doped molybdena-on-alumina catalysts as studied by X-ray absorption and Raman spectroscopy,” Langmuir 10 (1994) 3063-3072.

[87] N.F.D. Verbruggen, L.M.J. von Hippel, G. Mestl, B. Lengeler, H. Knoezinger, "Structure of K-doped molybdena-on-silica catalysts as studied by X-ray absorption and Raman spectroscopy,” Langmuir 10 (1994) 3073-3080. 
[88] Y. Fu, F. Zhao, "The adsorption characteristics of two Mo sites on a sulfided $\mathrm{MoO}_{3} / \gamma-\mathrm{Al}_{2} \mathrm{O}_{3}$ surface," Catalysis Letters 12 (1992) 117-125.

[89] F. Maugé, J.C. Lavalley, "FT-IR study of co adsorption on sulfided $\mathrm{Mo} / \mathrm{Al}_{2} \mathrm{O}_{3}$ unpromoted or promoted by metal carbonyls: Titration of sites," Journal of Catalysis 137 (1992) 69-76.

[90] B. Müller, A.D. van Langeveld, J.A. Moulijn, H. Knözinger, “Characterization of sulfided molybdenum/alumina catalysts by temperature-programmed reduction and low-temperature Fourier transform infrared spectroscopy of adsorbed carbon monoxide,” The Journal of Physical Chemistry 97 (1993) 9028-9033.

[91] A. Travert, C. Dujardin, F. Maugé, S. Cristol, J.F. Paul, E. Payen, et al., "Parallel between infrared characterisation and ab initio calculations of CO adsorption on sulphided Mo catalysts,” Catalysis Today 70 (2001) 255-269.

[92] A.A. Tsyganenko, F. Can, A. Travert, F. Maugé, "FTIR study of unsupported molybdenum sulfide-in situ synthesis and surface properties characterization," Applied Catalysis A: Genenral 268 (2004) 189-197.

[93] A. Travert, C. Dujardin, F. Maugé, E. Veilly, S. Cristol, J.-F. Paul, E. Payen, "CO Adsorption on CoMo and NiMo Sulfide Catalysts: A Combined IR and DFT Study," The Journal of Physical Chemistry B 110 (2006) 1261-1270.

[94] J. Raskó, J. Kiss, "Infrared study of the adsorption of $\mathrm{CO}$ and $\mathrm{CH}_{3}$ on silicasupported $\mathrm{MoO}_{3}$ and $\mathrm{Mo}_{2} \mathrm{C}$ catalysts,” Applied Catalysis A: General 253 (2003) 427-436.

[95] J.W. Han, L. Li, D.S. Sholl, "Density functional theory study of $\mathrm{H}$ and CO adsorption on alkali-promoted $\mathrm{Mo}_{2} \mathrm{C}$ surfaces," The Journal Physical Chemistry $\mathrm{C}$ 115 (2011) 6870-6876.

[96] Z. Li, Y. Fu, J. Bao, M. Jiang, T. Hu, T. Liu, Y. Xie, "Effect of cobalt promoter on Co-Mo-K/C catalysts used for mixed alcohol synthesis," Applied Catalysis A: General 220 (2001) 21-30.

[97] M. Xiang, D. Li, H. Xiao, J. Zhang, H. Qi, W. Li, B. Zhong, Y. Sun, "Synthesis of higher alcohols from syngas over Fischer-Tropsch elements modified $\mathrm{K} / \beta-\mathrm{Mo}_{2} \mathrm{C}$ catalysts,” Fuel 87 (2008) 599-603.

[98] A.J. Lucero, V.K. Sethi, W.H. Tuminello, "Process and catalyst for production of mixed alcohols from synthesis gas,” U.S. Patent 8048933, 2011, to University of Wyoming Research Corporation.

[99] H. Shou, D. Ferrari, D.G. Barton, C.W. Jones, R.J. Davis, “Influence of passivation on the reactivity of unpromoted and Rb-promoted $\mathrm{Mo}_{2} \mathrm{C}$ nanoparticles for $\mathrm{CO}$ hydrogenation,” ACS Catalysis 2 (2012) 1408-1416. 


\section{Chapter 2.}

\section{Reactivity and in situ X-ray absorption spectroscopy of Rb- promoted $\mathrm{Mo}_{2} \mathrm{C} / \mathrm{MgO}$ catalysts for higher alcohol synthesis}

Adapted from Journal of Catalysis, 282, Heng Shou and Robert J. Davis, "Reactivity and in situ X-ray absorption spectroscopy of Rb-promoted $\mathrm{Mo}_{2} \mathrm{C} / \mathrm{MgO}$ catalysts for higher alcohol synthesis,” 83-93, Copyright (2011), with permission from Elsevier

\section{Abstract}

The influences of MgO support and $\mathrm{Rb}_{2} \mathrm{CO}_{3}$ promoter on the activity and selectivity of $\mathrm{Mo}_{2} \mathrm{C}$-based catalysts for higher alcohols synthesis from syngas were explored. The reaction was performed in a fixed-bed reactor system operating at $573 \mathrm{~K}$,

30 bar, gas flow rate of $24,000 \mathrm{~cm}^{3} \mathrm{~g}_{\mathrm{M} 0}^{-1} \mathrm{~h}^{-1}$ and $\mathrm{H}_{2} / \mathrm{CO}=1$. When promoted by $\mathrm{Rb}_{2} \mathrm{CO}_{3}$, the selectivity of alcohols over $5 \mathrm{wt} \% \mathrm{Mo}_{2} \mathrm{C} / \mathrm{MgO}$ was able to reach $62 \mathrm{C} \%$ on a $\mathrm{CO}_{2}-$ free basis, with C1-C4 hydrocarbons being the main side-products. Production of higher alcohols was enhanced at high promoter loading and low conversion. Characterization by X-ray absorption spectroscopy (XAS) indicated that passivated $\mathrm{Mo}_{2} \mathrm{C} / \mathrm{MgO}$ was more oxidized than bulk $\mathrm{Mo}_{2} \mathrm{C}$, but exposure to reaction conditions for $4 \mathrm{~h}$ partially reduced the passivated sample. Electron microscopy and XAS confirmed that $\mathrm{Mo}_{2} \mathrm{C}$ was highly dispersed on $\mathrm{MgO}$. The $\mathrm{Rb} K$ edge structure suggested that the $\mathrm{Rb}_{2} \mathrm{CO}_{3}$ promoter was structurally modified in the reaction. 


\subsection{Introduction}

Synthesis gas, composed mainly of $\mathrm{CO}$ and $\mathrm{H}_{2}$, can be derived from carbon sources such as coal, oil, natural gas, or biomass. Although world-scale catalytic processes have been developed to convert synthesis gas to diesel fuel or methanol, there is a growing need for its direct conversion to higher alcohols [1-3]. These higher alcohols can be used as liquid carriers of hydrogen, which can be obtained by reforming, or as fuel additives based on their mutual solubility with gasoline and diesel fuels. Higher alcohols can also be dehydrated to olefin feedstocks used to produce polymers.

Molybdenum-based solids are among the most promising catalysts for higher alcohol synthesis (HAS) because of their relatively low cost compared to Pt-group metals. Additional advantages of Mo-based catalysts for practical applications include: less severe catalyst deactivation due to coke deposition (even with a syngas containing a low $\mathrm{H}_{2} / \mathrm{CO}$ ratio of less than 2), higher selectivity to linear alcohols (especially ethanol), and low sensitivity to $\mathrm{CO}_{2}$ in the syngas [4]. In the 1980's, The Dow Chemical Company developed potassium and cobalt promoted molybdenum sulfide $\left(\mathrm{MoS}_{2}\right)$ catalysts for HAS [5]. The alcohol formation rate over promoted $\mathrm{MoS}_{2}$ was reported to be 0.1-0.4 $\mathrm{g} \mathrm{gcat}^{-1}$ $\mathrm{h}^{-1}$ at 513-598 $\mathrm{K}$ and $48-207$ bars, with a selectivity to mixed alcohols (on a $\mathrm{CO}_{2}$-free basis) as high as $\sim 85 \%$ [6-9]. However, trace amounts of hydrogen sulfide $\left(\mathrm{H}_{2} \mathrm{~S}\right)$ in the feed were needed to sustain the performance of the $\mathrm{MoS}_{2}$ catalysts [6]. Thus, there is an incentive to explore the reactivity of non-sulfided catalysts for HAS, among which molybdenum carbide has demonstrated some promise when properly promoted.

Consistent with the landmark discovery by Levy and Boudart [10], the reactivity of transition metal carbides (TMCs) can be similar to that of expensive Pt-group metals 
[11-13], especially in reactions involving the transformation of $\mathrm{C}-\mathrm{H}$ bonds in hydrocarbons. For example, the hydrogenation performance of TMCs is at the same level of Pt-group metals $[14,15]$. Park et al. also examined the effect of potassium promotion on Fischer-Tropsch synthesis over bulk molybdenum carbide $\left(\mathrm{Mo}_{2} \mathrm{C}\right)$ catalysts. They found that unsupported molybdenum carbide produced mostly C1-C5 alkanes in CO hydrogenation at atmospheric pressure, and promotion of the catalyst with $\mathrm{K}_{2} \mathrm{CO}_{3}$ yielded mostly C2-C5 alkenes [16]. They also found that promotion of $\mathrm{Mo}_{2} \mathrm{C}$ by $\mathrm{K}_{2} \mathrm{CO}_{3}$ greatly enhanced the alcohol selectivity during CO hydrogenation and they reported 50.5\% alcohol selectivity at $10.3 \% \mathrm{CO}$ conversion at high pressure [17]. The formation of alcohols from CO hydrogenation over carbide catalysts is thought to be related to the uniformity of the alkali promoter on the carbide surface [18] and to the extent of carburization [19]. Although the promotion of alcohol synthesis by addition of alkali to $\mathrm{Mo}_{2} \mathrm{C}$ reduces the overall activity of the catalyst, the addition of $\mathrm{Fe}$, Co and $\mathrm{Ni}$ can improve the activity of the promoted system [20-27].

The objective of the current study is to explore the roles of structure and reaction conditions on catalyst performance in higher alcohol synthesis. In particular, the effects of reaction temperature, pressure and gas flow rate on the product distribution over a Rbpromoted, magnesia-supported $\mathrm{Mo}_{2} \mathrm{C}$ catalysts were investigated. Magnesia was selected as a support since basic compounds are well-recognized promoters of the reaction. X-ray absorption spectroscopy at the Mo and $\mathrm{Rb} K$ edges was used to monitor the catalyst structure in situ. Catalysts were also characterized by transmission electron microscopy (TEM), elemental analysis, X-ray powder diffraction and BET surface analysis. 


\subsection{Experimental methods}

\subsubsection{Catalyst synthesis}

A 5 wt.\% $\mathrm{Mo}_{2} \mathrm{C} / \mathrm{MgO}$ sample was prepared by temperature-programmed carburization of $\mathrm{MoO}_{3} / \mathrm{MgO}$ with a 20 vol.\% $\mathrm{CH}_{4} / \mathrm{H}_{2}$ mixture. Magnesia (UBE ultrafine single crystal, $>99.98 \%, \mathrm{~S}_{\mathrm{BET}}=35.7 \mathrm{~m}^{2} \mathrm{~g}^{-1}$ ) was first impregnated with an aqueous solution of $\left(\mathrm{NH}_{4}\right)_{6} \mathrm{Mo}_{7} \mathrm{O}_{24} \cdot 4 \mathrm{H}_{2} \mathrm{O}(99.98 \%$, Aldrich) and then dried overnight in air at 400 $\mathrm{K}$ and calcined at $773 \mathrm{~K}$ in flowing air for $4 \mathrm{~h}$ to produce a supported oxide denoted here as $\mathrm{MoO}_{3} / \mathrm{MgO}$. Carburization of $\mathrm{MoO}_{3} / \mathrm{MgO}$ was accomplished by temperatureprogrammed reaction (TPR) at temperatures between $673 \mathrm{~K}$ and $973 \mathrm{~K}$ with a 20 vol.\% $\mathrm{CH}_{4}$ (GTS-Welco, 99.997\%) and 80 vol.\% $\mathrm{H}_{2}$ mixture (GTS-Welco, 99.999\%) at a heating rate of $0.5 \mathrm{~K} \mathrm{~min}^{-1}$ according to the method of Woo et al. [17]. After TPR, the temperature was maintained at $973 \mathrm{~K}$ for $5 \mathrm{~h}$, followed by another $10 \mathrm{~h}$ at $773 \mathrm{~K}$. The catalyst was subsequently quenched to room temperature in flowing $\mathrm{H}_{2}$. Finally, the 5 wt.\% $\mathrm{Mo}_{2} \mathrm{C} / \mathrm{MgO}$ sample was passivated in a stream of 1 vol. $\% \mathrm{O}_{2} / \mathrm{N}_{2}$ mixture (GTS-Welco, 1.02 vol.\% $\mathrm{O}_{2}$ ) at room temperature (RT) for $12 \mathrm{~h}$ before exposure to air. The supported $\mathrm{Mo}_{2} \mathrm{C}$ was further promoted by physically mixing it with $\mathrm{Rb}_{2} \mathrm{CO}_{3}(99.975 \%$, Alfa Aesar). The $\mathrm{Rb}_{2} \mathrm{CO}_{3}$ loading was varied in the range of 0-15 wt.\%.

For comparison, an aqueous solution of $\mathrm{Rb}_{2} \mathrm{MoO}_{4}$ was impregnated onto $\mathrm{MgO}$. The sample was dried and carburized by the same method to produce carburized $\mathrm{Rb}_{2} \mathrm{MoO}_{4} / \mathrm{MgO}$. As a control, distilled, deionized water was added to pure MgO and the resulting sample was subjected to the same carburization conditions as samples containing Mo. 


\subsubsection{Catalyst characterization}

Elemental analyses were performed by Galbraith Laboratories (Knoxville, TN). The Mo loading of the catalysts was determined by inductively coupled plasma atomic emission spectroscopy (ICP-AES), while the C loading was evaluated by combustion.

Adsorption of $\mathrm{N}_{2}$ was performed on a Micromeritics ASAP 2020 automated adsorption system to obtain the BET surface area. A sample was heated under vacuum to $573 \mathrm{~K}$ for $10 \mathrm{~h}$ prior to adsorption of $\mathrm{N}_{2}$ at liquid nitrogen temperature.

Electron microscopy was performed on an FEI Titan 300 transmission electron microscope equipped with an EDS system operated at $200 \mathrm{kV}$. Two catalyst samples, 5 wt.\% $\mathrm{Mo}_{2} \mathrm{C} / \mathrm{MgO}$ and 5 wt.\% $\mathrm{Rb}-5$ wt. $\% \mathrm{Mo}_{2} \mathrm{C} / \mathrm{MgO}$, were reacted for $48 \mathrm{~h}$ and passivated with $1 \% \mathrm{O}_{2} / \mathrm{N}_{2}$ (GTS-Welco, $1.02 \% \mathrm{O}_{2}$ ) at RT before TEM analysis. Catalyst powders were dispersed in $n$-hexane and supported onto a holey carbon film and a continuous carbon film (double film) coated grid (Pacific Grid-Tech). Images were recorded with a Gatan 794 Multi Scan CCD camera and Fischione Instruments Model 3000 annular dark field detector.

The X-ray diffraction patterns were obtained on a Scintag XDS 2000 diffractometer using $\mathrm{Cu} \mathrm{K} \alpha$ radiation. Scans were collected from $2 \theta$ of $5^{\circ}$ to $90^{\circ}$ at a rate of $2^{\circ} \min ^{-1}$ for bulk materials and $0.8^{\circ} \min ^{-1}$ for supported catalysts.

\subsubsection{Hydrogenation of carbon monoxide}

Hydrogenation of CO was conducted in a fixed-bed stainless steel reactor (BTRS Jr., Autoclave Engineers) with $1.00 \mathrm{~g}$ catalyst ( $0.05 \mathrm{~g}$ nominal $\mathrm{Mo}_{2} \mathrm{C}$ ) of size 40-80 mesh diluted by $2.5 \mathrm{~g}$ SiC. The catalysts were tested at nominally identical conditions of $573 \mathrm{~K}$, 30 bar total pressure, syngas $\left(\mathrm{H}_{2}+\mathrm{CO}\right)$ flow of $20 \mathrm{~cm}^{3} \mathrm{~min}^{-1}$ (STP) and $\mathrm{H}_{2} / \mathrm{CO}$ ratio of 1 . 
The reactor was pressurized to $30 \mathrm{bar}$ at room temperature and heated to $573 \mathrm{~K}$ before sampling. The temperature of the catalyst bed was monitored by a thermocouple in contact with the catalyst bed. The purity of CO (GTS-Welco) was 99.9\% and $\mathrm{H}_{2}$ (GTSWelco) was $99.999 \%$. Additionally, CO was purified by passing it through a silica trap immersed in a Dewar containing a dry ice-acetone mixture (195 K) to remove any trace iron carbonyl before introduction into the reactor [28]. The products were analyzed by two Hewlett-Packard 5890 series II gas chromatographs. The first one was equipped with a flame ionization detector and a 50 m-long HP-1 cross-linked methyl silicone gum capillary column to monitor the formation of hydrocarbons and oxygenates. The second one was equipped with a thermal conductivity detector and a 6-ft long Alltech-8700 packed column and was used to monitor the formation of $\mathrm{CO}_{2}$.

According to Burch and Petch [29], the conversion of CO was derived from the fraction of $\mathrm{CO}$ that formed carbon-containing products. The conversion of $\mathrm{CO}$, if low, can be described as:

$$
\text { Conversion }(\%)=\sum n_{i} M_{i} \times 100 / M_{\mathrm{CO}} \text {, }
$$

where $n_{i}$ is the number of carbon atoms in product $i, M_{i}$ is the percentage of product i detected, and $\mathrm{M}_{\mathrm{CO}}$ is the percentage of $\mathrm{CO}$ in the syngas feed.

The selectivity to product $i$ is based on the total number of carbon atoms in the product and is therefore defined as:

$$
\text { Selectivity }(\%)=n_{i} M_{i} \times 100 / \sum n_{i} M_{i} .
$$

The quantitative products comprised more than $93 \%$ of the total peak area given by GC-FID. 


\subsubsection{X-ray absorption spectroscopy}

X-ray absorption spectroscopy (XAS) was carried out on a beamline X-18B at the National Synchrotron Light Source, Brookhaven National Laboratory. The NSLS storage ring was operated at $2.8 \mathrm{GeV}$ with a ring current of about $300 \mathrm{~mA}$. The XAS data were obtained in the transmission mode at the Mo $K$ edge (20 keV) and at the Rb $K$ edge (15.2 $\mathrm{keV}$ ) with a spot size of $0.5 \mathrm{~mm} \times 3 \mathrm{~mm}$.

Following the designs of Fingland et al. [30], an XAS cell depicted in Figure 2.1 was constructed in house specifically for this study. The XAS cell consists of a 6" borosilicate glass tube housed by stainless steel nuts and Teflon ferrules in a temperaturecontrolled aluminum heating block, with a $1 / 4$ " hole in the block to allow for the transmission of X-rays through the tube walls and the catalyst bed. The temperature of the catalyst bed was controlled by an internal K-type stainless steel thermocouple (Omega). The heat to the aluminum block was provided by four $1 / 4$ ” cartridge heaters connected to an Omega CN 2011 temperature controller. The cell allowed for interrogation of the catalyst under standard reaction conditions of $573 \mathrm{~K}$ and 30 bar flowing syngas.

The Mo $K$ edge and Rb $K$ edge spectra were measured in air at RT with Mo foil (0.015 mm, 99.9\%, Goodfellow) and $\mathrm{Rb}_{2} \mathrm{CO}_{3}$ (99.975\%, Alfa Aesar) as references, respectively. For in situ experiments, 0.2 g of 5 wt.\% $\mathrm{Mo}_{2} \mathrm{C} / \mathrm{MgO}$ or 5 wt.\% Rb-5 wt.\% $\mathrm{Mo}_{2} \mathrm{C} / \mathrm{MgO}$ were loaded into a reactor tube and assembled into the custom-designed XAS cell. After pressurizing the cell with syngas $\left(\mathrm{H}_{2} / \mathrm{CO}=1\right)$, it was then heated from RT to $573 \mathrm{~K}$, and held at $573 \mathrm{~K}$ for $4 \mathrm{~h}$, with a total syngas flow of $4 \mathrm{~cm}^{3} \mathrm{~min}^{-1}$ (STP). 
The Mo $K$ edge and $\mathrm{Rb} K$ edge spectra were recorded after the $4 \mathrm{~h}$ treatment under reaction conditions, and after quenching the catalysts to $\mathrm{RT}$ in $\mathrm{H}_{2}$.

To further probe the $\mathrm{Rb} K$ edge, $0.2 \mathrm{~g}$ of $5 \mathrm{wt} . \% \mathrm{Rb}-5 \mathrm{wt} . \% \mathrm{Mo}_{2} \mathrm{C} / \mathrm{MgO}$ or 5 wt.\% $\mathrm{Rb} / \mathrm{MgO}$ were loaded into a reactor tube and assembled into the cell. The cell was then heated from RT to $573 \mathrm{~K}$, and held at $573 \mathrm{~K}$ for $4 \mathrm{~h}$, in flowing Ar at $4 \mathrm{~cm}^{3} \mathrm{~min}^{-1}$. The $\mathrm{Rb} K$ edge spectra were recorded after the $4 \mathrm{~h}$ treatment, and after cooling the catalyst to $\mathrm{RT}$ in Ar. In addition, $\mathrm{Rb} K$ edge spectra of $\mathrm{Rb}_{2} \mathrm{CO}_{3}$ mixed with liquid water were treated at RT.

The XAS data were processed using the Athena [31] software for background removal, post-edge normalization, and X-ray absorption near edge structure (XANES) analysis. Because the Mo near edge structure has various features that complicate the determination of $E_{0}$, the edge energy, the value of $E_{0}$ was assigned here as the energy at the half step height. Metallic Mo foil (0.015 mm, 99.9\%, Goodfellow), $\mathrm{MoO}_{2}$ (99\%, Aldrich), and $\mathrm{Rb}_{2} \mathrm{MoO}_{4}$ (99.5\%, Alfa Aesar) were used as standards for Mo residing in 0, +4 and +6 formal oxidation states.

The Extended X-ray Absorption Fine Structure (EXAFS) data analysis was performed using the Artemis software package, which implemented FEFF6 [32]. The normalized EXAFS data were $k^{3}$-weighted and then Fourier transformed from k-space in the range 2-14 $\AA^{-1}$. Standard bulk $\mathrm{Mo}_{2} \mathrm{C}$ (Aldrich, 99.5\%) was used to determine the amplitude reduction factors $S_{0}^{2}$ for Mo-C and Mo-Mo, and $\mathrm{Rb}_{2} \mathrm{MoO}_{4}$ was used to determine $S_{0}^{2}$ for Mo-O. The values of $S_{0}^{2}$ utilized in the fitting of EXAFS data from the catalyst samples were $0.82,0.78$ and 0.79 for Mo-C, Mo-Mo and Mo-O, respectively. A two-shell fitting procedure was used to analyze carbides (Mo-C, Mo-Mo) and a one- 
shell fitting procedure was used to analyze the oxides (Mo-O). The interatomic distances $(r)$, coordination numbers $(\mathrm{CN})$, Debye-Waller factors $\left(\Delta \sigma^{2}\right)$ and energy shifts $\left(\Delta E_{0}\right)$ were derived from the results.

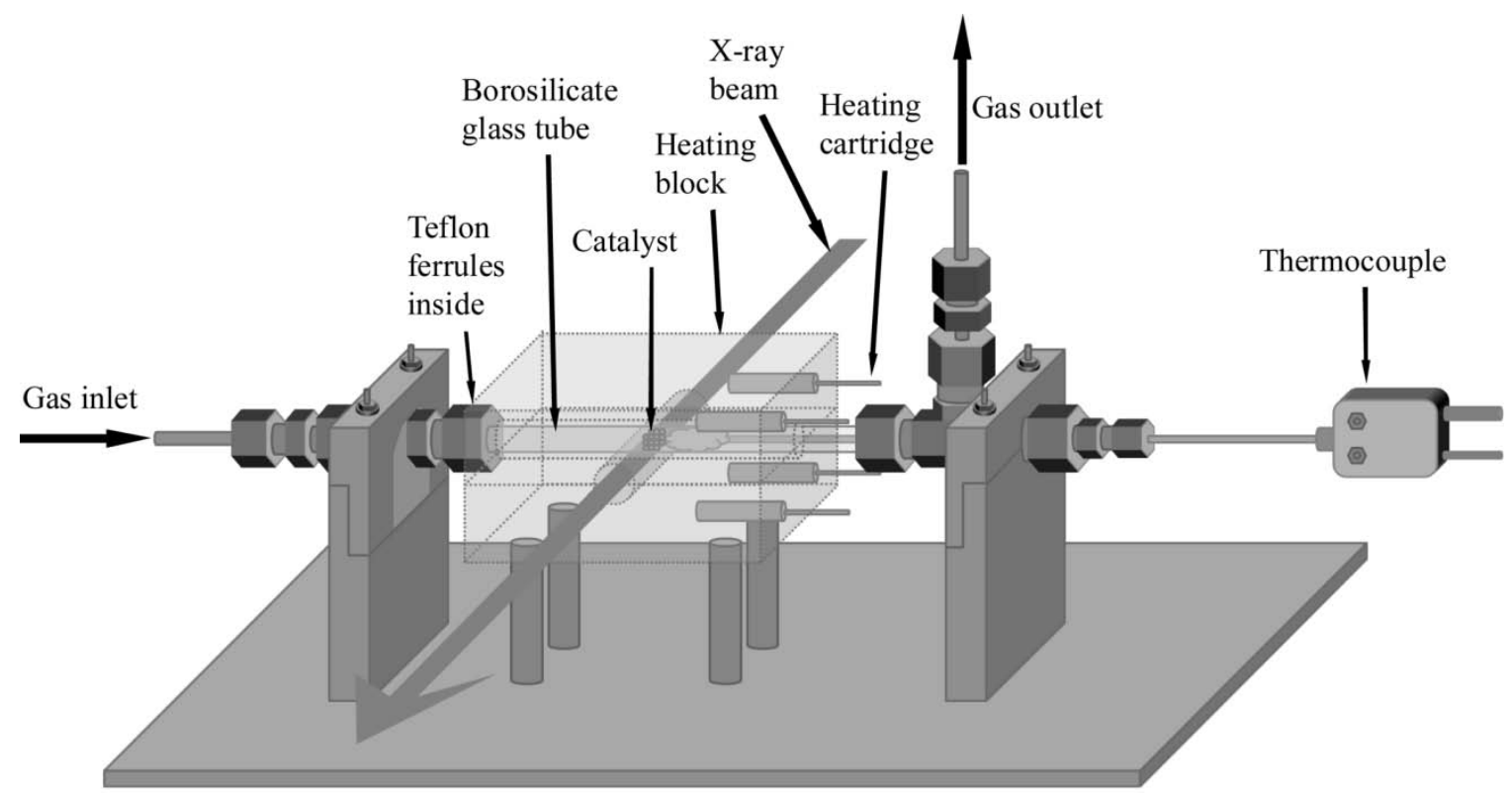

Figure 2.1 High pressure, borosilicate tubular reactor/X-ray cell.

\subsection{Results and discussion}

\subsubsection{Characterization by $\mathrm{X}$-ray diffraction, elemental analysis, $\mathrm{N}_{2}$ adsorption, and electron microscopy}

The X-ray diffraction patterns of representative samples are provided in Figure 2.2. The pattern for bulk $\mathrm{Mo}_{2} \mathrm{C}$ prepared at $973 \mathrm{~K}$ (Figure 2.2c) revealed peaks at 34.8, 38.2, 39.8, 62.1, and $75.2^{\circ}$, which are assigned to the $\{100\},\{002\},\{101\},\{110\}$, and an unresolved doublet of the $\{112\}$ and $\{201\}$ reflections of bulk hexagonal $\mathrm{Mo}_{2} \mathrm{C}$, respectively [33]. The passivated 5 wt.\% $\mathrm{Mo}_{2} \mathrm{C} / \mathrm{MgO}$ catalyst (Figure 2.2b) prepared at $973 \mathrm{~K}$ showed XRD peaks corresponding to the structure of MgO (Figure 2.2a) without any clear evidence for crystalline $\mathrm{Mo}_{2} \mathrm{C}$. This result suggests that the $\mathrm{Mo}_{2} \mathrm{C}$ particles were 
very well-dispersed on the support. It should be noted that $\mathrm{MgO}$ reconstructed to $\mathrm{Mg}(\mathrm{OH})_{2}$ (Figure 2.2d) after impregnation with a water solution followed by drying. However, after calcination at $773 \mathrm{~K}$, the original pattern for $\mathrm{MgO}$ was restored. The significant reconstructing of the MgO support during catalyst preparation may have influenced the dispersion of the Mo on the surface.

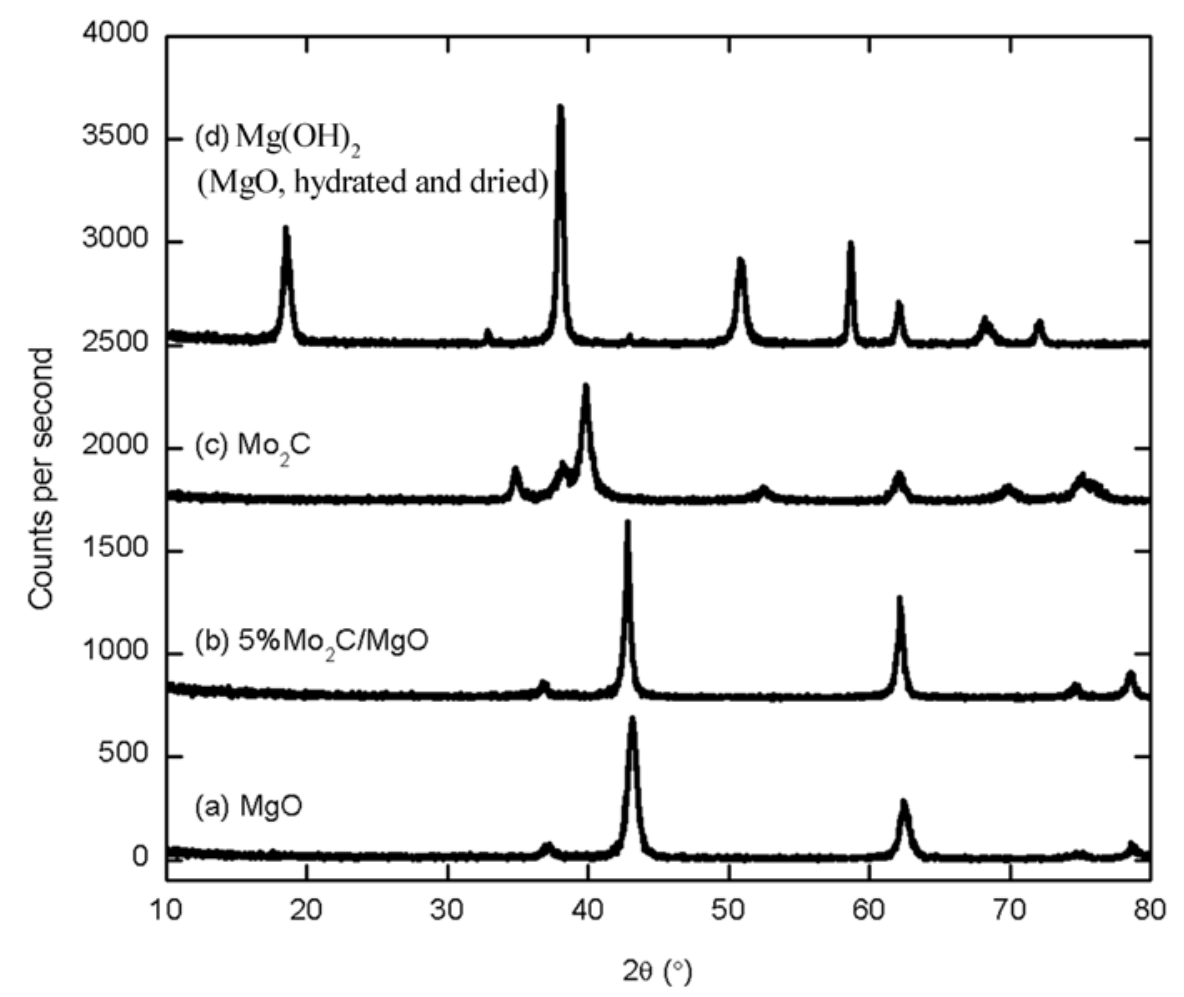

Figure 2.2 X-ray diffraction patterns of (a) $\mathrm{MgO}$, (b) $\mathrm{Mo}_{2} \mathrm{C} / \mathrm{MgO}$, (c) $\mathrm{Mo}_{2} \mathrm{C}$, and (d) hydrated MgO. Patterns are offset for clarity.

Table 2.1 Results from elemental analysis

\begin{tabular}{llllll}
\hline Catalyst composition (nominal) & \multicolumn{2}{c}{ Loading (wt \%) } & & \multicolumn{2}{c}{ C/Mo (atomic ratio) } \\
\cline { 2 - 3 } \cline { 5 - 6 } & Mo & $\mathrm{C}$ & & Measured & Corrected \\
\hline 5 wt.\% $\mathrm{Mo}_{2} \mathrm{C} / \mathrm{MgO}$ & 4.77 & 0.356 & & 0.596 & $0.424^{*}$ \\
"Carburized” MgO & - & 0.108 & & - & - \\
\hline
\end{tabular}

*Value has been subtracted by the level in "carburized” MgO.

The elemental analysis results for $\mathrm{Mo}_{2} \mathrm{C} / \mathrm{MgO}$ are listed in Table 2.1. Since MgO can adsorb $\mathrm{CO}_{2}$ from air, a control experiment was carried by using a "carburized" MgO sample that was exposed to the same treatment as the catalyst synthesis except that no 
molybdenum precursor was added. The measured carbon level in the $\mathrm{Mo}_{2} \mathrm{C} / \mathrm{MgO}$ catalyst was then corrected by the carbon level in the control sample without Mo to give a more reliable analysis. The corrected C/Mo atomic ratio was 0.424 , which is close to the expected stoichiometry of $\mathrm{Mo}_{2} \mathrm{C}(0.5)$. The small deviation may be caused by the passivation step which may oxidize some of the surface carbon on the sample.

Table 2.2 lists the results of BET surface area analysis of $\mathrm{MgO}$ and MgOsupported $\mathrm{Mo}_{2} \mathrm{C}$ catalysts prior to use in reaction. The BET surface area of $\mathrm{MgO}$ changed from $35.8 \mathrm{~m}^{2} \mathrm{~g}^{-1}$ to $64.8 \mathrm{~m}^{2} \mathrm{~g}^{-1}$ after loading with $\mathrm{Mo}_{2} \mathrm{C}$. Considering the small proportion of $\mathrm{Mo}_{2} \mathrm{C}$ on the sample, the change in the BET surface area of $\mathrm{MgO}$ most likely was the result of the structure change of $\mathrm{MgO}$ to $\mathrm{Mg}(\mathrm{OH})_{2}$ and back to $\mathrm{MgO}$ during catalyst synthesis. Addition of a high loading of $\mathrm{Rb}_{2} \mathrm{CO}_{3}$ to the sample by physically-mixing the two components decreased the overall area of the mixture.

Table 2.2 Results from $\mathrm{N}_{2}$ Adsorption

\begin{tabular}{|c|c|c|c|c|c|c|c|}
\hline \multirow{2}{*}{ Sample } & \multirow{2}{*}{$\mathrm{MgO}$} & \multicolumn{6}{|c|}{$5 \% \mathrm{Mo}_{2} \mathrm{C} / \mathrm{MgO}$} \\
\hline & & $0 \% \mathrm{Rb}$ & $1 \% \mathrm{Rb}$ & $5 \% \mathrm{Rb}$ & $5 \% \mathrm{Rb}$ & $10 \% \mathrm{Rb}$ & $15 \% \mathrm{Rb}$ \\
\hline $\mathrm{S}_{\mathrm{BET}}\left(\mathrm{m}^{2} \mathrm{~g}^{-1}\right)$ & 35.7 & 64.8 & 65.7 & 55.4 & 55.4 & 54.2 & 48.4 \\
\hline
\end{tabular}
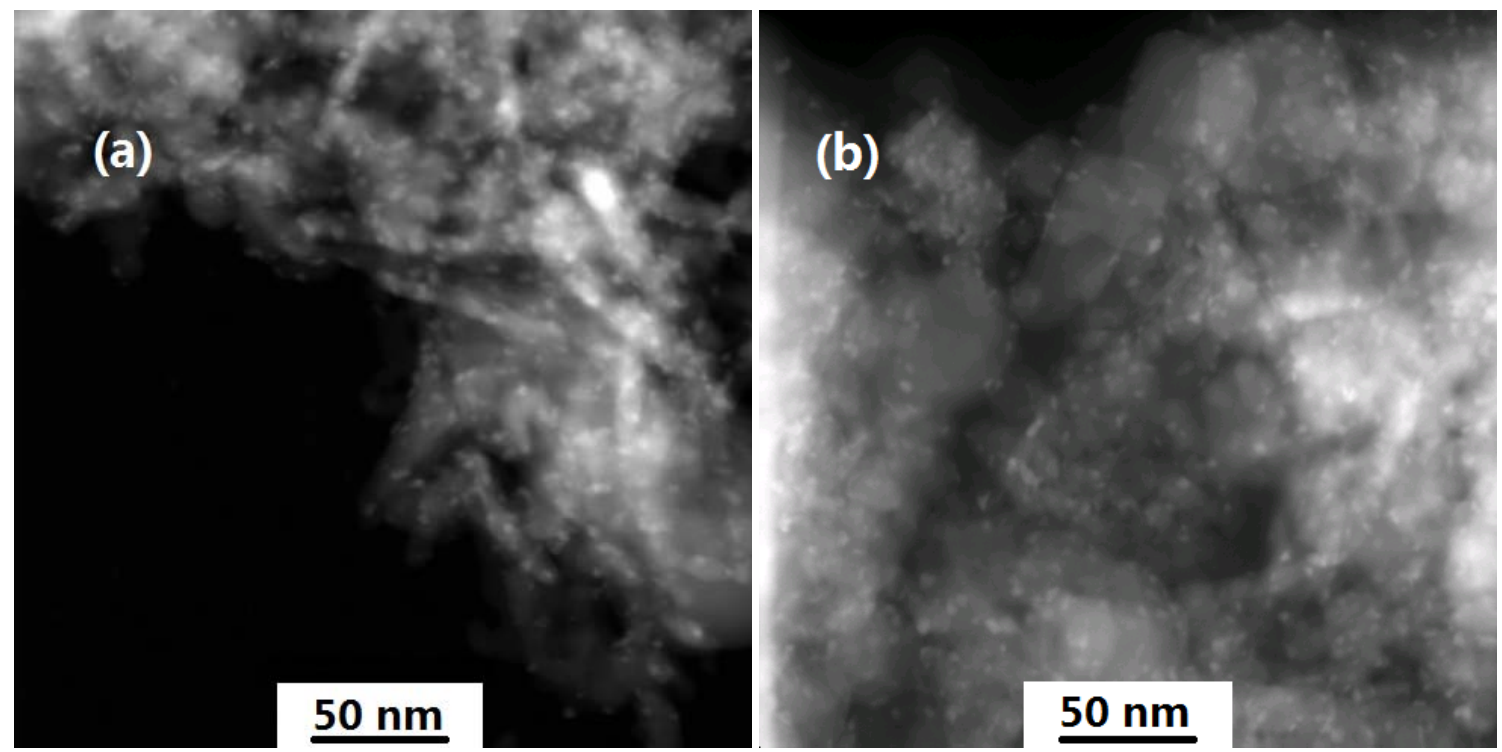

Figure 2.3 HAADF images of (a) $5 \% \mathrm{Mo}_{2} \mathrm{C} / \mathrm{MgO}$, (b) $5 \% \mathrm{Rb}-5 \% \mathrm{Mo}_{2} \mathrm{C} / \mathrm{MgO}$. Catalysts had been used for $48 \mathrm{~h}$ in $\mathrm{CO}$ hydrogenation before TEM analysis. 
The high angle annular dark field (HAADF) image of $5 \mathrm{wt} \% \mathrm{Mo}_{2} \mathrm{C} / \mathrm{MgO}$ (Figure 2.3) revealed that the average particle size of $\mathrm{Mo}_{2} \mathrm{C}$ was $2.8 \pm 0.3 \mathrm{~nm}$. The very small particle size observed by TEM is consistent with the lack of observable crystalline carbide phases by X-ray diffraction.

\subsubsection{Role of $\mathrm{Rb}$ loading on $\mathrm{Mo}_{2} \mathrm{C} / \mathrm{MgO}$}

The performance of unpromoted $\mathrm{Mo}_{2} \mathrm{C}$ catalysts in the reaction of syngas $\left(\mathrm{H}_{2} / \mathrm{CO}\right.$ : $=1$ ) at $573 \mathrm{~K}$ and 30 bar pressure is summarized in Table 2.3.

The first two columns in Table 2.3 compare the results from a bulk $\mathrm{Mo}_{2} \mathrm{C}$ catalyst and an MgO-supported $\mathrm{Mo}_{2} \mathrm{C}$ catalyst. Bulk $\mathrm{Mo}_{2} \mathrm{C}$ functions primarily as a FischerTropsch catalyst at $573 \mathrm{~K}$ and 30 bar syngas, producing mainly light hydrocarbons and very little alcohols (3.1\% on a $\mathrm{CO}_{2}$-free basis). Supporting the carbide on MgO increased the alcohol selectivity to $24 \%$, at nearly identical levels of CO conversion. Evidently the basic support $\mathrm{MgO}$ promoted alcohol production at the expense of hydrocarbon production, most likely at active sites near the carbide/support interface. It should be noted that the selectivity to $\mathrm{CO}_{2}$ produced via the water gas shift reaction was usually about $40 \%$, and should always be below $50 \%$ because of reaction stoichiometry.

Columns 3 through 7 in Table 2.3 illustrate the effect of $\mathrm{Rb}$ loading on higher alcohol synthesis over $\mathrm{Mo}_{2} \mathrm{C} / \mathrm{MgO}$. Addition of $\mathrm{Rb}_{2} \mathrm{CO}_{3}$ to supported $\mathrm{Mo}_{2} \mathrm{C}$ increased the selectivity to alcohols (on a $\mathrm{CO}_{2}$-free basis) while lowering the selectivity to hydrocarbons. However, addition of $\mathrm{Rb}_{2} \mathrm{CO}_{3}$ beyond 10 wt.\% did not substantially improve selectivity above about 60\% oxygenates but instead decreased CO conversion. Examination of the distribution of alcohols produced over the catalysts shows that the ratio of higher alcohols (ethanol, propanol, etc.) to methanol was nearly 1:1 over 
unpromoted $\mathrm{Mo}_{2} \mathrm{C} / \mathrm{MgO}$ but was 2.4 over Rb-promoted $\mathrm{Mo}_{2} \mathrm{C} / \mathrm{MgO}$. Moreover, the addition of $\mathrm{Rb}$ promoted the formation of alkenes, because the $\mathrm{C} 4+$ alkene/C4+ alkane ratio increased from 0.47 on unpromoted $5 \mathrm{wt} . \% \mathrm{Mo}_{2} \mathrm{C} / \mathrm{MgO}$ to 2.1 on $10 \mathrm{wt} . \% \mathrm{Rb}-5 \mathrm{wt} . \%$ $\mathrm{Mo}_{2} \mathrm{C} / \mathrm{MgO}$. These results are consistent with prior work on potassium-promoted bulk $\mathrm{Mo}_{2} \mathrm{C}$ catalysts $[17,34,35]$.

The fourth and fifth entries in Table 2.3 demonstrate the reproducibility of the reactivity results by reporting two separate runs of 5 wt.\% $\mathrm{Rb}-5$ wt.\% $\mathrm{Mo}_{2} \mathrm{C} / \mathrm{MgO}$ catalysts. The results suggest good experimental reproducibility since the conversion of CO (3.5\% and 3.0\%) and product distribution are very similar.

Table 2.3 Conversion of synthesis gas over Rb-promoted $5 \mathrm{wt} . \% \mathrm{Mo}_{2} \mathrm{C} / \mathrm{MgO}$ catalysts

\begin{tabular}{|c|c|c|c|c|c|c|c|}
\hline Catalyst & Bulk & & $5 \mathrm{w}$ & t.\% M & $\mathrm{O}_{2} \mathrm{C} / \mathrm{\Lambda}$ & & \\
\hline $\begin{array}{l}\text { Rb loading (wt.\%) } \\
\end{array}$ & 0 & 0 & 1 & 5 & 5 & 10 & 15 \\
\hline CO conversion (\%) & 6.6 & 5.7 & 3.8 & 3.5 & 3.0 & 2.8 & 2.3 \\
\hline $\mathrm{CO}_{2}$ selectivity (\%) & 45 & 45 & 46 & 38 & 37 & 35 & 39 \\
\hline Selectivity (C\%, on a $\mathrm{CO}_{2}$-free basis) ${ }^{\mathrm{a}}$ & & & & & & & \\
\hline Methane & 41 & 29 & 19 & 17 & 15 & 16 & 16 \\
\hline C2 hydrocarbons & 27 & 23 & 16 & 13 & 10 & 10 & 10 \\
\hline C3 hydrocarbons & 20 & 16 & 12 & 7.8 & 6.2 & 6.1 & 5.9 \\
\hline C4+ linear paraffins & 5.4 & 6.0 & 7.9 & 3.3 & 3.5 & 1.9 & 1.6 \\
\hline C4+ olefins & 2.8 & 2.8 & 4.5 & 4.4 & 5.2 & 3.9 & 4.0 \\
\hline Methanol & 2.0 & 12 & 15 & 19 & 19 & 19 & 18 \\
\hline Ethanol & 1.1 & 8.1 & 16 & 22 & 22 & 23 & 23 \\
\hline 1-Propanol & 0 & 3.5 & 7.0 & 11 & 12 & 14 & 16 \\
\hline 1-Butanol & 0 & 0 & 1.8 & 3.0 & 4.3 & 4.3 & 4.5 \\
\hline 1-Pentanol & 0 & 0 & 0 & 0 & 1.9 & 1.8 & 0 \\
\hline Rate of $\mathrm{CO}$ conversion $\left(\mathrm{mol}_{\mathrm{CO}} \mathrm{mol}_{\mathrm{Mo}}^{-1} \mathrm{~h}^{-1}\right)$ & 3.3 & 2.9 & 1.9 & 1.7 & 1.5 & 1.4 & 1.1 \\
\hline Rate of alcohol production $\left(\mathrm{g} \mathrm{g}_{\mathrm{Mo}}^{-1} \mathrm{~h}^{-1}\right)$ & 0.02 & 0.11 & 0.11 & 0.16 & 0.14 & 0.14 & 0.11 \\
\hline
\end{tabular}

Nominal conditions are $T=573 \mathrm{~K}, P=30 \mathrm{bar}, 0.05 \mathrm{~g}$ nominal $\mathrm{Mo}_{2} \mathrm{C}$ (made into $40-80$ mesh pellets if supported on $\mathrm{MgO}$ ), $2.5 \mathrm{~g} \mathrm{SiC}$ to dilute the bed, $\mathrm{H}_{2} / \mathrm{CO}=1$, syngas flow $=20 \mathrm{~cm}^{3}$ (STP) $\mathrm{min}^{-1}$. Data were recorded after $48 \mathrm{~h}$ reaction.

${ }^{a}$ All the alcohols are linear. 

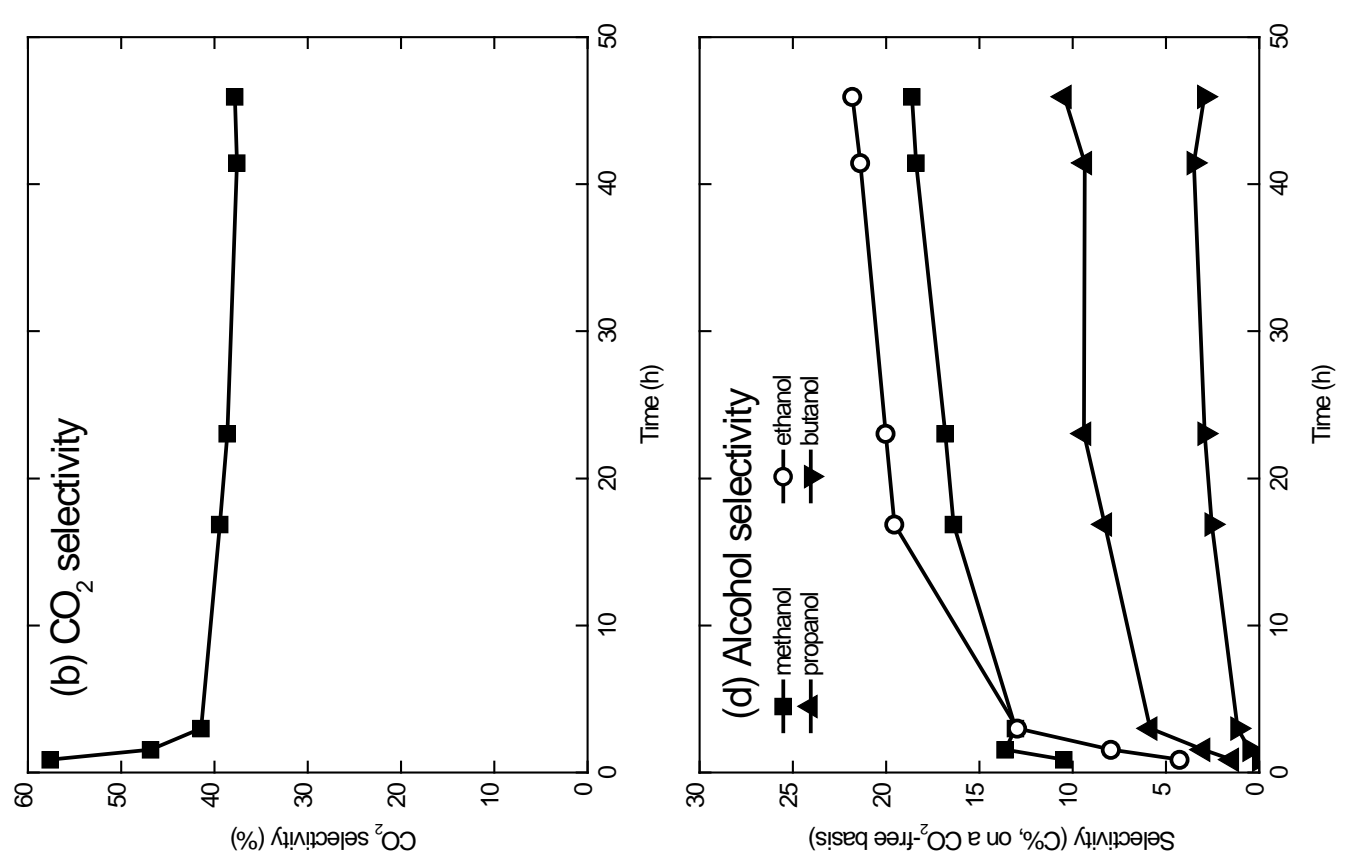

ีㅡ

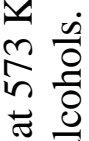

$\pi \frac{\pi}{\pi}$

옹 운

苟.

o.

는

त)

○ิ

药

寻

$\cup$

골

ว은

芳

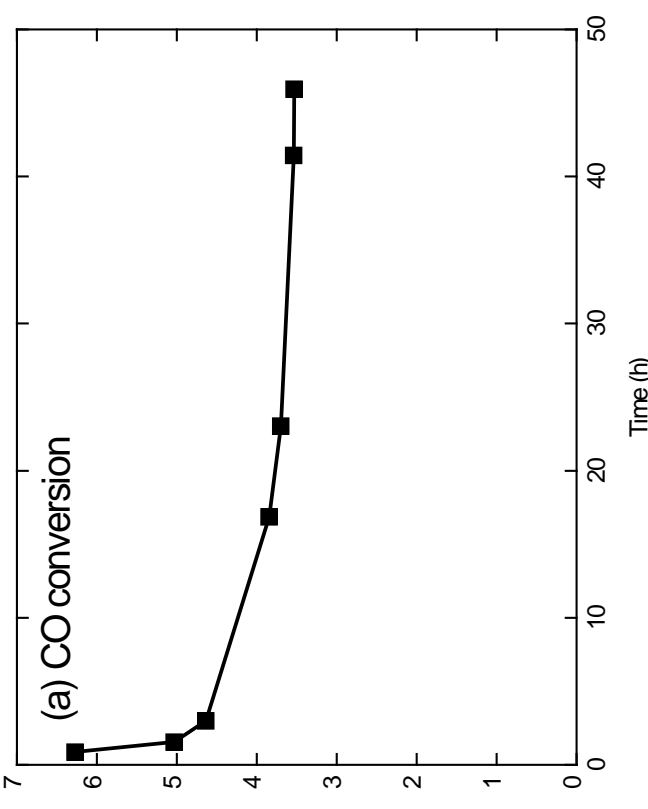

(\%) ио!ฺљәлиоэ оว

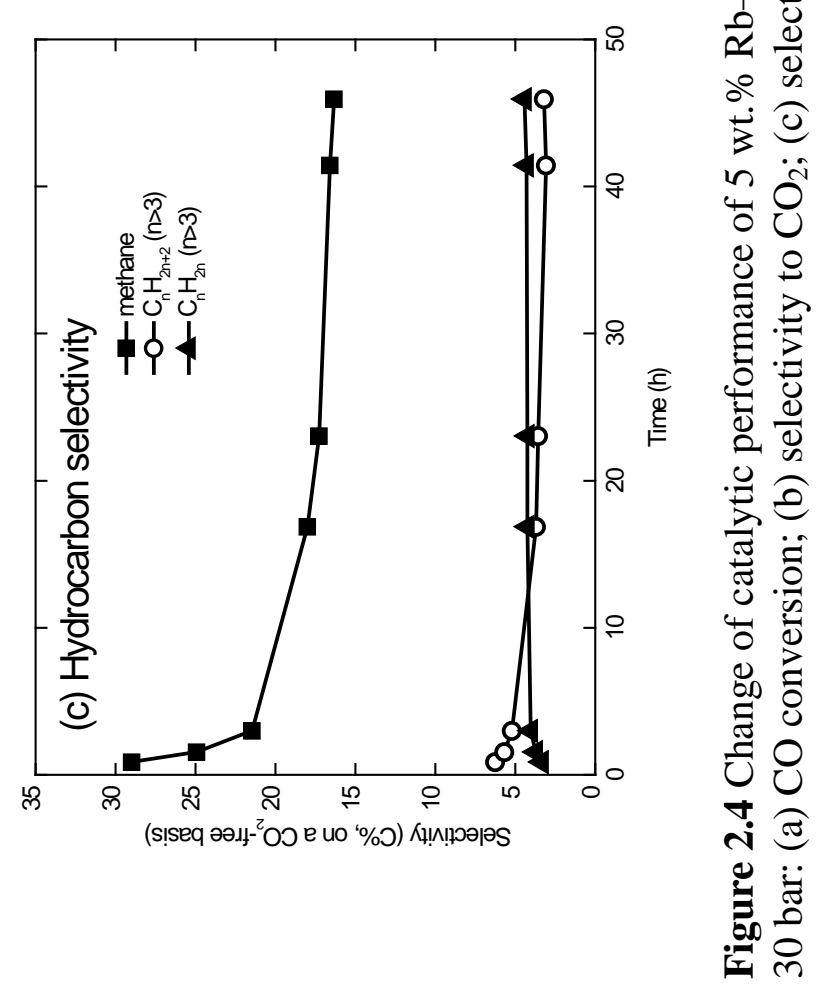


Figure 2.4 illustrates how the CO conversion and product selectivities over 5 wt.\% $\mathrm{Rb}-5$ wt.\% $\mathrm{Mo}_{2} \mathrm{C} / \mathrm{MgO}$ changed with time over a $48 \mathrm{~h}$ time interval. The catalyst deactivated about a third of its initial activity after about 24 hours, but remained fairly stable thereafter. The selectivity to hydrocarbons, alcohols and $\mathrm{CO}_{2}$ all changed sharply during the first $3 \mathrm{~h}$, and were relatively stable after about a day. Most importantly, the alcohol selectivity was very low initially and gradually increased with time on stream, suggesting a restructuring of the active phase during this start-up period. Generally, molybdenum-based catalysts for mixed alcohols synthesis exhibit an induction period during CO hydrogenation [16-18,35,37]. This induction period may coincide with the distribution of $\mathrm{Rb}$ promoter over the catalyst surface since it was initially physically mixed with $\mathrm{Mo}_{2} \mathrm{C} / \mathrm{MgO}$.

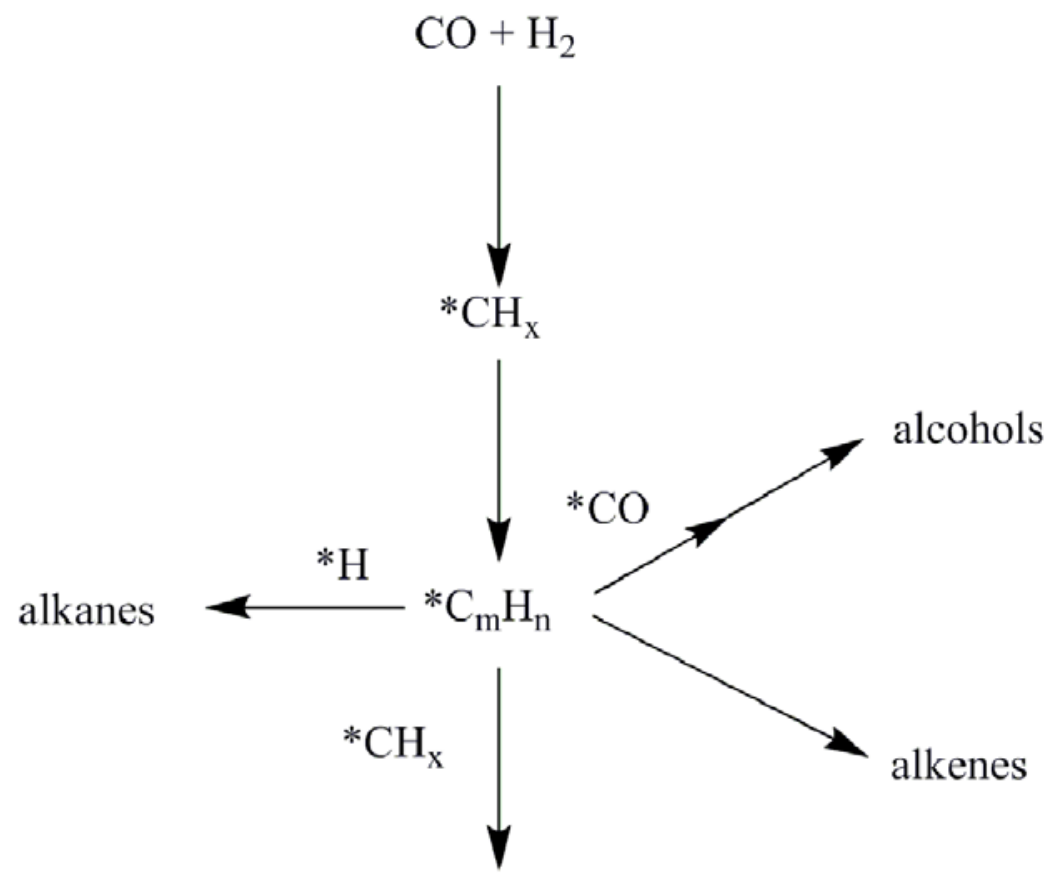

Figure 2.5 Reaction pathway for CO hydrogenation adapted from [18]

Lee et al. [18] depicted the simplified scheme (Figure 2.5) of CO conversion based on the ideas discussed by Ponec [38,39]. According to this scheme, all the products 
can be derived from an adsorbed intermediate ${ }^{*} \mathrm{C}_{\mathrm{m}} \mathrm{H}_{\mathrm{n}}$, (where $*$ denotes a surface site). This intermediate can undergo four different transformations to products namely: (1) hydrogenation to alkanes, (2) carbonylation to alcohol precursors, (3) desorption as olefins, and (4) further chain growth by inserting ${ }^{*} \mathrm{CH}_{\mathrm{x}}$. In this competitive process, hydrogenation activity of a catalyst needs to be partially suppressed to enhance production of alcohols and alkenes; thus, trends in alcohol and alkene selectivities should be similar, as reaction conditions or catalyst properties are varied. Lee et al. [18] suggested that alkali promoters on $\mathrm{Mo}_{2} \mathrm{C}$ catalysts for $\mathrm{CO}$ hydrogenation have two effects: an electronic effect and a geometric effect. The electronic effect is thought to increase the electron density of the catalyst, thus inhibiting the oxidative addition of hydrogen to the surface. The geometric effect involves the blockage of surface sites that are potential sites for the adsorption of reactants. They concluded that the geometric effect of adding $\mathrm{K}_{2} \mathrm{CO}_{3}$ on $\mathrm{Mo}_{2} \mathrm{C}$ was the primary mode of promoting alcohol formation during $\mathrm{CO}$ hydrogenation. Because the optimal ratio of $\mathrm{K}$ to Mo was different for alkene and alcohol formation, Lee et al. also suggested that alkene formation may be attributed to the combination of geometric and electronic effects. Muramatsu et al. [35] also studied the roles of potassium promoter on a Mo oxide catalyst for alcohol production from syngas, and concluded that potassium inhibits dehydration of alcohols to alkenes as well as the hydrogenation of alkenes to alkanes.

For $\mathrm{CO}$ hydrogenation over $\mathrm{Mo}_{2} \mathrm{C} / \mathrm{MgO}$ catalysts, the selectivities of both alcohols and alkenes increased with the loading of $\mathrm{Rb}_{2} \mathrm{CO}_{3}$ promoter, which is consistent with Figure 2.5. The EDS spectra of 5 wt.\% Rb-5 wt.\% $\mathrm{Mo}_{2} \mathrm{C} / \mathrm{MgO}$ catalyst after $48 \mathrm{~h}$ syngas reaction, corresponding to the sample in Figure 2.3b, revealed the presence of $\mathrm{Rb}$ 
distributed over the sample after reaction, which is consistent with a site blocking mechanism described above. However, the formation of higher alcohols with increased loading of $\mathrm{Rb}$ promoter may result from chain growth reactions on the promoted carbide catalyst or coupling of lower molecular weight alcohols over basic sites provided by $\mathrm{Rb}$ promoter. Further investigations are needed to explore this aspect.

\subsubsection{Influence of process variables: gas flow rate, temperature, pressure, and}

\section{$\mathrm{H}_{2} / \mathrm{CO}$ ratio}

The influence of gas flow rate on the overall CO conversion is shown in Figure 2.6 at the nominal conditions of 30 bar and a $\mathrm{H}_{2} / \mathrm{CO}$ ratio of 1 , with temperature varying from $553 \mathrm{~K}$ to $593 \mathrm{~K}$. As expected, CO conversion decreased with gas low rate and increased with temperature.

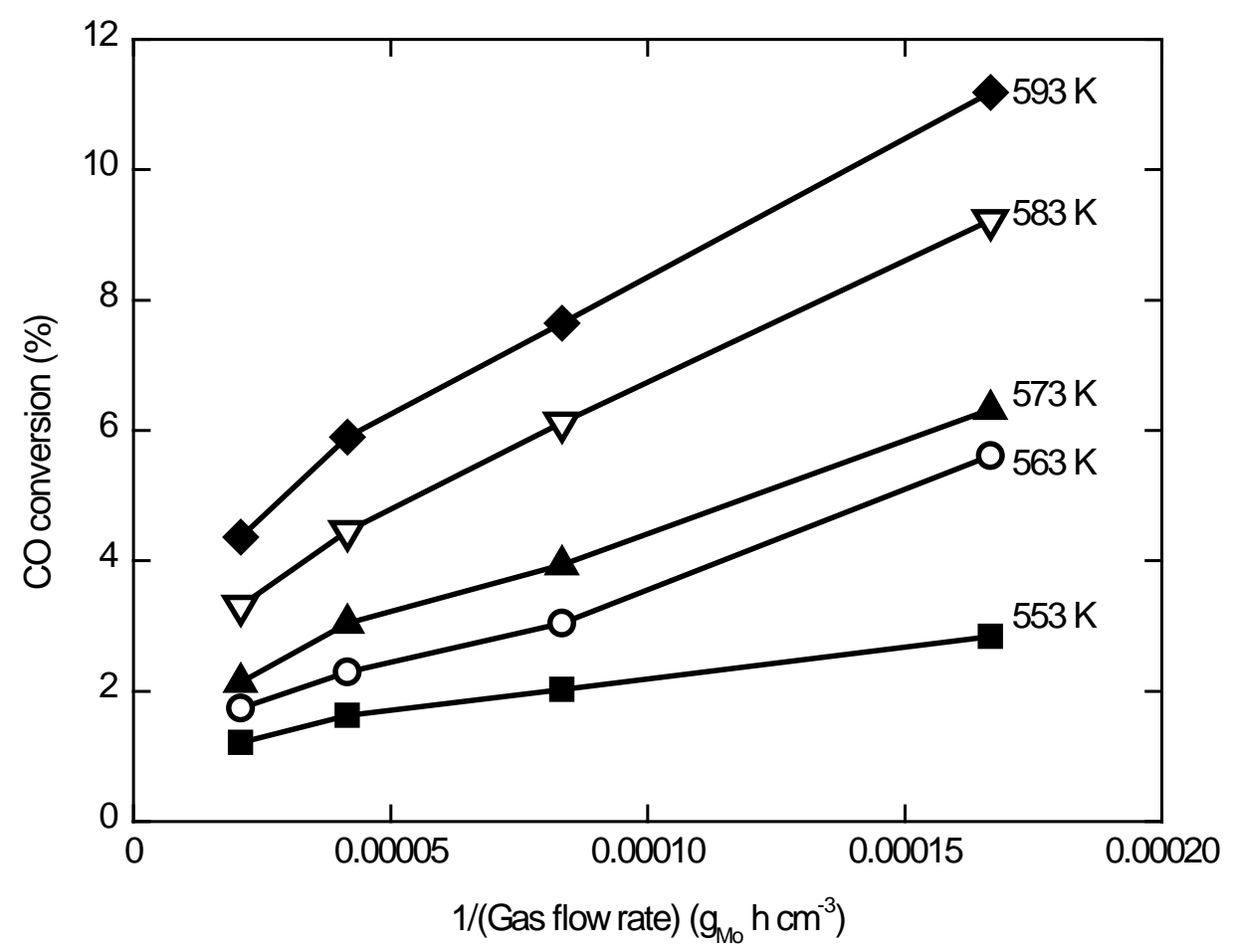

Figure 2.6 Influence of gas flow rate on $\mathrm{CO}$ conversion (including $\mathrm{CO}_{2}$ ) over 5 wt.\% $\mathrm{Rb}-5$ wt. $\% \mathrm{Mo}_{2} \mathrm{C} / \mathrm{MgO}\left(30 \mathrm{bar}, \mathrm{H}_{2} / \mathrm{CO}=1\right)$. 
Table 2.4 compares the behavior of 5 wt. $\% \mathrm{Rb}-5$ wt.\% $\mathrm{Mo}_{2} \mathrm{C} / \mathrm{MgO}$ at the same pressure (30 bar) and same CO conversion level by varying WHSV and temperature. The selectivity of alcohols was independent of temperature over the range of $573 \mathrm{~K}$ to $593 \mathrm{~K}$ at a constant conversion of $\mathrm{CO}$ equal to about $2.7 \%$ (excluding $\mathrm{CO}_{2}$ ). However, the selectivity to alcohols and hydrocarbons is a strong function of CO conversion, as revealed in Figure 2.7. At 30 bar syngas pressure, alcohol selectivity is preferred at low CO conversion, which is also observed over alkali-promoted $\mathrm{MoS}_{2}$-based catalysts for higher alcohol synthesis [37].

Table 2.4 Comparison of catalyst activity at similar CO conversion level by varying temperature and gas flow rate.

\begin{tabular}{llll}
\hline $\mathrm{CO}$ conversion (\%) & 4.2 & 4.5 & 4.4 \\
$\mathrm{CO}_{2}$ selectivity (\%) & 37 & 38 & 37 \\
$\mathrm{CO}$ conversion (\%, excluding $\mathrm{CO}_{2}$ ) & 2.6 & 2.7 & 2.7 \\
Pressure (bar) & 30 & 30 & 30 \\
Temperature (K) & 573 & 583 & 593 \\
$\mathrm{H}_{2} / \mathrm{CO}$ & 1 & 1 & 1 \\
Gas flow rate $\left(\mathrm{cm}^{3} \mathrm{~g}_{\mathrm{Mo}}^{-1} \mathrm{~h}^{-1}\right)$ & 12,000 & 24,000 & 48,000 \\
Selectivity (C\%, on a $\mathrm{CO}_{2}$-free basis) & & & \\
$\quad$ Methane & 16 & 18 & 18 \\
$\quad$ C2 hydrocarbons & 11 & 11 & 12 \\
$\quad$ C3 hydrocarbons & 7.0 & 6.9 & 7.0 \\
$\quad$ C4+ paraffins & 3.8 & 3.2 & 2.3 \\
$\quad$ C4+ olefins & 5.1 & 5.0 & 5.4 \\
$\quad$ Methanol & 18 & 19 & 18 \\
$\quad$ Ethanol & 20 & 20 & 20 \\
1-Propanol & 12 & 11 & 11 \\
1-Butanol & 3.9 & 3.7 & 4.1 \\
$\quad$ 1-Pentanol & 1.7 & 1.4 & 1.8 \\
\hline
\end{tabular}



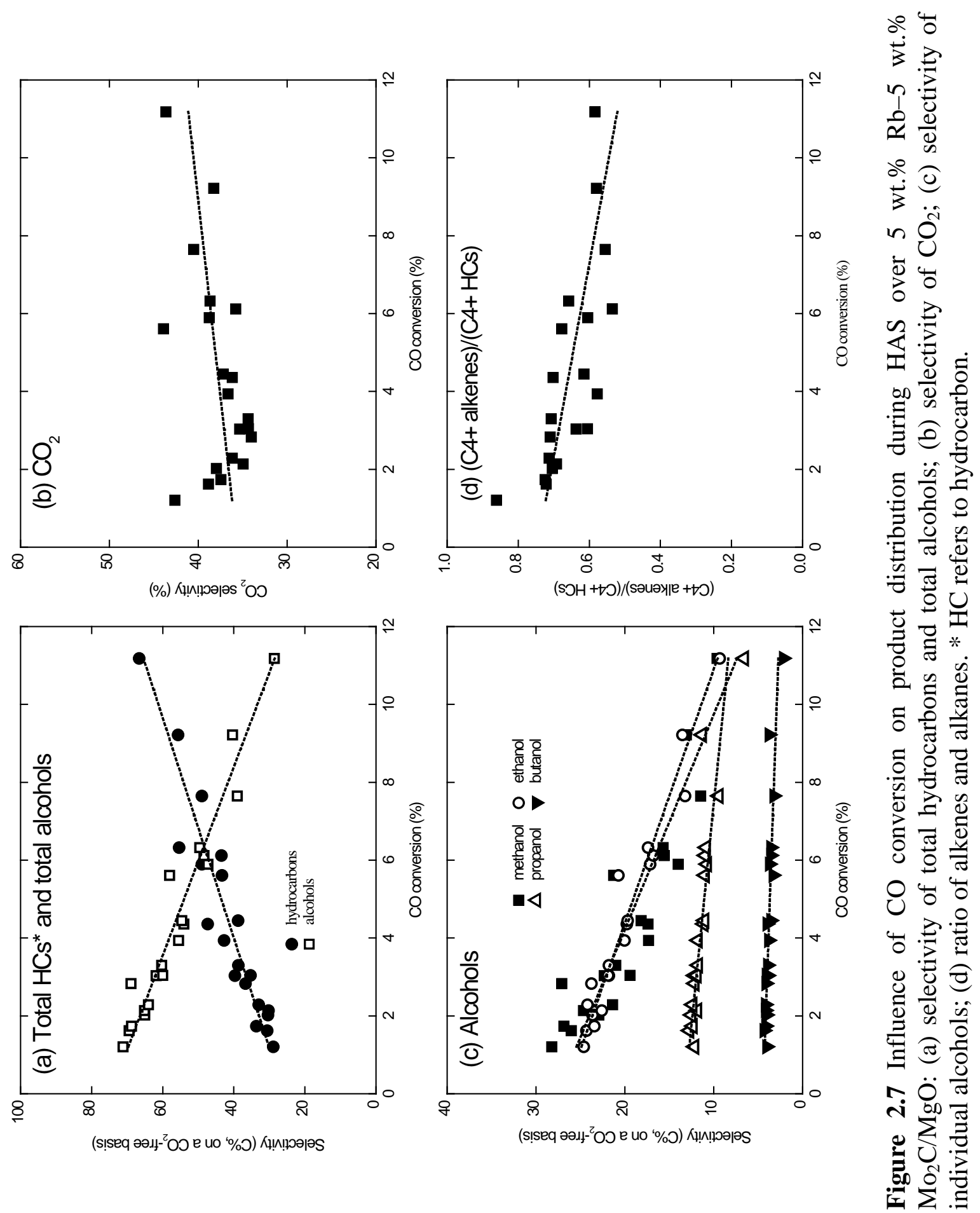
Table 2.5 Impact of partial pressure on production distribution of CO hydrogenation over 5 wt.\% Rb-5 wt.\% $\mathrm{Mo}_{2} \mathrm{C} / \mathrm{MgO}$ catalyst

\begin{tabular}{|c|c|c|c|}
\hline Temperature (K) & 573 & 573 & 573 \\
\hline$P_{\mathrm{CO}}(\mathrm{bar})$ & 7.5 & 15 & 15 \\
\hline$P_{\mathrm{H}_{2}}($ bar $)$ & 15 & 15 & 7.5 \\
\hline Total flow rate $\left(\mathrm{cm}^{3}(\mathrm{STP}) \mathrm{min}^{-1}, \mathrm{H}_{2}+\mathrm{CO}\right)$ & 15 & 20 & 15 \\
\hline CO conversion $(\%)$ & 4.8 & 3.2 & 2.1 \\
\hline Rate of CO conversion $\left(\mathrm{mol}_{\mathrm{CO}} \mathrm{mol}_{\mathrm{Mo}}^{-1} \mathrm{~h}^{-1}\right)$ & 0.024 & 0.016 & 0.010 \\
\hline $\mathrm{CO}_{2}$ selectivity $(\%)$ & 30 & 35 & 28 \\
\hline \multicolumn{4}{|l|}{ Selectivity (C\%, on a $\mathrm{CO}_{2}$-free basis) } \\
\hline Hydrocarbons & 46 & 39 & 41 \\
\hline Methane & 20 & 15 & 15 \\
\hline C2 hydrocarbons & 12 & 9.7 & 12 \\
\hline C3 hydrocarbons & 6.8 & 5.9 & 6.8 \\
\hline C4+ linear paraffins & 3.1 & 3.2 & 2.1 \\
\hline C4+ linear olefins & 3.7 & 4.8 & 5.2 \\
\hline Methanol & 22 & 19 & 20 \\
\hline Higher alcohols & 33 & 41 & 39 \\
\hline Ethanol & 20 & 22 & 21 \\
\hline 1-Propanol & 8.6 & 12 & 12 \\
\hline 1-Butanol & 2.8 & 4.1 & 4.0 \\
\hline 1-Pentanol & 1.0 & 1.9 & 1.7 \\
\hline
\end{tabular}

Table 2.5 summarizes the effect of reactant partial pressures on the CO conversion and product selectivity over 5 wt.\% Rb-5 wt.\% $\mathrm{Mo}_{2} \mathrm{C} / \mathrm{MgO}$ at $573 \mathrm{~K}$. The results indicate the overall reaction is positive order in $\mathrm{H}_{2}$ but is inhibited by $\mathrm{CO}$ at the tested conditions. The changes in conversion during the various runs in Table 2.5 account for observed changes in alcohol and hydrocarbon selectivity.

Table 2.6 presents the influence of total syngas pressure on the CO conversion and selectivity of $\mathrm{CO}$ hydrogenation over 5 wt.\% Rb-5 wt.\% $\mathrm{Mo}_{2} \mathrm{C} / \mathrm{MgO}$ at $573 \mathrm{~K}$ with $\mathrm{H}_{2} / \mathrm{CO}=1$ at a total flow rate of $20 \mathrm{~cm}^{3}$ (STP) $\mathrm{min}^{-1}$. The CO conversion increased with pressure over the range of 10 bar to 30 bar while simultaneously the selectivity to higher alcohols slightly improved from $37 \%$ to $41 \%$. 
Table 2.6 Effect of pressure on reactivity of CO hydrogenation over a 5 wt.\% Rb-5 wt.\% $\mathrm{Mo}_{2} \mathrm{C} / \mathrm{MgO}$ catalyst

\begin{tabular}{llll}
\hline Pressure (bar) & 10 & 20 & 30 \\
Temperature (K) & 573 & 573 & 573 \\
$\mathrm{H}_{2} / \mathrm{CO}$ & 1 & 1 & 1 \\
$\mathrm{H}_{2}+\mathrm{CO}\left(\mathrm{cm}^{3} \mathrm{~min}^{-1}\right)$ & 20 & 20 & 20 \\
$\mathrm{CO}$ conversion (\%) & 1.8 & 2.9 & 3.6 \\
$\mathrm{CO}_{2}$ selectivity (\%) & 32 & 38 & 41 \\
Selectivity (C\%, on a $\mathrm{CO}_{2}$-free basis) & & & \\
$\quad$ Hydrocarbons & 44 & 39 & 39 \\
$\mathrm{CH}_{4}$ & 18 & 16 & 15 \\
$\mathrm{C}_{4}$ hydrocarbons & 13 & 11 & 9.7 \\
C3 hydrocarbons & 6.8 & 5.9 & 5.9 \\
C4+ linear paraffins & 1.5 & 1.8 & 3.2 \\
C4+ linear olefins & 5.0 & 4.2 & 4.9 \\
Methanol & 19 & 22 & 20 \\
Higher alcohols & 37 & 39 & 41 \\
$\quad$ Ethanol & 22 & 22 & 22 \\
1-Propanol & 10 & 11 & 12 \\
1-Butanol & 3.4 & 4.2 & 4.1 \\
1-Pentanol & 1.4 & 1.7 & 1.9 \\
\hline
\end{tabular}

\subsubsection{X-ray absorption spectroscopy}

The X-ray absorption near edge structure (XANES) at the Mo $K$ edge of reference compounds and catalysts are provided in Figure 2.8 and a correlation of edge position of the samples (determined at half step height) to the oxidation state of standard Mo compounds is illustrated in Figure 2.9. The edge position of a sample prior to carburization indicated that calcined $\mathrm{Mo}$ on $\mathrm{MgO}$ was in a +6 oxidation state. Carburization resulted in significant reduction of Mo, which is consistent with the formation of a carbide surface compound. Bulk $\mathrm{Mo}_{2} \mathrm{C}$ showed a slightly higher absorption edge energy than Mo foil (Figure 2.8a and Figure 2.9), but the $\mathrm{Mo}$ in $\mathrm{Mo}_{2} \mathrm{C}$ was significantly reduced from that in $\mathrm{MoO}_{2}$. The absorption edge of passivated 5 wt.\% $\mathrm{Mo}_{2} \mathrm{C} / \mathrm{MgO}$ catalyst before reaction was shifted $+1.8 \mathrm{eV}$ from bulk $\mathrm{Mo}_{2} \mathrm{C}$ (Figure 2.8b), but was still $1.5 \mathrm{eV}$ lower than the edge position of $\mathrm{MoO}_{2}$, which indicates the supported 
$\mathrm{Mo}_{2} \mathrm{C}$ catalysts were partially oxidized, with the surface of the $\mathrm{Mo}_{2} \mathrm{C}$ particles likely being an oxycarbide. Most probably, passivation of the freshly prepared carbide catalysts is responsible for the oxidation. The in situ treatment of $\mathrm{Mo}_{2} \mathrm{C} / \mathrm{MgO}$ catalysts in 30 bar syngas at $573 \mathrm{~K}$ for $4 \mathrm{~h}$ partially reduced the passivated 5 wt.\% $\mathrm{Mo}_{2} \mathrm{C} / \mathrm{MgO}$ (Figure 2.8 and Figure 2.9), but the Mo was still more oxidized than in bulk $\mathrm{Mo}_{2} \mathrm{C}$ (Figure 2.9). The small shifts in $E_{0}$ illustrated in Figure 2.9 caused by the addition of $\mathrm{Rb}_{2} \mathrm{CO}_{3}$ to the corresponding unpromoted $\mathrm{Mo}_{2} \mathrm{C} / \mathrm{MgO}$ were within the experimental error.

The shift of the Mo $K$ edge to lower energy during the induction period of the reacting catalyst was likely caused by the removal of surface oxygen atoms that were introduced by passivation. Griboval-Constant et al. suggested that part of the surface oxygen introduced by passivation of hexagonal $\mathrm{Mo}_{2} \mathrm{C}$ probably reacted with carbidic carbon, which was removed from the uppermost surface layer during this induction period [39]. Ranhotra et al. hypothesized that removal of surface oxygen during the induction period must be coincident with the elimination of some surface carbon because oxygen atoms are more strongly bonded to Mo than carbon [41]. Clearly, the passivation layer on $\mathrm{Mo}_{2} \mathrm{C}$ can significantly affect the surface structure of the catalyst. Wu et al. observed that fresh hexagonal $\mathrm{Mo}_{2} \mathrm{C}$ had many more sites for $\mathrm{CO}$ adsorption than a passivated sample, and few of the passivated sites could be recovered by $\mathrm{H}_{2}$ reduction at $673 \mathrm{~K}$ and $773 \mathrm{~K}$. From our XANES results, we conclude that the passivated sites on $\mathrm{Mo}_{2} \mathrm{C} / \mathrm{MgO}$ catalysts could not be fully recovered since Mo remained partially oxidized in situ. 


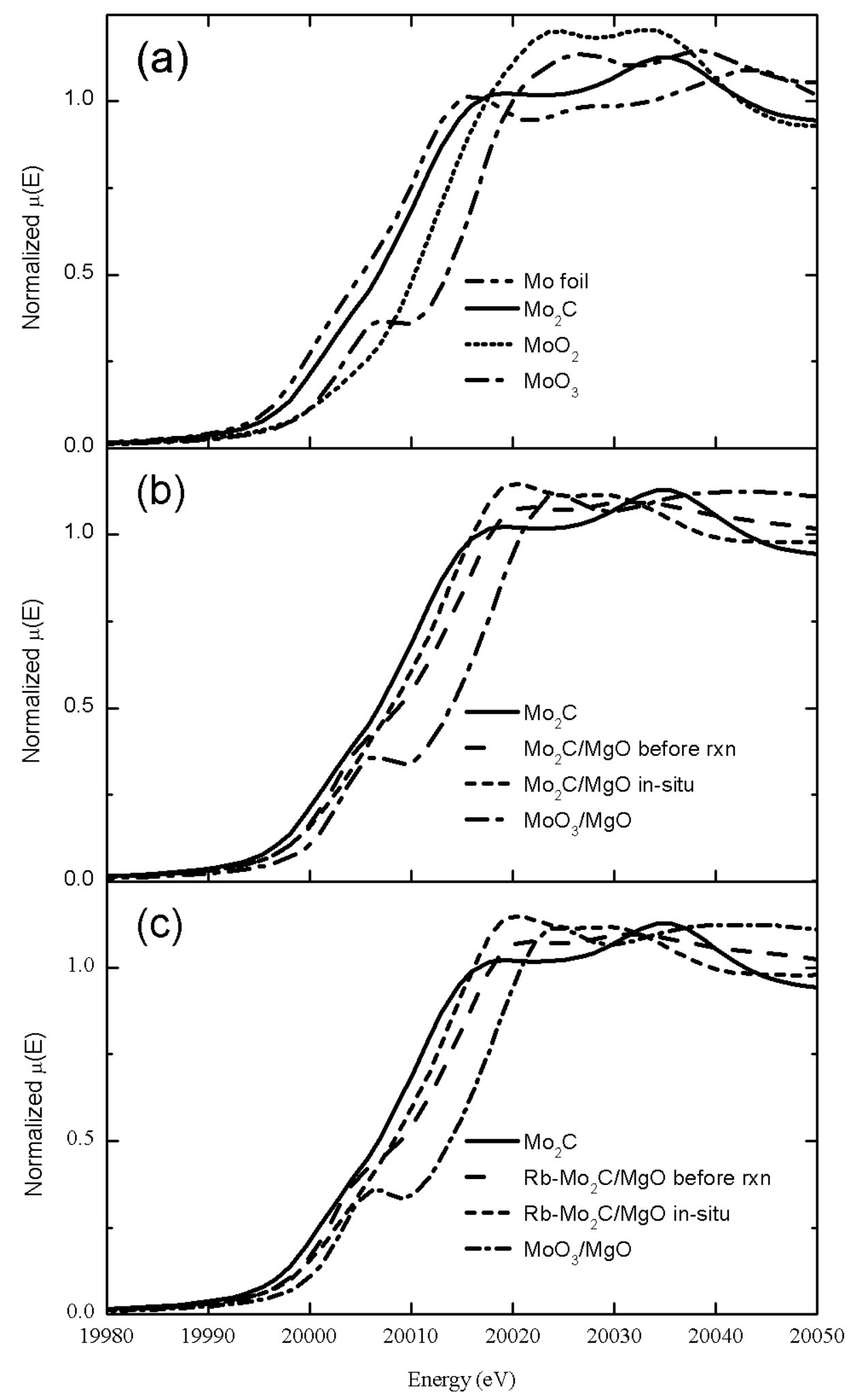

Figure 2.8 X-ray absorption near edge structure (XANES) at the Mo $K$ edge of: (a) Mo reference standards, (b) $\mathrm{Mo}_{2} \mathrm{C} / \mathrm{MgO}$, (c) $\mathrm{Rb}-\mathrm{Mo}_{2} \mathrm{C} / \mathrm{MgO} . \mathrm{MoO}_{3} / \mathrm{MgO}$ is the catalyst precursor before carburization. 


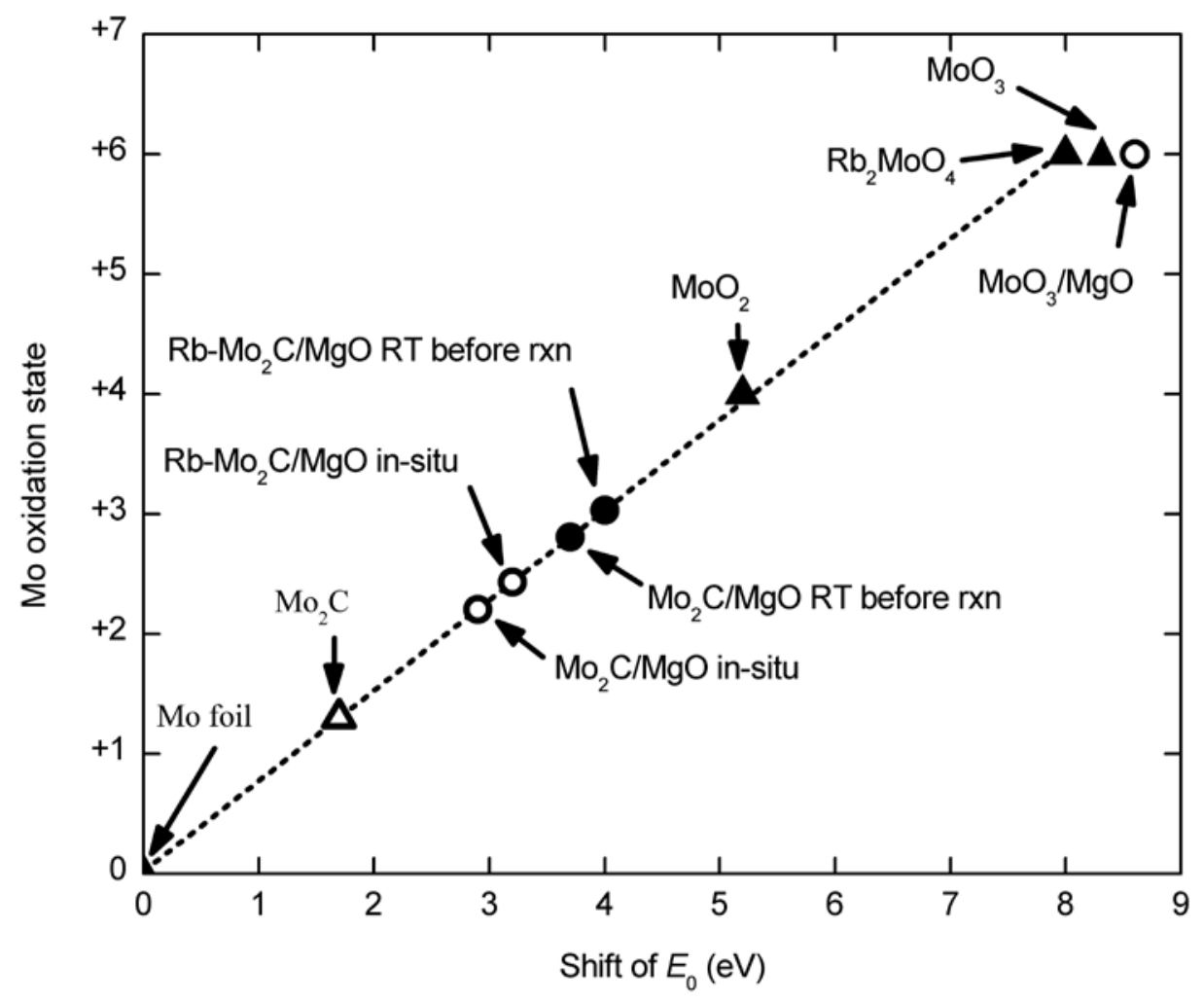

Figure 2.9 Correlation of the Mo $K$ edge energy ( $E_{0}$ defined as energy at half step) to the oxidation state of reference compounds (triangles) and supported catalyst (circles).

Fourier transforms of the Mo $K$ edge extended X-ray absorption fine structure (EXAFS) are presented in Figure 2.10. The coordination numbers (CN), interatomic distances $(r)$, and Debye-Waller factors $\left(\Delta \sigma^{2}\right)$ obtained by curve fitting are summarized in Table 2.7. Example curve fits associated with the results in Table 2.7 are compared to the experimental EXAFS for Mo $K$ edge EXAFS of 5 wt.\% Rb-5 wt.\% $\mathrm{Mo}_{2} \mathrm{C} / \mathrm{MgO}$ (treated in situ for $4 \mathrm{~h}$ ) in Figure 2.11. All of the $R$-factors of the fits are 0.1 or less. 


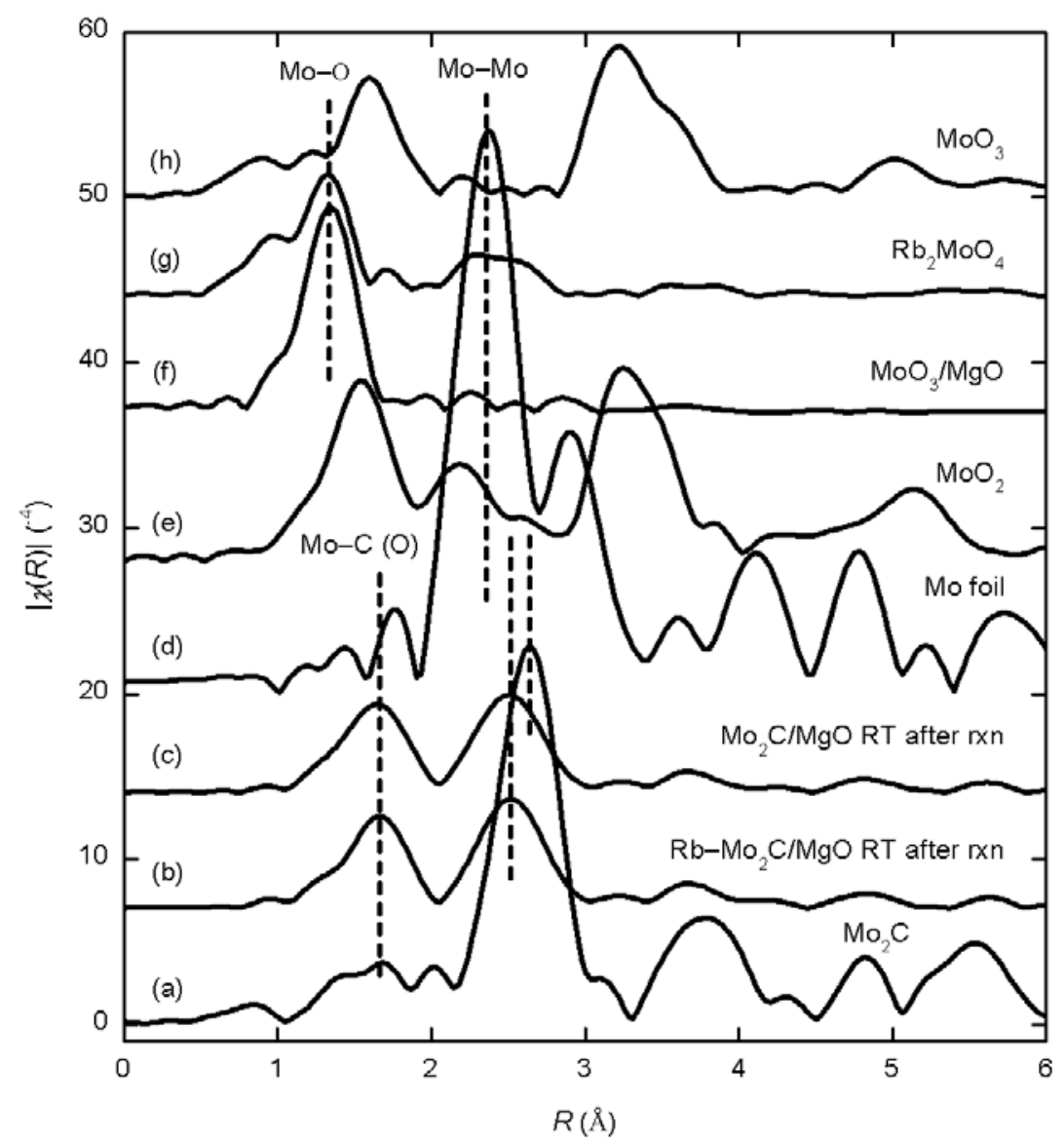

Figure 2.10 Magnitude of the Fourier transform (not corrected for phase shifts) of the $k^{3}$ weighted Mo $K$ edge EXAFS of Mo standards compared to MgO-supported Mo species: (a) $\mathrm{Mo}_{2} \mathrm{C}$, (b) $\mathrm{Rb}-\mathrm{Mo}_{2} \mathrm{C} / \mathrm{MgO} \mathrm{RT}$ after rxn, (c) $\mathrm{Mo}_{2} \mathrm{C} / \mathrm{MgO} \mathrm{RT}$ after rxn, (d) Mo foil, (e) $\mathrm{MoO}_{3} / \mathrm{MgO}$, (f) $\mathrm{Rb}_{2} \mathrm{MoO}_{4}$. Spectra are offset for clarity.

The Mo EXAFS of the $\mathrm{MoO}_{3} / \mathrm{MgO}$ sample (Figure 2.10e) before carburization was quite different from bulk $\mathrm{MoO}_{3}$ (Figure 2.10g). No Mo-Mo interaction was observed in the supported sample and the Mo-O appeared to be contracted from the bulk oxide. The lack of Mo-Mo contributions indicates that Mo was very highly dispersed on the $\mathrm{MgO}$ support. Indeed, $\left(\mathrm{NH}_{4}\right)_{6} \mathrm{Mo}_{7} \mathrm{O}_{24}$ precursor solution reacted with the $\mathrm{MgO}$ support during catalyst preparation because the odor of ammonia was detected during wet impregnation. In the EXAFS analysis, the Mo-O distance in $\mathrm{MoO}_{3} / \mathrm{MgO}$ was exactly the same as that in $\mathrm{Rb}_{2} \mathrm{MoO}_{4}$, which suggests that our precursor of $\mathrm{Mo}_{2} \mathrm{C}$ supported on $\mathrm{MgO}$ was a surface $\mathrm{Mg}$ molybdate. 
Table 2.7 Results from the analysis of Mo EXAFS

\begin{tabular}{|c|c|c|c|c|c|c|}
\hline Sample & Shell & $\mathrm{CN}$ & $\begin{array}{l}\Delta E_{0} \\
(\mathrm{eV})\end{array}$ & $\begin{array}{l}r \\
(\AA)\end{array}$ & $\begin{array}{l}\Delta \Delta \sigma^{2} \\
\left(10^{-3} \AA^{2}\right)\end{array}$ & $\begin{array}{l}R- \\
\text { factor }\end{array}$ \\
\hline $\mathrm{Rb}_{2} \mathrm{MoO}_{4}$ & Mo-O & $4^{\mathrm{a}}$ & $7.4 \pm 2.6$ & $1.77 \pm 0.01$ & $2.5 \pm 1.0$ & 0.023 \\
\hline $\mathrm{MoO}_{3} / \mathrm{MgO}$ & Mo-O & $3.0 \pm 0.4$ & $1.8 \pm 2.1$ & $1.77 \pm 0.01$ & $3.8 \pm 0.8$ & 0.013 \\
\hline $\mathrm{Mo}_{2} \mathrm{C}$ (bulk) & $\begin{array}{l}\text { Mo-C (O) } \\
\text { Mo-Mo }\end{array}$ & $\begin{array}{l}3^{\mathrm{a}} \\
12^{\mathrm{a}}\end{array}$ & $\begin{array}{l}4.0 \pm 3.5 \\
-3.1 \pm 0.8\end{array}$ & $\begin{array}{l}2.12 \pm 0.02 \\
2.97 \pm 0.00\end{array}$ & $\begin{array}{l}3.1 \pm 2.0 \\
5.9 \pm 3.8\end{array}$ & 0.005 \\
\hline $\begin{array}{l}\mathrm{Mo}_{2} \mathrm{C} / \mathrm{MgO} \text {, } \\
\text { in situ }\end{array}$ & $\begin{array}{l}\text { Mo-C (O) } \\
\text { Mo-Mo }\end{array}$ & $\begin{array}{l}5.1 \pm 1.7 \\
7.8 \pm 4.0\end{array}$ & $\begin{array}{l}-2.5 \pm 4.2 \\
-25 \pm 5\end{array}$ & $\begin{array}{l}2.15 \pm 0.02 \\
2.92 \pm 0.02\end{array}$ & $\begin{array}{l}6.2 \pm 2.8 \\
13 \pm 3\end{array}$ & 0.108 \\
\hline $\begin{array}{l}\mathrm{Mo}_{2} \mathrm{C} / \mathrm{MgO}, \\
\mathrm{RT} \text { after rxn }{ }^{\mathrm{b}}\end{array}$ & $\begin{array}{l}\text { Mo-C (O) } \\
\text { Mo-Mo }\end{array}$ & $\begin{array}{l}5.3 \pm 1.5 \\
9.0 \pm 3.2\end{array}$ & $\begin{array}{l}0.3 \pm 3.5 \\
-23 \pm 3\end{array}$ & $\begin{array}{l}2.16 \pm 0.02 \\
2.93 \pm 0.02\end{array}$ & $\begin{array}{l}5.0 \pm 2.2 \\
11 \pm 2\end{array}$ & 0.068 \\
\hline $\begin{array}{l}\mathrm{Rb}-\mathrm{Mo}_{2} \mathrm{C} / \mathrm{MgO} \text {, } \\
\text { in situ }\end{array}$ & $\begin{array}{l}\text { Mo-C (O) } \\
\text { Mo-Mo }\end{array}$ & $\begin{array}{l}5.1 \pm 1.6 \\
8.2 \pm 4.2\end{array}$ & $\begin{array}{l}-2.6 \pm 3.9 \\
-26 \pm 4\end{array}$ & $\begin{array}{l}2.15 \pm 0.02 \\
2.91 \pm 0.02\end{array}$ & $\begin{array}{l}6.0 \pm 2.5 \\
14 \pm 3\end{array}$ & 0.099 \\
\hline $\begin{array}{l}\mathrm{Rb}-\mathrm{Mo}_{2} \mathrm{C} / \mathrm{MgO} \text {, } \\
\mathrm{RT} \text { after rxn }{ }^{\mathrm{b}}\end{array}$ & $\begin{array}{l}\text { Mo-C (O) } \\
\text { Mo-Mo }\end{array}$ & $\begin{array}{l}5.8 \pm 1.8 \\
8.5 \pm 3.5\end{array}$ & $\begin{array}{l}-2.4 \pm 3.9 \\
-24 \pm 4\end{array}$ & $\begin{array}{l}2.15 \pm 0.02 \\
2.92 \pm 0.02\end{array}$ & $\begin{array}{l}5.7 \pm 2.5 \\
11 \pm 3\end{array}$ & 0.082 \\
\hline
\end{tabular}

In situ condition: $T=573 \mathrm{~K}, P=30 \mathrm{bar}$, syngas flow rate $=24000 \mathrm{~cm}^{3} \mathrm{~g}_{\mathrm{Mo}}{ }^{-1} \mathrm{~min}^{-1}$.

Fitting parameters: FT range $\Delta k: 2-14 \AA^{-1}$; fitting range $\Delta R$ : $1-3 \AA$; weighting: $k^{3}$; $S_{0}^{2}(\mathrm{Mo}-\mathrm{C})=0.82, S_{0}^{2}(\mathrm{Mo}-\mathrm{Mo})=0.78, S_{0}^{2}(\mathrm{Mo}-\mathrm{O})=0.77$.

${ }^{\mathrm{a}}$ Value was assigned in curving fitting based on standard structure. ${ }^{\mathrm{b}} \mathrm{R}_{\mathrm{bkg}}$ was set to $1.2 \mathrm{in}$ background removal to reduce the noise oscillation below $1 \AA$ in $\mathrm{R}$ space.

Contributions from Mo-Mo in the Mo EXAFS of the $\mathrm{Mo}_{2} \mathrm{C}$ catalysts were observed after carburization of the $\mathrm{MoO}_{3} / \mathrm{MgO}$ sample in $\mathrm{CH}_{4} / \mathrm{H}_{2}$. It should be noted that the low intensity of the Mo-Mo peaks in the Fourier transform of the carburized catalysts in Figure 2.11 were partly the result of a lower coordination number $(\mathrm{CN}=8 \sim 9$, Figure 2.11b and c) than that of the bulk hexagonal $\mathrm{Mo}_{2} \mathrm{C}$ standard ( $\mathrm{CN}=12$, Figure 2.11a). According to Jentys [41], the low Mo-Mo coordination numbers suggest that about 70\% of the Mo atoms were exposed to the surface of the $\mathrm{Mo}_{2} \mathrm{C}$ clusters, with a corresponding particle size of about $2 \mathrm{~nm}$, which is slightly smaller than that derived from TEM analysis (2.8 $\pm 0.3 \mathrm{~nm})$. This small difference could be the result of some particle aggregation observed in TEM, and/or the shape of the $\mathrm{Mo}_{2} \mathrm{C}$ clusters deviating from a perfect sphere. The $\Delta E_{0}$ values (about-20 eV) need to fit the Mo-Mo contributions in the supported 
catalysts were much greater than that reported for $\mathrm{Mo}_{2} \mathrm{C}$ supported on $\mathrm{Al}_{2} \mathrm{O}_{3}$ [11] and zeolite [43,44]. In Figure 2.10, the Mo-Mo peak position in $\mathrm{Mo}_{2} \mathrm{C} / \mathrm{MgO}$ catalysts deviates about $-0.12 \AA$ from that in bulk $\mathrm{Mo}_{2} \mathrm{C}$, and about $+0.15 \AA$ from metallic Mo. This shift might suggest the existence of metallic $\mathrm{Mo}$ in the $\mathrm{Mo}_{2} \mathrm{C} / \mathrm{MgO}$ catalyst. In fact, Lee and Boudart observed a Mo-Mo distance at $2.80 \AA$ in $\mathrm{Al}_{2} \mathrm{O}_{3}$ supported metallic Mo [11], which is between bulk Mo metal (2.72 $\AA$ ) and bulk $\mathrm{Mo}_{2} \mathrm{C}$ (2.97 $\AA$ ). However, results from XANES and elemental analysis both suggest the formation of carbidic Mo rather than metallic Mo. Therefore, we conclude that the $\mathrm{Mo}_{2} \mathrm{C} / \mathrm{MgO}$ catalysts have the local structure of carbidic Mo species, with a Mo-Mo distance (2.92 Å) contracted from the bulk $\mathrm{Mo}_{2} \mathrm{C}(2.97 \AA)$ because of the small particle size.

The Mo-C interaction in EXAFS of fresh supported $\mathrm{Mo}_{2} \mathrm{C}$ catalysts has been studied elsewhere [11,43,44], and the coordination number of Mo-C varies from 0.6 to 2 . In our study, the coordination numbers of the metal-nonmetal interactions in $\mathrm{Mo}_{2} \mathrm{C} / \mathrm{MgO}$ catalysts are all about 5, which exceed the value of 3 in bulk $\mathrm{Mo}_{2} \mathrm{C}$. Because the backscattering functions of $\mathrm{C}$ and $\mathrm{O}$ are similar, it was not possible to distinguish the different atom types in the EXAFS fitting. Considering the high percentage of surface Mo in $\mathrm{Mo}_{2} \mathrm{C} / \mathrm{MgO}$ catalysts, almost all the surface Mo atoms will likely be bonded to oxygen atoms from passivation and could result in a high $\mathrm{CN}$ for the nonmetal. This speculation is consistent with the finding of Hwu et al. [45], who claim that an oxygen modified $\mathrm{Mo}_{2} \mathrm{C}$ surface can exist at $600 \mathrm{~K}$. Although it is believed that some of the passivated Mo sites can be recovered by reduction to give sites for adsorption, the recovery could be fairly limited [33]. Moreover, even if some of the Mo sites are recovered, the reactant CO and absorbed reaction intermediates could also contribute to the coordination 
environment around Mo. In summary, the high $\mathrm{CN}$ of nonmetal $(\mathrm{C}$ and $\mathrm{O})$ in $\mathrm{Mo}_{2} \mathrm{C} / \mathrm{MgO}$ catalysts is a combination of carbidic carbon, oxygen coming from passivation and the chemically adsorbed reaction intermediates, with a Mo-C (O) distance of $2.15 \AA$, which is slightly elongated from the Mo-C bonds in bulk $\mathrm{Mo}_{2} \mathrm{C}(2.12 \AA)$.
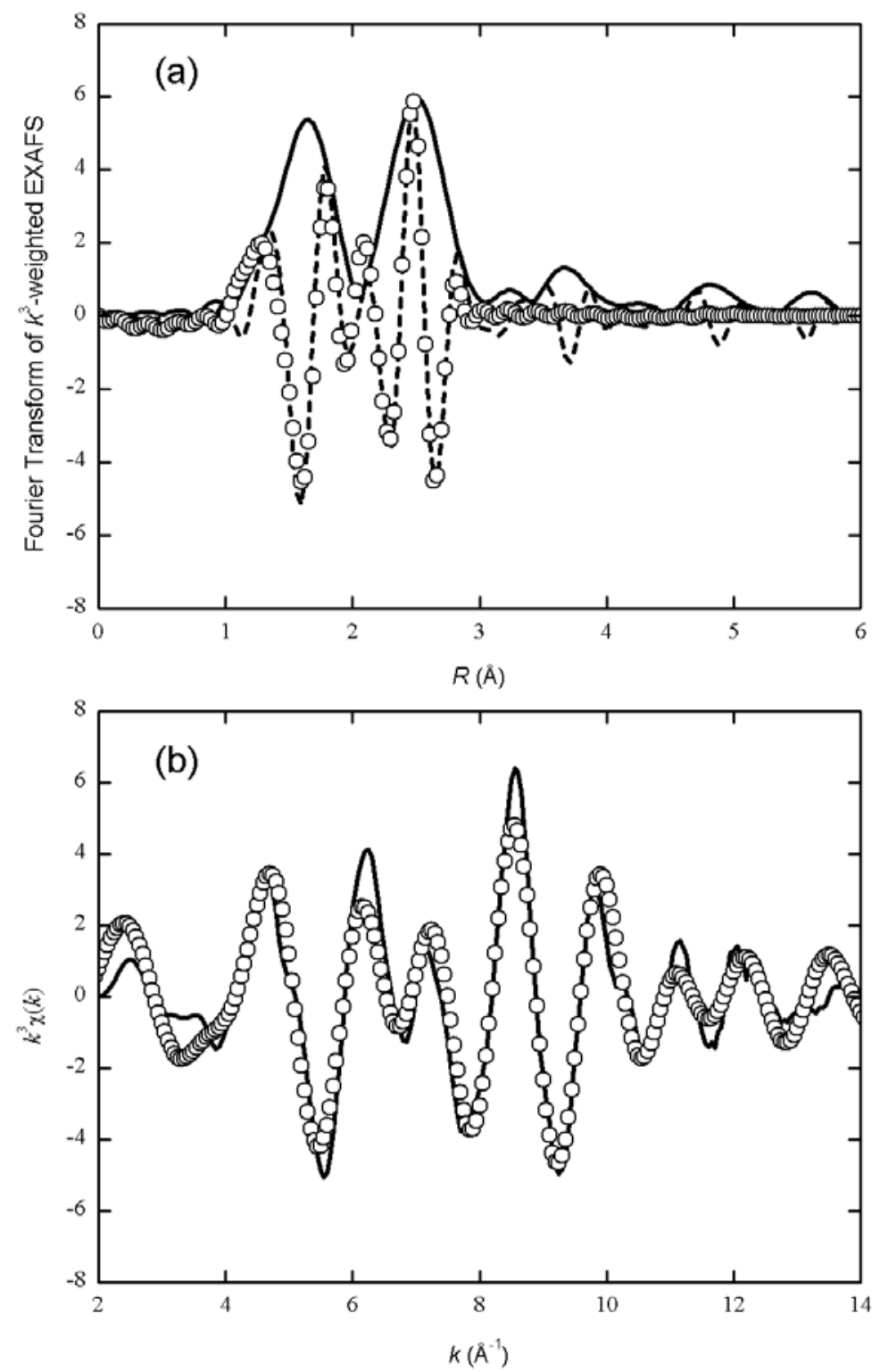

Figure 2.11 Comparison of curve fit to experimental Mo $K$ edge EXAFS of the 5 wt.\% Rb-5 wt.\% $\mathrm{Mo}_{2} \mathrm{C} / \mathrm{MgO}$ catalyst in 30 bar syngas at $573 \mathrm{~K}$ (a) Magnitude (solid line) and the imaginary part (dash line) of the Fourier transform of EXAFS compared to the result from the curve fit (circle); (b) $k^{3}$-weighted Mo $K$ edge EXAFS (solid line) and the result from curve fit (circle). 


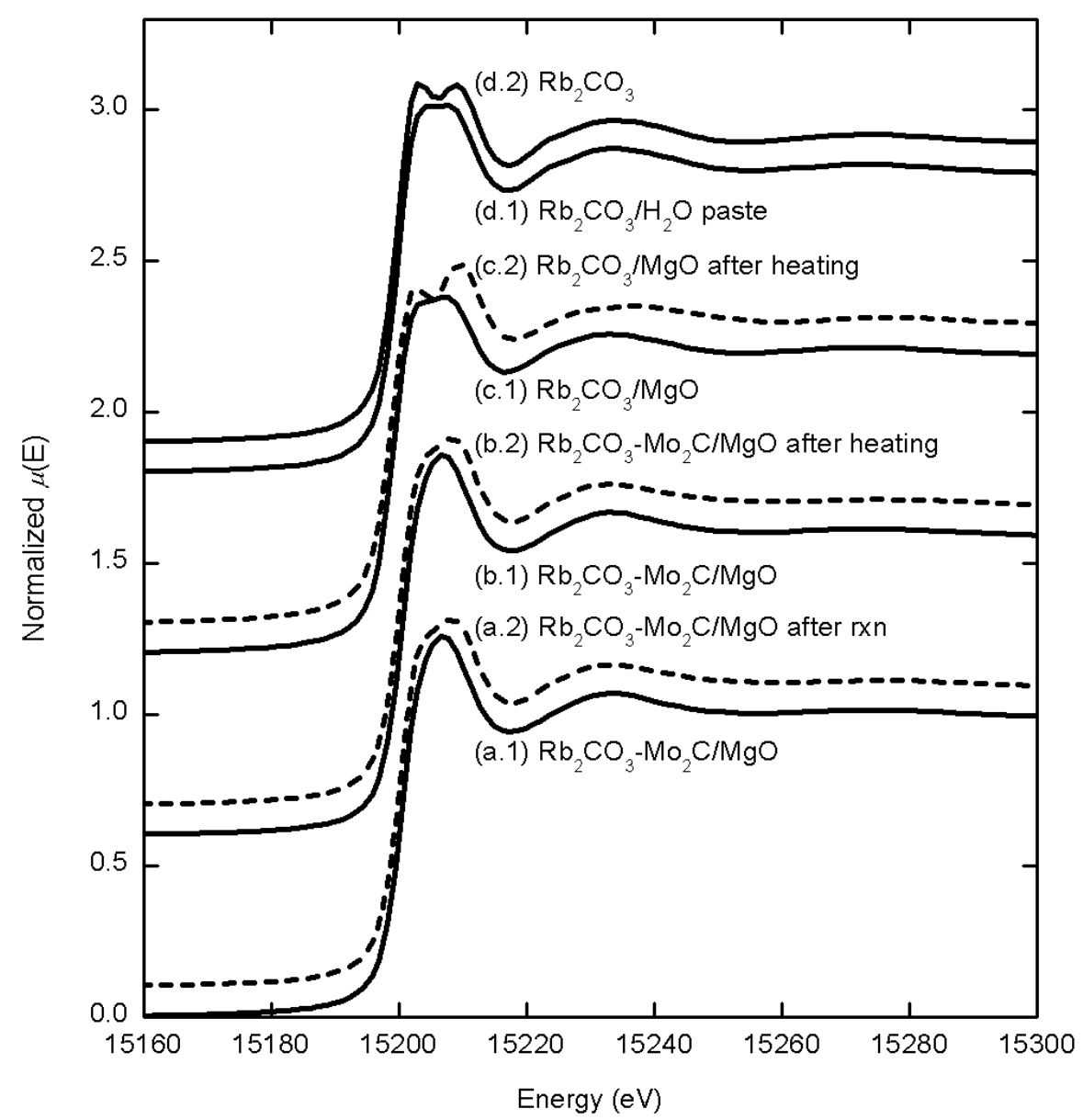

Figure 2.12 XANES at the Rb K edge. Solid lines are spectra recorded at RT without any pretreatment. Dashed lines are spectra recorded at RT after various treatments: (a) $\mathrm{Rb}_{2} \mathrm{CO}_{3}-\mathrm{Mo}_{2} \mathrm{C} / \mathrm{MgO}$ (before and after exposure to 30 bar syngas at $573 \mathrm{~K}$ for $4 \mathrm{~h}$ ), (b) $\mathrm{Rb}_{2} \mathrm{CO}_{3}-\mathrm{Mo}_{2} \mathrm{C} / \mathrm{MgO}$ (before and after heating in $\mathrm{Ar}$ at $573 \mathrm{~K}$ for $4 \mathrm{~h}$ ), (c) $\mathrm{Rb}_{2} \mathrm{CO}_{3} / \mathrm{MgO}$ (before and after heating in Ar at $573 \mathrm{~K}$ for $4 \mathrm{~h}$ ), (d.1) $\mathrm{Rb}_{2} \mathrm{CO}_{3} / \mathrm{H}_{2} \mathrm{O}$ paste at RT, (d.2) $\mathrm{Rb}_{2} \mathrm{CO}_{3}$ as received. Spectra are offset for clarity.

Figure 2.12 presents the near edge features of $\mathrm{Rb}$ species in different samples. The $\mathrm{Rb}_{2} \mathrm{CO}_{3}$ sample directly from the as-received bottle (Figure 2.12d.2) has a doublepeak near edge feature, which can be removed by hydration with a small amount of liquid water (Figure 2.12d.1). Physically-mixing $\mathrm{Rb}_{2} \mathrm{CO}_{3}$ with $\mathrm{MgO}$ or $\mathrm{Mo}_{2} \mathrm{C} / \mathrm{MgO}$, yielded a spectrum consistent with the hydrated sample (Figure 2.12c.1 and Figure 2.12d.1). As shown in Figure 2.12c, heating of $\mathrm{Rb}_{2} \mathrm{CO}_{3} / \mathrm{MgO}$ in $\mathrm{Ar}$ regenerated the double peak feature that is similar to bulk $\mathrm{Rb}_{2} \mathrm{CO}_{3}$ in Figure 2.12d.2. However, after heating the 
carbide sample in either Ar or syngas, the double peak edge structure of $\mathrm{Rb}_{2} \mathrm{CO}_{3}$ was not formed, which suggests a possible structural change of the $\mathrm{Rb}_{2} \mathrm{CO}_{3}$ on our active catalyst samples. Sarkar et al. observed similar $\mathrm{Rb} K$ edge spectra for rubidium promoted Fischer-Tropsch catalysts, but concluded the promoter resembled $\mathrm{Rb}_{2} \mathrm{CO}_{3}$ [45]. Additional studies are required to determine the nature of the supported $\mathrm{Rb}$ phase since the EXAFS above the Rb $K$ edge was uninformative. We speculate that Mo may catalyze the decomposition of $\mathrm{Rb}_{2} \mathrm{CO}_{3}$ to more basic oxides or hydroxides. Earlier work in our laboratory showed that $\mathrm{BaCO}_{3}$ decomposition was facilitated by $\mathrm{H}_{2}$ in the presence of a transition metal such as $\mathrm{Ru}$ [47].

\subsection{Conclusion}

The synthesis of higher alcohols during $\mathrm{CO}$ hydrogenation reactions over $\mathrm{Mo}_{2} \mathrm{C} / \mathrm{MgO}$ catalysts at 30 bar and $573 \mathrm{~K}$ was promoted by both the basic support $\mathrm{MgO}$ and the presence of added $\mathrm{Rb}_{2} \mathrm{CO}_{3}$ promoter. Bulk $\mathrm{Mo}_{2} \mathrm{C}$ was an effective FischerTropsch catalyst under the standard conditions used here and produced only trace alcohols. Supporting $\mathrm{Mo}_{2} \mathrm{C}$ onto $\mathrm{MgO}$ as 2-3 nm sized particles promoted the alcohol synthesis reaction, although hydrocarbons were still favored over alcohols. Addition of $\mathrm{Rb}_{2} \mathrm{CO}_{3}$ to $\mathrm{Mo}_{2} \mathrm{C} / \mathrm{MgO}$ substantially improved the selectivity to alcohols at the expense of hydrocarbons. Higher alcohol synthesis was favored at high syngas pressure and low CO conversion.

Results from X-ray diffraction, transmission electron microscopy and X-ray absorption fine structure confirmed the high dispersion of $\mathrm{Mo}_{2} \mathrm{C}$ on $\mathrm{MgO}$. Near edge spectroscopy followed the incomplete reduction of passivated $\mathrm{Mo}_{2} \mathrm{C} / \mathrm{MgO}$ at reaction conditions, and confirmed the presence of partially oxidized Mo during reaction. In situ 
EXAFS revealed that the $\mathrm{Mo}_{2} \mathrm{C}$ clusters had a longer average Mo-C (O) interatomic distance $(2.15 \AA)$ and a shorter average Mo-Mo distance $(2.92 \AA)$ than bulk $\mathrm{Mo}_{2} \mathrm{C}$, presumably because of the high dispersion on MgO. The relatively large coordination of $\mathrm{C}(\mathrm{O})$ to Mo suggested the existence of surface oxycarbide layer on $\mathrm{Mo}_{2} \mathrm{C}$ clusters. Electron microscopy and $\mathrm{Rb} K$ edge XANES indicated $\mathrm{Rb}$ was well-distributed over the surface, but was chemically modified from bulk $\mathrm{Rb}_{2} \mathrm{CO}_{3}$.

\section{References of Chapter 2}

[1] R.G. Herman, "Advances in catalytic synthesis and utilization of higher alcohols," Catalysis Today 55 (2000) 233-245.

[2] P. Forzatti, E. Tronconi, I. Pasquon, "Higher alcohol synthesis," Catalysis Reviews: Science and Engineering 33 (1991) 109-168.

[3] K. Fang, D. Li, M. Lin, M. Xiang, W. Wei, Y. Sun, "A short review of heterogeneous catalytic process for mixed alcohols synthesis via syngas," Catalysis Today 147 (2009) 133-138.

[4] V. Subramani, S.K. Gangwal, "A review of recent literature to search for an efficient catalytic process for the conversion of syngas to ethanol," Energy \& Fuels 22 (2008) 814-839.

[5] G.J. Quarderer, G.A. Cochran, "Catalytic process for producing mixed alcohols from hydrogen and carbon monoxide," European Patent EP0119609, 1984, to The Dow Chemical Company.

[6] M.M. Conway, C.B. Murchison, R.R. Stevens, "Method for adjusting methanol to higher alcohol ratios," U.S. Patent 4675344, 1987, to The Dow Chemical Company.

[7] G.J. Quarderer, G.A. Cochran, "Process for producing alcohols from synthesis gas," U.S. Patent 4749724, 1988, to The Dow Chemical Company.

[8] R.R. Stevens, "Process for producing alcohols from synthesis gas," U.S. Patent 4752622, 1988, to The Dow Chemical Company.

[9] R.R. Stevens, "Process for producing alcohols from synthesis gas," U.S. Patent 4882360, 1989, to The Dow Chemical Company.

[10] R.B. Levy, M. Boudart, "Platinum-like behavior of tungsten carbide in surface catalysis,” Science 181 (1973) 547-549. 
[11] J.S. Lee, M. Boudart, "In situ carburization of metallic molybdenum during catalytic reactions of carbon-containing gases,” Catalysis Letters 20 (1993) 97-106.

[12] J.S. Lee, S.T. Oyama, M. Boudart, “Molybdenum carbide catalysts: I. Synthesis of unsupported powders,” Journal of Catalysis 106 (1987) 125-133.

[13] J.S. Lee, S. Locatelli, S.T. Oyama, M. Boudart,” Molybdenum carbide catalysts 3. Turnover rates for the hydrogenolysis of n-butane," Journal of Catalysis 125 (1990) 157-170.

[14] S.T. Oyama, "Preparation and catalytic properties of transition metal carbides and nitrides,” Catalysis Today 15 (1992) 179-200.

[15] J.G. Chen, "Carbide and nitride overlayers on early transition metal surfaces: Preparation, characterization, and reactivities,” Chemical Reviews 96 (1996) 14771498.

[16] K.Y. Park, W.K. Seo, J.S. Lee, "Selective synthesis of light olefins from syngas over potassium-promoted molybdenum carbide catalysts," Catalysis Letters 11 (1991) 349-356.

[17] H.C. Woo, K.Y. Park, Y.G. Kim, I. Nam, J.S. Chung, J.S. Lee, "Mixed alcohol synthesis from carbon monoxide and dihydrogen over potassium-promoted molybdenum carbide catalysts,” Applied Catalysis 75 (1991) 267-280.

[18] J.S. Lee, S. Kim, Y.G. Kim, "Electronic and geometric effects of alkali promoters in CO hydrogenation over K/Mo ${ }_{2} \mathrm{C}$ catalysts,” Topics in Catalysis 2 (1995) 127140 .

[19] L. Leclercq, A. Almazouari, M. Dufour, G. Leclercq, "Carbide-oxide interactions in bulk and supported tungsten carbide catalyst for alcohol synthesis,” in: S.T. Oyama (Ed.), The Chemistry of Transition Metal Carbides and Nitrides, Springer, 1996: pp. 345-361.

[20] M. Xiang, D. Li, W. Li, B. Zhong, Y. Sun, "K/Fe/ $\beta-\mathrm{Mo}_{2} \mathrm{C}$ : A novel catalyst for mixed alcohols synthesis from carbon monoxide hydrogenation," Catalysis Communications 8 (2007) 88-90.

[21] M. Xiang, D. Li, W. Li, B. Zhong, Y. Sun, "Synthesis of higher alcohols from syngas over $\mathrm{K} / \mathrm{Co} / \beta-\mathrm{Mo}_{2} \mathrm{C}$ catalysts,” Catalysis Communications 8 (2007) 503507.

[22] M. Xiang, D. Li, W. Li, B. Zhong, Y. Sun, "Potassium and nickel doped $\beta-\mathrm{Mo}_{2} \mathrm{C}$ catalysts for mixed alcohols synthesis via syngas,” Catalysis Communications 8 (2007) 513-518. 
[23] M. Xiang, D. Li, H. Xiao, J. Zhang, W. Li, B. Zhong, Y. Sun, "K/Ni/ $/ \mathrm{Mo}_{2} \mathrm{C}$ : A highly active and selective catalyst for higher alcohols synthesis from CO hydrogenation," Catalysis Today 131 (2008) 489-495.

[24] M. Xiang, D. Li, H. Xiao, J. Zhang, H. Qi, W. Li, B. Zhong, Y. Sun, "Synthesis of higher alcohols from syngas over Fischer-Tropsch elements modified $\mathrm{K} / \beta-\mathrm{Mo}_{2} \mathrm{C}$ catalysts," Fuel 87 (2008) 599-603.

[25] N. Wang, K. Fang, M. Lin, D. Jiang, D. Li, Y. Sun, "Synthesis of higher alcohols from syngas over $\mathrm{Fe} / \mathrm{K} / \beta-\mathrm{Mo}_{2} \mathrm{C}$ catalyst,” Catalysis Letters 136 (2010) 9-13.

[26] N. Wang, K. Fang, D. Jiang, D. Li, Y. Sun, "Iron carbide promoted $\mathrm{K} / \beta-\mathrm{Mo}_{2} \mathrm{C}$ for higher alcohols synthesis,” Catalysis Today 158 (2010) 241-245.

[27] L. Zhao, K. Fang, D. Jiang, D. Li, Y. Sun, "Sol-gel derived Ni-Mo bimetallic carbide catalysts and their performance for CO hydrogenation," Catalysis Today 158 (2010) 490-495.

[28] J.T. Calla, R.J. Davis, "Oxygen-exchange reactions during CO oxidation over titania- and alumina-supported Au nanoparticles,” Journal of Catalysis 241 (2006) 407-416.

[29] R. Burch, M. Petch, "Investigation of the synthesis of oxygenates from carbon monoxide/hydrogen mixtures on supported rhodium catalysts," Applied Catalysis A: General 88 (1992) 39-60.

[30] B. Fingland, F. Ribeiro, J. Miller, "Simultaneous measurement of X-ray absorption spectra and kinetics: A fixed-bed, plug-flow operando reactor," Catalysis Letters 131 (2009) 1-6.

[31] B. Ravel, M. Newville, "ATHENA, ARTEMIS, HEPHAESTUS: Data analysis for X-ray absorption spectroscopy using IFEFFIT,” Journal of Synchrotron Radiation 12 (2005) 537-541.

[32] S. Zabinsky, J.J. Rehr, A. Ankudinov, R.C. Albers, M.J. Eller, "Multiple-scattering calculations of x-ray-absorption spectra," Physical Review B 52 (1995) 2995-3009.

[33] W. Wu, Z. Wu, C. Liang, X. Chen, P. Ying, C. Li, "In situ FT-IR spectroscopic studies of $\mathrm{CO}$ adsorption on fresh $\mathrm{Mo}_{2} \mathrm{C} / \mathrm{Al}_{2} \mathrm{O}_{3}$ catalyst," The Journal of Physical Chemistry B 107 (2003) 7088-7094.

[34] M. Xiang, D. Li, W. Li, B. Zhong, Y. Sun, "Performances of mixed alcohols synthesis over potassium promoted molybdenum carbides,” Fuel 85 (2006) 26622665.

[35] H. Kim, K.H. Lee, J.S. Lee, "Carbon monoxide hydrogenation over molybdenum carbide catalysts,” Research on Chemical Intermediates 26 (2000) 427-443. 
[36] Muramatsu, T. Tatsumi, H. Tominaga, "Mixed alcohol synthesis from $\mathrm{CO}-\mathrm{H}_{2}$ by use of $\mathrm{KCl}$-promoted $\mathrm{Mo} / \mathrm{SiO}_{2}$ catalysts," Bulletin of the Chemical Society of Japan 60 (1987) 3157-3161.

[37] J. Christensen, P. Mortensen, R. Trane, P. Jensen, A. Jensen, "Effects of $\mathrm{H}_{2} \mathrm{~S}$ and process conditions in the synthesis of mixed alcohols from syngas over alkali promoted cobalt-molybdenum sulfide,” Applied Catalysis A: General 366 (2009) 29-43.

[38] V. Ponec, “Active centres for synthesis gas reactions," Catalysis Today 12 (1992) 227-254.

[39] G. van der Lee, V. Ponec, "On some problems of selectivity in syngas reactions on the group VIII metals," Catalysis Reviews: Science and Engineering 29 (1987) 183-218.

[40] Griboval-Constant, J. Giraudon, G. Leclercq, L. Leclercq, "Catalytic behavior of cobalt or ruthenium supported molybdenum carbide catalysts for FT reaction," Applied Catalysis A: General 260 (2004) 35-45.

[41] G.S. Ranhotra, A.T. Bell, J.A. Reimer, "Catalysis over molybdenum carbides and nitrides: II. Studies of $\mathrm{CO}$ hydrogenation and $\mathrm{C}_{2} \mathrm{H}_{6}$ hydrogenolysis," Journal of Catalysis 108 (1987) 40-49.

[42] Jentys, "Estimation of mean size and shape of small metal particles by EXAFS," Physical Chemistry Chemical Physics 1 (1999) 4059-4063.

[43] S. Liu, L. Wang, R. Ohnishi, M. Ichikawa, "Bifunctional catalysis of Mo/HZSM-5 in the dehydroaromatization of methane to benzene and naphthalene XAFS/TG/DTA/MASS/FTIR characterization and supporting effects," Journal of Catalysis 181 (1999) 175-188.

[44] W. Ding, S. Li, G. D Meitzner, E. Iglesia, "Methane conversion to aromatics on Mo/H-ZSM5: Structure of molybdenum species in working catalysts," The Journal of Physical Chemistry B 105 (2001) 506-513.

[45] H.H. Hwu, M.B. Zellner, J.G. Chen, "The chemical and electronic properties of oxygen-modified C/Mo(110): A model system for molybdenum oxycarbides," Journal of Catalysis 229 (2005) 30-44.

[46] Sarkar, G. Jacobs, Y. Ji, H.H. Hamdeh, B.H. Davis, "Fischer-Tropsch synthesis: Characterization Rb promoted iron catalyst,” Catalysis Letters 121 (2008) 1-11.

[47] B.C. McClaine, S.E. Siporin, R.J. Davis, "X-ray and IR spectroscopy of bariumpromoted, zeolite-supported ruthenium catalysts for ammonia synthesis," The Journal of Physical Chemistry B 105 (2001) 7525-7532. 


\section{Chapter 3.}

\section{Influence of passivation on the reactivity of unpromoted and Rb-promoted $\mathrm{Mo}_{2} \mathrm{C}$ nanoparticles for $\mathrm{CO}$ hydrogenation}

Adapted with permission from Heng Shou, Daniela Ferrari, David G. Barton, Christopher W. Jones and Robert J. Davis, "Influence of passivation on the reactivity of unpromoted and Rb-promoted $\mathrm{Mo}_{2} \mathrm{C}$ nanoparticles for CO hydrogenation,” ACS Catalysis 2 (2012) 1408-1416, Copyright (2012) American Chemical Society

\section{Abstract}

Unpromoted and Rb-promoted $\mathrm{Mo}_{2} \mathrm{C}$ nanoparticles ( $\sim \mathrm{nm}$ in size) were synthesized on $\alpha$-alumina and used for CO hydrogenation. The reaction was performed in a fixed-bed reactor system operating at $573 \mathrm{~K}$ and 30 bar with a gas flow rate of 24,000 $\mathrm{cm}^{3} \mathrm{~g}_{\mathrm{Mo}}^{-1} \mathrm{~h}^{-1}$ and $\mathrm{H}_{2} / \mathrm{CO}=1$. Unpromoted $\mathrm{Mo}_{2} \mathrm{C}$ functioned as a Fischer-Tropsch catalyst producing mostly hydrocarbons at the standard conditions. Passivation of freshly synthesized $\mathrm{Mo}_{2} \mathrm{C}$ nanoparticles in $1 \% \mathrm{O}_{2}$ prior to $\mathrm{CO}$ hydrogenation decreased the Fischer-Tropsch activity of the catalyst by about $40 \%$ compared to a non-passivated sample. Addition of $\mathrm{Rb}$ promoter to $\mathrm{Mo}_{2} \mathrm{C}$ shifted the selectivity of the catalyst by inhibiting the formation of hydrocarbons while enhancing the formation of alcohols. The presence of $\mathrm{Rb}$ with $\mathrm{Mo}_{2} \mathrm{C}$ also reduced substantially the sensitivity of the catalyst to passivation by $1 \% \mathrm{O}_{2}$ compared to unpromoted $\mathrm{Mo}_{2} \mathrm{C}$. The partial oxidation of the $\mathrm{Mo}_{2} \mathrm{C}$ nanoparticles by passivation and partial reduction by syngas was confirmed by Mo $K$ edge X-ray absorption spectroscopy. 


\subsection{Introduction}

Limited crude oil reserves and competition with the food industry associated with fermentation-based biofuel production inspire new efforts on effective catalytic transformations of alternative carbon sources to produce energy carriers and chemical feedstocks. Production of higher alcohols from the catalytic conversion of synthesis gas $\left(\mathrm{CO}+\mathrm{H}_{2}\right)$ derived from coal, natural gas or renewable biomass is one strategy that has shown some promise [1-4].

Although Rh-based catalysts are effective for the formation of ethanol and other C2-oxygenates from syngas [5-7], the very high cost of Rh likely prohibits its large scale utilization. Several non-precious metal catalysts for higher alcohol synthesis have thus been evaluated and include, for example, $\mathrm{MoS}_{2}$, Cu-Co, $\mathrm{Cu}-\mathrm{Zn}-\mathrm{Al}$ and $\mathrm{Zn}-\mathrm{Cr}-\mathrm{K}$, but improvements in the overall catalytic activity, alcohol selectivity, and long-term stability of these materials are still needed [2].

Early transition metal carbides are also recognized as potential substitutes to precious metal catalysts because of their similar surface electronic properties [8-10]. For example, molybdenum carbide catalysts are well-known to produce hydrocarbons from syngas via Fischer-Tropsch synthesis [11-13], but the selectivity of the reaction shifts from hydrocarbons to higher alcohols when appropriate promoters and reaction conditions are used $[14,15]$. The highly reactive carbide surface is very sensitive to oxygen and therefore needs to be passivated before exposure to air. Prior works have described the various behaviors of oxygen-modified carbide surfaces in different reactions. For example, Ribeiro et al. and Iglesia et al. claimed that surface oxygen inhibits the very high reactivity of fresh tungsten carbide for hydrogenolysis of 
hydrocarbons. However, partial oxidation of the tungsten carbide surface also forms acid sites that catalyze hydrocarbon isomerization reactions through coupled dehydrogenation and carbenium ion reactions [16-20]. For a reaction such as higher alcohol synthesis from syngas, the presence of acid sites on the catalyst formed by passivation would likely be detrimental to the desired product distribution. In other work, Liu et al. reported that a carbide-modified W(111) surface was highly selective for the dehydrogenation of cyclohexane to benzene after exposure to $\mathrm{O}_{2}$ at $900 \mathrm{~K}$, but was inactive to cyclohexane after exposure to $\mathrm{O}_{2}$ at $<600 \mathrm{~K}$ [21]. Similarly, Hwu et al. found that a carbide-modified Mo(110) surface exposed to $\mathrm{O}_{2}$ at $900 \mathrm{~K}$ exhibited decomposition activity for cyclohexene, ethylene and methanol, whereas the carbide surface was relatively unreactive toward those substrates after $\mathrm{O}_{2}$ exposure at $600 \mathrm{~K}$ [22]. Nagai et al. also showed that passivation of molybdenum carbide with dilute $\mathrm{O}_{2}$ at room temperature reduced its activity in $\mathrm{CO}_{2}$ hydrogenation to form $\mathrm{CO}$ and $\mathrm{CH}_{4}$ [23]. Using FT-IR spectroscopy, Wu et al. revealed that a surface passivation procedure with dilute $\mathrm{O}_{2}$ at room temperature irreversibly modified a fresh molybdenum carbide surface, hence significantly reducing the number of sites for CO adsorption [24,25].

Evidently, carbidic carbon atoms and/or metal atoms react with the $\mathrm{O}_{2}$ used in passivation, which can significantly modify the observed reactivity of carbide catalysts. Therefore, the influence of $\mathrm{O}_{2}$ on reactivity must be examined as part of any comprehensive study of carbidic materials for catalysis. In this work, the influence of passivation on the structure and $\mathrm{CO}$ hydrogenation activity of alumina-supported $\mathrm{Mo}_{2} \mathrm{C}$ catalysts, with and without alkali metal promoter, was explored. 


\subsection{Experimental methods}

\subsubsection{Catalyst synthesis}

Incorporation of Mo onto the alumina support (Mager Scientific, >99.98\%, predominantly $\alpha$-phase, $\mathrm{S}_{\mathrm{BET}}=26.8 \mathrm{~m}^{2} \mathrm{~g}^{-1}$ ) was accomplished by incipient wetness impregnation of an aqueous solution of $\left(\mathrm{NH}_{4}\right)_{6} \mathrm{Mo}_{7} \mathrm{O}_{24} \cdot 4 \mathrm{H}_{2} \mathrm{O}$ (99.98\%, Aldrich) followed by drying in air for $12 \mathrm{~h}$ at $400 \mathrm{~K}$ and calcining in flowing air for $5 \mathrm{~h}$ at $773 \mathrm{~K}$ to produce a supported molybdenum oxide, denoted here as $\mathrm{MoO}_{3} / \mathrm{Al}_{2} \mathrm{O}_{3}$. The sample of $\mathrm{MoO}_{3} / \mathrm{Al}_{2} \mathrm{O}_{3}$ was then reduced at $673 \mathrm{~K}$ in flowing $\mathrm{H}_{2}$ (GTS-Welco, 99.999\%) for $5 \mathrm{~h}$ prior to carburization. The supported oxide sample after reduction is denoted here as $\mathrm{MoO}_{2} / \mathrm{Al}_{2} \mathrm{O}_{3}$ for reference. (The formation of a partially reduced Mo species is verified by X-ray absorption spectroscopy reported later.) The partially reduced $\mathrm{MoO}_{2} / \mathrm{Al}_{2} \mathrm{O}_{3}$ sample was either carburized or promoted with $\mathrm{Rb}$ prior to carburization. The $\mathrm{Rb}$ promoted $\mathrm{MoO}_{2} / \mathrm{Al}_{2} \mathrm{O}_{3}$ samples were prepared by grinding $\mathrm{Rb}_{2} \mathrm{CO}_{3}$ (99.975\%, Alfa Aesar) together with $\mathrm{MoO}_{2} / \mathrm{Al}_{2} \mathrm{O}_{3}$ in a mortar and pestle. Carburization of $\mathrm{MoO}_{2} / \mathrm{Al}_{2} \mathrm{O}_{3}$ and $\mathrm{Rb}$ promoted $\mathrm{MoO}_{2} / \mathrm{Al}_{2} \mathrm{O}_{3}$ was performed in a stainless steel tube reactor $(26.7 \mathrm{~cm}$ length, $1.27 \mathrm{~cm} \mathrm{OD,} 0.85 \mathrm{~cm} \mathrm{ID,} \mathrm{see} \mathrm{Figure} \mathrm{3.1a)} \mathrm{by} \mathrm{heating} \mathrm{at} \mathrm{a} \mathrm{rate} \mathrm{of} 5 \mathrm{~K} \mathrm{~min}^{-1}$ from room temperature to $673 \mathrm{~K}$ and at a rate of $1 \mathrm{~K} \mathrm{~min}^{-1}$ from $673 \mathrm{~K}$ to $900 \mathrm{~K}$ in 11.1 vol. $\% \mathrm{C}_{2} \mathrm{H}_{6}$ (GTS-Welco, 99.997\%) and 88.9 vol.\% $\mathrm{H}_{2}$ (GTS-Welco, 99.999\%) at a total gas flow rate of $67.5 \mathrm{~cm}^{3} \mathrm{~min}^{-1}$. After ramping to $900 \mathrm{~K}$ in $\mathrm{C}_{2} \mathrm{H}_{6} / \mathrm{H}_{2}$, the temperature was maintained at $900 \mathrm{~K}$ for $8 \mathrm{~h}$. Ethane was used as a carbon source instead of methane to reduce the temperature for carburization [26,27], since elemental analysis revealed that $74 \%$ of the total $\mathrm{Rb}$ was vaporized during carburization in $\mathrm{CH}_{4} / \mathrm{H}_{2}$ at $973 \mathrm{~K}$. The catalyst was subsequently cooled to room temperature in flowing Ar (GTS-Welco, 99.999\%, 
additionally purified by an OMI-2 purifier (Sigma-Aldrich)). The catalysts were used "as carburized" or passivated in a stream of 1.04 vol. $\% \mathrm{O}_{2} / \mathrm{N}_{2}$ mixture (GTS-Welco) at room temperature for $12 \mathrm{~h}$. After carburization or passivation, the reactor containing the catalyst (Figure 3.1a) was purged with purified flowing Ar, sealed by a cap (Swagelok) on the downstream end and a 3-way valve (Swagelok) on the upstream end, and installed in the high pressure CO hydrogenation reactor system.

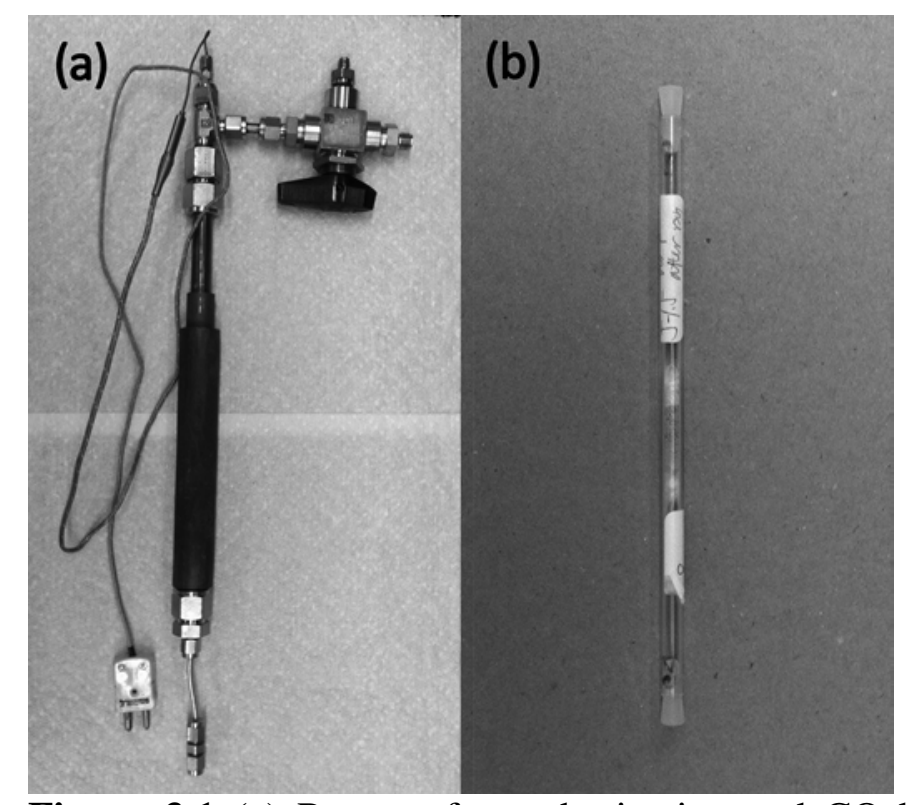

Figure 3.1 (a) Reactor for carburization and CO hydrogenation, and (b) XAS sample tube. Both were used for air-free handling.

\subsubsection{Hydrogenation of carbon monoxide}

Hydrogenation of CO was conducted in a BTRS Jr. system (Autoclave Engineers) equipped with the fixed-bed stainless steel reactor (Figure 3.1a) used to carburize the catalyst. The reactor contained nominally $0.05 \mathrm{~g} \mathrm{Mo}_{2} \mathrm{C}$, composed of about $1.0 \mathrm{~g}$ of $\mathrm{Mo}_{2} \mathrm{C} / \mathrm{Al}_{2} \mathrm{O}_{3}$ or $\mathrm{Rb}$-promoted $\mathrm{Mo}_{2} \mathrm{C} / \mathrm{Al}_{2} \mathrm{O}_{3}$. The catalysts were tested at identical conditions of $573 \mathrm{~K}$, 30 bar total pressure, syngas $\left(\mathrm{H}_{2}+\mathrm{CO}\right)$ flow of $20 \mathrm{~cm}^{3} \mathrm{~min}^{-1}$ (STP) and $\mathrm{H}_{2} / \mathrm{CO}=1$. The reactor was pressurized to $30 \mathrm{bar}$ at room temperature and heated to $573 \mathrm{~K}$ before sampling. The catalyst temperature was monitored with a thermocouple in 
contact with the catalyst bed. The purity of CO (GT\&S) was $99.9 \%$ and $\mathrm{H}_{2}$ (GT\&S) was 99.999\%. Additionally, CO was purified by passing it through a silica trap immersed in a dry ice-acetone mixture (195 K) to remove any trace iron carbonyl before introduction to the reactor. The products were analyzed by two Hewlett-Packard 5890 series II gas chromatographs. The first one was equipped with a flame ionization detector and a $50 \mathrm{~m}$ long HP-1 cross-linked methyl silicone gum capillary column to monitor the formation of hydrocarbons (C1-C10) and alcohols (C1-C7). The second one was equipped with a thermal conductivity detector and a 6-ft long Alltech-8700 packed column and was used to monitor the formation of $\mathrm{CO}_{2}$.

The conversion of CO was derived from the fraction of $\mathrm{CO}$ that formed carboncontaining products. The conversion of CO, if low, can be described as:

$$
\text { Conversion }(\%)=\sum n_{i} M_{i} \times 100 / M_{\mathrm{CO}}[28] \text {, }
$$

where $n_{i}$ is the number of carbon atoms in product $i, M_{i}$ is the percentage of product $i$ detected, and $\mathrm{M}_{\mathrm{CO}}$ is the percentage of $\mathrm{CO}$ in the syngas feed.

The selectivity to product $i$ is based on the total number of carbon atoms in the product and is therefore defined as:

$$
\text { Selectivity }(\%)=n_{i} M_{i} \times 100 / \sum n_{i} M_{i} \text {. }
$$

The conversion and selectivities were based on the identified products, which present 93\%-95\% of the total peak area in GC chromatograms.

\subsubsection{Catalyst characterization}

Elemental analyses of representative samples were performed by Galbraith Laboratories (Knoxville, TN). The loading of molybdenum and rubidium was determined 
by inductively coupled plasma atomic emission spectroscopy (ICP-AES), while the loading of carbon was evaluated by combustion and coulometric measurement.

Electron microscopy was performed on an FEI Titan transmission electron microscope operated at $200 \mathrm{kV}$. Two passivated catalysts, 5 wt.\% $\mathrm{Mo}_{2} \mathrm{C} / \mathrm{Al}_{2} \mathrm{O}_{3}$ and 1.5 wt.\% Rb-5 wt.\% $\mathrm{Mo}_{2} \mathrm{C} / \mathrm{Al}_{2} \mathrm{O}_{3}$, were reacted in syngas for $48 \mathrm{~h}$ and subsequently passivated again with 1.02 vol.\% $\mathrm{O}_{2} / \mathrm{N}_{2}$ (GTS-Welco) at room temperature before TEM analysis. Catalyst powders were dispersed in $n$-hexane and supported onto a lacey carbon film coated grid. Images were recorded with a Gatan 794 Multi Scan CCD camera.

X-ray absorption spectroscopy (XAS) was performed at the National Synchrotron Light Source (NSLS), Brookhaven National Laboratory. The non-passivated samples before reaction and all of the samples after reaction were sealed in the reactor and transferred into a glovebox. In the glovebox, all the samples were loaded into borosilicate glass tubes (15 cm length, $0.64 \mathrm{~cm}$ OD, $0.40 \mathrm{~cm}$ ID, see Figure 3.1b) and sealed with silicone plugs on both ends to avoid exposure to air. The sealed glass tubes were further wrapped in parafilm and stored in air-tight plastic bags before being taken out of the glovebox. The samples in these sealed tubes were used for ex situ XAS studies on beam lines X23A2 and X18B at the NSLS. The storage ring was typically operated at $2.8 \mathrm{GeV}$ with a ring current of about $300 \mathrm{~mA}$. The XAS data were obtained in the transmission mode at the Mo $K$ edge $(20 \mathrm{keV})$ with a spot size of $0.5 \mathrm{~mm} \times 3 \mathrm{~mm}$ at $\mathrm{X}-18 \mathrm{~B}$ and 0.5 $\mathrm{mm} \times 5 \mathrm{~mm}$ at X-23A2. The Mo $K$ edge spectra were measured at room temperature with Mo foil (0.015 mm, 99.9\%, Goodfellow) as a reference.

The XAS data were processed using the Athena [29] software for background removal, post-edge normalization, and X-ray absorption near edge structure (XANES) 
analysis. Because the Mo near edge structure has various features that complicate the determination of $E_{0}$, the edge energy, the value of $E_{0}$ was assigned here as the energy at the half step height. Metallic Mo foil, $\mathrm{MoO}_{2}$ (99\%, Aldrich), and $\mathrm{MoO}_{3}$ (99.99\%, Aldrich) were used as standards for Mo residing in $0,+4$ and +6 formal oxidation states. Standard bulk $\mathrm{Mo}_{2} \mathrm{C}$ (Aldrich, 99.5\%) was used to determine the amplitude reduction factors $S_{0}^{2}$

for Mo-C and Mo-Mo. The values of $S_{0}^{2}$ utilized in the fitting of extended X-ray absorption fine structure (EXAFS) data from the catalyst samples were 0.86 and 0.76 for Mo-C and Mo-Mo, respectively. The EXAFS results were fitted in $R$-space using two shells (Mo-C \& Mo-Mo) generated theoretically using FEFF 6.0A [30]. The interatomic distances $(r)$, coordination numbers $(\mathrm{CN})$, Debye-Waller factors $\left(\Delta \sigma^{2}\right)$ and energy shifts $\left(\Delta E_{0}\right)$ were derived from the fitting results in the Artemis software package [29].

\subsection{Results and discussion}

Although elemental analysis of a 5 wt. $\% \mathrm{Mo}_{2} \mathrm{C} / \mathrm{Al}_{2} \mathrm{O}_{3}$ catalyst showed a C/Mo molar ratio of 0.39 , which is slightly lower than the expected value from stoichiometry (0.5), the EXAFS results discussed later confirmed the formation of a supported carbide. Elemental analysis of a 1.5 wt.\% $\mathrm{Rb}-5$ wt. $\% \mathrm{Mo}_{2} \mathrm{C} / \mathrm{Al}_{2} \mathrm{O}_{3}$ revealed a $\mathrm{Rb} / \mathrm{Mo}$ molar ratio of 0.31 , which was close to the nominal value (0.34). Evidently, the low temperature carburization with $\mathrm{C}_{2} \mathrm{H}_{6} / \mathrm{H}_{2}$ successfully avoided the volatilization of $\mathrm{Rb}$ promoter.

The performance of non-passivated alumina-supported $\mathrm{Mo}_{2} \mathrm{C}$ catalysts in the reaction of syngas $\left(\mathrm{H}_{2} / \mathrm{CO}=1\right)$ at $573 \mathrm{~K}$ and 30 bar pressure is summarized in Table 3.1. Unpromoted $\mathrm{Mo}_{2} \mathrm{C} / \mathrm{Al}_{2} \mathrm{O}_{3}$ functions primarily as an active Fischer-Tropsch catalyst with 20\% CO conversion, producing mainly hydrocarbons ( $98 \%$ on a $\mathrm{CO}_{2}$-free basis). The 
addition of $1,1.5$ or 2 wt. $\% \mathrm{Rb}_{2} \mathrm{CO}_{3}$ to 5 wt. $\% \mathrm{Mo}_{2} \mathrm{C} / \mathrm{Al}_{2} \mathrm{O}_{3}$ increased the selectivity to alcohols (42\%, $56 \%$ or $64 \%$, respectively) at the expense of overall CO conversion (down to $2.6 \%$ at the highest promoter loading), which is consistent with our previous study on a Rb-promoted $\mathrm{Mo}_{2} \mathrm{C} / \mathrm{MgO}$ catalyst [31], and with prior work on potassiumpromoted bulk $\mathrm{Mo}_{2} \mathrm{C}$ catalysts [14,15,32]. Clearly, there is a trade-off between rate of CO conversion and selectivity to alcohols.

Table 3.1 Reactivity of non-passivated 5 wt. $\% \mathrm{Mo}_{2} \mathrm{C} / \mathrm{Al}_{2} \mathrm{O}_{3}$ catalysts in syngas reaction

\begin{tabular}{|c|c|c|c|c|}
\hline Rb loading (wt.\%) & 0 & 1.0 & 1.5 & 2.0 \\
\hline CO conversion (\%) & 20 & 11 & 5.0 & 2.6 \\
\hline $\mathrm{CO}_{2}$ selectivity (\%) & 47 & 45 & $52^{\mathrm{a}}$ & 42 \\
\hline \multicolumn{5}{|l|}{ Selectivity (C \%, on a $\mathrm{CO}_{2}$-free basis) } \\
\hline Total hydrocarbons & 98 & 58 & 44 & 36 \\
\hline Methane & 31 & 16 & 15 & 12 \\
\hline C2 hydrocarbons & 25 & 14 & 11 & 9.4 \\
\hline C3 hydrocarbons & 21 & 12 & 7.5 & 5.8 \\
\hline C4+ linear paraffins & 12 & 7.0 & 2.8 & 2.0 \\
\hline C4+ linear olefins & 2.1 & 6.5 & 5.7 & 5.1 \\
\hline Branched hydrocarbons & 5.8 & 2.3 & 1.5 & 1.3 \\
\hline Total alcohols & 2.4 & 42 & 56 & 64 \\
\hline Methanol & 1.5 & 12 & 16 & 18 \\
\hline Ethanol & 0.7 & 15 & 21 & 22 \\
\hline 1-Propanol & 0.3 & 8.6 & 12 & 15 \\
\hline 1-Butanol & 0.0 & 2.7 & 4.2 & 4.6 \\
\hline 2-Butanol & 0.0 & 1.4 & 1.0 & 0.8 \\
\hline C5+ alcohols & 0.0 & 1.7 & 1.9 & 4.3 \\
\hline$(\mathrm{C} 2+$ alcohols $) /($ methanol $)$ & 0.66 & 2.5 & 2.5 & 2.5 \\
\hline Rate of CO consumption $\left(\mathrm{mol}_{\mathrm{CO}} \mathrm{mol}_{\mathrm{Mo}}^{-1} \mathrm{~h}^{-1}\right)$ & 9.9 & 5.5 & 2.5 & 1.3 \\
\hline Rate of hydrocarbon production ( $\mathrm{g} \mathrm{g}_{\mathrm{M}_{0}}^{-1} \mathrm{~h}^{-1}$ ) & 0.80 & 0.28 & 0.082 & 0.044 \\
\hline Rate of alcohol production $\left(\mathrm{g} \mathrm{g}_{\mathrm{M}_{0}}^{-1} \mathrm{~h}^{-1}\right)$ & 0.037 & 0.32 & 0.17 & 0.12 \\
\hline
\end{tabular}




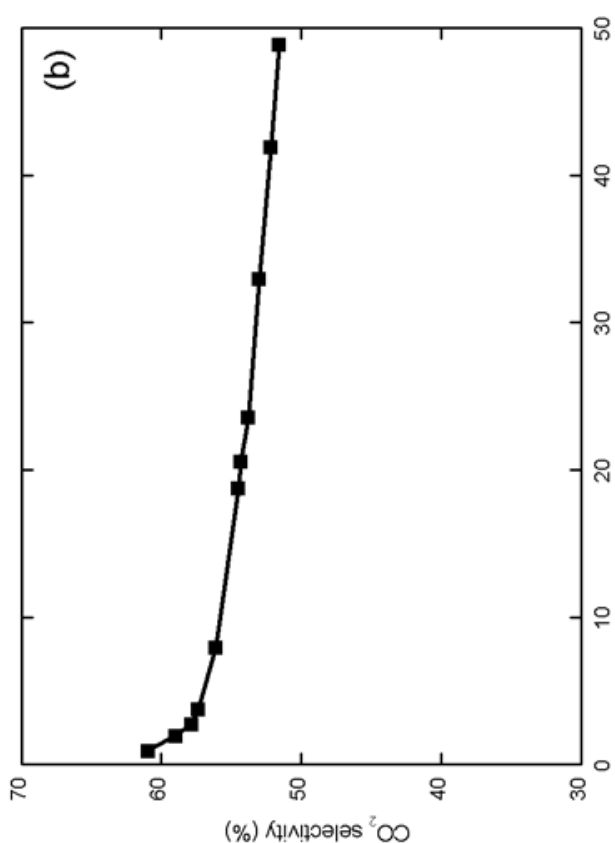

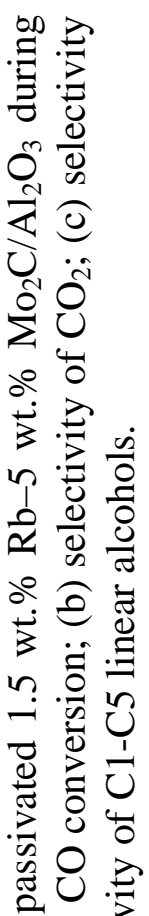
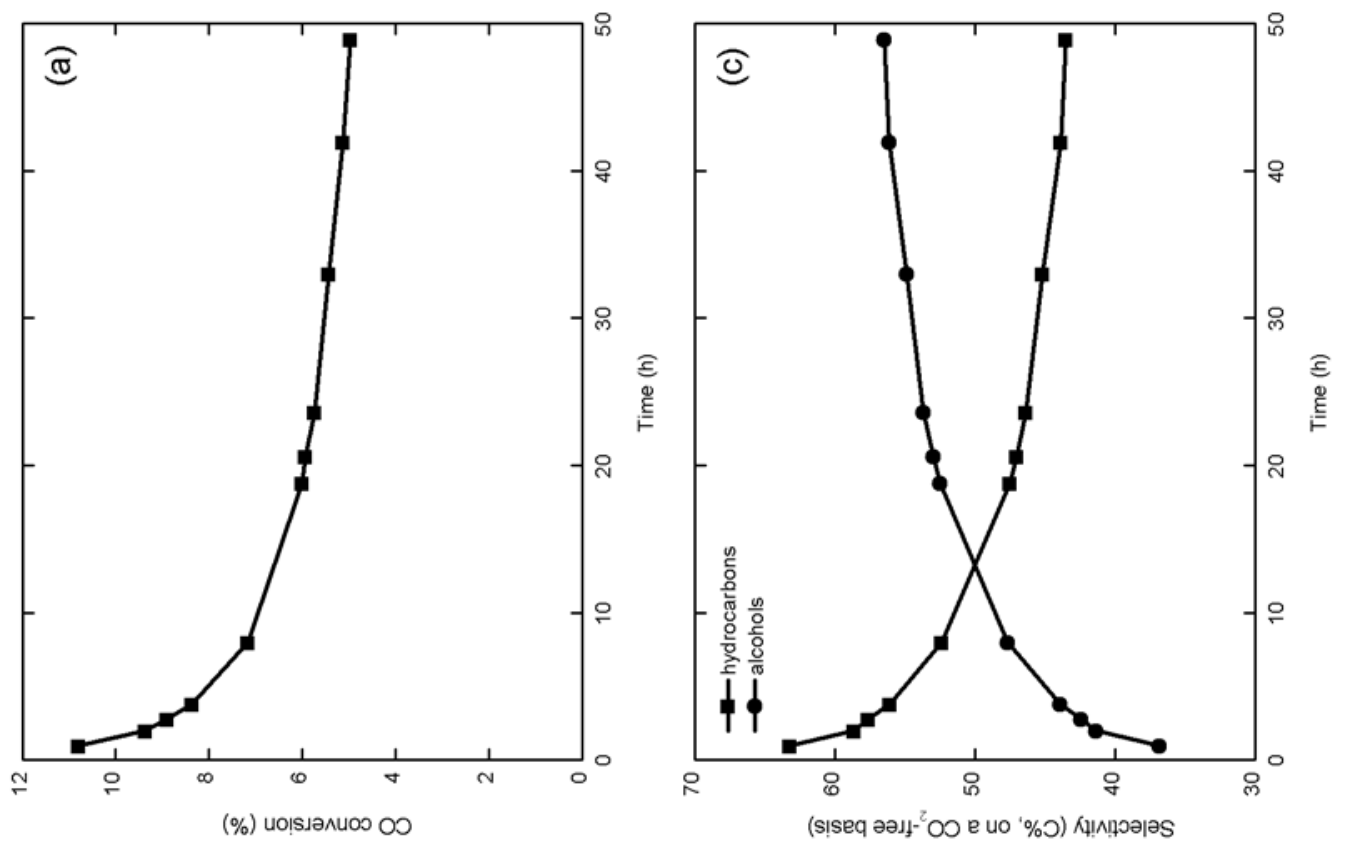

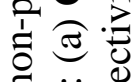

ํㅝㅇ

ัง

过

当 的

틍 층

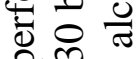

n

등

预艺

ชู

$\exists$ เก

$\exists \div$

कू 둥

콕 을 흘

릉

พ

ํㅓㄴ

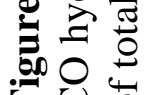


The change of catalytic performance with time for non-passivated $1.5 \mathrm{wt} . \% \mathrm{Rb}-5$ wt.\% $\mathrm{Mo}_{2} \mathrm{C} / \mathrm{Al}_{2} \mathrm{O}_{3}$ catalyst is presented in Figure 3.2 as an example. Although the catalyst deactivated continuously over the run, most of the deactivation occurred over the first $20 \mathrm{~h}$, during which the conversion of $\mathrm{CO}$ declined by half. Likewise, the major changes in selectivity to hydrocarbons and alcohols occurred during the initial $20 \mathrm{~h}$.
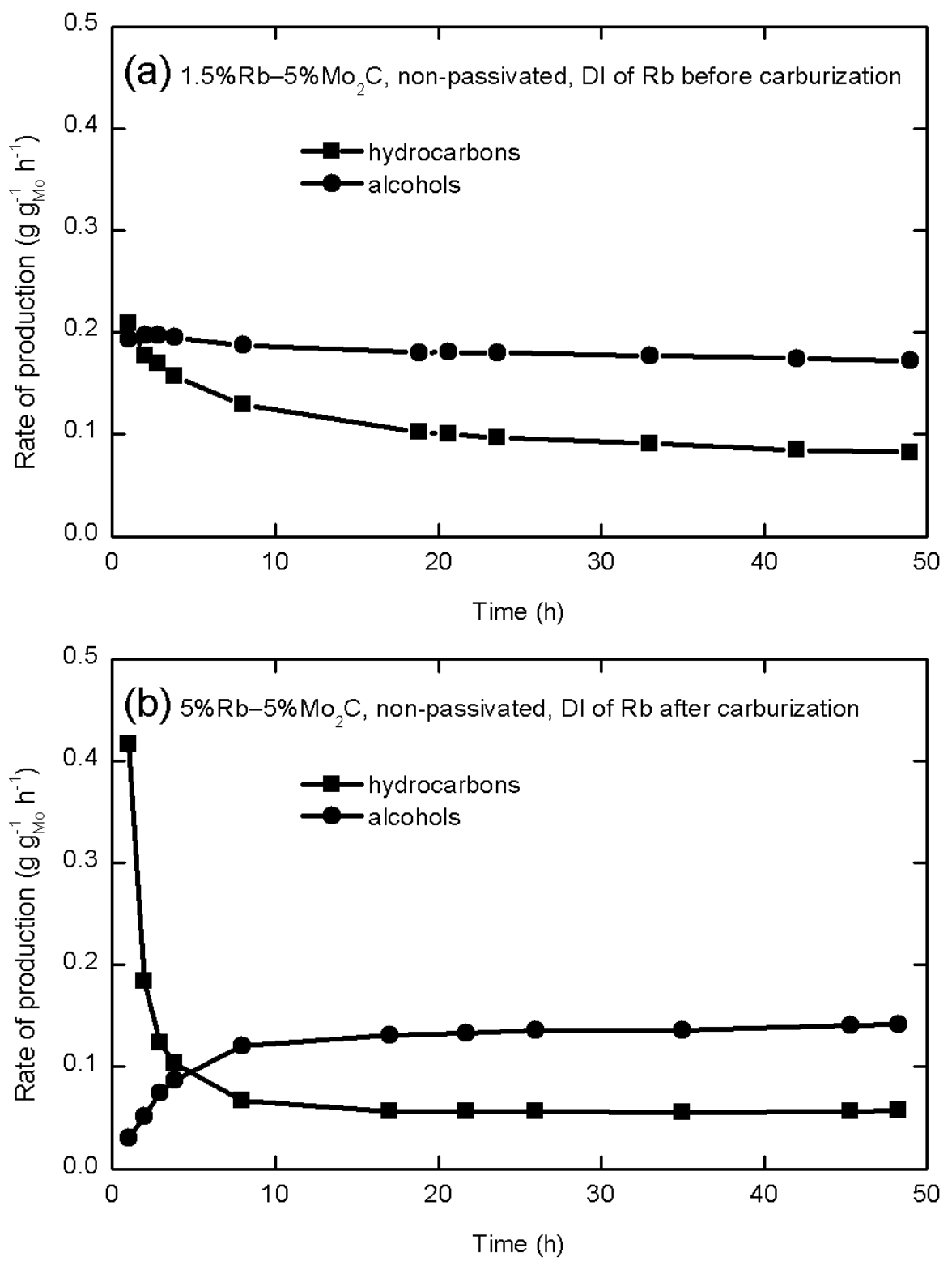

Figure 3.3 Change in production rates of hydrocarbons (square) and alcohols (circle) during $\mathrm{CO}$ hydrogenation at $573 \mathrm{~K}$ and 30 bar over: (a) 1.5 wt.\% Rb-5 wt.\% $\mathrm{Mo}_{2} \mathrm{C} / \mathrm{Al}_{2} \mathrm{O}_{3}$, non-passivated, dry impregnation (DI) of $\mathrm{Rb}_{2} \mathrm{CO}_{3}$ before carburization; (b) 5 wt.\% Rb-5 wt.\% $\mathrm{Mo}_{2} \mathrm{C} / \mathrm{Al}_{2} \mathrm{O}_{3}$, non-passivated, DI of $\mathrm{Rb}_{2} \mathrm{CO}_{3}$ after carburization. 
To explore the influence of carburization on the effectiveness of the Rb promoter, dry impregnation of $\mathrm{Rb}_{2} \mathrm{CO}_{3}$ onto non-passivated $5 \mathrm{wt} . \% \mathrm{Mo}_{2} \mathrm{C} / \mathrm{Al}_{2} \mathrm{O}_{3}$ was performed in a glovebox to achieve a 5 wt.\% Rb-5 wt. $\% \mathrm{Mo}_{2} \mathrm{C} / \mathrm{Al}_{2} \mathrm{O}_{3}$. The catalytic performance of a 1.5 wt.\% Rb-5 wt.\% $\mathrm{Mo}_{2} \mathrm{C} / \mathrm{Al}_{2} \mathrm{O}_{3}$ catalyst prepared with promoter incorporated prior to carburization and the 5 wt. $\%$ Rb-5 wt. $\% \mathrm{Mo}_{2} \mathrm{C} / \mathrm{Al}_{2} \mathrm{O}_{3}$ catalyst with promoter impregnated after carburization is compared in Figure 3.3a and Figure 3.3b, respectively. Evidently, when the $\mathrm{Rb}_{2} \mathrm{CO}_{3}$ promoter was added after carburization (Figure 3.3b), the catalyst exhibited a negligible initial production rate of alcohols and a relatively high initial production rate of hydrocarbons. However, the production rates varied sharply during the first $8 \mathrm{~h}$ of reaction. In contrast, when the $\mathrm{Rb}_{2} \mathrm{CO}_{3}$ promoter was added before carburization, a relatively steady production rate of alcohols was observed from the beginning of the reaction (Figure 3.3a). These results are consistent with the mechanism of promotion of $\mathrm{MoS}_{2}$ and $\mathrm{Mo}_{2} \mathrm{C}$ catalysts for $\mathrm{CO}$ hydrogenation proposed by Lee et al. [33,34], which involves the spreading of the alkali metal promoter over the active sulfide or carbide at reaction conditions. For a sample that was promoted prior to carburization (Figure 2a), the carburization treatment at elevated temperature evidently facilitated the effective spreading of the promoter over the catalyst, whereas for a sample promoted after carburization (Figure 3.3b), at least $8 \mathrm{~h}$ of syngas reaction were needed to disperse the $\mathrm{Rb}$ promoter. A previous study of Rb-promoted $\mathrm{Mo}_{2} \mathrm{C}$ supported on $\mathrm{MgO}$ concluded that the structure of bulk $\mathrm{Rb}_{2} \mathrm{CO}_{3}$ added to the catalyst was altered by exposure to syngas reaction conditions, as observed by Rb K-edge spectroscopy [31]. However, the chemical state of the spreading promoter is not yet known. It is important to note that the production rate of hydrocarbons on the sample that was promoted prior to carburization 
(Figure 3.3a) declined by a half over the first $20 \mathrm{~h}$ of reaction before reaching a fairly steady rate, whereas the production rate of alcohols deactivated much less severely. The results reported here suggest that although carburization facilitated the spreading of $\mathrm{Rb}$ promoter to the active $\mathrm{Mo}_{2} \mathrm{C}$ nanoclusters, additional exposure of the catalyst to syngas conditions likely improved the interaction of the promoter with the carbide, which enhanced alcohol selectivity with time on stream during CO hydrogenation.

Table 3.2 Influence of passivation on the reactivity of unpromoted and Rb-promoted 5 wt. $\% \mathrm{Mo}_{2} \mathrm{C} / \mathrm{Al}_{2} \mathrm{O}_{3}$ catalysts at similar $\mathrm{CO}$ conversion levels

\begin{tabular}{|c|c|c|c|c|}
\hline \multirow{2}{*}{$\frac{\text { Rb loading (wt.\%) }}{\text { Passivation }}$} & \multicolumn{2}{|c|}{0} & \multicolumn{2}{|c|}{1.5} \\
\hline & No & Yes & No & Yes \\
\hline Syngas flow rate $\left(\mathrm{cm}^{3} \mathrm{~g}_{\mathrm{Mo}}^{-1} \mathrm{~h}^{-1}\right)$ & 96,000 & 53,000 & 24,000 & 24,000 \\
\hline CO conversion (\%) & 5.6 & 5.5 & 5.0 & 4.7 \\
\hline $\mathrm{CO}_{2}$ selectivity $(\%)$ & 46 & 48 & $52^{\mathrm{a}}$ & 44 \\
\hline \multicolumn{5}{|l|}{ Selectivity (C \%, on a $\mathrm{CO}_{2}$-free basis) } \\
\hline Total hydrocarbons & 89 & 98 & 44 & 47 \\
\hline Methane & 33 & 45 & 15 & 18 \\
\hline C2 hydrocarbons & 24 & 27 & 11 & 13 \\
\hline C3 hydrocarbons & 17 & 17 & 7.5 & 7.9 \\
\hline C4+ linear paraffins & 6.5 & 4.4 & 2.8 & 2.4 \\
\hline C4+ linear olefins & 2.0 & 1.3 & 5.7 & 4.4 \\
\hline Branched hydrocarbons & 7.0 & 4.3 & 1.5 & 1.3 \\
\hline Total alcohols & 11 & 1.6 & 56 & 53 \\
\hline Methanol & 4.9 & 0.89 & 16 & 16 \\
\hline Ethanol & 4.1 & 0.70 & 21 & 19 \\
\hline 1-Propanol & 1.8 & 0.0 & 12 & 12 \\
\hline 1-Butanol & 0.0 & 0.0 & 4.2 & 3.8 \\
\hline 2-Butanol & 0.0 & 0.0 & 1.0 & 0.8 \\
\hline 1-Pentanol & 0.0 & 0.0 & 1.9 & 1.6 \\
\hline (C2+ alcohols)/(methanol) & 1.2 & 0.79 & 2.5 & 2.4 \\
\hline Rate of CO consumption $\left(\mathrm{mol}_{\mathrm{CO}} \mathrm{mol}_{\mathrm{Mo}}^{-1} \mathrm{~h}^{-1}\right)$ & 11 & 6.9 & 2.5 & 2.3 \\
\hline Rate of hydrocarbon production $\left(\mathrm{g} \mathrm{g}_{\mathrm{Mo}}^{-1} \mathrm{~h}^{-1}\right)$ & 0.85 & 0.57 & 0.082 & 0.098 \\
\hline Rate of alcohol production $\left(\mathrm{g} \mathrm{g}_{\mathrm{M}_{0}}^{-1} \mathrm{~h}^{-1}\right)$ & 0.18 & 0.017 & 0.17 & 0.17 \\
\hline
\end{tabular}
$\mathrm{T}=573 \mathrm{~K}, \mathrm{P}=30 \mathrm{bar}, \mathrm{H}_{2} / \mathrm{CO}=1$. Data were recorded after $48 \mathrm{~h}$ reaction.

${ }^{a}$ The excess beyond the theoretical limit (50\%) is likely due to experimental error in analysis. 
The influence of passivation on the reactivity of unpromoted and Rb-promoted $\mathrm{Mo}_{2} \mathrm{C} / \mathrm{Al}_{2} \mathrm{O}_{3}$ catalysts can be seen in Table 3.2. Since we have observed in prior work a strong correlation between CO conversion and hydrocarbon selectivity over supported $\mathrm{Mo}_{2} \mathrm{C}$ [31], a direct comparison of the selectivities requires the same level of $\mathrm{CO}$ conversion. Therefore, the loading of unpromoted 5 wt. $\% \mathrm{Mo}_{2} \mathrm{C} / \mathrm{Al}_{2} \mathrm{O}_{3}$ (non-passivated and passivated) was adjusted in the reactor to give a comparable conversion of $\mathrm{CO}$ at standard conditions with those of the Rb-promoted catalysts. As expected, the unpromoted catalysts produced mainly hydrocarbons, with selectivities of 89 and $98 \%$ (on a $\mathrm{CO}_{2}$-free basis) over the non-passivated and passivated catalysts, respectively. Passivation decreased the activity of unpromoted 5 wt. $\% \mathrm{Mo}_{2} \mathrm{C} / \mathrm{Al}_{2} \mathrm{O}_{3}$ catalyst by $37 \%$ (reducing the CO consumption rate from 11 to $6.9 \mathrm{~mol}_{\mathrm{CO}} \mathrm{mol}_{\mathrm{Mo}}^{-1} \mathrm{~h}^{-1}$ ), indicating a strong influence of surface oxygen on the activity of $\mathrm{Mo}_{2} \mathrm{C}$. This result is reminiscent of the work of Wu et al., who claimed that passivation of $\mathrm{Mo}_{2} \mathrm{C}$ with an $\mathrm{O}_{2} / \mathrm{N}_{2}$ mixture partially oxidized the surface of $\mathrm{Mo}_{2} \mathrm{C}$ and irreversibly deactivated most of the sites for $\mathrm{CO}$ adsorption $[24,25]$. The rate of alcohol production over the non-passivated unpromoted catalyst at low conversion was $0.18 \mathrm{~g} \mathrm{~g} \mathrm{~g}_{\mathrm{M} 0}^{-1} \mathrm{~h}^{-1}$, which is nearly identical to the alcohol production rate over the promoted catalyst (Table 3.2), whereas promoter addition decreased the rate of hydrocarbon formation by almost an order of magnitude. These results are similar to those of Tsai et al. who used isotopic transient analysis to probe the promotion of a Co-based Fischer-Tropsch catalyst by $\mathrm{Cu}$ to form a higher alcohol synthesis catalyst [35]. The addition of $\mathrm{Cu}$ promoter significantly decreased the hydrocarbon formation rate on the Co catalyst without affecting the parallel oxygenate synthesis rate, effectively shifting the selectivity of the catalyst from hydrocarbons to 
oxygenates. Although the total alcohol production rate over non-passivated $\mathrm{Mo}_{2} \mathrm{C}$ was essentially unchanged by the addition of $1.5 \mathrm{wt} . \% \mathrm{Rb}$ (Table 3.2), the ratio of higher alcohols to methanol (from carbon-based selectivity at constant CO conversion) increased from 1.2 to 2.5 by addition of the promoter. However, the alcohol production rate over an unpromoted catalyst was severely reduced from 0.18 to $0.017 \mathrm{~g} \mathrm{~g}_{\mathrm{Mo}_{0}}^{-1} \mathrm{~h}^{-1}$ by passivation, which is additional evidence of an irreversible surface modification of $\mathrm{Mo}_{2} \mathrm{C}$ by oxygen. On the other hand, passivation had only a negligible influence on the activity of Rbpromoted 5 wt. $\% \mathrm{Mo}_{2} \mathrm{C} / \mathrm{Al}_{2} \mathrm{O}_{3}$ catalyst (Table 3.2), indicating that interactions of the $\mathrm{Mo}_{2} \mathrm{C}$ with the alkali metal promoter dominate the surface reactivity over that of added oxygen. It should be noted that the selectivity to $\mathrm{CO}_{2}$, presumably via the water-gas-shift reaction, was high in all cases ( $40-50 \%)$, regardless of passivation or promotion. According to reaction stoichiometry, the maximum selectivity to $\mathrm{CO}_{2}$ cannot exceed $50 \%$.

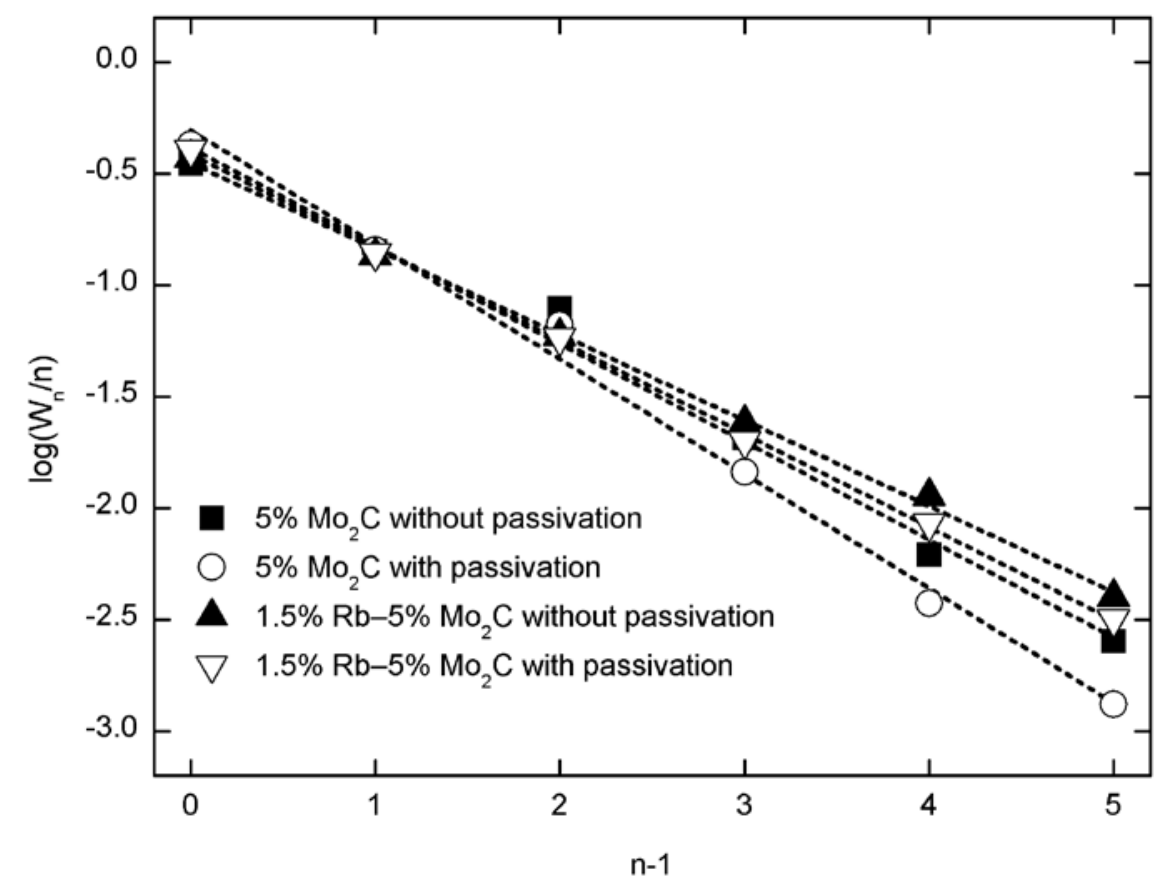

Figure 3.4 Evaluation of chain growth probability of linear hydrocarbons (paraffins and olefins combined) 
Table 3.3 Chain growth probability of hydrocarbons (paraffins and olefins combined)

\begin{tabular}{lc}
\hline Sample & Chain growth probability \\
\hline 5 wt.\% $\mathrm{Mo}_{2} \mathrm{C} / \mathrm{Al}_{2} \mathrm{O}_{3}$ without passivation & 0.36 \\
5 wt.\% $\mathrm{Mo}_{2} \mathrm{C} / \mathrm{Al}_{2} \mathrm{O}_{3}$ with passivation & 0.31 \\
1.5 wt.\% Rb-5 wt.\% $\mathrm{Mo}_{2} \mathrm{C} / \mathrm{Al}_{2} \mathrm{O}_{3}$ without passivation & 0.41 \\
1.5 wt.\% Rb-5 wt.\% $\mathrm{Mo}_{2} \mathrm{C} / \mathrm{Al}_{2} \mathrm{O}_{3}$ with passivation & 0.38 \\
\hline
\end{tabular}

The chain growth probability $(\alpha)$ based on the C1 to C6 linear hydrocarbons (paraffins and olefins combined) was calculated from the Anderson-Schulz-Flory (ASF) distribution, expressed as:

$$
W_{n} / n=(1-\alpha)^{2} \alpha^{n-1},
$$

where $W_{\mathrm{n}}$ is the weight fraction of hydrocarbon molecules containing $\mathrm{n}$ carbon atoms among all the hydrocarbons considered. After transforming the ASF distribution to:

$$
\log \left(W_{n} / n\right)=(n-1) \log \alpha+2 \log (1-\alpha)
$$

the value of $\alpha$ can be determined from the linear fit shown in Figure 3.4. The resulting chain growth probabilities are summarized in Table 3.3. Neither passivation nor Rb promoter had a significant influence on the value of hydrocarbon chain growth probability, which varied from 0.31 to 0.41 .

The X-ray absorption near edge structure (XANES) at the Mo $K$ edge of reference compounds and catalysts is summarized in Table 3.4 and Figure 3.5. The shift in the edge position, determined at half step height, is defined as the increase of $E_{0}$ value from that of the metallic Mo foil. The calcined alumina-supported Mo species had a similar $K$ edge energy shift $(8.2 \mathrm{eV})$ to that of the $\mathrm{Mo}(\mathrm{VI})$ standard, $\mathrm{MoO}_{3}(8.5 \mathrm{eV})$. After reduction in $\mathrm{H}_{2}$, the energy shift of $E_{0}$ for the alumina-supported Mo species was significantly decreased to $6.2 \mathrm{eV}$, which is close to that of $\mathrm{Mo}(\mathrm{IV})$ in $\mathrm{MoO}_{2}$ (5.6 eV shift). The addition of $\mathrm{Rb}$ promoter did not significantly change the energy shift for $\mathrm{MoO}_{2} / \mathrm{Al}_{2} \mathrm{O}_{3}$. 
Carburization of $\mathrm{MoO}_{2} / \mathrm{Al}_{2} \mathrm{O}_{3}$ and Rb-promoted $\mathrm{Mo}_{2} \mathrm{C}$ further reduced the Mo oxidation state, resulting in an $E_{0}$ shift of $2.4 \mathrm{eV}$ for $\mathrm{Mo}_{2} \mathrm{C} / \mathrm{Al}_{2} \mathrm{O}_{3}$, which approaches that of bulk $\mathrm{Mo}_{2} \mathrm{C}(1.5 \mathrm{eV})$. However, non-passivated $\mathrm{Mo}_{2} \mathrm{C} / \mathrm{Al}_{2} \mathrm{O}_{3}$ still was more oxidized than bulk $\mathrm{Mo}_{2} \mathrm{C}$, which may be attributed to incomplete carburization of the highly dispersed $\mathrm{Mo}_{2} \mathrm{C}$ clusters and/or the interaction of Mo with the underlying support. According to the shifts in $E_{0}$ reported in Table 3.4, both passivation and addition of $\mathrm{Rb}$ promoter resulted in partial oxidation of the $\mathrm{Mo}_{2} \mathrm{C}$ clusters. For example, a non-passivated sample of $\mathrm{Mo}_{2} \mathrm{C} / \mathrm{Al}_{2} \mathrm{O}_{3}$ before reaction had an $E_{0}$ shift of $2.4 \mathrm{eV}$ relative to Mo foil whereas a passivated sample had an $E_{0}$ shift of $3.3 \mathrm{eV}$. The difference between the $E_{0}$ of the nonpassivated 1.5 wt.\% Rb-5 wt.\% $\mathrm{Mo}_{2} \mathrm{C} / \mathrm{Al}_{2} \mathrm{O}_{3}$ sample (2.8 eV) and the corresponding passivated one $(3.1 \mathrm{eV})$ suggests that the presence of Rb promoter inhibited oxidation of the carbide surface. The shifts in $E_{0}$ caused by the CO hydrogenation reaction that are reported in Table 3.4 confirmed that the supported $\mathrm{Mo}_{2} \mathrm{C}$ clusters (with and without passivation, with and without promoter) can be reduced by the reactive syngas environment, which is consistent with the observation on an Rb-promoted $\mathrm{Mo}_{2} \mathrm{C} / \mathrm{MgO}$ catalyst [31]. The very small difference in $E_{0}(0.1 \mathrm{eV})$ before and after reaction of nonpassivated 5 wt.\% $\mathrm{Mo}_{2} \mathrm{C} / \mathrm{Al}_{2} \mathrm{O}_{3}$ confirmed the success of our air-free handling of the samples. 


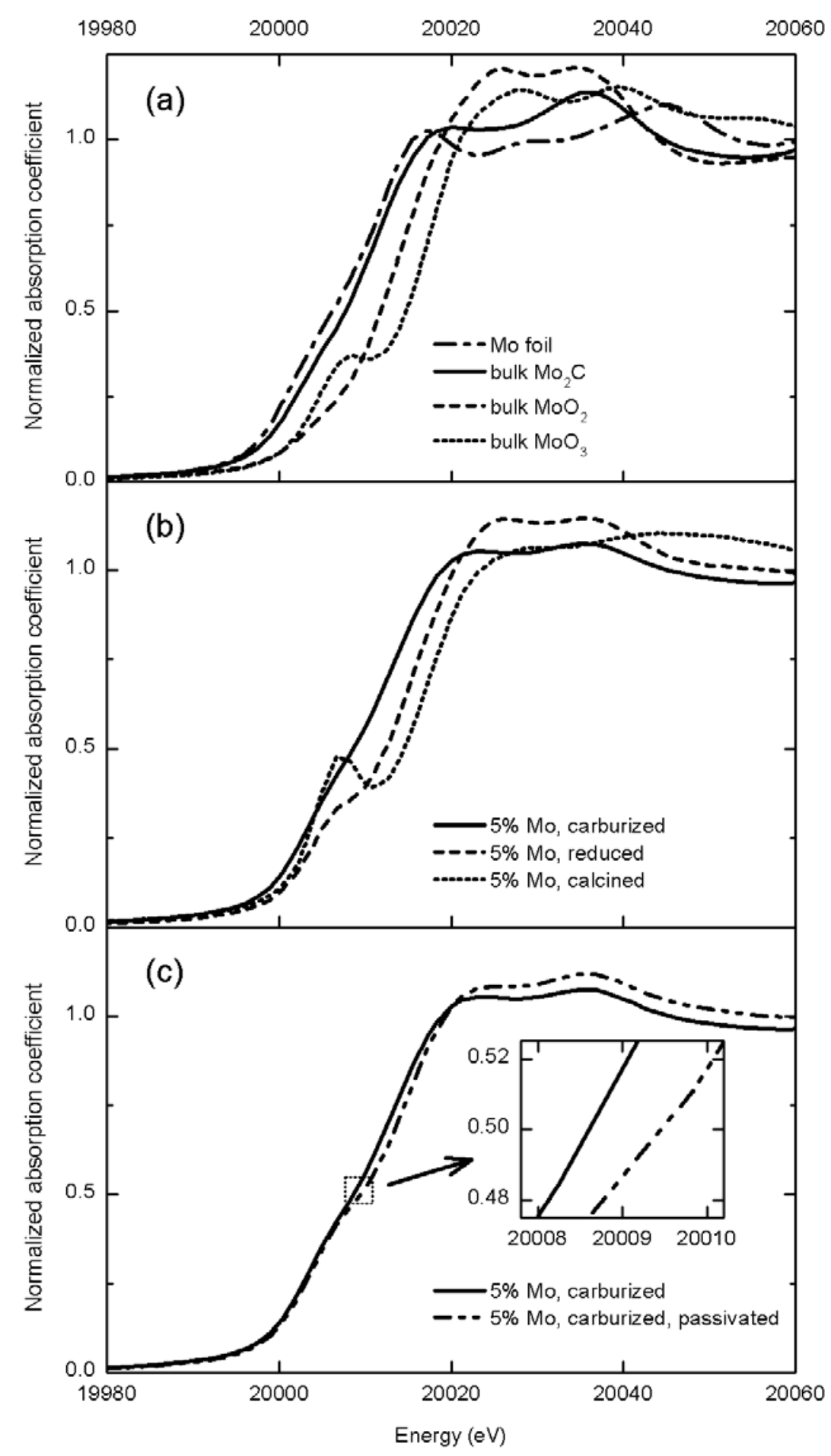

Figure 3.5 X-ray absorption near edge structure (XANES) at the Mo $K$ edge of: (a) Mo reference standards, (b) alumina-supported Mo species, $\mathrm{MoO}_{3} / \mathrm{Al}_{2} \mathrm{O}_{3}$ (calcined), $\mathrm{MoO}_{2} / \mathrm{Al}_{2} \mathrm{O}_{3}$ (reduced) and $\mathrm{Mo}_{2} \mathrm{C} / \mathrm{Al}_{2} \mathrm{O}_{3}$ (carburized), (c) a comparison between freshly prepared and passivated $\mathrm{Mo}_{2} \mathrm{C} / \mathrm{Al}_{2} \mathrm{O}_{3}$. 
Table 3.4 Shift of the Mo K Edge Energy from Mo foil

\begin{tabular}{lll}
\hline Mo samples & Shift of $E_{0}(\mathrm{eV})$ \\
\hline $\mathrm{Mo}$ foil & & 0.0 \\
$\mathrm{MoO}_{2}$ & & 5.6 \\
$\mathrm{MoO}_{3}$ & & 8.5 \\
$\mathrm{Bulk} \mathrm{Mo} \mathrm{C}_{2} \mathrm{C}$ & 1.5 \\
$5 \% \mathrm{Mo} / \mathrm{Al}_{2} \mathrm{O}_{3}$, calcined & & 8.2 \\
$5 \% \mathrm{Mo} / \mathrm{Al}_{2} \mathrm{O}_{3}$, reduced & & 6.2 \\
$1.5 \% \mathrm{Rb}-5 \% \mathrm{Mo}^{-} \mathrm{Al}_{2} \mathrm{O}_{3}$, reduction & & 6.7 \\
$5 \% \mathrm{Mo}_{2} \mathrm{C} / \mathrm{Al}_{2} \mathrm{O}_{3}$ without passivation & before rxn & 2.4 \\
& after rxn & 2.3 \\
$5 \% \mathrm{Mo}_{2} \mathrm{C} / \mathrm{Al}_{2} \mathrm{O}_{3}$ with passivation & before rxn & 3.3 \\
& after rxn & 2.8 \\
$1.5 \% \mathrm{Rb}-5 \% \mathrm{Mo}_{2} \mathrm{C} / \mathrm{Al}_{2} \mathrm{O}_{3}$ without passivation & before rxn & 2.8 \\
& after rxn & 2.2 \\
$1.5 \% \mathrm{Rb}-5 \% \mathrm{Mo}_{2} \mathrm{C} / \mathrm{Al}_{2} \mathrm{O}_{3}$ with passivation & before rxn & 3.1 \\
& after rxn & 2.9 \\
\hline
\end{tabular}

The structural evolution of the Mo phase during catalyst synthesis can be followed in the Mo $K$ edge extended X-ray absorption fine structure (EXAFS). Thus, Fourier transforms of the $k^{3}$-weighted EXAFS of the samples at various stages of the synthesis procedure were compared to those of the reference bulk compounds. According to the EXAFS in Figure 3.6a and the shift in $E_{0}$ in Table 3.4, the alumina-supported Mo oxide after calcination is a highly dispersed $\mathrm{Mo}(\mathrm{VI})$ oxide with no clear evidence of a Mo-Mo shell. After reduction in $\mathrm{H}_{2}$, the FT of the EXAFS of alumina-supported Mo oxide (Figure 3.6c and Figure 3.6d) and the shift in $E_{0}$ reported in Table 3.4 suggested the formation of a highly dispersed Mo suboxide, likely Mo(IV), as an intermediate during the catalyst synthesis procedure. After carburization, the FT of the EXAFS of both unpromoted (Figure 3.6f) and Rb-promoted (Figure 3.6g) samples revealed a Mo-Mo shell at the same position as the one in bulk $\mathrm{Mo}_{2} \mathrm{C}$ (Figure 3.6h), which confirmed the formation of alumina-supported $\mathrm{Mo}_{2} \mathrm{C}$. Kojima and Aika reported that when Cs was 
added onto a $\mathrm{MoO}_{3}$ precursor prior to carburization, the final material tended to form metallic Mo rather than carbidic Mo [36]. However, our procedure involving the addition of $\mathrm{Rb}$ promoter prior to carburization was able to produce supported Mo carbide rather than metallic Mo.

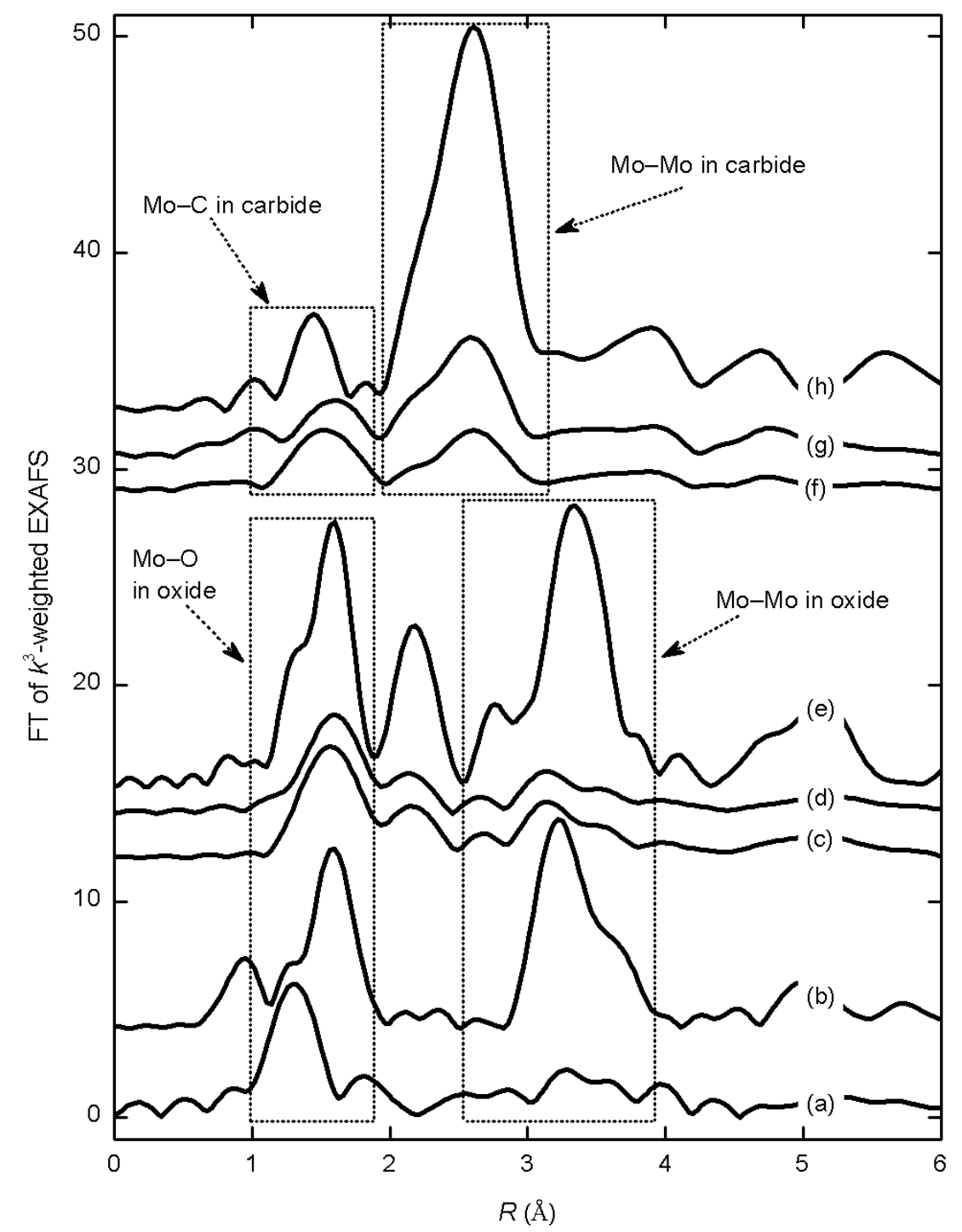

Figure 3.6 Fourier transform (not corrected for phase shifts) of $k^{3}$-weighted Mo EXAFS: (a) $5 \% \mathrm{Mo} / \mathrm{Al}_{2} \mathrm{O}_{3}$, calcined; (b) bulk $\mathrm{MoO}_{3}$; (c) 5 wt.\% $\mathrm{Mo} / \mathrm{Al}_{2} \mathrm{O}_{3}$, reduced; (d) 1.5 wt.\% $\mathrm{Rb}-5$ wt.\% Mo/ $/ \mathrm{Al}_{2} \mathrm{O}_{3}$, reduced; (e) bulk $\mathrm{MoO}_{2}$; (f) 5 wt.\% Mo, carburized; (g) 1.5 wt.\% Rb-5 wt.\% Mo, carburized; (h) bulk $\mathrm{Mo}_{2} \mathrm{C}$. Spectra are offset for clarity.

The coordination numbers $(\mathrm{CN})$, interatomic distances $(r)$, and Debye-Waller factors $\left(\Delta \sigma^{2}\right)$ obtained by curve fitting of the $k^{3}$-weighted EXAFS of the carbide samples 
are summarized in Table 3.5. The number of reliable parameters that can be measured is limited by the Nyquist theorem, given here as $\frac{2 \Delta k \Delta R}{\pi}=15$, and exceeds the number of fitted parameters reported in Table 3.5. Additionally, the $R$-factors in Table 3.5 are all smaller than 0.07. A sample of the results from curve fitting of 1.5 wt.\% Rb-5 wt.\% $\mathrm{Mo}_{2} \mathrm{C} / \mathrm{Al}_{2} \mathrm{O}_{3}$ (without passivation, before reaction) is provided in Figure 6 to illustrate the quality of the fits.

Table 3.5 Results from the analysis of Mo EXAFS from carbide catalyst

\begin{tabular}{|c|c|c|c|c|c|c|}
\hline Catalyst $^{a}$ & Shell & $\mathrm{CN}$ & $\begin{array}{l}r \\
(\AA)\end{array}$ & $\begin{array}{l}\Delta \sigma^{2} \\
\left(10^{-3} \AA^{2}\right)\end{array}$ & $\begin{array}{l}\Delta E_{0} \\
(\mathrm{eV})\end{array}$ & $\begin{array}{l}R- \\
\text { factor }\end{array}$ \\
\hline \multirow[t]{2}{*}{ Bulk $\mathrm{Mo}_{2} \mathrm{C}$} & Mo-C & $3^{b}$ & $2.11 \pm 0.03$ & $3.4 \pm 3.4$ & $0.9 \pm 5.0$ & \multirow[t]{2}{*}{0.009} \\
\hline & Mo-Mo & $12^{\mathrm{b}}$ & $2.97 \pm 0.01$ & $5.6 \pm 0.7$ & $-7.8 \pm 1.1$ & \\
\hline \multirow{2}{*}{$\begin{array}{l}5 \% \mathrm{Mo}_{2} \mathrm{C} / \mathrm{Al}_{2} \mathrm{O}_{3} \\
\text { without passivation }\end{array}$} & Mo-C & $3.3 \pm 0.8$ & $2.12 \pm 0.02$ & $5.8 \pm 2.3$ & $-3.2 \pm 3.1$ & \multirow[t]{2}{*}{0.047} \\
\hline & Mo-Mo & $2.5 \pm 0.9$ & $2.98 \pm 0.01$ & $7.8 \pm 2.1$ & $-5.4 \pm 3.0$ & \\
\hline \multirow{2}{*}{$\begin{array}{l}5 \% \mathrm{Mo}_{2} \mathrm{C} / \mathrm{Al}_{2} \mathrm{O}_{3} \\
\text { with passivation }\end{array}$} & Mo-C & $1.8 \pm 0.8$ & $2.05 \pm 0.02$ & $0.0 \pm 2.6$ & $-24 \pm 8$ & \multirow[t]{2}{*}{0.066} \\
\hline & Mo-Mo & $2.8 \pm 1.1$ & $2.98 \pm 0.02$ & $6.6 \pm 2.4$ & $-7.5 \pm 3.6$ & \\
\hline \multirow{2}{*}{$\begin{array}{l}1.5 \% \mathrm{Rb}-5 \% \mathrm{Mo}_{2} \mathrm{C} / \mathrm{Al}_{2} \mathrm{O}_{3} \\
\text { without passivation }{ }^{\mathrm{c}}\end{array}$} & Mo-C & $2.2 \pm 1.2$ & $2.11 \pm 0.03$ & $1.9 \pm 3.8$ & $-11 \pm 8$ & \multirow[t]{2}{*}{0.053} \\
\hline & Mo-Mo & $5.2 \pm 1.7$ & $2.97 \pm 0.01$ & $7.2 \pm 1.9$ & $-13 \pm 3$ & \\
\hline \multirow{2}{*}{$\begin{array}{l}1.5 \% \mathrm{Rb}-5 \% \mathrm{Mo}_{2} \mathrm{C} / \mathrm{Al}_{2} \mathrm{O}_{3} \\
\text { with passivation }{ }^{\mathrm{c}}\end{array}$} & Mo-C & $1.8 \pm 1.1$ & $2.08 \pm 0.03$ & $3.0 \pm 3.4$ & $-22 \pm 10$ & \multirow[t]{2}{*}{0.061} \\
\hline & Mo-Mo & $4.6 \pm 1.6$ & $2.97 \pm 0.01$ & $7.3 \pm 2.0$ & $-13 \pm 3$ & \\
\hline
\end{tabular}

Fitting parameters: Fourier transform range $\Delta k: 2-11.8 \AA^{-1}$; fitting range $\Delta R$ : $1-3.4 \AA$; weighting: $k^{3} ; S_{0}^{2}(\mathrm{Mo}-\mathrm{C})=0.86, S_{0}^{2}(\mathrm{Mo}-\mathrm{Mo})=0.76$.

${ }^{a}$ Catalysts are all before reaction.

${ }^{\mathrm{b}}$ Value was assigned in curving fitting based on standard structure.

${ }^{\mathrm{c}} R_{\mathrm{bkg}}$ was set to 1.2 in background removal to remove the noise oscillation below $1 \AA$ in $\mathrm{R}$ space.

The low Mo-Mo coordination numbers (2.5-5.2) indicate that the Mo carbide clusters are very highly dispersed on the alumina support, which is consistent with the average particle size of about $1 \mathrm{~nm}$ as observed by electron microscopy (Figure 3.8). The formation of very highly dispersed $\mathrm{Mo}_{2} \mathrm{C}$ clusters has also been observed on H-ZSM-5 
zeolite [37] and $\gamma-\mathrm{Al}_{2} \mathrm{O}_{3}$ [38], with Mo-Mo coordination numbers derived from EXAFS as low as 2.6 and 4 , respectively.
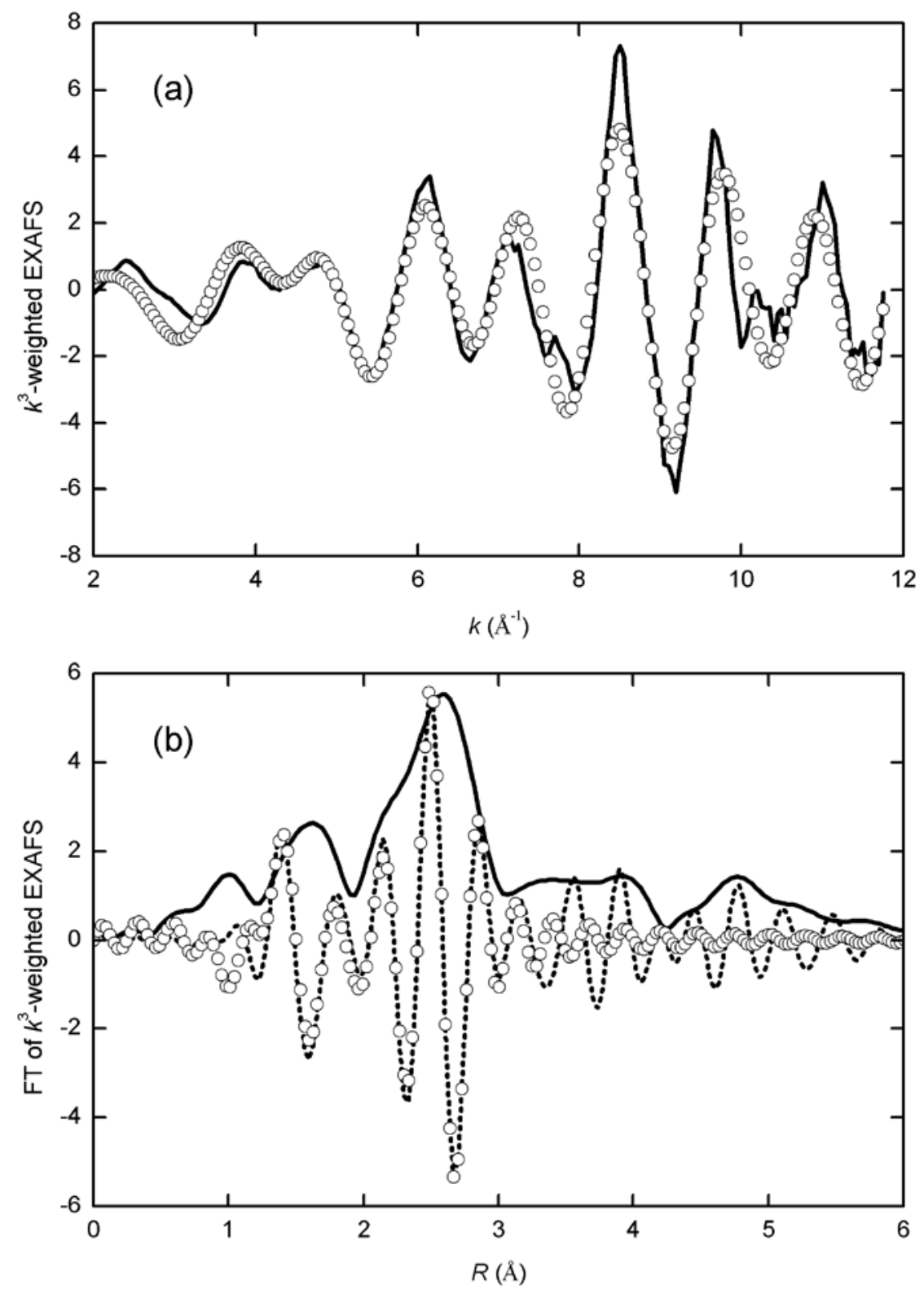

Figure 3.7 Comparison of the curve fit to experimental Mo $K$ edge EXAFS of the 1.5 wt.\% Rb-5 wt.\% $\mathrm{Mo}_{2} \mathrm{C} / \mathrm{Al}_{2} \mathrm{O}_{3}$ catalyst without passivation, before reaction. (a) $k^{3}$ weighted Mo $K$ edge EXAFS (solid line) and the result from curve fit (circles); (b) Magnitude (solid line) and the imaginary part (dashed line) of the Fourier transform of EXAFS compared to the result from the curve fit (circles). 


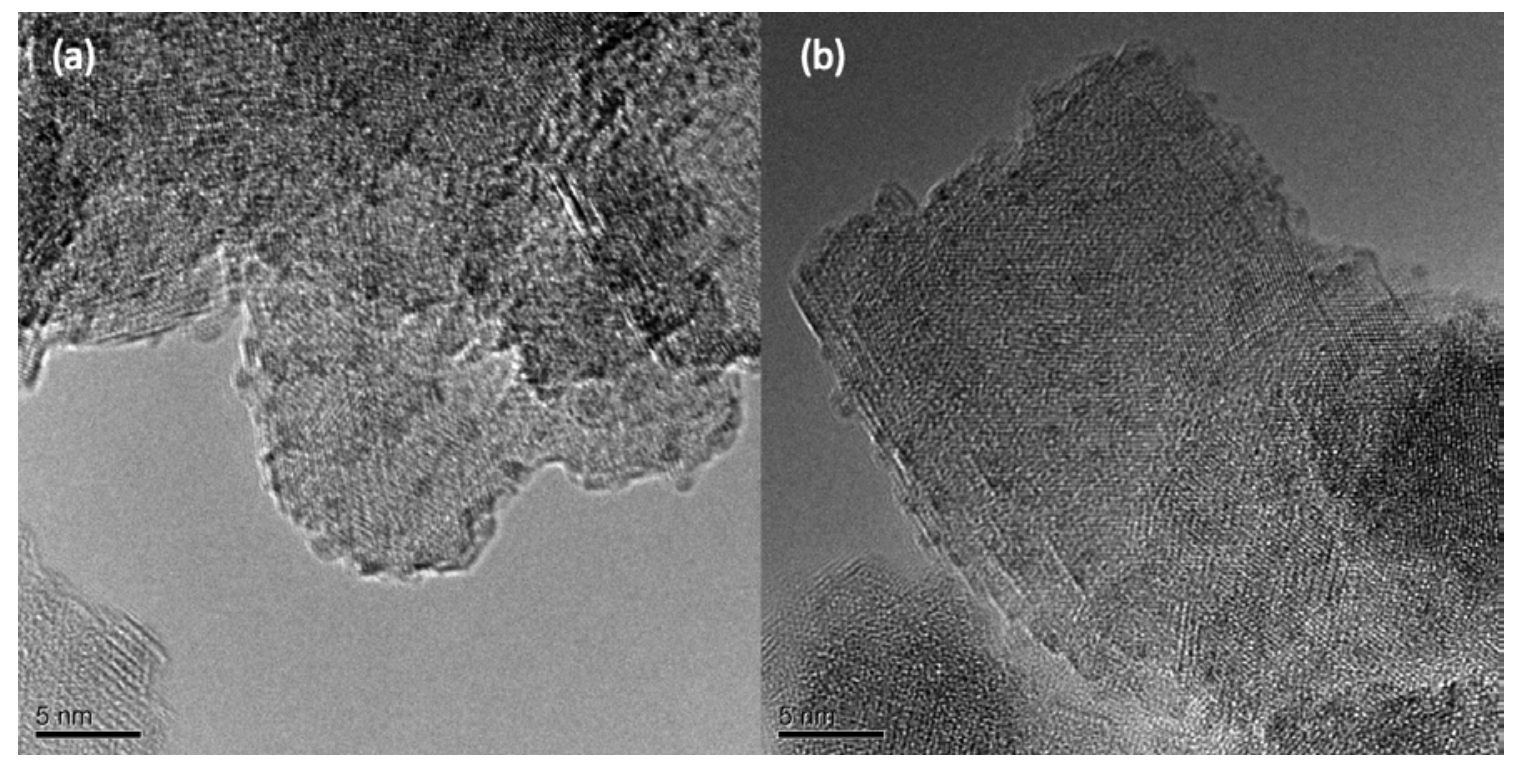

Figure 3.8 Electron micrographs of (a) 5 wt. $\% \mathrm{Mo}_{2} \mathrm{C} / \mathrm{Al}_{2} \mathrm{O}_{3}$ with passivation after reaction, (b) 1.5 wt.\% $\mathrm{Rb}-5$ wt. $\% \mathrm{Mo}_{2} \mathrm{C} / \mathrm{Al}_{2} \mathrm{O}_{3}$ with passivation and after reaction. Catalysts were used for $48 \mathrm{~h}$ in CO hydrogenation before TEM analysis. The scale bars are $5 \mathrm{~nm}$.

\subsection{Conclusions}

A modified catalyst synthesis method for preparing alkali-promoted supported $\mathrm{Mo}_{2} \mathrm{C}$ was developed, with the incorporation of alkali metal promoter accomplished prior to carburization. The new procedure gives $1 \mathrm{~nm} \mathrm{Mo}_{2} \mathrm{C}$ nanoparticles supported on $\alpha$ alumina. An unpromoted sample of $\mathrm{Mo}_{2} \mathrm{C} / \mathrm{Al}_{2} \mathrm{O}_{3}$ was active in the Fischer-Tropsch reaction and produced mostly hydrocarbons with a chain growth probability of about 0.36 , whereas addition of $\mathrm{Rb}$ shifted the selectivity to alcohols primarily by inhibiting the rate of hydrocarbon formation. However, increasing the loading of Rb promoter beyond 1 wt.\% decreased the rate of alcohol production, presumably because of blockage of the active sites for alcohol synthesis. The primary role of $\mathrm{Rb}$ on the supported carbide clusters appears to be the deactivation of sites used to form hydrocarbons, although we cannot rule out a promotion of higher alcohol synthesis rates on the carbide surfaces or catalysis of alcohol coupling reactions. Passivation of unpromoted 5 wt.\% $\mathrm{Mo}_{2} \mathrm{C} / \mathrm{Al}_{2} \mathrm{O}_{3}$ with a 
dilute stream of $\mathrm{O}_{2}$ decreased the overall activity of the catalyst by $37 \%$ and reduced the rate of alcohol production by an order of magnitude, whereas passivation of promoted (1.5 wt.\% Rb) 5 wt.\% $\mathrm{Mo}_{2} \mathrm{C} / \mathrm{Al}_{2} \mathrm{O}_{3}$ did not significantly affect the activity and product distribution of the catalyst. Spectroscopic characterization at Mo $K$ edge was used to follow the evolution of the structure of the catalyst throughout the synthesis procedure as well as to monitor the partial oxidation and reduction of the carbide catalysts during passivation and CO hydrogenation, respectively. The Mo XANES confirmed the reduction of $\mathrm{Mo}(\mathrm{VI})$ to $\mathrm{Mo}(\mathrm{IV})$ to $\mathrm{Mo}_{2} \mathrm{C}$. However, the supported $\mathrm{Mo}_{2} \mathrm{C}$ was always partially oxidized compared to bulk $\mathrm{Mo}_{2} \mathrm{C}$.

\subsection{Acknowledgements}

The authors acknowledge financial support from The Dow Chemical Company and helpful discussions with collaborators Dr. Pradeep Agrawal, Dr. David Sholl and Mr. Michael Morrill at the Georgia Institute of Technology. The authors also acknowledge Mr. Richard White at University of Virginia for acquisition of the transmission electron micrographs. Use of the NSLS was supported by the US Department of Energy, Office of Science, Office of Basic Energy Sciences, under Contract No. DE-AC02-98CH10886. Beamline X18B at the NSLS is supported in part by the Synchrotron Catalysis Consortium, US Department of Energy Grant No. DE-FG02-05ER15688. The authors acknowledge with gratitude the invaluable assistance received from the X-23A2 beam line personnel, Dr. Bruce Ravel, and the X-18B beam line personnel, Dr. Nebojsa Marinkovic and Dr. Syed Khalid. 


\section{References of Chapter 3}

[1] P. Forzatti, E. Tronconi, I. Pasquon, "Higher alcohol synthesis,” Catalysis Reviews: Science Engineering 33 (1991) 109-168.

[2] I. Wender, “Reactions of synthesis gas,” Fuel Processing Technology 48 (1996) 189-297.

[3] R.G. Herman, "Advances in catalytic synthesis and utilization of higher alcohols," Catalysis Today 55 (2000) 233-245.

[4] K. Fang, D. Li, M. Lin, M. Xiang, W. Wei, Y. Sun, "A short review of heterogeneous catalytic process for mixed alcohols synthesis via syngas," Catalysis Today 147 (2009) 133-138.

[5] M.M. Bhasin, G.L. O’Connor, “Procede de preparation selective de derives hydrocarbones oxygenes a deux atomes de carbone,” Belgian Patent 824822, 1975.

[6] J.J. Spivey, A. Egbebi, "Heterogeneous catalytic synthesis of ethanol from biomass-derived syngas,” Chemical Society Reviews 36 (2007) 1514-1528.

[7] V. Subramani, S.K. Gangwal, "A review of recent literature to search for an efficient catalytic process for the conversion of syngas to ethanol," Energy \& Fuels 22 (2008) 814-839.

[8] R.B. Levy, M. Boudart, "Platinum-like behavior of tungsten carbide in surface catalysis,” Science 181 (1973) 547-549.

[9] J.G. Chen, "Carbide and nitride overlayers on early transition metal surfaces: Preparation, characterization, and reactivities,” Chemical Reviews 96 (1996) 14771498.

[10] H.H. Hwu, J.G. Chen, "Surface chemistry of transition metal carbides," Chemical Reviews 105 (2005) 185-212.

[11] K.Y. Park, W.K. Seo, J.S. Lee, "Selective synthesis of light olefins from syngas over potassium-promoted molybdenum carbide catalysts," Catalysis Letters 11 (1991) 349-356.

[12] D.-V.N. Vo, A.A. Adesina, "Fischer-Tropsch synthesis over alumina-supported molybdenum carbide catalyst,” Applied Catalysis A: General 399 (2011) 221-232.

[13] D.-V.N. Vo, T.-H. Nguyen, E.M. Kennedy, B.Z. Dlugogorski, A.A. Adesina, "Fischer-Tropsch synthesis: Effect of promoter type on alumina-supported Mo carbide catalysts,” Catalysis Today 175 (2011) 450-459. 
[14] H.C. Woo, K.Y. Park, Y.G. Kim, I.S. Nam, J.S. Chung, J.S. Lee, "Mixed alcohol synthesis from carbon monoxide and dihydrogen over potassium-promoted molybdenum carbide catalysts,” Applied Catalysis 75 (1991) 267-280.

[15] M. Xiang, D. Li, W. Li, B. Zhong, Y. Sun, "Performances of mixed alcohols synthesis over potassium promoted molybdenum carbides,” Fuel 85 (2006) 26622665.

[16] F.H. Ribeiro, R.A. Dalla Betta, M. Boudart, J. Baumgartner, E. Iglesia, "Reactions of neopentane, methylcyclohexane, and 3,3-dimethylpentane on tungsten carbides: The effect of surface oxygen on reaction pathways," Journal of Catalysis 130 (1991) 86-105.

[17] F.H. Ribeiro, M. Boudart, R.A. Dalla Betta, E. Iglesia, "Catalytic reactions of $n$ alkanes on $\beta-\mathrm{W}_{2} \mathrm{C}$ and $\mathrm{WC}$ : The effect of surface oxygen on reaction pathways," Journal of Catalysis 130 (1991) 498-513.

[18] E. Iglesia, J.E. Baumgartner, F.H. Ribeiro, M. Boudart, "Bifunctional reactions of alkanes on tungsten carbides modified by chemisorbed oxygen," Journal of Catalysis 131 (1991) 523-544.

[19] E. Iglesia, F.H. Ribeiro, M. Boudart, J.E. Baumgartner, "Synthesis, characterization, and catalytic properties of clean and oxygen-modified tungsten carbides,” Catalysis Today 15 (1992) 307-337.

[20] E. Iglesia, F.H. Ribeiro, M. Boudart, J.E. Baumgartner, “Tungsten carbides modified by chemisorbed oxygen: A new class of bifunctional catalysts,” Catalysis Today 15 (1992) 455-458.

[21] N. Liu, S.A. Rykov, J.G. Chen, “A comparative surface science study of carbide and oxycarbide: The effect of oxygen modification on the surface reactivity of C/W(111)," Surface Science 487 (2001) 107-117.

[22] H.H. Hwu, M.B. Zellner, J.G. Chen, "The chemical and electronic properties of oxygen-modified C/Mo(110): A model system for molybdenum oxycarbides,” Journal of Catalysis 229 (2005) 30-44.

[23] M. Nagai, T. Kurakami, S. Omi, “Activity of carbided molybdena-alumina for $\mathrm{CO}_{2}$ hydrogenation,” Catalysis Today 45 (1998) 235-239.

[24] W. Wu, Z. Wu, C. Liang, X. Chen, P. Ying, C. Li, "In situ FT-IR spectroscopic studies of $\mathrm{CO}$ adsorption on fresh $\mathrm{Mo}_{2} \mathrm{C} / \mathrm{Al}_{2} \mathrm{O}_{3}$ catalyst," The Journal of Physical Chemistry B 107 (2003) 7088-7094.

[25] W. Wu, Z. Wu, C. Liang, P. Ying, Z. Feng, C. Li, "An IR study on the surface passivation of $\mathrm{Mo}_{2} \mathrm{C} / \mathrm{Al}_{2} \mathrm{O}_{3}$ catalyst with $\mathrm{O}_{2}, \mathrm{H}_{2} \mathrm{O}$ and $\mathrm{CO}_{2}$," Physical Chemistry Chemical Physics 6 (2004) 5603-5608. 
[26] S. Li, W.B. Kim, J.S. Lee, "Effect of the reactive gas on the solid-state transformation of molybdenum trioxide to carbides and nitrides," Chemistry of Materials 10 (1998) 1853-1862.

[27] J.B. Claridge, A.P.E. York, A.J. Brungs, M.L.H. Green, "Study of the temperatureprogrammed reaction synthesis of early transition metal carbide and nitride catalyst materials from oxide precursors,” Chemistry of Materials 12 (2000) 132-142.

[28] R. Burch, M.I. Petch, "Investigation of the synthesis of oxygenates from carbon monoxide/hydrogen mixtures on supported rhodium catalysts," Applied Catalysis A: General 88 (1992) 39-60.

[29] B. Ravel, M. Newville, “ATHENA, ARTEMIS, HEPHAESTUS: Data analysis for X-ray absorption spectroscopy using IFEFFIT,” Journal of Synchrotron Radiation 12 (2005) 537-541.

[30] S.I. Zabinsky, J.J. Rehr, A. Ankudinov, R.C. Albers, M.J. Eller, "Multiplescattering calculations of x-ray-absorption spectra,” Physical Review B 52 (1995) 2995-3009.

[31] H. Shou, R.J. Davis, "Reactivity and in situ X-ray absorption spectroscopy of Rbpromoted $\mathrm{Mo}_{2} \mathrm{C} / \mathrm{MgO}$ catalysts for higher alcohol synthesis," Journal of Catalysis 282 (2011) 83-93.

[32] H.G. Kim, K.H. Lee, J.S. Lee, “Carbon monoxide hydrogenation over molybdenum carbide catalysts,” Research on Chemical Intermediates 26 (2000) 427-443.

[33] J.S. Lee, S. Kim, K.H. Lee, I.-S. Nam, J.S. Chung, Y.G. Kim, H.C. Woo, "Role of alkali promoters in $\mathrm{K} / \mathrm{MoS}_{2}$ catalysts for $\mathrm{CO}-\mathrm{H}_{2}$ reactions," Applied Catalysis A: General 110 (1994) 11-25.

[34] J.S. Lee, S. Kim, Y.G. Kim, "Electronic and geometric effects of alkali promoters in CO hydrogenation over $\mathrm{K} / \mathrm{Mo}_{2} \mathrm{C}$ catalysts," Topics in Catalysis 2 (1995) 127140 .

[35] Y.-T. Tsai, X. Mo, J.G. Goodwin, "The synthesis of hydrocarbons and oxygenates during $\mathrm{CO}$ hydrogenation on CoCuZnO catalysts: Analysis at the site level using multiproduct SSITKA,” Journal of Catalysis 285 (2012) 242-250.

[36] R. Kojima, K. Aika, "Molybdenum nitride and carbide catalysts for ammonia synthesis,” Applied Catalysis A: General 219 (2001) 141-147.

[37] W. Ding, S. Li, G.D. Meitzner, E. Iglesia, "Methane conversion to aromatics on Mo/H-ZSM5: Structure of molybdenum species in working catalysts," The Journal of Physical Chemistry B 105 (2001) 506-513.

[38] J.S. Lee, M. Boudart, "In situ carburization of metallic molybdenum during catalytic reactions of carbon-containing gases,” Catalysis Letters 20 (1993) 97-106. 


\section{Chapter 4.}

\section{Use of infrared spectroscopy and density functional theory to study the influence of rubidium on alumina-supported molybdenum carbide catalyst for higher alcohol synthesis from syngas}

Adapted from Journal of Catalysis, 299, Heng Shou, Liwei Li, Daniela Ferrari, David S. Sholl and Robert J. Davis, "Use of infrared spectroscopy and density functional theory to study the influence of rubidium on alumina-supported molybdenum carbide catalyst for higher alcohol synthesis from syngas,” 150-161, Copyright (2013), with permission from Elsevier

Density-functional-theory calculations were performed by Liwei Li and Dr. David S. Sholl at Georgia Institute of Technology and are included here for completeness.

\section{Abstract}

Molybdenum carbide nanoclusters supported on alumina were promoted by $\mathrm{Rb}_{2} \mathrm{CO}_{3}$ and tested for higher alcohol synthesis from syngas. At $573 \mathrm{~K}$ and 30 bar syngas $\left(\mathrm{H}_{2} / \mathrm{CO}=1\right)$, the promoted catalyst demonstrated $63 \%$ selectivity to alcohols (on a $\mathrm{CO}_{2}$ free basis), with hydrocarbons and ethers as side products. In contrast, the alcohol selectivity of an unpromoted $\mathrm{Mo}_{2} \mathrm{C} / \mathrm{Al}_{2} \mathrm{O}_{3}$ catalyst was very low. Diffuse reflectance infrared Fourier transform spectroscopy of adsorbed $\mathrm{CO}$ on $\mathrm{Mo}_{2} \mathrm{C} / \mathrm{Al}_{2} \mathrm{O}_{3}$ revealed a significant red shift in the $\mathrm{CO}$ band with added Rb promoter, which correlated to a decrease in hydrocarbon production rate and therefore an increase in alcohol selectivity. A quantum chemical description of $\mathrm{CO}$ adsorbed on a model $\mathrm{Mo}_{2} \mathrm{C}$ surface identified several possible binding modes of the CO. Both reactivity studies and DRIFTS of adsorbed $\mathrm{CO}$ demonstrated that mobility of the $\mathrm{Rb}$ promoter was enhanced in the presence of water vapor, which facilitates dispersion of Rb across the catalyst surface and effectively neutralizes acid sites that are deleterious to alcohol selectivity. 


\subsection{Introduction}

Limited crude oil reserves and competition with the food industry associated with fermentation-based biofuel production inspire new research efforts on effective catalytic transformations of alternative carbon sources to produce energy carriers and chemical feedstocks. Synthesis gas $\left(\mathrm{CO}+\mathrm{H}_{2}\right)$ can be derived from coal, natural gas or renewable biomass, and is a platform for the synthesis of fuels and chemicals.

Fischer-Tropsch synthesis (FTS) of hydrocarbons has received growing attention as a source of low-sulfur diesel fuel because of the uncertainty of crude oil prices. However, higher alcohol (C2+ alcohols) synthesis from synthesis gas, as a source of chemical feedstocks, might be more commercially attractive. For example, Celanese Corporation reported an expected ethanol price of \$1.4/gallon with their new coal-toethanol technology via acetic acid [1,2], and E. I. du Pont de Nemours and Company and BP have a stated goal for a butanol price of $\$ 1 /$ gallon with their bio-based process currently under development [3]. Considering that methanol is currently produced from natural-gas-based syngas at the world scale, it is reasonable to expect a comparably low price for higher alcohols produced by a similar catalytic process, assuming production and selectivity achievements are realized.

Because of methanol's low solubility in gasoline, it needs to be further converted to another molecule such as methyl tert-butyl ether (MTBE) before being used as a gasoline blend. However, MTBE is being phased out as a fuel additive due to environmental concerns. Higher alcohols, on the other hand, have mutual solubility with gasoline and ethanol has been widely used in the US as a gasoline additive. Since almost 
all the ethanol used for fuel is produced from fermentation, there is still a need for a more efficient catalytic process for the production of ethanol (and other higher alcohols).

An effective catalyst for the production of higher alcohols from syngas is necessarily multifunctional since CO activation, hydrogenation, carbon chain growth, and potentially alcohol coupling processes are all important steps in the reaction. Thus, no single-component transition metal catalyst has been discovered to effectively catalyze higher alcohol synthesis.

Exploratory research on higher alcohol synthesis has discovered some promising candidates [4-8]. Rh-based catalysts are effective for the formation of ethanol and other C2-oxygenates from syngas [9-11], but the very high cost of Rh likely prohibits its largescale utilization. Several non-precious metal catalysts for higher alcohol synthesis have thus been evaluated and include, for example, $\mathrm{Cu}-\mathrm{Co}, \mathrm{Cu}-\mathrm{Zn}-\mathrm{Al}$ and $\mathrm{Zn}-\mathrm{Cr}-\mathrm{K}$ [5], but improvements in the overall catalytic activity, alcohol selectivity, and long-term stability of these catalytic materials for higher alcohol synthesis are still needed.

Molybdenum-based catalysts have been widely used in many hydro-treating processes because of their high activities in desulfurization and denitrogenation with $\mathrm{H}_{2}$. When promoted by alkali metals, Mo-based catalysts also show encouraging properties for higher alcohol synthesis from CO hydrogenation. Both supported and unsupported $\mathrm{MoS}_{2}$-based catalysts have been heavily investigated for higher alcohol synthesis [12-15] since it was firstly developed by The Dow Chemical Company in the 1980's [16-20]. However, trace amounts of $\mathrm{H}_{2} \mathrm{~S}$ in the feed were required to sustain the performance of the $\mathrm{MoS}_{2}$-based catalysts [17]. Moreover, small amounts of sulfur may enter the carbon skeleton of the products, which is problematic as the world moves toward the use of very- 
low-sulfur fuels. Thus, there is a need for a non-sulfided alternative for $\mathrm{MoS}_{2}$-based catalyst in this process, among which molybdenum carbide has demonstrated some promise when properly promoted [21-25]. Early transition metal carbides are also recognized as potential substitutes to precious metal catalysts because of their similar surface electronic properties [26-28].

The selectivity towards alcohols over alkali-metal-promoted $\mathrm{MoS}_{2}$-based and $\mathrm{Mo}_{2} \mathrm{C}$-based catalysts in the syngas reaction was reported to be low initially but increased significantly with time on-stream over a period of several hours to several days [23,2931]. Lee et al. suggested that the promotional effect of alkali metal species on $\mathrm{MoS}_{2} 13$ and $\mathrm{Mo}_{2} \mathrm{C} 32$ catalysts for alcohol formation during $\mathrm{CO}$ hydrogenation was mostly the result of the surface sites being blocked from adsorbing reactants. By using diffuse reflectance infrared Fourier-transform spectroscopy (DRIFTS), Koizumi et al. claimed that syngas adsorption on a $\mathrm{MoS}_{2} / \gamma-\mathrm{Al}_{2} \mathrm{O}_{3}$ catalyst for $\mathrm{CO}$ hydrogenation was significantly suppressed by K species and the K-promoted Mo species were likely more oxidized than those on K-free $\mathrm{MoS}_{2}$ [33]. Muramatsu et al. also studied the role of a $\mathrm{K}$ promoter on a Mo oxide catalyst for alcohol production from syngas and concluded that $\mathrm{K}$ inhibits both dehydration of alcohols to alkenes and the hydrogenation of alkenes to alkanes [34]. For supported $\mathrm{MoS}_{2}$-based catalysts, interactions between K promoters and Mo begins with the oxidized catalyst precursors $[12,29,35,36]$ and that some K-Mo-S and/or K-Mo-S-O species are formed after sulfidation. However, it is still unclear whether the promoters enhance the activity of the catalysts for higher alcohol synthesis. Although CO adsorption has been used to probe the surfaces of $\mathrm{MoS}_{2}$-based [37-42] and $\mathrm{Mo}_{2} \mathrm{C}$-based [43-47] catalysts, few of these studies addressed the promotional influence 
of the alkali metals on higher alcohol synthesis. X-ray absorption spectroscopy of Rbpromoted $\mathrm{Mo}_{2} \mathrm{C} / \mathrm{MgO}$ catalysts demonstrated that the local environment around the $\mathrm{Rb}_{2} \mathrm{CO}_{3}$ promoter was structurally-modified during reaction [23], but the actual structural form of the working promoter is not yet known.

The present study uses diffuse reflectance infrared Fourier transform spectroscopy (DRIFTS) of adsorbed CO combined with density functional theory (DFT) to investigate the interactions between $\mathrm{Rb}$ and supported- $\mathrm{Mo}_{2} \mathrm{C}$ particles. Results from DRIFTS and DFT are used to interpret observed reactivity trends of working catalysts.

\subsection{Methods}

\subsubsection{Catalyst synthesis}

Incorporation of Mo onto the alumina support (Mager Scientific, >99.98\%, predominantly $\gamma$-phase, $\mathrm{S}_{\mathrm{BET}}=76 \mathrm{~m}^{2} \mathrm{~g}^{-1}$ ) was accomplished by incipient wetness impregnation of an aqueous solution of $\left(\mathrm{NH}_{4}\right)_{6} \mathrm{Mo}_{7} \mathrm{O}_{24} \cdot 4 \mathrm{H}_{2} \mathrm{O}$ (99.98\%, Aldrich) followed by drying in air for $12 \mathrm{~h}$ at $400 \mathrm{~K}$ and calcining in flowing air for $5 \mathrm{~h}$ at $773 \mathrm{~K}$ to produce a supported molybdenum oxide, denoted here as $\mathrm{MoO}_{3} / \mathrm{Al}_{2} \mathrm{O}_{3}$. Carburization of $\mathrm{MoO}_{3} / \mathrm{Al}_{2} \mathrm{O}_{3}$ was performed in a quartz tube by heating at a rate of $5 \mathrm{~K} \mathrm{~min}^{-1}$ from room temperature to $573 \mathrm{~K}$ and at a rate of $1 \mathrm{~K} \mathrm{~min}^{-1}$ from $573 \mathrm{~K}$ to $1033 \mathrm{~K}$ in 20 vol.\% $\mathrm{CH}_{4}$ (GTS-Welco, 99.997\%) and 80 vol.\% $\mathrm{H}_{2}$ (GTS-Welco, 99.999\%) at a total gas flow rate of $75 \mathrm{~cm}^{3} \mathrm{~min}^{-1}$ (STP). After ramping to $1033 \mathrm{~K}$ in $\mathrm{CH}_{4} / \mathrm{H}_{2}$, the temperature was maintained at $1033 \mathrm{~K}$ for $1 \mathrm{~h}$. The catalyst was subsequently cooled to $673 \mathrm{~K}$ in flowing He (GTS-Welco, 99.999\%, additionally purified by a Sigma-Aldrich OMI-2 purifier) and held at $673 \mathrm{~K}$ for $5 \mathrm{~h}$ in flowing purified $\mathrm{H}_{2}$ at a flow rate of $60 \mathrm{~cm}^{3}$ (STP) $\mathrm{min}^{-1}$. The catalyst was then cooled to room temperature in flowing purified He before passivation in 
a $20 \mathrm{~cm}^{3} \min ^{-1}$ (STP) stream of 1.04 vol.\% $\mathrm{O}_{2} / \mathrm{N}_{2}$ mixture (GTS-Welco) at room temperature for $12 \mathrm{~h}$. The alkali-metal-promoted $\mathrm{Mo}_{2} \mathrm{C} / \mathrm{Al}_{2} \mathrm{O}_{3}$ samples were prepared by grinding $\mathrm{Rb}_{2} \mathrm{CO}_{3}$ (99.975\%, Alfa Aesar) together with passivated $\mathrm{Mo}_{2} \mathrm{C} / \mathrm{Al}_{2} \mathrm{O}_{3}$ in a mortar and pestle.

\subsubsection{Hydrogenation of carbon monoxide}

Hydrogenation of CO was conducted in a fixed-bed stainless steel reactor (BTRS Jr., Autoclave Engineers) with about $1.25 \mathrm{~g}$ catalyst (0.025 g nominal $\mathrm{Mo}_{2} \mathrm{C}$ ). The catalysts were tested at nominally identical conditions of $573 \mathrm{~K}, 30$ bar total pressure, syngas $\left(\mathrm{H}_{2}+\mathrm{CO}\right)$ flow of $10 \mathrm{~cm}^{3} \mathrm{~min}^{-1}(\mathrm{STP})$ and $\mathrm{H}_{2} / \mathrm{CO}=1$. Additional experimental details can be found in our previous works [23,25].

In another series of studies on representative samples, water was introduced to the catalyst by flowing $\mathrm{N}_{2}$ (GTS-Welco, 99.999\%, additionally purified by a Sigma-Aldrich OMI-2 purifier) to the fixed bed reactor through a saturator with liquid water at $300 \mathrm{~K}$. The samples were sequentially treated at ambient pressure with $50 \mathrm{~cm}^{3} \mathrm{~min}^{-1}$ (STP) $\mathrm{H}_{2} \mathrm{O} / \mathrm{N}_{2}$ at $300 \mathrm{~K}$ for $2 \mathrm{~h}$ and with $50 \mathrm{~cm}^{3} \mathrm{~min}^{-1}$ (STP) $\mathrm{H}_{2}$ (GTS-Welco, 99.999\%) at 573 $\mathrm{K}$ for $12 \mathrm{~h}$ prior to syngas reaction.

In control experiments without water, the samples were pretreated with $50 \mathrm{~cm}^{3}$ $\min ^{-1}$ (STP) $\mathrm{H}_{2}$ (GTS-Welco, 99.999\%) at $573 \mathrm{~K}$ for $12 \mathrm{~h}$ prior to syngas reaction.

\subsubsection{Catalyst characterization}

The X-ray diffraction patterns were obtained on a Scintag XDS 2000 diffractometer using $\mathrm{Cu} \mathrm{K} \alpha$ radiation. Scans were collected over a range of $2 \theta$ from $5^{\circ}$ to $90^{\circ}$ at a rate of $2^{\circ} \mathrm{min}^{-1}$ for bulk materials and $0.8^{\circ} \mathrm{min}^{-1}$ for supported catalysts. 
Elemental analyses of representative samples were performed by Galbraith Laboratories (Knoxville, TN). The loading of molybdenum and rubidium was determined by inductively coupled plasma atomic emission spectroscopy (ICP-AES), and the loading of carbon was evaluated by combustion and coulometric measurement.

X-ray absorption spectroscopy (XAS) was performed on beam lines X23A2 and X18B at the National Synchrotron Light Source (NSLS), Brookhaven National Laboratory. The storage ring was typically operated at $2.8 \mathrm{GeV}$ with a ring current of about $300 \mathrm{~mA}$. The XAS data were obtained in the transmission mode at the Mo $K$ edge (20 keV) with a spot size of $0.5 \mathrm{~mm} \times 5 \mathrm{~mm}$. The Mo $K$ edge spectra were measured at room temperature with Mo foil (Goodfellow) as a reference. The air-free handling protocols for the non-passivated, unpromoted catalyst before reaction and the Rbpromoted catalyst after syngas reaction have been discussed in our previous work [25]. The XAS data were processed using the Athena [48] software for background removal, post-edge normalization, and X-ray absorption near edge structure (XANES) analysis. The value of $E_{0}$ was assigned here as the energy at the half step height. Metallic Mo foil, $\mathrm{MoO}_{2}$ (99\%, Aldrich) and $\mathrm{MoO}_{3}$ (99.99\%, Aldrich) were used as standard references for Mo in various oxidation states. Standard bulk $\mathrm{Mo}_{2} \mathrm{C}$ (Alfa Aesar, 99.5\%) was used to determine the amplitude reduction factors $S_{0}^{2}$ for Mo-C and Mo-Mo in the fitting of the extended X-ray absorption fine structure (EXAFS). The EXAFS results were fitted in Rspace using two shells (Mo-C \& Mo-Mo) generated theoretically using FEFF 6.0 [49]. The interatomic distances $(r)$, coordination numbers $(\mathrm{CN})$, Debye-Waller factors $\left(\Delta \sigma^{2}\right)$ and energy shifts $\left(\Delta E_{0}\right)$ were derived from the fitting results in the Artemis software package [48]. 


\subsubsection{Diffuse reflectance infrared Fourier transform spectroscopy}

A Bio-Rad FTIR (FTS-60A) spectrometer outfitted with an MCT detector and an in situ reactor cell for DRIFTS (Harrick) was used for the CO adsorption studies. To obtain the spectra, 100 scans were co-added at resolution of $4 \mathrm{~cm}^{-1}$. Samples of 2 wt.\% $\mathrm{Mo}_{2} \mathrm{C} / \mathrm{Al}_{2} \mathrm{O}_{3}$ catalysts with $\mathrm{Rb}$ loading varying from $0-10$ wt.\% were examined by DRIFTS according to the following procedure. A catalyst sample of $30 \mathrm{mg}$ was diluted in $90 \mathrm{mg}$ of $\mathrm{KBr}$ powder (Varian Inc.) before being loaded into the DRIFTS cell.

The loaded cell was then purged with He (GTS-Welco, 99.999\%, additionally purified by Sigma-Aldrich OMI-2) at a flow rate of $50 \mathrm{~cm}^{3} \mathrm{~min}^{-1}$ (STP) at room temperature for 10 min before being pressurized with equal flow rates of $\mathrm{H}_{2}$ (GTS-Welco, 99.999\%, additionally purified by Alltech All-Pure) and purified CO (GTS-Welco, 99.997\%) to 30 bar. The purification system for CO was comprised of a CRS Model $1000 \mathrm{O}_{2}$ trap, a homemade carbonyl trap (silica gel in a copper tube immersed in a dry ice/acetone cold bath), a homemade $\mathrm{CO}_{2}$ trap (Ascarite $\mathrm{II} \mathrm{CO}_{2}$ absorbent in a copper tube) and a homemade moisture trap (Fluka molecular sieves $3 \AA$ loaded in a copper tube). Subsequently, the cell was heated to $573 \mathrm{~K}$ at a rate of $10 \mathrm{~K} \mathrm{~min}^{-1}$ and held at $573 \mathrm{~K}$ for $12 \mathrm{~h}$ in 30 bar flowing syngas $\left(\mathrm{H}_{2} / \mathrm{CO}=1\right)$ with a total flow rate of $4 \mathrm{~cm}^{3} \mathrm{~min}^{-1}$ (STP). The cell was depressurized after $12 \mathrm{~h}$ treatment at reaction conditions and purged with 50 $\mathrm{cm}^{3} \min ^{-1}$ (STP) $\mathrm{H}_{2}$ at $573 \mathrm{~K}$, ambient pressure, for an additional $1 \mathrm{~h}$ before cooling to room temperature in flowing He. After recording a background spectrum of the sample, flowing He was replaced with purified CO flowing at a rate of $50 \mathrm{~mL} \mathrm{~min}^{-1}$ for $15 \mathrm{~min}$. The sample was finally purged with flowing purified He at $50 \mathrm{~mL} \mathrm{~min}{ }^{-1}$ for 15 min before recording a spectrum of adsorbed CO at $300 \mathrm{~K}$. 
In another series of studies on representative samples, water was introduced to the catalyst by flowing He to the DRIFTS cell through a saturator with liquid water at $300 \mathrm{~K}$. The samples were sequentially treated with the following conditions: 1 bar $\mathrm{H}_{2} \mathrm{O} / \mathrm{He}$ (50 $\mathrm{cm}^{3} \mathrm{~min}^{-1}$, STP $)$ at $300 \mathrm{~K}$ for $2 \mathrm{~h}$ and $1 \mathrm{bar} \mathrm{He}\left(50 \mathrm{~cm}^{3} \mathrm{~min}^{-1}\right.$, STP $)$ at $423 \mathrm{~K}$ for $1 \mathrm{~h} ; 1$ bar $\mathrm{H}_{2}\left(50 \mathrm{~cm}^{3} \mathrm{~min}^{-1}\right.$, STP $)$ at $573 \mathrm{~K}$ for $12 \mathrm{~h}$; 30 bar syngas $\left(\mathrm{H}_{2} / \mathrm{CO}=1\right.$, total flow rate at STP of $4 \mathrm{~cm}^{3} \mathrm{~min}^{-1}$ ) for $12 \mathrm{~h}$ and in 1 bar $\mathrm{H}_{2}\left(50 \mathrm{~cm}^{3} \mathrm{~min}^{-1}\right.$, STP) for $1 \mathrm{~h} ; 1$ bar $\mathrm{H}_{2}$ (50 $\mathrm{cm}^{3} \mathrm{~min}^{-1}$, STP) at $573 \mathrm{~K}$ for $12 \mathrm{~h}$. After each step of the pretreatment sequence, the sample was cooled to $300 \mathrm{~K}$ in flowing purified $\mathrm{He}\left(50 \mathrm{~cm}^{3} \mathrm{~min}^{-1}\right.$, STP). The background spectra were subsequently recorded at $300 \mathrm{~K}$ in flowing $\mathrm{He}$ before introducing purified $\mathrm{CO}\left(50 \mathrm{~cm}^{3} \mathrm{~min}^{-1}\right.$, STP) for $15 \mathrm{~min}$. After purging with flowing purified He at $50 \mathrm{~cm}^{3} \mathrm{~min}^{-1}$ for $15 \mathrm{~min}$, the IR spectra of adsorbed CO were recorded at $300 \mathrm{~K}$.

In control experiments without water, the samples were pretreated with $50 \mathrm{~cm}^{3}$ $\min ^{-1}$ (STP) purified $\mathrm{H}_{2}$ at $573 \mathrm{~K}$ for $12 \mathrm{~h}$ and purged in purified He before introducing purified $\mathrm{CO}$ at $300 \mathrm{~K}$.

\subsubsection{Computational methods}

Plane wave DFT calculations were performed with the Vienna $a b$ initio simulation package (VASP). We employed the revised Perdew-Burke-Ernzerhof (rPBE) generalized gradient functional [50,51] along with the projector augmented wave (PAW) [52,53] method to describe ionic cores. A plane wave expansion with a cutoff of $400 \mathrm{eV}$ was used for all calculations. Geometries were relaxed using a conjugate gradient algorithm until the forces on all unconstrained atoms were less than $0.03 \mathrm{eV} / \AA$. 


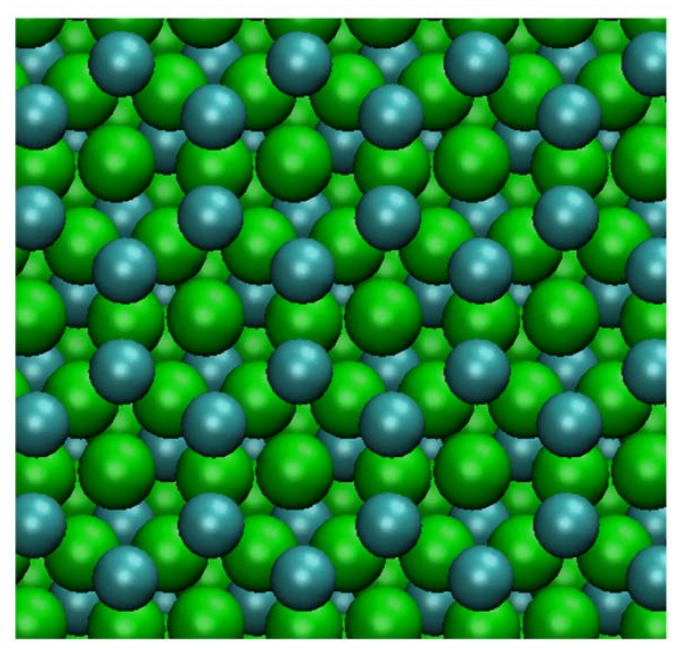

Figure 4.1 Reconstructed bare hexagonal $\mathrm{Mo}_{2} \mathrm{C}(001)$ surface. Mo atoms are shown as green spheres and $\mathrm{C}$ atoms as cyan spheres.

The surface structure of the molybdenum carbide catalyst modeled in this work is based on the reconstructed C-terminated hexagonal $\mathrm{Mo}_{2} \mathrm{C}(001)$ surface discussed in a previous study [54], which is illustrated in Figure 4.1. In that study, by comparing surface free energy and adsorption energy of alkali metal ( $\mathrm{K}$ and $\mathrm{Rb}$ ) atoms for different lowMiller-index surfaces of $\mathrm{Mo}_{2} \mathrm{C}$, the $\mathrm{Mo}_{2} \mathrm{C}(001)$ surface was found to be one of the major surfaces in predicted $\mathrm{Mo}_{2} \mathrm{C}$ particles as well as have the greatest affinity and dipole moment for $\mathrm{Rb}$ atoms. This surface is also known to favor a reconstruction in the absence of adsorbates [55-57], which results in both Mo-top and C-top sites for CO adsorption. Moreover, in spite of the potential support effect, the behavior of bulk $\mathrm{Mo}_{2} \mathrm{C}$ catalysts and $\mathrm{Mo}_{2} \mathrm{C}$ catalysts [21,22] and $\mathrm{Mo}_{2} \mathrm{C}$ catalysts on various supports ( $\mathrm{MgO}$ [23], $\alpha-\mathrm{Al}_{2} \mathrm{O}_{3}$ [25] and mixed-phase $\mathrm{Al}_{2} \mathrm{O}_{3}$ as illustrated in Section 3.3) is similar, which suggests that the actual sites on various $\mathrm{Mo}_{2} \mathrm{C}$ catalysts for $\mathrm{CO}$ hydrogenation would have a similar configuration. Given all the factors mentioned above, $\mathrm{Mo}_{2} \mathrm{C}(001)$ was chosen as a representative surface for modeling. 
A $6 \times 6 \times 1$ Monkhorst-Pack k-point mesh was used for $(1 \times 1)$ surface unit cell, which was sufficient to give well-converged results. For calculations on a $(2 \times 2)$ surface unit cell, the number of k-points in the Monkhorst-Pack meshes was reduced to $3 \times 3 \times 1$.

Geometries and energies for gas phase species were calculated using supercells equivalent to those for the largest slab calculations. When examining adsorption, molecules were placed on only one side of the slab. Dipole corrections were therefore applied in computing all of the energies reported below [58,59]. The adsorption energy, $E_{\text {adsorption }}$, of an atom or molecule was defined by

$$
E_{\text {adsorption }}=E_{\text {surface }}+E_{\text {adsorbate }}-E_{\text {total }} \text {, }
$$

where $E_{\text {total }}$ is the total energy of the system containing the adsorbed species, $E_{\text {surface }}$ is the total energy for the optimized bare surface, and $E_{\text {adsorbate }}$ is the total energy for the adsorbate in the gas phase. With this definition, positive adsorption energies correspond to energetically favored states. Adsorbate coverages were defined by considering a surface with an adsorbed species on every surface molybdenum atom to have a coverage of 1 monolayer (ML). This means that placing one adsorbate in a $1 \times 1$ unit cell gives a coverage of $0.25 \mathrm{ML}$.

Vibrational frequency calculations were performed with VASP package where the Hessian Matrix was calculated by finite difference approximation with step size of $0.03 \AA$ and only the adsorbate plus the surface atom to which it directly bonds were allowed to move. In order to compare with IR experiment, the calculated frequencies for the CO adsorbates are scaled by a factor of 1.009 , which reflects the difference between the observed $\left(2143 \mathrm{~cm}^{-1}\right)$ and calculated vibrational frequencies $\left(2124 \mathrm{~cm}^{-1}\right)$ of gaseous CO. 


\subsection{Results and discussion}

\subsubsection{Characterization by X-ray diffraction and X-ray absorption} spectroscopy

The X-ray diffraction patterns of representative samples are provided in Figure 4.2. Although the alumina support (Figure 4.2b) used for the catalysts has features of $\gamma$ $\mathrm{Al}_{2} \mathrm{O}_{3}$ (Figure 4.2c) and $\alpha-\mathrm{Al}_{2} \mathrm{O}_{3}$ (Figure 4.2d). The 2 wt. $\% \mathrm{Mo}_{2} \mathrm{C} / \mathrm{Al}_{2} \mathrm{O}_{3}$ catalyst (Figure 4.2a) prepared at $1033 \mathrm{~K}$ showed $\mathrm{XRD}$ peaks corresponding to the structure of the alumina support (Figure 4.2b) without any clear evidence for crystalline $\mathrm{Mo}_{2} \mathrm{C}$ (Figure 4.2e, the synthesis method can be found in previous work [23]). This result suggests that the $\mathrm{Mo}_{2} \mathrm{C}$ particles were well dispersed on the alumina support.

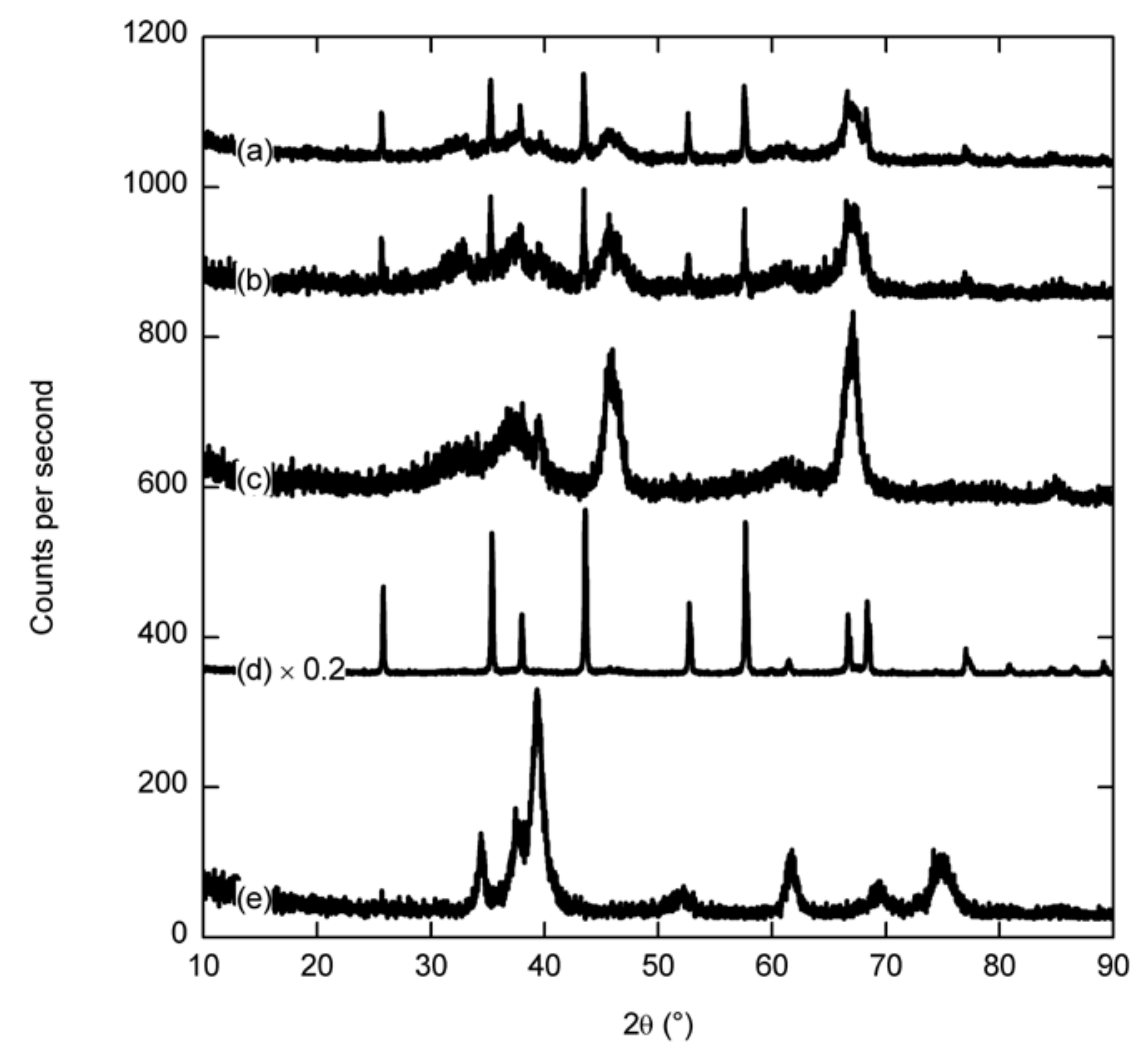

Figure 4.2 X-ray diffraction patterns of (a) 2 wt.\% $\mathrm{Mo}_{2} \mathrm{C} / \mathrm{Al}_{2} \mathrm{O}_{3}$, (b) $\mathrm{Al}_{2} \mathrm{O}_{3}$ (Mager Scientific) used to support $\mathrm{Mo}_{2} \mathrm{C}$, (c) $\gamma-\mathrm{Al}_{2} \mathrm{O}_{3}$ reference (Alfa-Aesar), (d) $\alpha-\mathrm{Al}_{2} \mathrm{O}_{3}$ (Mager Scientific) and (e) bulk $\mathrm{Mo}_{2} \mathrm{C}$. Patterns are offset for clarity. 


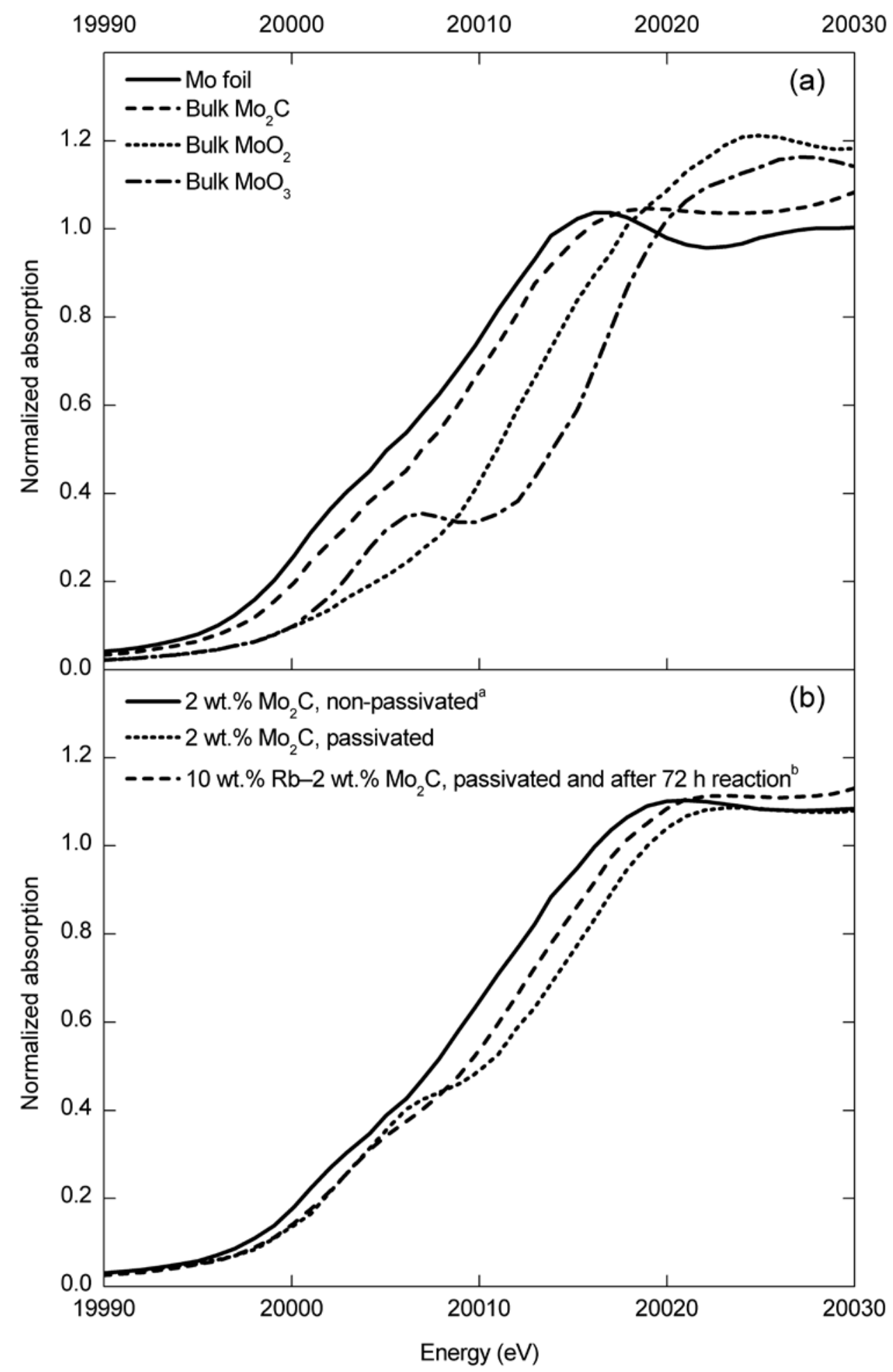

Figure 4.3 Mo K edge XANES of: (a) Mo standards; (b) alumina-supported Mo samples.

${ }^{\text {a }}$ Purged in He after carburization, air-free handling for sample preparation

${ }^{b}$ Purged in $\mathrm{N}_{2}$ after syngas reaction, air-free handling for sample preparation 
Table 4.1 Shift of the Mo K Edge Energy from Mo foil

\begin{tabular}{lc}
\hline Mo samples & Shift of $E_{0}(\mathrm{eV})$ \\
\hline Mo foil & 0.0 \\
Bulk $\mathrm{MoO}_{2}$ & 5.7 \\
Bulk $\mathrm{MoO}_{3}$ & 8.8 \\
Bulk $\mathrm{Mo}_{2} \mathrm{C}$ & 1.8 \\
2 wt.\% $\mathrm{Mo}_{2} \mathrm{C} / \mathrm{Al}_{2} \mathrm{O}_{3}$, non-passivated & a \\
2 wt.\% $\mathrm{Mo}_{2} \mathrm{C} / \mathrm{Al}_{2} \mathrm{O}_{3}$, passivated & 2.4 \\
10 wt.\% Rb-2 wt.\% $\mathrm{Mo}_{2} \mathrm{C} / \mathrm{Al}_{2} \mathrm{O}_{3}$, passivated and after 72 h reaction ${ }^{\text {b }}$ & 5.2 \\
\hline
\end{tabular}

${ }^{\mathrm{a}}$ Purged in He after carburization, air-free handling for sample preparation

${ }^{\mathrm{b}}$ Purged in $\mathrm{N}_{2}$ after syngas reaction, air-free handling for sample preparation

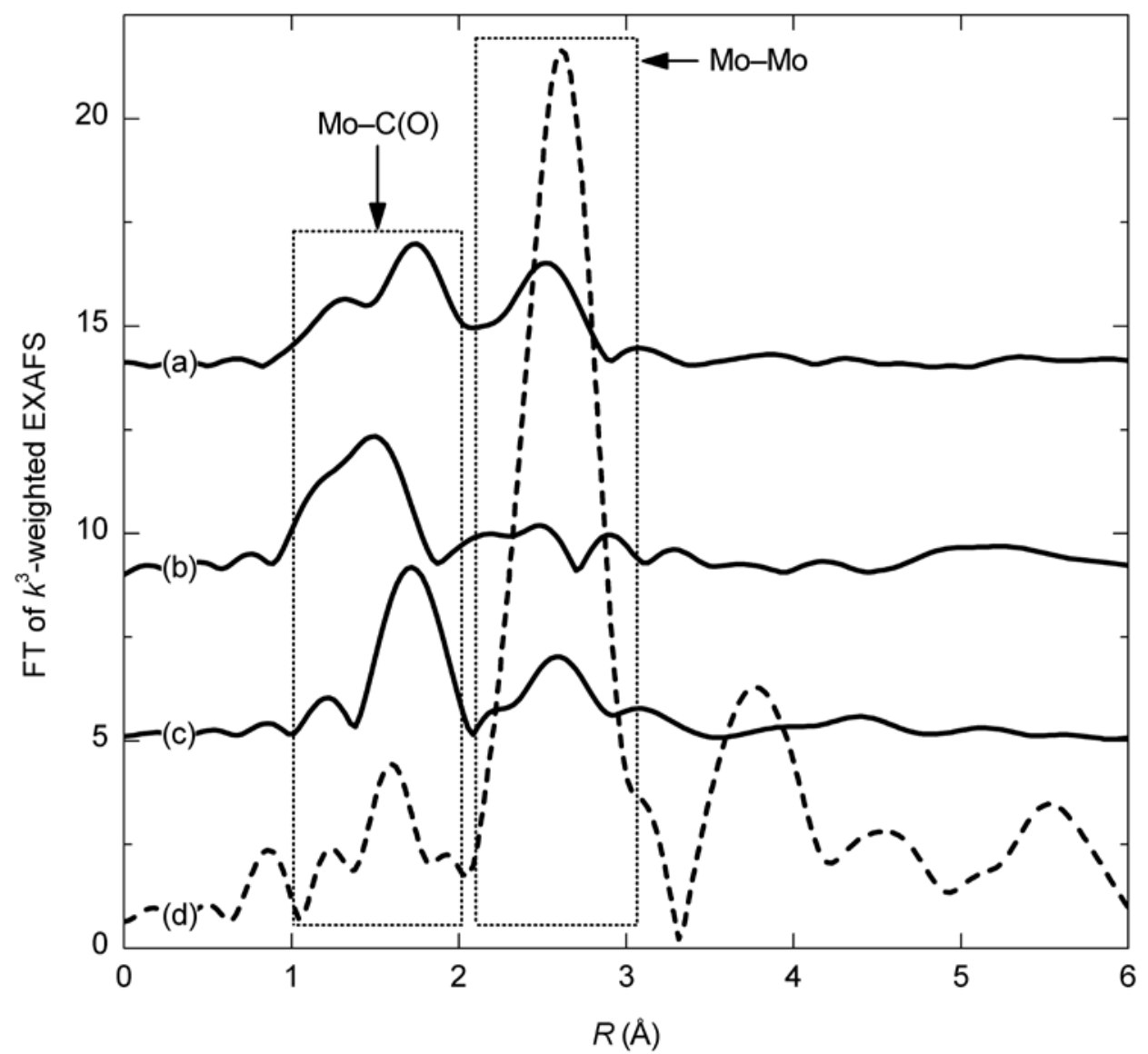

Figure 4.4 Fourier transform (not corrected for phase shifts) of $k^{3}$-weighted EXAFS of: (a) 2 wt.\% $\mathrm{Mo}_{2} \mathrm{C} / \mathrm{Al}_{2} \mathrm{O}_{3}$, non-passivated (purged in $\mathrm{He}$ after carburization, air-free handling for sample preparation); (b) $2 \mathrm{wt} \% \mathrm{Mo}_{2} \mathrm{C} / \mathrm{Al}_{2} \mathrm{O}_{3}$, passivated; (c) $10 \mathrm{wt} \% \mathrm{Rb}-2$ wt.\% $\mathrm{Mo}_{2} \mathrm{C} / \mathrm{Al}_{2} \mathrm{O}_{3}$, passivated and after $72 \mathrm{~h}$ reaction (purged in $\mathrm{N}_{2}$ after syngas reaction, air-free handling for sample preparation); (d) $\mathrm{Mo}_{2} \mathrm{C}$ standard. Spectra are offset for clarity. 
Table 4.2 Results from the analysis of Mo EXAFS from molybdenum carbide samples

\begin{tabular}{|c|c|c|c|c|c|c|}
\hline Sample & Shell & $\mathrm{CN}$ & $r(\AA)$ & $\begin{array}{l}\Delta \sigma^{2} \\
\left(10^{-3} \AA^{2}\right)\end{array}$ & $\Delta E_{0}(\mathrm{eV})$ & $\begin{array}{l}R- \\
\text { factor }\end{array}$ \\
\hline \multirow[t]{2}{*}{ Bulk $\mathrm{Mo}_{2} \mathrm{C}$ standard } & Mo-C & $3^{\mathrm{a}}$ & $2.12 \pm 0.02$ & $0.2 \pm 3.0$ & $1.7 \pm 2.9$ & \multirow[t]{2}{*}{0.015} \\
\hline & Mo-Mo & $12^{\mathrm{a}}$ & $2.97 \pm 0.01$ & $4.6 \pm 0.7$ & $-8.4 \pm 0.3$ & \\
\hline \multirow{2}{*}{$\begin{array}{l}2 \% \mathrm{Mo}_{2} \mathrm{C} / \mathrm{Al}_{2} \mathrm{O}_{3}{ }^{\mathrm{b}, \mathrm{d}} \\
\text { (non-passivated, air-free) }\end{array}$} & $\mathrm{Mo}-\mathrm{C}(\mathrm{O})$ & $4.1 \pm 0.7$ & $2.21 \pm 0.02$ & $6.0 \pm 2.6$ & $4.4 \pm 1.5$ & \multirow[t]{2}{*}{0.042} \\
\hline & Mo-Mo & $3.2 \pm 1.0$ & $2.89 \pm 0.02$ & $10 \pm 3$ & $-3.4 \pm 1.9$ & \\
\hline \multirow{2}{*}{$\begin{array}{l}10 \% \mathrm{Rb}-2 \% \mathrm{Mo}_{2} \mathrm{C} / \mathrm{Al}_{2} \mathrm{O}_{3},{ }^{\mathrm{c}, \mathrm{d}} \\
\text { passivated and after } 72 \mathrm{~h} \text { rxn }\end{array}$} & $\mathrm{Mo}-\mathrm{C}(\mathrm{O})$ & $2.6 \pm 0.5$ & $2.22 \pm 0.02$ & $0.0 \pm 2.0$ & $6.5 \pm 1.7$ & \multirow[t]{2}{*}{0.099} \\
\hline & Mo-Mo & $2.1 \pm 1.2$ & $2.92 \pm 0.02$ & & $-1.7 \pm 3.2$ & \\
\hline
\end{tabular}

Fitting parameters:

FT range $\Delta k$ : 2.5-12.5 $\AA^{-1}$; fitting range $\Delta R$ : 1-3.4 $\AA$; weighting: $k^{1}$ and $k^{3} ; S_{0}^{2}(\mathrm{Mo}-\mathrm{C})=0.67$, $S_{0}^{2}(\mathrm{Mo}-\mathrm{Mo})=0.67$. Two-shell fits excluded passivated $2 \mathrm{wt} . \% \mathrm{Mo}_{2} \mathrm{C} / \mathrm{Al}_{2} \mathrm{O}_{3}$ because of the lack of an obvious Mo-Mo shell (see Figure 4.4b).

${ }^{\mathrm{a}}$ Value was assigned in curving fitting based on standard structure. ${ }^{\mathrm{b}}$ Purged in He after carburization, air-free handling for sample preparation ${ }^{\mathrm{c}}$ Purged in $\mathrm{N}_{2}$ after syngas reaction, airfree handling for sample preparation ${ }^{\mathrm{d}} R_{\mathrm{bkg}}$ was set to 1.2 in background removal to remove the noise oscillation below $1 \AA$ in $R$ space.

The X-ray absorption near edge structure (XANES) at the Mo $K$ edge of reference compounds and catalysts is summarized in Figure 4.3 and Table 4.1, with the shift in the edge position (determined at half step height) defined as the increase of $E_{0}$ value from that of the Mo foil. The Fourier transforms (FT) of $k^{3}$-weighted extended X-ray absorption fine structure (EXAFS) are shown in Figure 4.4 and the structural parameters derived from the corresponding curve fits are presented in Table 4.2. A representative curve fit is presented in Figure 4.5. Non-passivated 2 wt. $\% \mathrm{Mo}_{2} \mathrm{C} / \mathrm{Al}_{2} \mathrm{O}_{3}$ (air-free) has a Mo-Mo coordination number of 2.8 (Table 4.2) and an $E_{0}$ shift of $2.4 \mathrm{eV}$ (Table 4.1), which is close to that of bulk $\mathrm{Mo}_{2} \mathrm{C}(1.8 \mathrm{eV})$. Passivation significantly oxidized the supported carbide as demonstrated by the $5.2 \mathrm{eV}$ shift of $E_{0}$ and the reduced magnitude of the Mo-Mo peak in FT of the EXAFS (Figure 4.4b). The value of $E_{0}$ of the passivated sample $(5.2 \mathrm{eV})$ was close to that of bulk $\mathrm{MoO}_{2}$. Elemental analysis of the passivated “ $\mathrm{Mo}_{2} \mathrm{C}$ " $/ \mathrm{Al}_{2} \mathrm{O}_{3}$ revealed 1.9 wt.\% $\mathrm{Mo}$ and a carbon-deficient stoichiometry of the 
supported molybdenum carbide, which is equivalent to $\mathrm{MoC}_{0.22}$. It should be noted that the carbon level of a "carburized" $\mathrm{Al}_{2} \mathrm{O}_{3}$ sample that was exposed to the same treatment as the catalyst synthesis, except that no molybdenum precursor was added, was subtracted from the analysis. The results from XANES, EXAFS and elemental analysis indicate that partial oxidation of the freshly prepared molybdenum carbide occurred during the passivation of the catalyst. The oxidation of 2 wt. $\% \mathrm{Mo}_{2} \mathrm{C} / \mathrm{Al}_{2} \mathrm{O}_{3}$ after passivation was more severe than the oxidation of 5 wt. $\% \mathrm{Mo}_{2} \mathrm{C}$ supported on $\mathrm{MgO}$ [23] or $\alpha-\mathrm{Al}_{2} \mathrm{O}_{3}$ [25], perhaps because of the lower weight loading and very high dispersion of Mo. Evidently there was a strong interaction between the Mo species and the $\mathrm{Al}_{2} \mathrm{O}_{3}$ support [60,61], which prevented agglomeration of the metal and may have formed a stable surface molybdate species on $\gamma-\mathrm{Al}_{2} \mathrm{O}_{3}$ [60]. Treatment of a passivated catalyst by reaction in syngas reduced the $E_{0}$ shift to $4.2 \mathrm{eV}$ and restored the Mo-Mo peak in the Fourier transform of Mo the EXAFS (Figure 4.4c), giving a Mo-Mo coordination number of 2.1 (Table 4.2). Thus, molybdenum oxycarbide domains appear to exist under syngas reaction conditions, although we will continue to refer to the catalyst as supported $\mathrm{Mo}_{2} \mathrm{C} / \mathrm{Al}_{2} \mathrm{O}_{3}$. The highly dispersed molybdenum oxycarbide has a longer Mo-C(O) distance and a shorter Mo-Mo distance than the corresponding values in bulk $\mathrm{Mo}_{2} \mathrm{C}$ (Table 4.2). Low Mo-Mo coordination numbers in very highly dispersed $\mathrm{Mo}_{2} \mathrm{C}$ clusters have also been reported on H-ZSM-5 zeolite [63], $\alpha-\mathrm{Al}_{2} \mathrm{O}_{3}$ [25] and $\gamma-\mathrm{Al}_{2} \mathrm{O}_{3}$ [64], with Mo-Mo coordination numbers derived from EXAFS as low as 2.6, 2.5 and 4, respectively. 

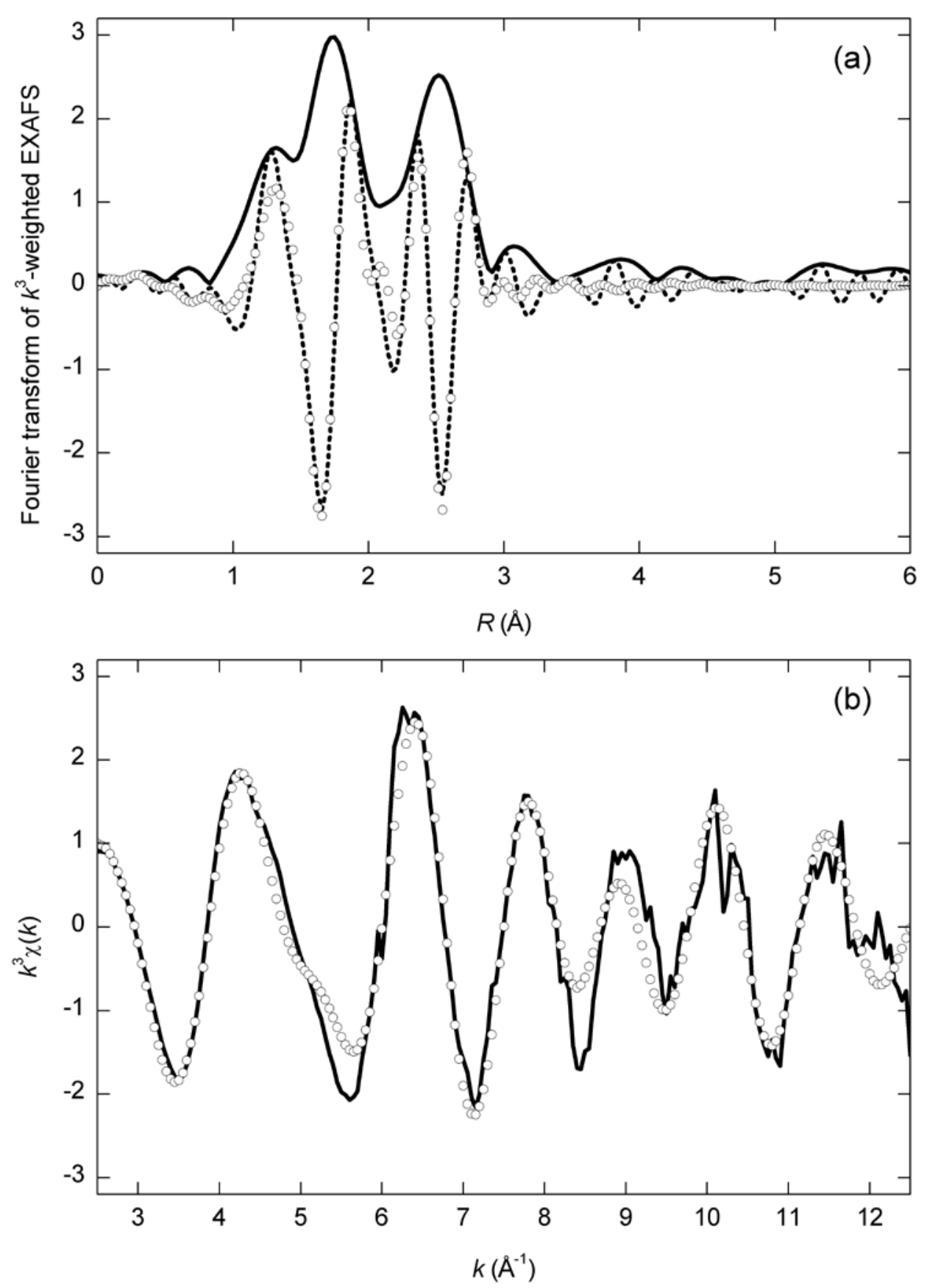

Figure 4.5 Comparison of curve fit to experimental Mo $K$ edge EXAFS of the nonpassivated 2 wt.\% $\mathrm{Mo}_{2} \mathrm{C} / \mathrm{Al}_{2} \mathrm{O}_{3}$ (air-free): (a) magnitude (solid line) and the imaginary part (dash line) of the FT of EXAFS compared with the result from the curve fit (circle); (b) $k^{3}$-weighted Mo $K$ edge EXAFS (solid line) and the result from curve fit (circle). 


\subsection{2 $\mathrm{CO}$ adsorption on $\mathrm{Mo}_{2} \mathrm{C}$ and $\mathrm{Rb}$-promoted $\mathrm{Mo}_{2} \mathrm{C}$}

The formation of products during the syngas pretreatment ( $573 \mathrm{~K}, 30$ bar syngas, $\mathrm{H}_{2} / \mathrm{CO}=1,12 \mathrm{~h}$ reaction in syngas) in the DRIFTS experiments was verified by monitoring the IR spectrum during reaction over a 5 wt.\% Rb-2 wt.\% $\mathrm{Mo}_{2} \mathrm{C} / \mathrm{Al}_{2} \mathrm{O}_{3}$ catalyst, which is shown in Figure 4.6. The IR spectrum at reaction conditions was obtained after removal of a background that was recorded after the sample was purged at $573 \mathrm{~K}$ for $1 \mathrm{~h}$ in $\mathrm{H}_{2}$ at ambient pressure. During the reaction, the bands associated with $\mathrm{CH}_{4}, \mathrm{CO}_{2}, \mathrm{H}_{2} \mathrm{O}, \mathrm{CH}_{3} \mathrm{CH}_{2} \mathrm{OH}$ and $\mathrm{CH}_{3} \mathrm{OH}$, which appear at 3015, 2360, 1650, 1062 and $1030 \mathrm{~cm}^{-1}$, respectively, were observed during reaction over 5 wt.\% Rb-2 wt.\% $\mathrm{Mo}_{2} \mathrm{C} / \mathrm{Al}_{2} \mathrm{O}_{3}$ catalysts (Figure 4.6).

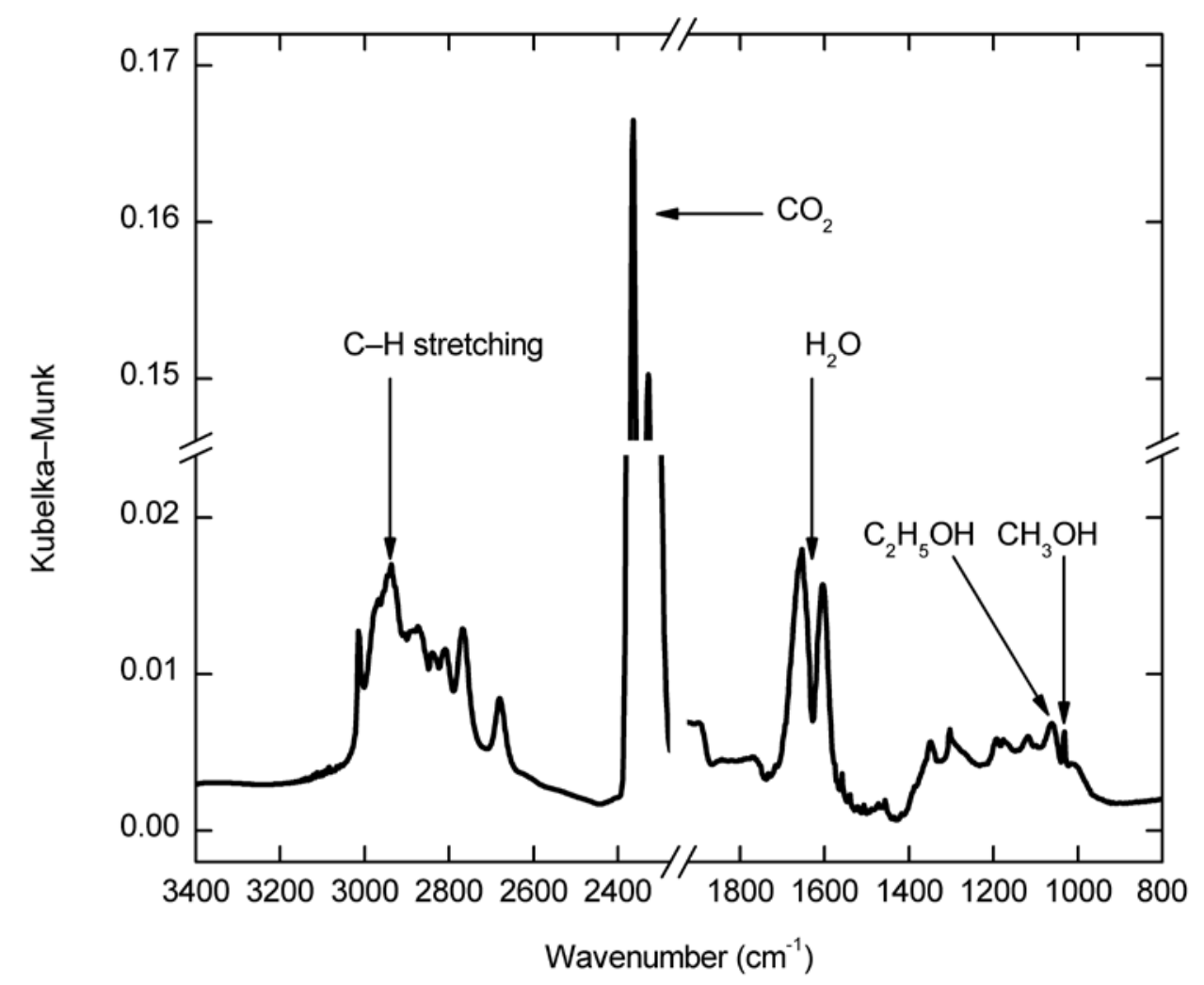

Figure 4.6 IR spectroscopy of gaseous species in $\mathrm{CO}$ hydrogenation at $573 \mathrm{~K}$, 30 bar syngas over 5 wt. $\% \mathrm{Rb}-2 \mathrm{wt} . \% \mathrm{Mo}_{2} \mathrm{C} / \mathrm{Al}_{2} \mathrm{O}_{3}$ 
The IR spectrum of adsorbed $\mathrm{CO}$ on unpromoted 2 wt.\% $\mathrm{Mo}_{2} \mathrm{C} / \mathrm{Al}_{2} \mathrm{O}_{3}$ at room temperature after being treated at $573 \mathrm{~K}$, in 30 bar syngas $\left(\mathrm{H}_{2} / \mathrm{CO}=1\right)$ for $12 \mathrm{~h}$ and in 1 bar $\mathrm{H}_{2}$ for $1 \mathrm{~h}$, is shown in Figure 4.7. The spectrum of adsorbed $\mathrm{CO}$ on the unpromoted $\mathrm{Mo}_{2} \mathrm{C} / \mathrm{Al}_{2} \mathrm{O}_{3}$ catalyst, which was very low in intensity, revealed two bands at 2105 and $2014 \mathrm{~cm}^{-1}$, and very small features at $2173 \mathrm{~cm}^{-1}$ and $1946 \mathrm{~cm}^{-1}$. A sample of "carburized" $\mathrm{Al}_{2} \mathrm{O}_{3}$ pretreated with the same condition showed no feature in the IR spectrum attributed to adsorbed CO.

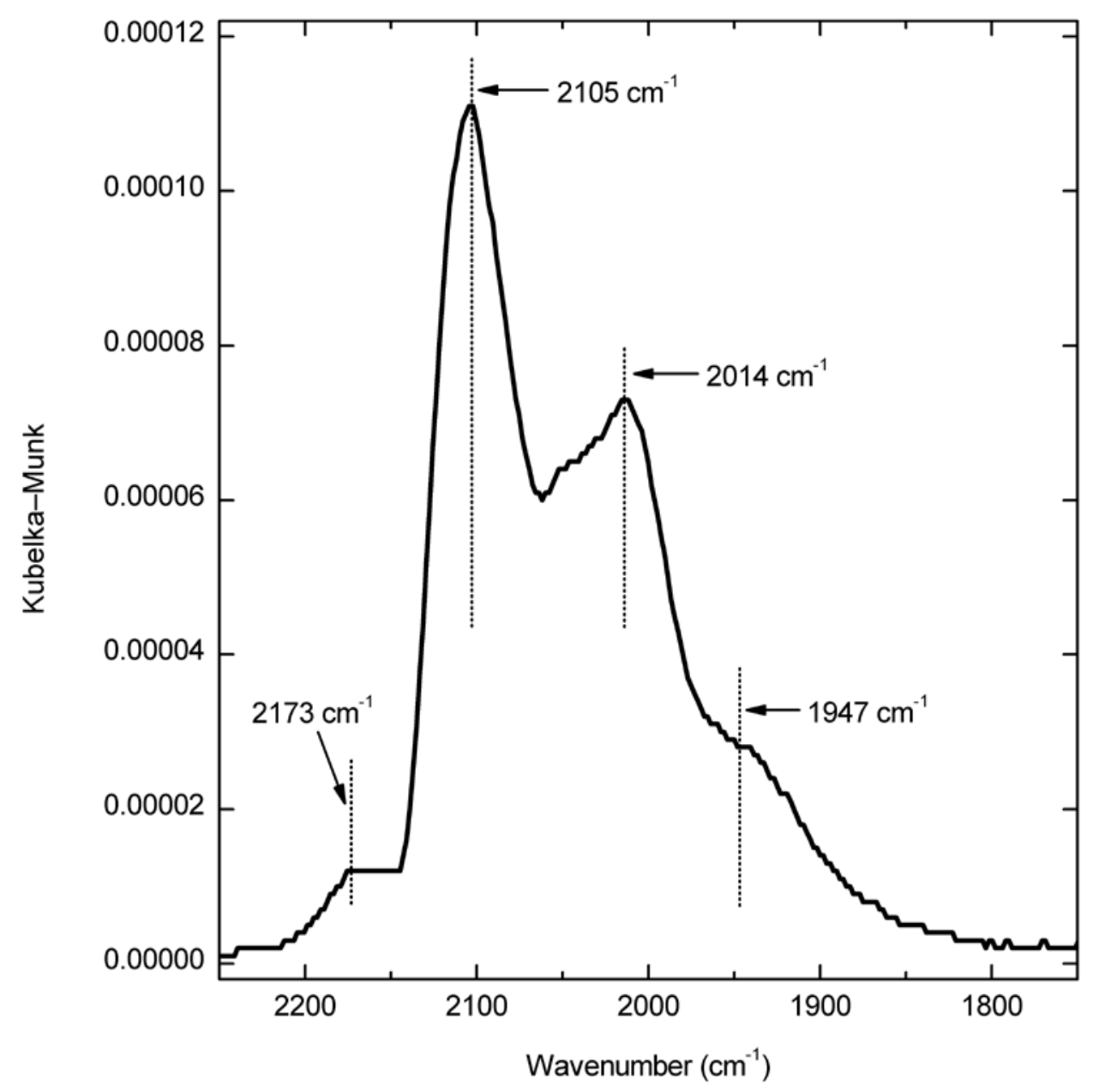

Figure 4.7 Diffuse reflectance Fourier transform spectra of adsorbed CO on 2 wt.\% $\mathrm{Mo}_{2} \mathrm{C} / \mathrm{Al}_{2} \mathrm{O}_{3}$ at room temperature after being pretreated at $573 \mathrm{~K}$, in 30 bar syngas $\left(\mathrm{H}_{2} / \mathrm{CO}=1\right)$ for $12 \mathrm{~h}$ and in 1 bar $\mathrm{H}_{2}$ for $1 \mathrm{~h}$. 

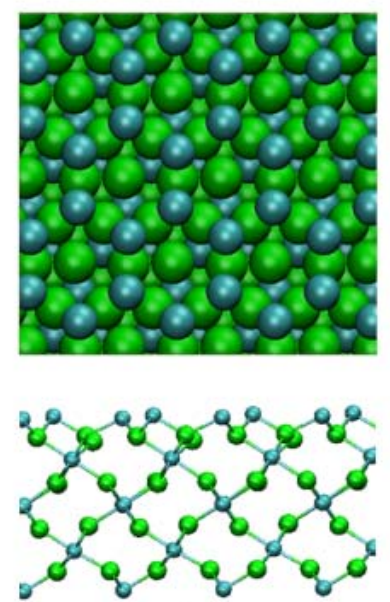

(a)

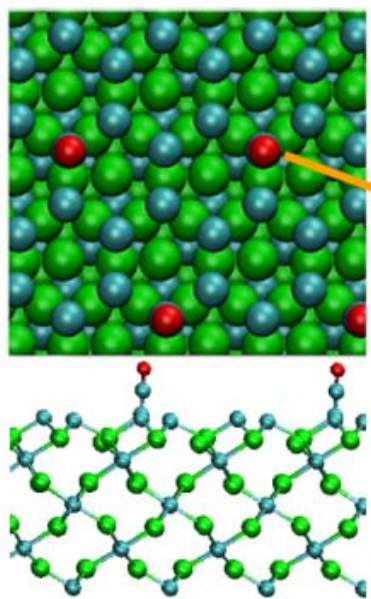

(b)

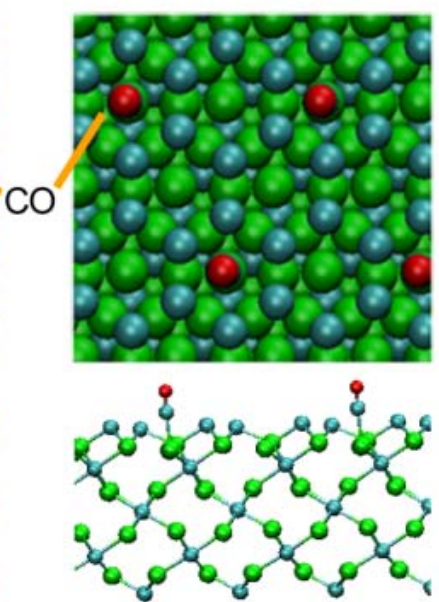

(c)

Figure 4.8 Top and side view of $\mathrm{CO}$ adsorption on reconstructed hexagonal $\mathrm{Mo}_{2} \mathrm{C}(001)$ surface: (a) CO-free, (b) CO adsorbed on C-top sites, (c) CO adsorbed on Mo-top sites. $\mathrm{Mo}, \mathrm{C}$, and $\mathrm{O}$ atoms are shown as green, cyan, and red spheres, respectively.

The corresponding vibrational frequencies derived from DFT calculations of CO adsorbed on a reconstructed hexagonal $\mathrm{Mo}_{2} \mathrm{C}(001)$ surface (Figure 4.8) are shown in Table 4.3. With a low CO coverage of 0.0625 monolayer (ML), the vibrational frequency of adsorbed CO appears at $2121 \mathrm{~cm}^{-1}$ and $1989 \mathrm{~cm}^{-1}$ on C-top sites (Figure 4.8b) and on Mo-top sites (Figure 4.8c), respectively, with Mo-top sites providing a stronger binding energy $(1.62 \mathrm{eV})$ than C-top sites $(1.55 \mathrm{eV})$. High CO coverages typically cause a blue shift of the vibrational frequency of adsorbed CO $[45,65]$, in part, a result of the dipoledipole coupling of adsorbed CO molecules [64]. The DFT calculation results also show that on the unmodified $\mathrm{Mo}_{2} \mathrm{C}$ surface with a $\mathrm{CO}$ coverage of 0.25 monolayer (ML), the vibrational frequencies of adsorbed CO on both C-top sites and on Mo-top sites were shifted to higher frequency by $20 \mathrm{~cm}^{-1}$. Similar shifts in the CO band were also observed on a $\mathrm{W}_{2} \mathrm{C}(0001)$ surface by Aizawa and Otani [67], who claimed the features belong to surface ketenylidene (CCO) species formed by adsorbed $\mathrm{CO}$ on carbidic carbon. Nevertheless, the assignment of bands associated with $\mathrm{CO}$ adsorbed on $\mathrm{Mo}_{2} \mathrm{C}$ is not straightforward, as discussed below. 
Table 4.3 DFT-simulated CO adsorption on reconstructed $\mathrm{Mo}_{2} \mathrm{C}(001)$ surface

\begin{tabular}{cccccc}
\hline \multirow{2}{*}{$\begin{array}{c}\text { CO } \\
\text { coverage } \\
(\mathrm{ML})\end{array}$} & $\begin{array}{c}\text { Wavenumber } \\
\left(\mathrm{cm}^{-1}\right)\end{array}$ & $\begin{array}{c}\text { Adsorption } \\
\text { energy }(\mathrm{eV})\end{array}$ & & $\begin{array}{c}\text { Cavenumber } \\
\left(\mathrm{cm}^{-1}\right)\end{array}$ & $\begin{array}{c}\text { Adsorption } \\
\text { energy }(\mathrm{eV})\end{array}$ \\
\hline 0.0625 & 2121 & 1.55 & & 1989 & 1.62 \\
0.250 & 2141 & 1.26 & & 2009 & 1.56 \\
\hline
\end{tabular}

Aegerter et al. attributed a feature of $2178 \mathrm{~cm}^{-1}$ to $\mathrm{CO}$ adsorption on coordinatively-unsaturated $\mathrm{Mo}(\mathrm{IV})$ on a passivated $\mathrm{Mo}_{2} \mathrm{C} / \gamma-\mathrm{Al}_{2} \mathrm{O}_{3}$ catalyst after activation in $\mathrm{H}_{2}$ [46]. Peri has also reported that $\mathrm{CO}$ adsorbed on $\mathrm{Mo(IV)}$ appears near $2190 \mathrm{~cm}^{-1}$ [68]. Based on the these prior assignments, we attribute the minor peak at $2173 \mathrm{~cm}^{-1}$ in Figure 4.8 to $\mathrm{CO}$ adsorbed on oxidized molybdenum species or to the residual gaseous $\mathrm{CO}$ in the IR cell.

The features in the range of 2071-2054 $\mathrm{cm}^{-1}$ have been assigned to linearly adsorbed $\mathrm{CO}$ on a clean hexagonal $\mathrm{Mo}_{2} \mathrm{C}$ foil [45], on carbidic Mo sites present on $\mathrm{Mo}_{2} \mathrm{C} / \gamma-\mathrm{Al}_{2} \mathrm{O}_{3}$ catalysts $[43,44,46]$, and on modeled surfaces of hexagonal $\mathrm{Mo}_{2} \mathrm{C}$ described by DFT [69,70]. A shoulder CO band at $2125 \mathrm{~cm}^{-1}$ has also been reported when $\mathrm{Mo}_{2} \mathrm{C}$ foil was pre-exposed to $\mathrm{O}_{2}$ [45]. Bands for linearly adsorbed $\mathrm{CO}\left(2015 \mathrm{~cm}^{-1}\right)$ and bridge-bonded CO $\left(1850 \mathrm{~cm}^{-1}\right)$ were also seen by high-resolution electron energy loss spectroscopy (HREELS) on a Mo (110) single crystal with a surface carbide layer [71]. Consistent with the XANES of bulk $\mathrm{Mo}_{2} \mathrm{C}$ [23,25], the close packed structure of Mo in $\mathrm{Mo}_{2} \mathrm{C}$, and the similar electronegativity values of $\mathrm{C}$ (2.55) and $\mathrm{Mo}$ (2.16) [72], Mo in $\mathrm{Mo}_{2} \mathrm{C}$ should be close to the metallic state so that adsorbed $\mathrm{CO}$ on metallic Mo would have similar vibrational frequencies to those on carbidic Mo. In fact, bands for linearly adsorbed CO on metallic Mo have been reported at 2055-2015 cm $\mathrm{cm}^{-1}[68,73]$, whereas the features of bridged-bonded CO are in the range of $1975-1920 \mathrm{~cm}^{-1}$ [73]. The asymmetric 
C-O stretching frequencies of ketenylidene (CCO) species varied from 2130 to 2100 $\mathrm{cm}^{-1}$ depending on the groups that attached to the CCO structure [74]. Ketenylidene species has been proven to be the most stable configuration of adsorbed $\mathrm{CO}$ on a Cterminated $\mathrm{Mo}_{2} \mathrm{C}$ surface by DFT [75]. Ketenylidene also formed when $\mathrm{CO}$ was adsorbed on a $\mathrm{W}_{2} \mathrm{C}$ surface that processed a similar structure to $\mathrm{Mo}_{2} \mathrm{C}$, giving $\mathrm{C}-\mathrm{O}$ stretching frequencies varying from $1954 \mathrm{~cm}^{-1}$ to $2041 \mathrm{~cm}^{-1}$ with increasing CO coverage [67]. Interestingly, DFT calculations suggest that ketenylidene may be involved in the initiation of the carbon chain growth process in Fisher-Tropsch synthesis over iron carbide [76].

Müller et al. studied $\mathrm{CO}$ adsorption on a $\mathrm{MoS}_{2} / \gamma-\mathrm{Al}_{2} \mathrm{O}_{3}$ catalyst, which demonstrates very similar catalytic behavior in $\mathrm{CO}$ hydrogenation to $\mathrm{Mo}_{2} \mathrm{C}$, and reported a major IR feature at $2105 \mathrm{~cm}^{-1}$ for $\mathrm{CO}$ on $\mathrm{Mo}^{2+}$ along the edge of the crystallites with a shoulder at $2060 \mathrm{~cm}^{-1}$ attributed to CO on less coordinated corner sites [39].

Since the XANES of supported $\mathrm{Mo}_{2} \mathrm{C}$ catalysts (Table 4.1, Figure 4.3b, and in Ref. $[23,25])$ suggest that the supported $\mathrm{Mo}_{2} \mathrm{C}$ catalysts are actually oxycarbides even after syngas reaction, the $2105 \mathrm{~cm}^{-1}$ peak in Figure 4.7 may result from $\mathrm{CO}$ on oxycarbidic Mo sites, and the secondary peak at $2014 \mathrm{~cm}^{-1}$ could be attributed to CO on the Mo sites with lower valence. However, the difference between them may be also caused by different coordinative environments of Mo, such as corner vs. edge sites as described above for $\mathrm{MoS}_{2}$ catalysts. Moreover, it is possible that the $2105 \mathrm{~cm}^{-1}$ peak is from the ketenylidene-like species with CO linearly adsorbed on C-top sites over the reconstructed hexagonal $\mathrm{Mo}_{2} \mathrm{C}(001)$ surface (Figure 4.8), as suggested by the DFT calculation (Table 4.4). 
Figure 4.9 summarizes the IR spectra of $\mathrm{CO}$ adsorbed on $\mathrm{Mo}_{2} \mathrm{C} / \mathrm{Al}_{2} \mathrm{O}_{3}$, as the weight loading of $\mathrm{Rb}$ increased from $0 \%$ to $10 \%$. Upon addition of promoter, the IR band of CO at $2105 \mathrm{~cm}^{-1}$ diminished and the entire band associated with CO red shifted according to the amount of $\mathrm{Rb}$ added. On a 10 wt.\% $\mathrm{Rb}-2$ wt.\% $\mathrm{Mo}_{2} \mathrm{C} / \mathrm{Al}_{2} \mathrm{O}_{3}$ catalyst (Figure 4.9e), a very weak CO band appeared at $1900 \mathrm{~cm}^{-1}$. A physical mixture of $\mathrm{Rb}_{2} \mathrm{CO}_{3}$ and "carburized" $\mathrm{Al}_{2} \mathrm{O}_{3}$ (ground with mortar and pestle) showed no feature of adsorbed CO after the same pretreatment conditions.

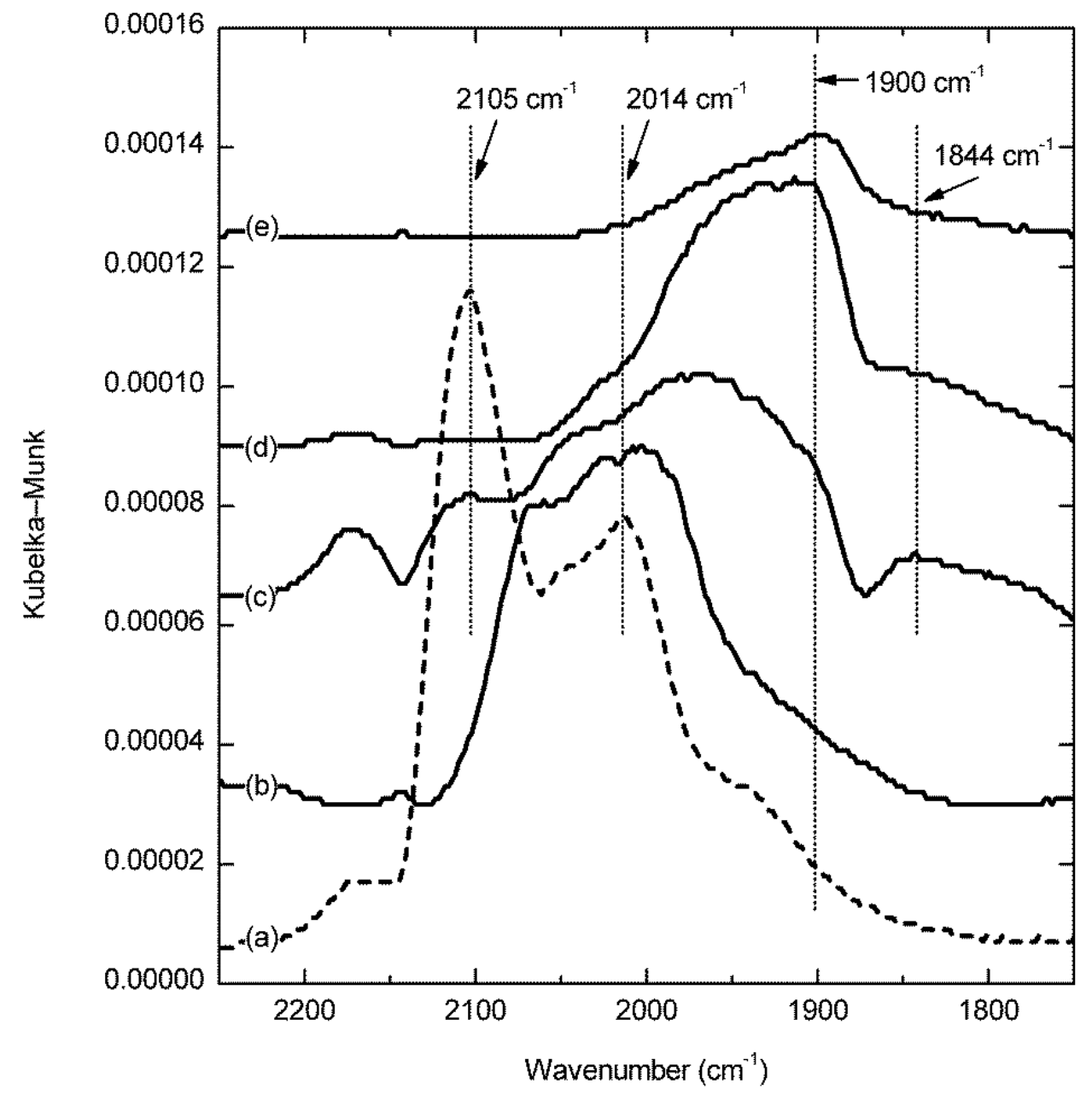

Figure 4.9 Diffuse reflectance Fourier transform spectra of adsorbed CO on samples at room temperature after being pretreated at $573 \mathrm{~K}$, in 30 bar syngas $\left(\mathrm{H}_{2} / \mathrm{CO}=1\right)$ for $12 \mathrm{~h}$ and in 1 bar $\mathrm{H}_{2}$ for $1 \mathrm{~h}$ (a) 2 wt.\% $\mathrm{Mo}_{2} \mathrm{C} / \mathrm{Al}_{2} \mathrm{O}_{3}$, (b) $2 \mathrm{wt} \% \mathrm{Rb}-2 \mathrm{wt} . \% \mathrm{Mo}_{2} \mathrm{C} / \mathrm{Al}_{2} \mathrm{O}_{3}$, (c) 5 wt.\% Rb-2 wt. $\% \mathrm{Mo}_{2} \mathrm{C} / \mathrm{Al}_{2} \mathrm{O}_{3}$, (d) 7.5 wt.\% Rb-2 wt.\% $\mathrm{Mo}_{2} \mathrm{C} / \mathrm{Al}_{2} \mathrm{O}_{3}$, (e) 10 wt.\% Rb-2 wt. $\% \mathrm{Mo}_{2} \mathrm{C} / \mathrm{Al}_{2} \mathrm{O}_{3}$. Spectra are offset for clarity. 
In an effort to interpret the DRIFTS results, $\mathrm{Rb}$ and $\mathrm{RbO}$ were added to the reconstructed hexagonal $\mathrm{Mo}_{2} \mathrm{C}(001)$ surface previously described by DFT (Figure 4.1 and Figure 4.8) and vibrational frequencies of adsorbed $\mathrm{CO}$ on this promoted surface were calculated. Figure 4.10 provides illustrations of $\mathrm{Rb}$ - and $\mathrm{RbO}$-modified $\mathrm{Mo}_{2} \mathrm{C}$ surfaces, with and without added CO. The corresponding vibrational frequencies of adsorbed $\mathrm{CO}$ on the Rb-modified surfaces are listed in Table 4.4. At the identical CO coverage of $0.0625 \mathrm{ML}$, the vibrational frequencies of adsorbed CO were observed to red shift by about $34 \mathrm{~cm}^{-1}$ on the C-top sites (Figure $4.10 \mathrm{~b}$ and e) and by $47 \mathrm{~cm}^{-1}$ on the Motop sites (Figure 4.10c and f) after the surface modification with either Rb or RbO. The calculated red shifts are in good agreement with the IR observations of CO adsorption on the $\mathrm{Mo}_{2} \mathrm{C} / \mathrm{Al}_{2} \mathrm{O}_{3}$ catalysts with increasing $\mathrm{Rb}$ loading (Figure 4.9b-e). It is also instructive to compare the binding energy of $\mathrm{CO}$ on the promoted and unpromoted surfaces. For instance, the binding energy of $\mathrm{CO}$ on C-top sites (1.53 eV, Table 4.4) was almost unchanged from the unpromoted C-top sites $(1.55 \mathrm{eV}$, Table 4.3) at a coverage of 0.0625 ML on the RbO-modified $\mathrm{Mo}_{2} \mathrm{C}$ surface. However, the binding energy of $\mathrm{CO}$ on the Motop sites increased by $0.1 \mathrm{eV}$ as a result of the added RbO, which might explain the decrease and eventual disappearance of the CO peak at about $2100 \mathrm{~cm}^{-1}$ over the Rbpromoted $\mathrm{Mo}_{2} \mathrm{C} / \mathrm{Al}_{2} \mathrm{O}_{3}$ (Figure 4.9b-e). It is possible that the presence of the Rb species shifts the preferred binding from C-top to Mo-Topics in It should be noted that the calculations presented here are specific to one type of $\mathrm{Mo}_{2} \mathrm{C}$ surface, and that the size, composition and morphology of the supported " $\mathrm{Mo}_{2} \mathrm{C}$ ” nanoparticles are very different from the defect-free surface with long range order used for modeling. Since the supported carbide samples investigated in this work were passivated in dilute $\mathrm{O}_{2}$ prior to reaction or 
DRIFTS investigation, the actual catalysts interrogated experimentally were likely to be oxycarbides rather than pure carbides. Indeed, the relatively high binding energy of CO on the simulated $\mathrm{Mo}_{2} \mathrm{C}$ surface is consistent with the high affinity of pristine carbides for simple adsorbates. Nevertheless, we used the DFT studies of a model carbide surface to explore the nature of the $\mathrm{CO}$ binding mode and the trend in the vibrational frequency of CO with alkali metal addition to that surface.

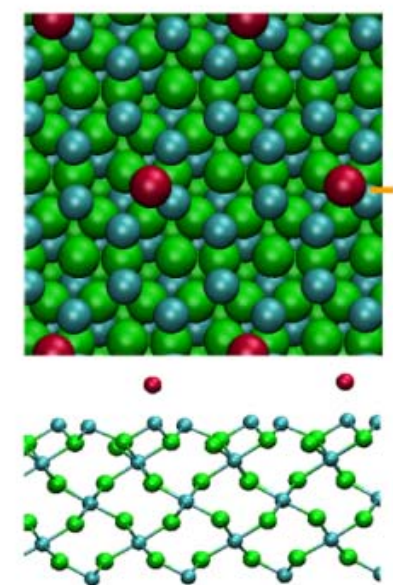

(a)

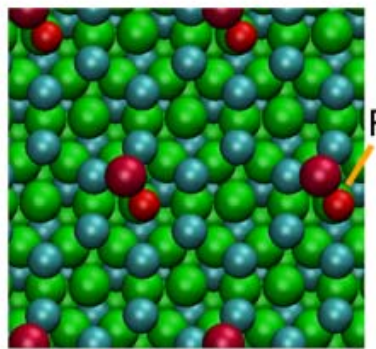

-

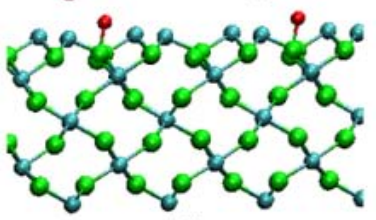

(d)

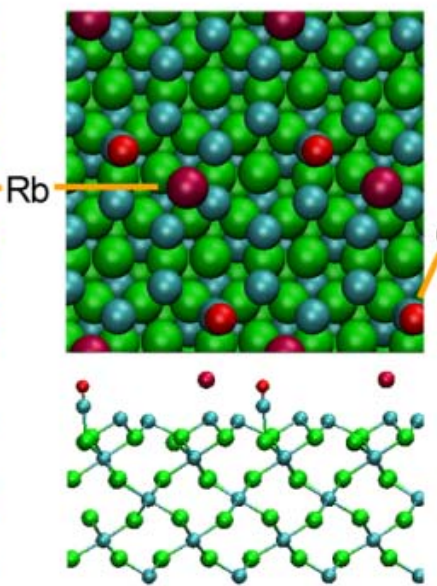

(b)

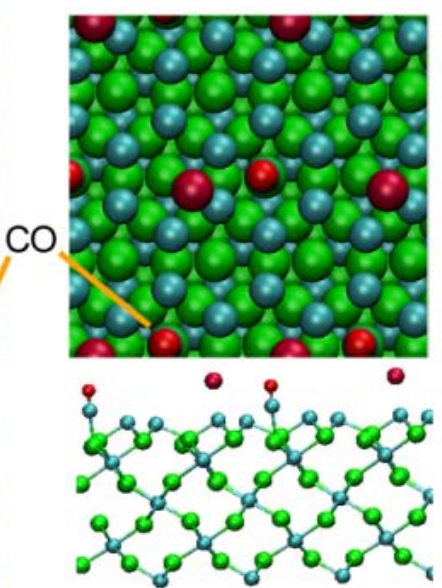

(c)

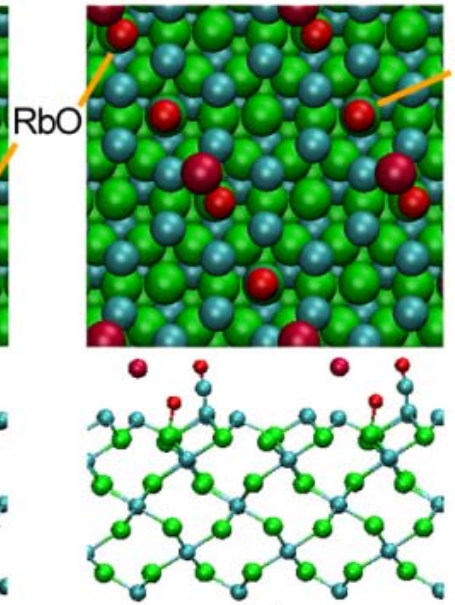

(e)
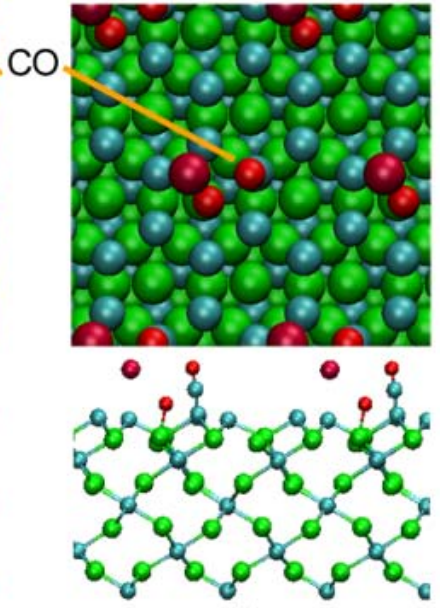

(f)

Figure 4.10 Top and side view of $\mathrm{CO}$ adsorption on Rb-modified reconstructed hexagonal $\mathrm{Mo}_{2} \mathrm{C}(001)$ surface: (a) no adsorbed $\mathrm{CO}$, (b) $\mathrm{CO}$ adsorbed on C-top sites, (c) $\mathrm{CO}$ adsorbed on Mo-top sites; and $\mathrm{CO}$ adsorption on Rb-modified reconstructed hexagonal $\mathrm{Mo}_{2} \mathrm{C}(001)$ surface: (d) no adsorbed CO, (e) CO adsorbed on C-top sites, (f) $\mathrm{CO}$-adsorbed on Mo-top sites. Mo, C, O and Rb atoms are shown as green, cyan, red and purple spheres, respectively. 
Table 4.4 DFT-simulated CO adsorption on modified re-constructed $\mathrm{Mo}_{2} \mathrm{C}(001)$ surface

\begin{tabular}{|c|c|c|c|c|c|}
\hline \multirow[b]{2}{*}{ Surface } & \multirow{2}{*}{$\begin{array}{c}\text { CO } \\
\text { coverage } \\
(\mathrm{ML})\end{array}$} & \multicolumn{2}{|c|}{ C-top site } & \multicolumn{2}{|c|}{ Mo-top site } \\
\hline & & $\begin{array}{c}\text { Wavenumber } \\
\left(\mathrm{cm}^{-1}\right)\end{array}$ & $\begin{array}{l}\text { Adsorption } \\
\text { energy }(\mathrm{eV})\end{array}$ & $\begin{array}{c}\text { Wavenumber } \\
\left(\mathrm{cm}^{-1}\right)\end{array}$ & $\begin{array}{l}\text { Adsorption } \\
\text { energy }(\mathrm{eV})\end{array}$ \\
\hline Rb-modified & 0.0625 & 2088 & 1.41 & 1942 & 1.70 \\
\hline RbO-modified & 0.0625 & 2086 & 1.53 & 1942 & 1.72 \\
\hline
\end{tabular}

Bugyi and Solymosi studied the interaction of CO with clean and K-covered $\mathrm{Mo}_{2} \mathrm{C} / \mathrm{Mo}(100)$ surfaces by HREELS [77]. They found that CO adsorbed molecularly on the clean $\mathrm{Mo}_{2} \mathrm{C} / \mathrm{Mo}(100)$ surface at $140 \mathrm{~K}$, giving an energy loss at $2100 \mathrm{~cm}^{-1}$. Preadsorbed $\mathrm{K}$ atoms at intermediate coverages (0.5-0.8 monolayer) at $140 \mathrm{~K}$ led to an HREELS feature for CO at $1320-1375 \mathrm{~cm}^{-1}$, attributed to a short-range interaction, while the development of features at $1670-1685$ and $1860 \mathrm{~cm}^{-1}$ was attributed to long-range interaction in the $\mathrm{K}-\mathrm{CO}$ co-adsorbed layer $[78,79]$. They also suggested that $\mathrm{K}$ atoms were stabilized mainly by $\mathrm{O}$ atoms arising from the decomposition of $\mathrm{CO}$.

Indeed, given the high oxophilicity of both $\mathrm{Mo}_{2} \mathrm{C}$ and atomic $\mathrm{Rb}$, neither bare $\mathrm{Rb}$ atoms nor oxygen-free $\mathrm{Mo}_{2} \mathrm{C}$ surface can likely exist in syngas reaction conditions. Comparing the observed vibrational frequencies of $\mathrm{CO}$ adsorbed on Rb-promoted $\mathrm{Mo}_{2} \mathrm{C} / \mathrm{Al}_{2} \mathrm{O}_{3}$ at the surface science results for $\mathrm{CO}$ adsorbed on K-modified molybdenum carbide surfaces [77] at relatively low CO coverages, a similar trend is found in the shifts of peaks caused by the addition of alkali metal species. However, the shift in position is about $-200 \mathrm{~cm}^{-1}$ from Rb-free $\mathrm{Mo}_{2} \mathrm{C} / \mathrm{Al}_{2} \mathrm{O}_{3}$ to 10 wt.\% Rb-promoted $\mathrm{Mo}_{2} \mathrm{C} / \mathrm{Al}_{2} \mathrm{O}_{3}$, which is much less than the approximately $-700 \mathrm{~cm}^{-1}$ shift observed on a K-modified $\mathrm{Mo}_{2} \mathrm{C} / \mathrm{Mo}(100)$ surface from a corresponding K-free surface [77]. This implies that the interaction of $\mathrm{CO}$ with cluster of molybdenum carbide was much less influenced by promoter compared to that of the extended surface in ultra high vacuum. 
In summary, the shifts in CO band position in Figure 4.9 may indicate a change of preferred binding site for CO molecules from C-top to Mo-top, as suggested by DFT calculations (Table 4.4 and Table 4.5), or a coverage-dependent asymmetric $\mathrm{C}-\mathrm{O}$ stretching frequency of CCO species formed on the carbide surface [67]. Additionally, the shift could also result from CO moving from a linearly adsorbed configuration to a bridge-bonded one [72]. The low frequency tail of the CO band on unpromoted $\mathrm{Mo}_{2} \mathrm{C} / \mathrm{Al}_{2} \mathrm{O}_{3}$ (Figure 4.7, Figure 4.9a) extends to the region around $1900 \mathrm{~cm}^{-1}$, which is the position of $\mathrm{CO}$ on the highly promoted $\mathrm{Mo}_{2} \mathrm{C}_{/} \mathrm{Al}_{2} \mathrm{O}_{3}$. Therefore, addition of the $\mathrm{Rb}$ promoter may simply deactivate the sites for $\mathrm{CO}$ adsorption at wavenumbers higher than $2000 \mathrm{~cm}^{-1}$, leaving behind only sites with the lower characteristic frequencies. Unfortunately, at this point in time a more definitive explanation of the observed shifts in the spectrum of adsorbed CO cannot be provided.

\subsubsection{Reactivity of $\mathrm{Mo}_{2} \mathrm{C} / \mathrm{Al}_{2} \mathrm{O}_{3}$ catalysts}

The performance of alumina-supported $\mathrm{Mo}_{2} \mathrm{C}$ catalysts in the reaction of syngas $\left(\mathrm{H}_{2} / \mathrm{CO}=1\right)$ at $573 \mathrm{~K}$ and 30 bar pressure is summarized in Figure 4.5. Unpromoted $2 \mathrm{wt} . \%$ $\mathrm{Mo}_{2} \mathrm{C} / \mathrm{Al}_{2} \mathrm{O}_{3}$ functions primarily as an active Fischer-Tropsch catalyst producing mainly hydrocarbons (91\% on a $\mathrm{CO}_{2}$-free basis) at $17 \% \mathrm{CO}$ conversion. A significant amount of ethers was also observed over the unpromoted catalyst, but the amounts were substantially reduced at high loadings of the $\mathrm{Rb}$ promoter. The formation of ethers suggests that alcohols are primary products on unpromoted $\mathrm{Mo}_{2} \mathrm{C}$ catalysts, but they are further converted to ethers on the acid sites of the $\gamma-\mathrm{Al}_{2} \mathrm{O}_{3}$ portion of the support. This result is consistent with our previous observation concerning the intrinsic alcohol formation activity of unpromoted, non-passivated $\mathrm{Mo}_{2} \mathrm{C} / \alpha-\mathrm{Al}_{2} \mathrm{O}_{3}$, which is comparable to 
the rate of alcohol formation over a 1.5 wt.\% $\mathrm{Rb}-5$ wt. $\% \mathrm{Mo}_{2} \mathrm{C} / \alpha-\mathrm{Al}_{2} \mathrm{O}_{3}$ [25]. The addition of 2, 5, 7.5 or 10 wt. $\% \mathrm{Rb}_{2} \mathrm{CO}_{3}$ to 2 wt. $\% \mathrm{Mo}_{2} \mathrm{C} / \mathrm{Al}_{2} \mathrm{O}_{3}$ increased the selectivity to alcohols $(12 \%, 50 \%, 62 \%$ or $67 \%$, respectively) at the expense of overall CO conversion (down to $4.9 \%$ at the highest promoter loading), which is also consistent with our previous study on $\mathrm{Rb}$-promoted $\mathrm{Mo}_{2} \mathrm{C} / \mathrm{MgO}$ catalysts [23], and with prior works on potassium-promoted bulk $\mathrm{Mo}_{2} \mathrm{C}$ catalysts $[21,22,80]$. The alcohol production rate peaked at $0.25 \mathrm{~g} \mathrm{~g}_{\mathrm{Mo}}^{-1} \mathrm{~h}^{-1}$ when the Rb loading was $7.5 \mathrm{wt} . \%$ and slightly decreased to 0.24 $\mathrm{g} \mathrm{g}_{\mathrm{Mo}}^{-1} \mathrm{~h}^{-1}$ on a 10 wt.\% $\mathrm{Rb}-2$ wt.\% $\mathrm{Mo}_{2} \mathrm{C} / \mathrm{Al}_{2} \mathrm{O}_{3}$ catalyst. With the addition of $\mathrm{Rb}$ promoter, the shift of performance of the $\mathrm{Mo}_{2} \mathrm{C} / \mathrm{Al}_{2} \mathrm{O}_{3}$ catalysts in $\mathrm{CO}$ hydrogenation from hydrocarbons to alcohols also correlates well to the red shift of the IR band of adsorbed $\mathrm{CO}$ (Figure 4.9). It should be noted that in our previous studies of $\mathrm{Mo}_{2} \mathrm{C}$ supported on $\mathrm{MgO}$ [23] or $\alpha-\mathrm{Al}_{2} \mathrm{O}_{3}$ [25], we did not report ethers in the product stream since they were present in very small amounts relative to $\mathrm{Mo}_{2} \mathrm{C}$ on alumina containing the $\gamma$-phase. No conversion of $\mathrm{CO}$ was observed over a mixture of $\mathrm{Rb}_{2} \mathrm{CO}_{3}$ and $\mathrm{Al}_{2} \mathrm{O}_{3}$ under typical reaction conditions, which proves that molybdenum is associated with the active site.

Given that passivated carbides are also known to possess surface acid sites after exposure to dioxygen [81-86], one interaction between $\mathrm{Rb}_{2} \mathrm{CO}_{3}$ promoter and $\mathrm{Mo}_{2} \mathrm{C} / \mathrm{Al}_{2} \mathrm{O}_{3}$ catalysts is to neutralize the acid sites on the carbide component and $\mathrm{Al}_{2} \mathrm{O}_{3}$ support, resulting in an increasing selectivity towards alcohols and decreasing selectivity towards hydrocarbons and ethers. 
Table 4.5 Reactivity of 2 wt. $\% \mathrm{Mo}_{2} \mathrm{C} / \mathrm{Al}_{2} \mathrm{O}_{3}$ catalysts in syngas reaction

\begin{tabular}{|c|c|c|c|c|c|}
\hline Rb loading (wt.\%) & 0 & 2.0 & 5.0 & 7.5 & 10 \\
\hline CO conversion (\%) & 19 & 9.1 & 5.4 & 5.2 & 4.9 \\
\hline $\mathrm{CO}_{2}$ selectivity (\%) & 39 & 37 & 44 & 40 & 41 \\
\hline \multicolumn{6}{|l|}{ Selectivity (C \%, on a $\mathrm{CO}_{2}$-free basis) } \\
\hline Total hydrocarbons & 75 & 45 & 35 & 30 & 27 \\
\hline Methane & 27 & 20 & 16 & 13 & 12 \\
\hline C2 hydrocarbons & 26 & 12 & 7.5 & 6.9 & 7.0 \\
\hline C3 hydrocarbons & 16 & 8.2 & 6.5 & 5.1 & 4.3 \\
\hline C4+ linear paraffins & 5.5 & 3.8 & 1.8 & 1.6 & 0.86 \\
\hline C4+ linear olefins & 0.19 & 0.76 & 1.8 & 2.1 & 2.2 \\
\hline Branched hydrocarbons & 3.1 & 0.89 & 1.0 & 1.2 & 0.66 \\
\hline Total ethers ${ }^{a}$ & 22 & 43 & 15 & 7.7 & 6.6 \\
\hline Total alcohols & 3.2 & 12 & 50 & 62 & 67 \\
\hline Methanol & 3.0 & 7.4 & 23 & 23 & 18 \\
\hline Ethanol & 0.24 & 3.1 & 12 & 15 & 18 \\
\hline 1-Propanol & 0.0 & 1.3 & 12 & 18 & 23 \\
\hline 1-Butanol & 0.0 & 0.0 & 2.5 & 4.3 & 5.0 \\
\hline C5+ alcohols & 0.0 & 0.0 & 1.1 & 2.8 & 2.6 \\
\hline (C2+ alcohols)/methanol & 0.08 & 0.59 & 1.2 & 1.6 & 2.7 \\
\hline Rate of $\mathrm{CO}$ consumption $\left(\mathrm{mol}_{\mathrm{CO}} \mathrm{mol}_{\mathrm{Mo}}^{-1} \mathrm{~h}^{-1}\right)$ & 9.3 & 4.5 & 2.7 & 2.6 & 2.5 \\
\hline Rate of hydrocarbon production $\left(\mathrm{g} \mathrm{g}_{\mathrm{Mo}}^{-1} \mathrm{~h}^{-1}\right)$ & 0.67 & 0.21 & 0.085 & 0.074 & 0.062 \\
\hline Rate of ether production $\left(\mathrm{g} \mathrm{g}_{\mathrm{Mo}_{0}}^{-1} \mathrm{~h}^{-1}\right)$ & 0.30 & 0.28 & 0.046 & 0.023 & 0.018 \\
\hline Rate of alcohol production $\left(\mathrm{g} \mathrm{g}_{\mathrm{Mo}}^{-1} \mathrm{~h}^{-1}\right)$ & 0.06 & 0.10 & 0.21 & 0.25 & 0.24 \\
\hline
\end{tabular}

$\mathrm{T}=573 \mathrm{~K}, \mathrm{P}=30 \mathrm{bar}, \mathrm{H}_{2} / \mathrm{CO}=1$, syngas flow rate $=24,000 \mathrm{~cm}^{3} \mathrm{~g}_{\mathrm{Mo}}^{-1} \mathrm{~h}^{-1}$. Data were recorded after $72 \mathrm{~h}$ reaction. ${ }^{\mathrm{a}}$ Including dimethyl ether, ethyl methyl ether, methyl propyl ether, butyl methyl ether, etc.

\subsubsection{Influence of $\mathrm{H}_{2} \mathrm{O}$ on Rb-promoted $\mathrm{Mo}_{2} \mathrm{C} / \mathrm{Al}_{2} \mathrm{O}_{3}$}

Since the movement of $\mathrm{Rb}$ promoter across the catalyst surface is critical to achieve selective alcohol formation, we studied the role of water on activation of the catalyst.

The IR spectra of adsorbed $\mathrm{CO}$ on 2 wt.\% $\mathrm{Mo}_{2} \mathrm{C} / \mathrm{Al}_{2} \mathrm{O}_{3}$ (Figure 4.11) and 7.5 wt.\% $\mathrm{Rb}-2$ wt.\% $\mathrm{Mo}_{2} \mathrm{C} / \mathrm{Al}_{2} \mathrm{O}_{3}$ (Figure 4.12) catalysts were recorded after various pretreatment conditions. Water was introduced to the catalyst by flowing He to the DRIFTS cell 
through a saturator with liquid water at room temperature. Likewise the rates of production of various molecules (hydrocarbons, ethers, alcohols and total oxygenates) over 7.5 wt.\% $\mathrm{Rb}-2$ wt.\% $\mathrm{Mo}_{2} \mathrm{C} / \mathrm{Al}_{2} \mathrm{O}_{3}$ catalysts, with and without water pretreatment, are summarized in Figure 4.13.

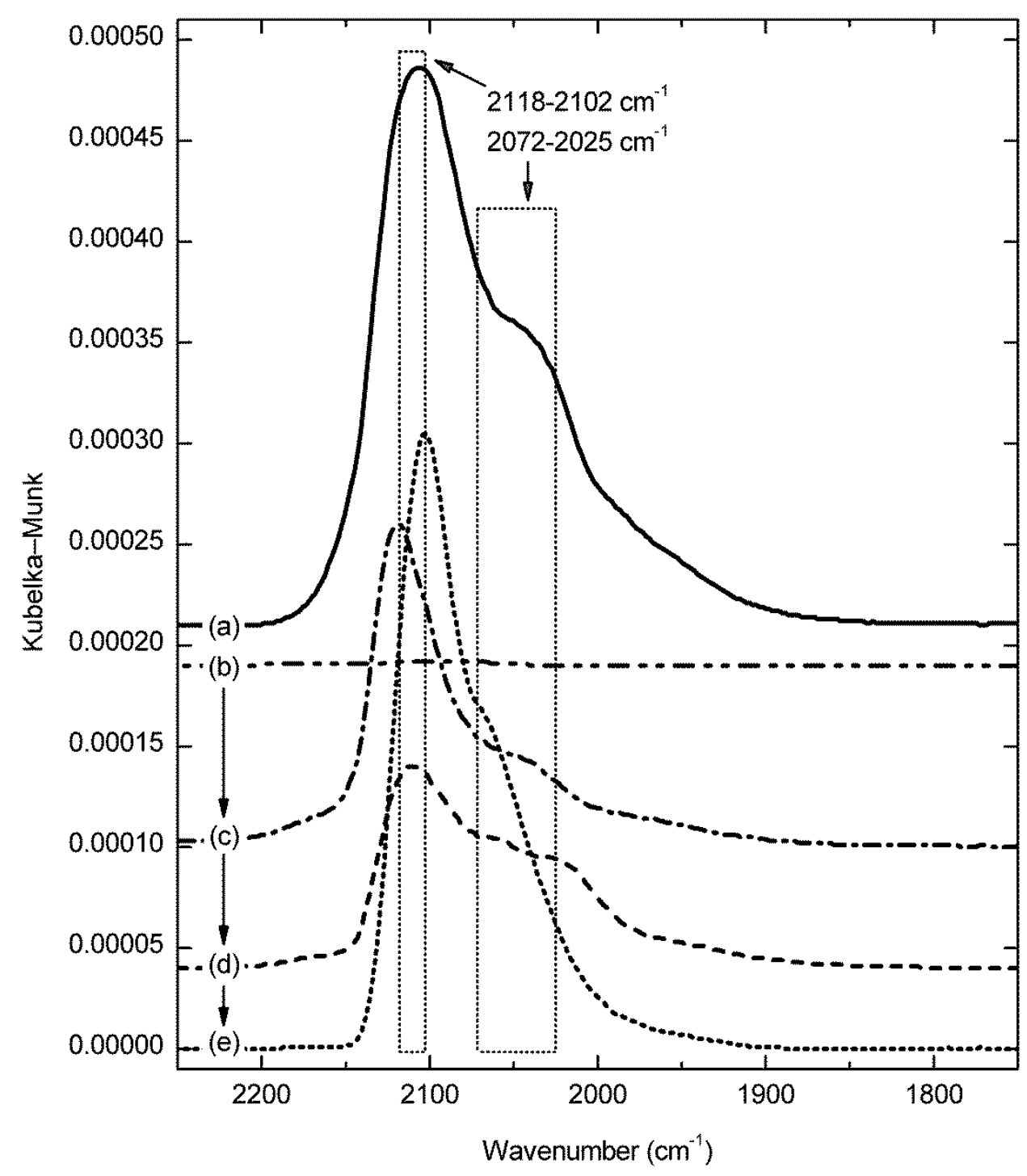

Figure 4.11 Influence of pretreatment conditions on the IR bands of adsorbed CO on 2 wt. $\% \mathrm{Mo}_{2} \mathrm{C} / \mathrm{Al}_{2} \mathrm{O}_{3}$ with various pretreatment conditions, with (b) - (e) sequentially performed on a separate sample from (a): (a) 1 bar $\mathrm{H}_{2}$ at $573 \mathrm{~K}$ for $12 \mathrm{~h}$; (b) 1 bar $\mathrm{H}_{2} \mathrm{O} / \mathrm{He}$ at $300 \mathrm{~K}$ for $2 \mathrm{~h}$ and 1 bar He at $423 \mathrm{~K}$ for $1 \mathrm{~h}$; (c) 1 bar $\mathrm{H}_{2}$ at $573 \mathrm{~K}$ for $12 \mathrm{~h}$; (d) 30 bar syngas $\left(\mathrm{H}_{2} / \mathrm{CO}=1\right)$ for $12 \mathrm{~h}$ and in 1 bar $\mathrm{H}_{2}$ for $1 \mathrm{~h}$; (e) $1 \mathrm{bar}_{2}$ at $573 \mathrm{~K}$ for $12 \mathrm{~h}$. Spectra are offset for clarity. 


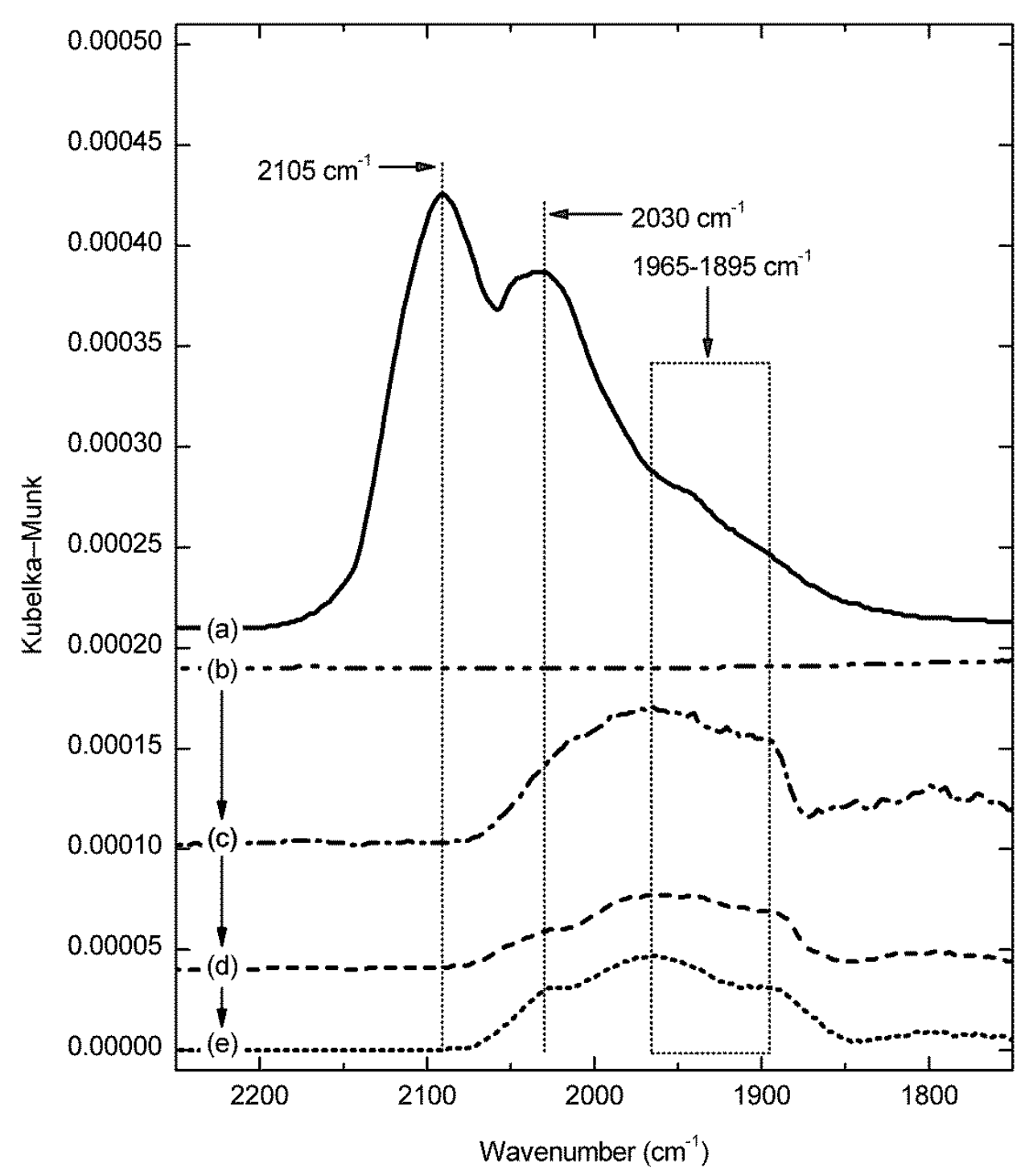

Figure 4.12 Influence of pretreatment conditions on the IR bands of adsorbed CO on 7.5 wt.\% Rb-2 wt.\% $\mathrm{Mo}_{2} \mathrm{C} / \mathrm{Al}_{2} \mathrm{O}_{3}$ with various pretreatment conditions, with (b) - (e) sequentially performed on a separate sample from (a): (a) 1 bar $\mathrm{H}_{2}$ at $573 \mathrm{~K}$ for $12 \mathrm{~h}$; (b) 1 bar $\mathrm{H}_{2} \mathrm{O} / \mathrm{He}$ at $300 \mathrm{~K}$ for $2 \mathrm{~h}$ and 1 bar He at $423 \mathrm{~K}$ for $1 \mathrm{~h}$; (c) 1 bar $\mathrm{H}_{2}$ at $573 \mathrm{~K}$ for 12

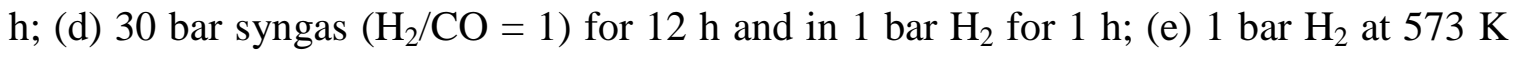
for $12 \mathrm{~h}$. Spectra are offset for clarity. 


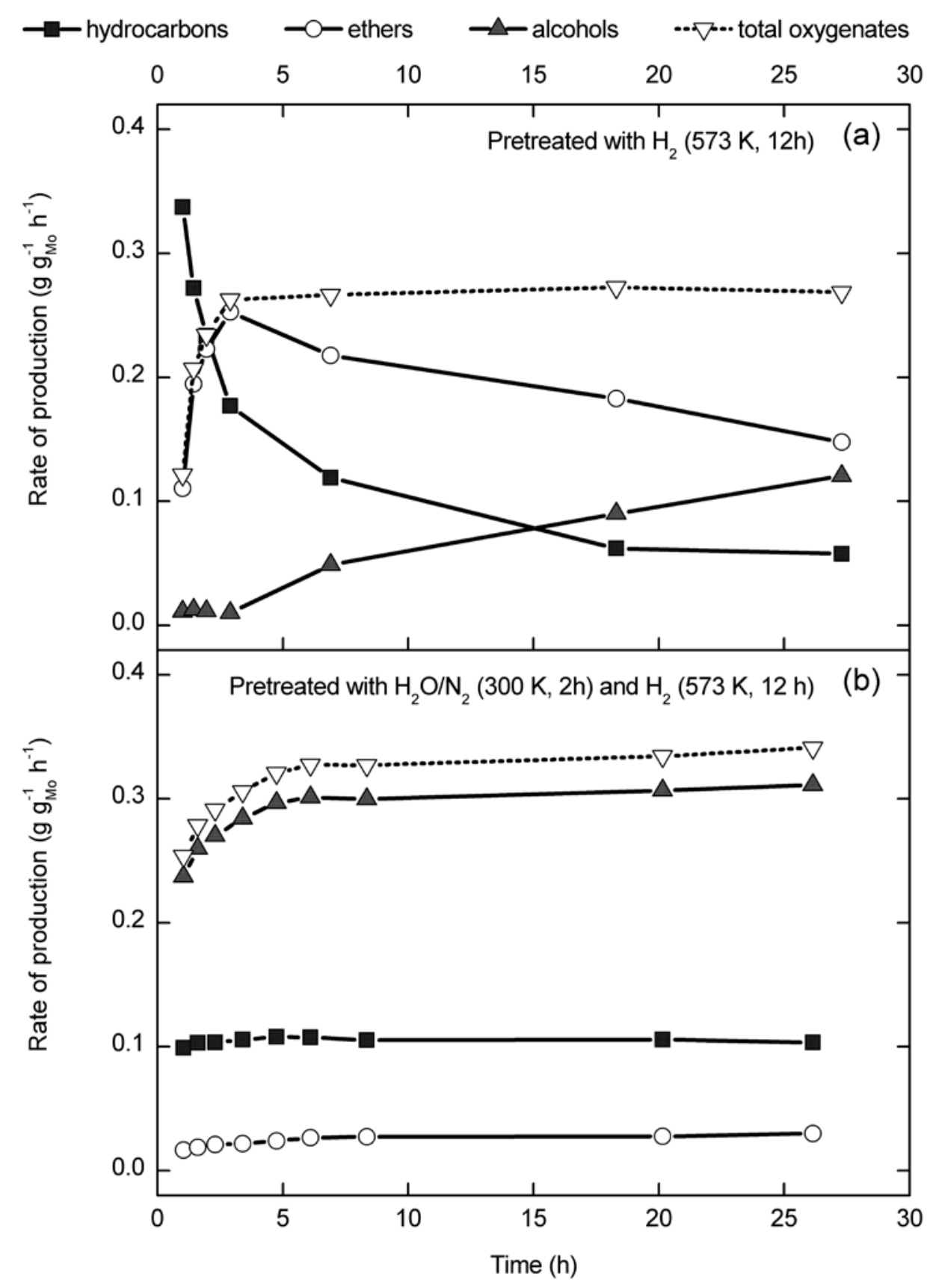

Figure 4.13 Change in the production rates of hydrocarbons (solid squares), ethers (open circles), alcohols (solid up triangles) and total oxygenates (open down triangles, alcohols and esters combined) over 7.5 wt.\% Rb-2 wt.\% $\mathrm{Mo}_{2} \mathrm{C} / \mathrm{Al}_{2} \mathrm{O}_{3}$ pretreated with: (a) 1 bar $\mathrm{H}_{2}$ at $573 \mathrm{~K}$ for $12 \mathrm{~h}$; (b) 1 bar $\mathrm{H}_{2} \mathrm{O} / \mathrm{N}_{2}$ at $300 \mathrm{~K}$ for $2 \mathrm{~h}$, followed with 1 bar $\mathrm{H}_{2}$ at $573 \mathrm{~K}$ for $12 \mathrm{~h}$.

Despite the different pretreatment conditions (water or no water), the unpromoted $\mathrm{Mo}_{2} \mathrm{C} / \mathrm{Al}_{2} \mathrm{O}_{3}$ catalyst always had a major band for adsorbed $\mathrm{CO}$ between $2118 \mathrm{~cm}^{-1}$ and $2102 \mathrm{~cm}^{-1}$ and a secondary peak/shoulder at 2072-2025 $\mathrm{cm}^{-1}$. The results suggest that, 
without promoter present, the influence of the water pretreatment was minimal and the catalyst will function primarily as a hydrocarbon formation catalyst, consistent with the known catalytic properties of unpromoted $\mathrm{Mo}_{2} \mathrm{C}$ in Table 4.3 and elsewhere [21-25,87]. With pretreatment in $\mathrm{H}_{2}$, the IR spectra of $\mathrm{CO}$ adsorbed on 7.5 wt.\% Rb-2 wt.\%

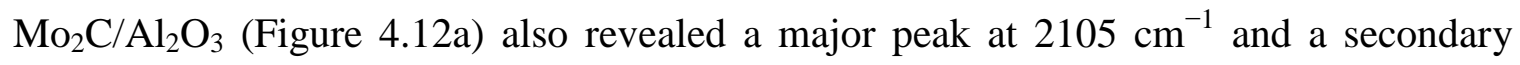
peak at $2030 \mathrm{~cm}^{-1}$. According to the observed correlation between IR peak position of adsorbed CO in Figure 4.9 and the product distribution reported in Table 4.3, this result would predict that hydrocarbons would be the initial products of CO hydrogenation over the $\mathrm{H}_{2}$-pretreated promoted $\mathrm{Mo}_{2} \mathrm{C}_{/} \mathrm{Al}_{2} \mathrm{O}_{3}$ catalyst. In fact, the initial rates of production over $\mathrm{H}_{2}$-pretreated 7.5 wt.\% Rb-2 wt.\% $\mathrm{Mo}_{2} \mathrm{C} / \mathrm{Al}_{2} \mathrm{O}_{3}$ catalyst (Figure 4.13a) are 0.34 for hydrocarbons and $0.011 \mathrm{~g} \mathrm{~g}_{\mathrm{Mo}}^{-1} \mathrm{~h}^{-1}$ for alcohols, which are comparable to the corresponding productivities over the unpromoted $\mathrm{Mo}_{2} \mathrm{C}_{/} \mathrm{Al}_{2} \mathrm{O}_{3}$ catalyst (Table 4.3). Therefore, pretreatment involving only $\mathrm{H}_{2}$ at reaction temperature does not efficiently disperse the Rb promoter across the catalyst. However, pretreatment with water vapor in flowing $\mathrm{He}$ at $300 \mathrm{~K}$ for $2 \mathrm{~h}$ before $\mathrm{H}_{2}$-treatment at $573 \mathrm{~K}$ (Figure 4.12c) completely removed the major IR peak of adsorbed $\mathrm{CO}$ on $7.5 \mathrm{wt} . \% \mathrm{Rb}-2 \mathrm{wt} \% \mathrm{Mo}_{2} \mathrm{C} / \mathrm{Al}_{2} \mathrm{O}_{3}$ at 2105 $\mathrm{cm}^{-1}$ and instead resulted in a band centered at $1965 \mathrm{~cm}^{-1}$ (Figure 4.12c), which suggests a strong interaction between the $\mathrm{Rb}$ promoter and the $\mathrm{Mo}_{2} \mathrm{C}$ catalyst. This peak position for adsorbed CO correlates well to the high alcohol productivity of the water-treated catalyst and very short induction period (Figure 4.13b). The IR band of adsorbed CO remained unchanged after syngas reaction and further treatment in $\mathrm{H}_{2}$ at $573 \mathrm{~K}$. Since the peak for adsorbed CO above $2100 \mathrm{~cm}^{-1}$ was not restored by additional treatment in $\mathrm{H}_{2}$, the interaction between the $\mathrm{Rb}$ promoter and the $\mathrm{Mo}_{2} \mathrm{C}$ catalysts that is facilitated by 
water is not reversible. These reactivity results coupled to IR spectroscopy clearly show how water plays a critical role in the distribution of the Rb promoter over the $\mathrm{Mo}_{2} \mathrm{C}$ clusters, and presumably over the alumina support as well. Since $\mathrm{H}_{2} \mathrm{O}$ is a product of $\mathrm{CO}$ hydrogenation, the in situ formation of water likely facilitates distribution of Rb during the reaction and likely accounts for the induction time observed in Figure 4.13a.

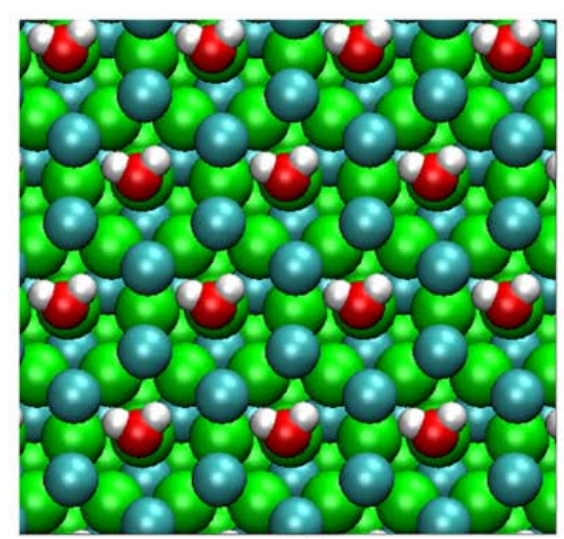

(a)

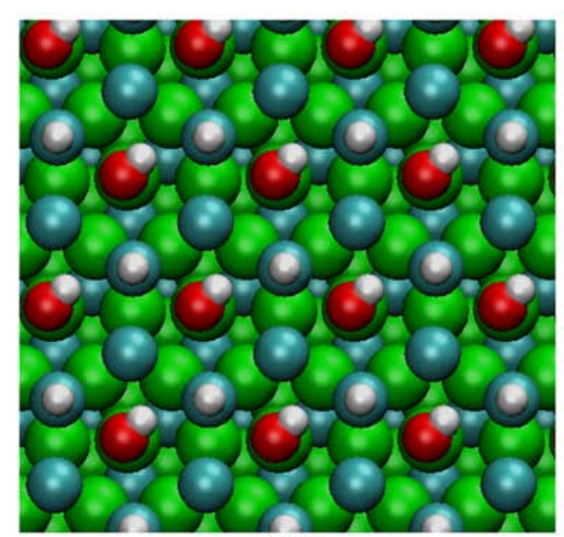

(b)

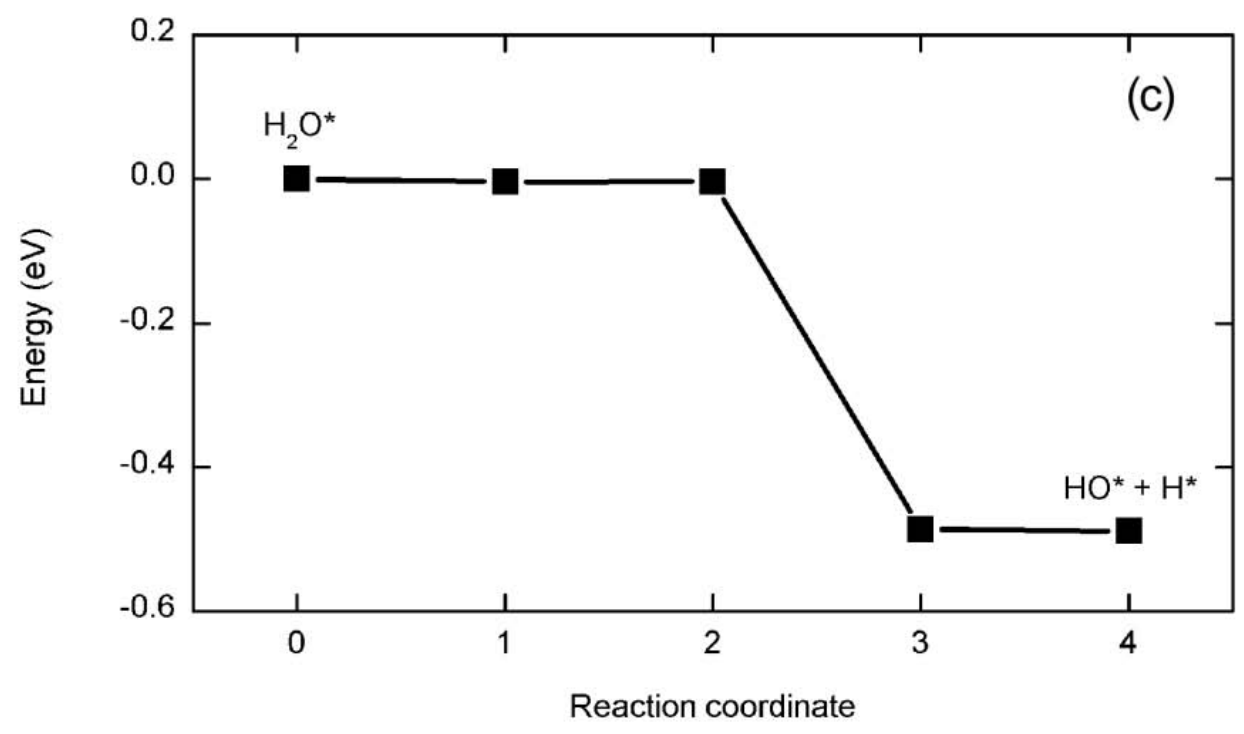

Figure 4.14 Schematic illustration of (a) $\mathrm{H}_{2} \mathrm{O}$ molecules absorbed on $\mathrm{Mo}_{2} \mathrm{C}$ surface; (b) $\mathrm{OH}$ groups and $\mathrm{H}$ atoms adsorbed on $\mathrm{Mo}_{2} \mathrm{C}$ surface after the dissociation of adsorbed $\mathrm{H}_{2} \mathrm{O}$; (c) the energy profile of $\mathrm{H}_{2} \mathrm{O}$ dissociation. $\mathrm{Mo}, \mathrm{C}, \mathrm{H}$ and $\mathrm{O}$ atoms are shown as green, cyan, white and red spheres, respectively. The energy of the initial state $\left(\mathrm{H}_{2} \mathrm{O}^{*}\right)$ is defined as zero. 
The shift of peak position observed in the IR bands of adsorbed CO on $\mathrm{Mo}_{2} \mathrm{C} / \mathrm{Al}_{2} \mathrm{O}_{3}$ with the addition of $\mathrm{Rb}$ promoter and the deviation of the $\mathrm{CO}$ feature on the unpromoted $\mathrm{Mo}_{2} \mathrm{C} / \mathrm{Al}_{2} \mathrm{O}_{3}$ catalyst in IR spectroscopy from that on freshly carburized $\mathrm{Mo}_{2} \mathrm{C} / \gamma-\mathrm{Al}_{2} \mathrm{O}_{3}[43,44]$ confirm that $\mathrm{Mo}_{2} \mathrm{C}$ surfaces are modified by surface passivation, promoter impregnation and syngas reaction.

According to our DFT calculations, $\mathrm{H}_{2} \mathrm{O}$ can easily dissociate to form hydroxyl $(\mathrm{OH})$ groups on the $\mathrm{Mo}_{2} \mathrm{C}$ surface with no energy barrier (Figure 4.14), which is consistent with the findings by Tominaga and Nagai [69]. Additionally, Chia et al. used DFT to show that hydroxyl groups on oxophilic molybdenum atoms associated with platinum clusters are acidic in nature [88]. Since interstitial carbide is known to modify the $\mathrm{d}$ band of molybdenum metal so that carbides exhibit some similar catalytic properties to platinum [27,89], strongly adsorbed hydroxyl groups on molybdenum associated with molybdenum carbide may also be fairly acidic. According to the correlation between the deprotonation energy of surface hydroxyl groups and the corresponding oxygen binding energy reported by Chia et al., a strong metal-oxygen bond weakens the $\mathrm{O}-\mathrm{H}$ bond, which imparts strong acidity to the surface $\mathrm{OH}$ group [86]. In accordance with the DFT correlation by Chia et al., $\mathrm{OH}$ groups with deprotonation energies typical of strong acids have oxygen binding energies greater than $5 \mathrm{eV}$. The calculated oxygen binding energy on the surface of $\mathrm{Mo}_{2} \mathrm{C}$ is $-7.37 \mathrm{eV}$, which suggests that a surface hydroxyl group on $\mathrm{Mo}_{2} \mathrm{C}$ will be strongly acidic. Thus, alkali metal promoters are needed to neutralize the acidic hydroxyl groups on passivated $\mathrm{Mo}_{2} \mathrm{C}$ catalysts. In fact, Lee et al. studied the performance of multiple potassium-based promoters on bulk $\mathrm{Mo}_{2} \mathrm{C}$ catalysts in $\mathrm{CO}$ hydrogenation [32]. Auger electron 
spectroscopy revealed that the K promoters that enhanced the selectivity towards alcohols $\left(\mathrm{K}_{2} \mathrm{CO}_{3}, \mathrm{KOH}, \mathrm{CH}_{3} \mathrm{COOK}\right.$ and $\mathrm{K}_{2} \mathrm{~S}$ ) distributed over the $\mathrm{Mo}_{2} \mathrm{C}$ surface fairly evenly after syngas reaction, while those did not possess great mobility over the $\mathrm{Mo}_{2} \mathrm{C}$ surface $(\mathrm{KCl}$ and $\mathrm{K}_{2} \mathrm{SO}_{4}$ ) did not substantially increase alcohol selectivity [32]. The difference in the mobility of the various potassium compounds in light of the neutralization reaction between the surface acidic groups on $\mathrm{Mo}_{2} \mathrm{C}$ and the alkali metal salts. Clearly, the effective $\mathrm{K}$ promoters $\left(\mathrm{K}_{2} \mathrm{CO}_{3}, \mathrm{KOH}, \mathrm{CH}_{3} \mathrm{COOK}\right.$ and $\left.\mathrm{K}_{2} \mathrm{~S}\right)$ are the salts of weak acids that can neutralize the surface acidity over $\mathrm{Mo}_{2} \mathrm{C}$, whereas the ineffective promoters are the salts of strong acids. A neutralization mechanism was also hypothesized by Tatsumi et al. to interpret how $\mathrm{K}$ promoter interacts with $\mathrm{MoS}_{2}$ catalysts during alcohol synthesis from syngas [90].

\subsubsection{Model of catalyst evolution}

A working model of the surface of $\mathrm{Mo}_{2} \mathrm{C}$ catalysts for $\mathrm{CO}$ hydrogenation is sketched in Figure 4.15. In the model, the carbide surface is firstly covered by oxygen atoms after surface passivation. Water in the ambient air and formed in situ during syngas reaction can dissociate on the carbide surface to form acidic hydroxyl groups, which are detrimental to alcohol selectivity. Addition of $\mathrm{Rb}_{2} \mathrm{CO}_{3}$ is needed to both neutralize surface acidity on $\mathrm{Mo}_{2} \mathrm{C}$ and $\mathrm{Al}_{2} \mathrm{O}_{3}$ and inhibit hydrocarbon formation on $\mathrm{Mo}_{2} \mathrm{C}$. However, water that is added to the catalyst or generated in situ during CO hydrogenation is needed to distribute the $\mathrm{Rb}$ promoter across the catalyst surface. Exposure of the passivated catalysts to the syngas environment partially reduces the passivated carbide to create an active catalyst. The highly promoted catalyst has $\mathrm{Rb}$ on the carbide phase, 
which perturbed the adsorption mode of CO on the surface and shifted product selectivity from hydrocarbons to alcohols.

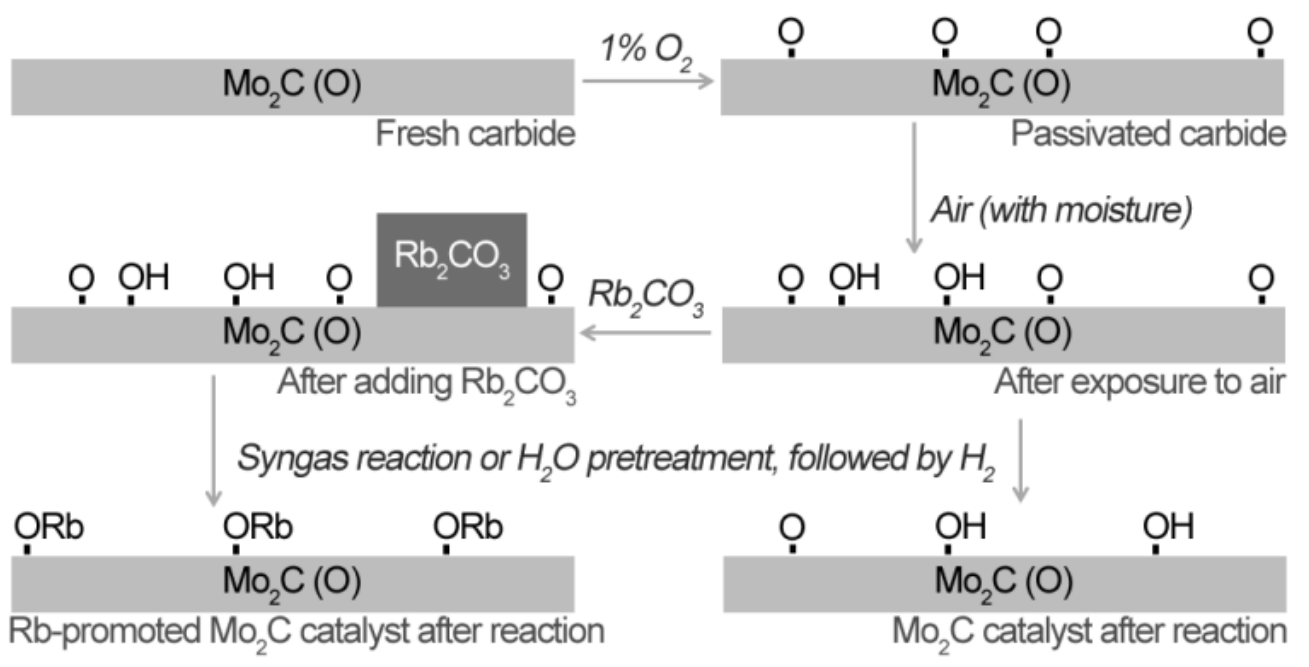

Figure 4.15 Working model of the modified $\mathrm{Mo}_{2} \mathrm{C}$ surfaces for $\mathrm{CO}$ hydrogenation

\subsection{Conclusions}

An unpromoted sample of $\mathrm{Mo}_{2} \mathrm{C} / \mathrm{Al}_{2} \mathrm{O}_{3}$ was active in the Fischer-Tropsch reaction and produced mostly hydrocarbons from syngas at $573 \mathrm{~K}$ and 30 bar. Moreover, the IR spectrum of $\mathrm{CO}$ adsorbed on the unpromoted carbide catalyst revealed features at $2105 \mathrm{~cm}^{-1}$ and $2014 \mathrm{~cm}^{-1}$. The addition of $\mathrm{Rb}$ promoter to $\mathrm{Mo}_{2} \mathrm{C} / \mathrm{Al}_{2} \mathrm{O}_{3}$ gradually shifted the selectivity of the syngas reaction toward alcohols, primarily by inhibiting hydrocarbon and ether formation. The IR features of adsorbed $\mathrm{CO}$ on $\mathrm{Mo}_{2} \mathrm{C}$ nanoclusters shifted substantially to lower frequencies upon addition of $\mathrm{Rb}$ promoter $\left(\sim 200 \mathrm{~cm}^{-1}\right.$ shift from an unpromoted sample to a $10 \mathrm{wt} \% \mathrm{Rb}$-promoted sample). Results from DFT qualitatively reproduced the trends observed by IR spectroscopy and were used to interpret the various features. The interaction of the $\mathrm{Rb}$ promoter and the $\mathrm{Mo}_{2} \mathrm{C}$ catalyst was facilitated by $\mathrm{H}_{2} \mathrm{O}$ added during catalyst pretreatment, and presumably by in situ formation of $\mathrm{H}_{2} \mathrm{O}$ during syngas reaction. Results from reactivity studies, IR 
spectroscopy and DFT were used to derive a model of catalyst evolution during synthesis, pretreatment and reaction.

\subsection{Acknowledgements}

The authors acknowledge financial support from The Dow Chemical Company and helpful discussions with Dr. David Barton, Dr. Gerolamo Budroni and Dr. Billy Bardin at The Dow Chemical Company, and Dr. Christopher Jones, Dr. Pradeep Agrawal, Mr. Michael Morrill and Ms. Hiroko Okatsu at the Georgia Institute of Technology. The authors also acknowledge Dr. Brent Gunnoe, Mr. Jiajun Mei and Ms. Samantha Burgess at University of Virginia for the use of their glovebox for air-free sample preparation. Use of the NSLS was supported by the US Department of Energy, Office of Science, Office of Basic Energy Sciences, under Contract No. DE-AC02-98CH10886. Beamline $\mathrm{X} 18 \mathrm{~B}$ at the NSLS is supported in part by the Synchrotron Catalysis Consortium, US Department of Energy Grant No. DE-FG02-05ER15688. The authors acknowledge with gratitude the invaluable assistance received from the X-23A2 beam line personnel, Dr. Bruce Ravel, and the X-18B beam line personnel, Dr. Nebojsa Marinkovic and Dr. Syed Khalid.

\section{References of Chapter 4}

[1] V.J. Johnston, L. Chen, B.F. Kimmich, J.T. Chapman, J.H. Zink, "Direct and selective production of ethanol from acetic acid utilizing a platinum/tin catalyst,” U.S. Patent 7863489, 2011, to Celanese Corporation.

[2] V.J. Johnston, L. Chen, B.F. Kimmich, J.T. Chapman, J.H. Zink, "Direct and selective production of ethanol from acetic acid utilizing a platinum/tin catalyst," U.S. Patent 8071821, 2011, to Celanese Corporation.

[3] G. Hess, "BP and DuPont plan 'biobutanol'," Chemical \& Engineering News 84 (2006) 9 . 
[4] P. Forzatti, E. Tronconi, I. Pasquon, "Higher alcohol synthesis," Catalysis Reviews: Science Engineering 33 (1991) 109-168.

[5] I. Wender, "Reactions of synthesis gas," Fuel Processing Technology 48 (1996) 189-297.

[6] R.G. Herman, "Advances in catalytic synthesis and utilization of higher alcohols," Catalysis Today 55 (2000) 233-245.

[7] K. Fang, D. Li, M. Lin, M. Xiang, W. Wei, Y. Sun, "A short review of heterogeneous catalytic process for mixed alcohols synthesis via syngas," Catalysis Today 147 (2009) 133-138.

[8] S. Zaman, K.J. Smith, "A review of molybdenum catalysts for synthesis gas conversion to alcohols: Catalysts, mechanisms and kinetics," Catalysis Reviews: Science and Engineering 54 (2012) 41-132.

[9] J.J. Spivey, A. Egbebi, "Heterogeneous catalytic synthesis of ethanol from biomass-derived syngas," Chemical Society Reviews 36 (2007) 1514-1528.

[10] V. Subramani, S.K. Gangwal, "A review of recent literature to search for an efficient catalytic process for the conversion of syngas to ethanol," Energy and Fuels 22 (2008) 814-839.

[11] M.A. Haider, M.R. Gogate, R.J. Davis, "Fe-promotion of supported Rh catalysts for direct conversion of syngas to ethanol,” Journal of Catalysis 261 (2009) 9-16.

[12] Y. Avila, C. Kappenstein, S. Pronier, J. Barrault, "Alcohol synthesis from syngas over supported molybdenum catalysts,” Applied Catalysis A: General 132 (1995) 97-109.

[13] J.S. Lee, S. Kim, K.H. Lee, I.-S. Nam, J.S. Chung, Y.G. Kim, H.C. Woo, "Role of alkali promoters in $\mathrm{K} / \mathrm{MoS}_{2}$ catalysts for $\mathrm{CO}-\mathrm{H}_{2}$ reactions," Applied Catalysis A: General 110 (1994) 11-25.

[14] J.M. Christensen, P.M. Mortensen, R. Trane, P.A. Jensen, A.D. Jensen, "Effects of $\mathrm{H}_{2} \mathrm{~S}$ and process conditions in the synthesis of mixed alcohols from syngas over alkali promoted cobalt-molybdenum sulfide,” Applied Catalysis A: General 366 (2009) 29-43.

[15] V.R. Surisetty, A. Tavasoli, A.K. Dalai, "Synthesis of higher alcohols from syngas over alkali promoted $\mathrm{MoS}_{2}$ catalysts supported on multi-walled carbon nanotubes," Applied Catalysis A: General 365 (2009) 243-251.

[16] G.J. Quarderer, G.A. Cochran, "Catalytic process for producing mixed alcohols from hydrogen and carbon monoxide," European Patent EP0119609, 1984, to The Dow Chemical Company. 
[17] M.M. Conway, C.B. Murchison, R.R. Stevens, "Method for adjusting methanol to higher alcohol ratios," U.S. Patent 4675344, 1987, to The Dow Chemical Company.

[18] G.J. Quarderer, G.A. Cochran, "Process for producing alcohols from synthesis gas," U.S. Patent 4749724, 1988, to The Dow Chemical Company.

[19] R.R. Stevens, "Process for producing alcohols from synthesis gas," U.S. Patent 4752622, 1988, to The Dow Chemical Company.

[20] R.R. Stevens, "Process for producing alcohols from synthesis gas," U.S. Patent 4882360, 1989, to The Dow Chemical Company.

[21] H.C. Woo, K.Y. Park, Y.G. Kim, I.S. Nam, J.S. Chung, J.S. Lee, "Mixed alcohol synthesis from carbon monoxide and dihydrogen over potassium-promoted molybdenum carbide catalysts,” Applied Catalysis 75 (1991) 267-280.

[22] M. Xiang, D. Li, W. Li, B. Zhong, Y. Sun, "Performances of mixed alcohols synthesis over potassium promoted molybdenum carbides," Fuel 85 (2006) 26622665.

[23] H. Shou, R.J. Davis, "Reactivity and in situ X-ray absorption spectroscopy of Rbpromoted $\mathrm{Mo}_{2} \mathrm{C} / \mathrm{MgO}$ catalysts for higher alcohol synthesis," Journal of Catalysis 282 (2011) 83-93.

[24] J.M. Christensen, L.D.L. Duchstein, J.B. Wagner, P.A. Jensen, B. Temel, A.D. Jensen, "Catalytic conversion of syngas into higher alcohols over carbide catalysts,” Industrial \& Engineering Chemistry Research 51 (2012) 4161-4172.

[25] H. Shou, D. Ferrari, D.G. Barton, C.W. Jones, R.J. Davis, "Influence of Passivation on the Reactivity of Unpromoted and Rb-Promoted $\mathrm{Mo}_{2} \mathrm{C}$ Nanoparticles for $\mathrm{CO}$ Hydrogenation,” ACS Catalysis 2 (2012) 1408-1416.

[26] R.B. Levy, M. Boudart, "Platinum-like behavior of tungsten carbide in surface catalysis, Science 181 (1973) 547-549.

[27] J.G. Chen, "Carbide and nitride overlayers on early transition metal surfaces: Preparation, characterization, and reactivities," Chemical Reviews 96 (1996) 14771498.

[28] H.H. Hwu, J.G. Chen, "Surface chemistry of transition metal carbides," Chemical Reviews 105 (2005) 185-212.

[29] M. Jiang, G.-Z. Bian, Y.-L. Fu, "Effect of the K-Mo interaction in $\mathrm{K}-\mathrm{MoO}_{3} / \gamma$ $\mathrm{Al}_{2} \mathrm{O}_{3}$ catalysts on the properties for alcohol synthesis from syngas," Journal of Catalysis 146 (1994) 144-154. 
[30] G.-Z. Bian, Y.-L. Fu, M. Yamada, "Reaction stability and structure studies of sulfided $\mathrm{KMoO}_{3} / \gamma-\mathrm{Al}_{2} \mathrm{O}_{3}$ catalyst for the synthesis of mixed alcohols," Applied Catalysis A: General 144 (1996) 79-91.

[31] H.C. Woo, J.C. Kim, I.S. Nam, J.S. Lee, J.S. Chung, Y.G. Kim, "Surface species on the oxidized $\mathrm{K}_{2} \mathrm{CO}_{3} / \mathrm{MoS}_{2}$ and their effects on catalytic carbon monoxide hydrogenation,” Applied Catalysis A: General 104 (1993) 199-214.

[32] J.S. Lee, S. Kim, Y.G. Kim, "Electronic and geometric effects of alkali promoters in CO hydrogenation over K/Mo $\mathrm{Mo}_{2} \mathrm{C}$ catalysts,” Topics in Catalysis 2 (1995) 127140.

[33] N. Koizumi, G. Bian, K. Murai, T. Ozaki, M. Yamada, “In situ DRIFT studies of sulfided $\mathrm{K}-\mathrm{Mo} / \gamma-\mathrm{Al}_{2} \mathrm{O}_{3}$ catalysts," Journal of Molecular Catalysis A: Chemical 207 (2004) 173-182.

[34] A. Muramatsu, T. Tatsumi, H. Tominaga, "Mixed alcohol synthesis from $\mathrm{CO}-\mathrm{H}_{2}$ by use of KCl-promoted $\mathrm{Mo} / \mathrm{SiO}_{2}$ catalysts," Bulletin of the Chemical Society of Japan 60 (1987) 3157-3161.

[35] N.F.D. Verbruggen, G. Mestl, L.M.J. von Hippel, B. Lengeler, H. Knoezinger, "Structure of K-doped molybdena-on-alumina catalysts as studied by X-ray absorption and Raman spectroscopy,” Langmuir 10 (1994) 3063-3072.

[36] N.F.D. Verbruggen, L.M.J. von Hippel, G. Mestl, B. Lengeler, H. Knoezinger, "Structure of K-doped molybdena-on-silica catalysts as studied by X-ray absorption and Raman spectroscopy,” Langmuir 10 (1994) 3073-3080.

[37] Y. Fu, F. Zhao, "The adsorption characteristics of two Mo sites on a sulfided $\mathrm{MoO}_{3} / \gamma-\mathrm{Al}_{2} \mathrm{O}_{3}$ surface," Catalysis Letters 12 (1992) 117-125.

[38] F. Maugé, J.C. Lavalley, "FT-IR study of CO adsorption on sulfided $\mathrm{Mo} / \mathrm{Al}_{2} \mathrm{O}_{3}$ unpromoted or promoted by metal carbonyls: Titration of sites," Journal of Catalysis 137 (1992) 69-76.

[39] B. Müller, A.D. van Langeveld, J.A. Moulijn, H. Knözinger, “Characterization of sulfided molybdenum/alumina catalysts by temperature-programmed reduction and low-temperature Fourier transform infrared spectroscopy of adsorbed carbon monoxide,” The Journal of Physical Chemistry 97 (1993) 9028-9033.

[40] A. Travert, C. Dujardin, F. Maugé, S. Cristol, J.F. Paul, E. Payen, D. Bougeard, "Parallel between infrared characterisation and ab initio calculations of CO adsorption on sulphided Mo catalysts,” Catalysis Today 70 (2001) 255-269.

[41] A.A. Tsyganenko, F. Can, A. Travert, F. Maugé, "FTIR study of unsupported molybdenum sulfide-in situ synthesis and surface properties characterization,” Applied Catalysis A: General 268 (2004) 189-197. 
[42] A. Travert, C. Dujardin, F. Maugé, E. Veilly, S. Cristol, J.-F. Paul, E. Payen, “CO adsorption on CoMo and NiMo sulfide catalysts: A combined IR and DFT study," The Journal Physical Chemistry B 110 (2006) 1261-1270.

[43] W. Wu, Z. Wu, C. Liang, X. Chen, P. Ying, C. Li, "In Situ FT-IR spectroscopic studies of $\mathrm{CO}$ adsorption on fresh $\mathrm{Mo}_{2} \mathrm{C} / \mathrm{Al}_{2} \mathrm{O}_{3}$ catalyst," The Journal Physical Chemistry B 107 (2003) 7088-7094.

[44] W. Wu, Z. Wu, C. Liang, P. Ying, Z. Feng, C. Li, “An IR study on the surface passivation of $\mathrm{Mo}_{2} \mathrm{C} / \mathrm{Al}_{2} \mathrm{O}_{3}$ catalyst with $\mathrm{O}_{2}, \mathrm{H}_{2} \mathrm{O}$ and $\mathrm{CO}_{2}$," Physical Chemistry Chemical Physics 6 (2004) 5603-5608.

[45] J. Wang, M. Castonguay, P.H. McBreen, S. Ramanathan, S.T. Oyama, "Chemisorption of CO and NO molybdenum carbide foils,” in: S.T. Oyama (Ed.), The Chemistry of Transition Metal Carbides and Nitrides, Springer, 1996: pp. 426438.

[46] P.A. Aegerter, W.W.C. Quigley, G.J. Simpson, D.D. Ziegler, J.W. Logan, K.R. McCrea, S. Glazier, M.E. Bussell, “Thiophene hydrodesulfurization over aluminasupported molybdenum carbide and nitride catalysts: Adsorption sites, catalytic activities, and nature of the active surface,” Journal of Catalysis 164 (1996) 109121.

[47] J. Raskó, J. Kiss, "Infrared study of the adsorption of $\mathrm{CO}$ and $\mathrm{CH}_{3}$ on silicasupported $\mathrm{MoO}_{3}$ and $\mathrm{Mo}_{2} \mathrm{C}$ catalysts,” Applied Catalysis A: General 253 (2003) 427-436.

[48] B. Ravel, M. Newville, “ATHENA, ARTEMIS, HEPHAESTUS: Data analysis for X-ray absorption spectroscopy using IFEFFIT,” Journal of Synchrotron Radiation 12 (2005) 537-541.

[49] S.I. Zabinsky, J.J. Rehr, A. Ankudinov, R.C. Albers, M.J. Eller, "Multiplescattering calculations of x-ray-absorption spectra,” Physical Review B 52 (1995) 2995-3009.

[50] J.P. Perdew, K. Burke, M. Ernzerhof, “Generalized gradient approximation made simple,” Physical Review Letters 77 (1996) 3865-3868.

[51] J.P. Perdew, K. Burke, M. Ernzerhof, “Generalized gradient approximation made simple,” Physical Review Letters 78 (1997) 1396.

[52] P.E. Blöchl, "Projector augmented-wave method," Physical Review B 50 (1994) 17953-17979.

[53] G. Kresse, D. Joubert, "From ultrasoft pseudopotentials to the projector augmentedwave method,” Physical Review B 59 (1999) 1758-1775. 
[54] J.W. Han, L. Li, D.S. Sholl, "Density functional theory study of $\mathrm{H}$ and CO adsorption on alkali-promoted $\mathrm{Mo}_{2} \mathrm{C}$ surfaces," The Journal Physical Chemistry C 115 (2011) 6870-6876.

[55] R.-L. Lo, K. Fukui, S. Otani, Y. Iwasawa, "High resolution images of $\mathrm{Mo}_{2} \mathrm{C}(0001)-$ $(3 \times 3) \mathrm{R} 30^{\circ}$ structure by scanning tunneling microscopy," Surface Science 440 (1999) L857-L862.

[56] R.-L. Lo, K. Fukui, S. Otani, S.T. Oyama, Y. Iwasawa, "C-terminated reconstruction and C-chain structure on $\mathrm{Mo}_{2} \mathrm{C}(0001)$ surface studied by low energy electron diffraction and scanning tunneling microscopy," Japanese Journal of Applied Physics 38 (1999) 3813-3815.

[57] T. Aizawa, S. Hishita, T. Tanaka, S. Otani, "Surface reconstruction of $\mathrm{W}_{2} \mathrm{C}(0001)$," Journal of Physics: Condensed Matter 23 (2011) 305007.

[58] J. Neugebauer, M. Scheffler, "Adsorbate-substrate and adsorbate-adsorbate interactions of $\mathrm{Na}$ and K adlayers on Al(111)," Physical Review B 46 (1992) 16067-16080.

[59] L. Bengtsson, "Dipole correction for surface supercell calculations," Physical Review B 59 (1999) 12301-12304.

[60] B. Scheffer, P. Arnoldy, J.A. Moulijn, "Sulfidability and hydrodesulfurization activity of Mo catalysts supported on alumina, silica, and carbon," Journal of Catalysis 112 (1988) 516-527.

[61] P. Da Costa, C. Potvin, J.-M. Manoli, M. Breysse, G. Djéga-Mariadassou, "Novel phosphorus-doped alumina-supported molybdenum and tungsten carbides: Synthesis, characterization and hydrogenation properties," Catalysis Letters 72 (2001) 91-97.

[62] B.C. Gates, J.R. Katzer, G.C.A. Schuit, Chemistry of catalytic processes, McGrawHill, 1979.

[63] W. Ding, S. Li, G.D. Meitzner, E. Iglesia, "Methane conversion to aromatics on Mo/H-ZSM5: Structure of molybdenum species in working catalysts," The Journal Physical Chemistry B 105 (2001) 506-513.

[64] J.S. Lee, M. Boudart, "In situ carburization of metallic molybdenum during catalytic reactions of carbon-containing gases," Catalysis Letters 20 (1993) 97-106.

[65] J. Wang, M. Castonguay, J. Deng, P.H. McBreen, "RAIRS and TPD study of CO and $\mathrm{NO}$ on $\beta-\mathrm{Mo}_{2} \mathrm{C}$," Surface Science 374 (1997) 197-207.

[66] A. Crossley, D.A. King, "Infrared spectra for co isotopes chemisorbed on Pt "111": Evidence for strong adsorbate coupling interactions," Surface Science 68 (1977) 528-538. 
[67] T. Aizawa, S. Otani, "Adsorption of $\mathrm{CO}$ and $\mathrm{O}_{2}$ on $\mathrm{W}_{2} \mathrm{C}(0001)$," The Journal of Chemical Physics 135 (2011) 144704.

[68] J.B. Peri, "Computerized infrared studies of $\mathrm{Mo} / \mathrm{Al}_{2} \mathrm{O}_{3}$ and $\mathrm{Mo} / \mathrm{SiO}_{2}$ catalysts," The Journal of Physical Chemistry 86 (1982) 1615-1622.

[69] H. Tominaga, M. Nagai, "Density functional theory of water-gas shift reaction on molybdenum carbide," The Journal Physical Chemistry B 109 (2005) 2041520423.

[70] X.-R. Shi, J. Wang, K. Hermann, "CO and NO adsorption and dissociation at the $\beta$ $\mathrm{Mo}_{2} \mathrm{C}(0001)$ surface: A density functional theory study," The Journal Physical Chemistry C 114 (2010) 13630-13641.

[71] B. Frühberger, J.G. Chen, "Modification of the surface reactivity of Mo(110) upon carbide formation,” Surface Science 342 (1995) 38-46.

[72] W.M. Haynes, ed., CRC Handbook of Chemistry and Physics, 92nd ed., Taylor \& Francis, 2011.

[73] M.L. Colaianni, J.G. Chen, W.H. Weinberg, J.T. Yates, "The adsorption and dissociation of carbon monoxide on clean and oxygen-modified molybdenum(110) surfaces,” Journal of the American Chemical Society 114 (1992) 3735-3743.

[74] B.D. Wagner, B.R. Arnold, G.S. Brown, J. Lusztyk, "Spectroscopy and absolute reactivity of ketenes in acetonitrile studied by laser flash photolysis with timeresolved infrared detection,” Journal of the American Chemical Society 120 (1998) 1827-1834.

[75] J. Ren, C.-F. Huo, J. Wang, Y.-W. Li, H. Jiao, "Surface structure and energetics of oxygen and CO adsorption on $\alpha-\mathrm{Mo}_{2} \mathrm{C}(000$ 1)," Surface Science 596 (2005) 212221.

[76] L.-J. Deng, C.-F. Huo, X.-W. Liu, X.-H. Zhao, Y.-W. Li, J. Wang, H. Jiao, "Density functional theory study on surface $\mathrm{C}_{\mathrm{x}} \mathrm{H}_{\mathrm{y}}$ formation from $\mathrm{CO}$ activation on $\mathrm{Fe}_{3} \mathrm{C}(100)$," The Journal Physical Chemistry C 114 (2010) 21585-21592.

[77] L. Bugyi, F. Solymosi, "Effects of potassium on the chemisorption of $\mathrm{CO}$ on the $\mathrm{Mo}_{2} \mathrm{C} / \mathrm{Mo}(100)$ surface," The Journal Physical Chemistry B 105 (2001) 43374342.

[78] K.J. Uram, L. Ng, J.T. Yates, "Electrostatic effects between adsorbed species-the $\mathrm{K}-\mathrm{Co}$ interaction on $\mathrm{Ni}(111)$ as studied by infrared reflection-absorption spectroscopy,” Surface Science 177 (1986) 253-277.

[79] M.D. Alvey, A.-M. Lanzillotto, J.T. Yates, "The effect of potassium on the molecular orientation of CO chemisorbed on Ni(111): An esdiad study," Surface Science 177 (1986) 278-290. 
[80] H.G. Kim, K.H. Lee, J.S. Lee, "Carbon monoxide hydrogenation over molybdenum carbide catalysts," Research on Chemical Intermediates 26 (2000) 427-443.

[81] F.H. Ribeiro, R.A. Dalla Betta, M. Boudart, J. Baumgartner, E. Iglesia, "Reactions of neopentane, methylcyclohexane, and 3,3-dimethylpentane on tungsten carbides: The effect of surface oxygen on reaction pathways," Journal of Catalysis 130 (1991) 86-105.

[82] F.H. Ribeiro, M. Boudart, R.A. Dalla Betta, E. Iglesia, "Catalytic reactions of $n$ alkanes on $\beta-\mathrm{W}_{2} \mathrm{C}$ and WC: The effect of surface oxygen on reaction pathways," Journal of Catalysis 130 (1991) 498-513.

[83] E. Iglesia, J.E. Baumgartner, F.H. Ribeiro, M. Boudart, "Bifunctional reactions of alkanes on tungsten carbides modified by chemisorbed oxygen," Journal of Catalysis 131 (1991) 523-544.

[84] E. Iglesia, F.H. Ribeiro, M. Boudart, J.E. Baumgartner, "Synthesis, characterization, and catalytic properties of clean and oxygen-modified tungsten carbides," Catalysis Today 15 (1992) 307-337.

[85] E. Iglesia, F.H. Ribeiro, M. Boudart, J.E. Baumgartner, "Tungsten carbides modified by chemisorbed oxygen: A new class of bifunctional catalysts," Catalysis Today 15 (1992) 455-458.

[86] S.K. Bej, C.A. Bennett, L.T. Thompson, "Acid and base characteristics of molybdenum carbide catalysts,” Applied Catalysis A: General 250 (2003) 197-208.

[87] D.-V.N. Vo, A.A. Adesina, "Fischer-Tropsch synthesis over alumina-supported molybdenum carbide catalyst,” Applied Catalysis A: General 399 (2011) 221-232.

[88] M. Chia, Y.J. Pagán-Torres, D. Hibbitts, Q. Tan, H.N. Pham, A.K. Datye, M. Neurock, R.J. Davis, J.A. Dumesic, "Selective Hydrogenolysis of Polyols and Cyclic Ethers over Bifunctional Surface Sites on Rhodium-Rhenium Catalysts," Journal of the American Chemical Society 133 (2011) 12675-12689.

[89] S.T. Oyama, "Preparation and catalytic properties of transition metal carbides and nitrides," Catalysis Today 15 (1992) 179-200.

[90] T. Tatsumi, A. Muramatsu, H. Tominaga, "Mechanism of CO hydrogenation to alcohols on potassium-promoted $\mathrm{Mo} / \mathrm{SiO}_{2}$," Applied Catalysis 34 (1987) 77-88. 


\section{Chapter 5.}

\section{Influence of Cobalt on Rubidium-Promoted Alumina- Supported Molybdenum Carbide Catalysts for Higher Alcohol Synthesis from Syngas}

Modified with permission from Kehua Yin [+], Heng Shou [+], Daniela Ferrari, Christopher W. Jones and Robert J. Davis, "Influence of cobalt on rubidium-promoted alumina-supported molybdenum carbide catalysts for higher alcohol synthesis from syngas,” Topics in Catalysis, 2013. [+] Equal contribution.

Catalyst synthesis and syngas reactivity tests were performed mostly by Kehua Yin and are included here for completeness.

\section{Abstract}

The influence of Co addition on the activity and selectivity of Rb-promoted $\mathrm{Mo}_{2} \mathrm{C} / \alpha-\mathrm{Al}_{2} \mathrm{O}_{3}$ catalysts in $\mathrm{CO}$ hydrogenation was explored. The reaction was performed in a fixed-bed reactor system operating at $573 \mathrm{~K}, 30 \mathrm{bar}$, and $\mathrm{CO} / \mathrm{H}_{2}$ ratio of 1 . Addition of Co enhanced the production rates of hydrocarbons and higher alcohols over Rbpromoted $\mathrm{Mo}_{2} \mathrm{C} / \alpha-\mathrm{Al}_{2} \mathrm{O}_{3}$ by about $60 \%$ without significantly increasing the production rate of methanol, thus shifting the alcohol selectivity toward larger molecules. The addition of Co also lessened the negative impact of $\mathrm{CO}$ conversion on oxygenate selectivity over Rb-promoted $\mathrm{Mo}_{2} \mathrm{C} / \alpha-\mathrm{Al}_{2} \mathrm{O}_{3}$. Results from X-ray absorption spectroscopy revealed that highly dispersed Co and Mo domains remained more reduced in the bimetallic carbide samples than the corresponding monometallic samples. 


\subsection{Introduction}

The increasing price and limited reserve of crude oil motivate the research of alternatives to petroleum-derived fuels and chemicals. Synthesis gas, commonly referred to as syngas, is a mixture of $\mathrm{CO}$ and $\mathrm{H}_{2}$ that can be derived from natural gas and coal via steam reforming and subsequently converted to liquid fuels and chemicals. Given the abundant reserves of coal and natural gas in North America, there is a motivation to convert coal and natural gas into liquid fuels and chemicals via syngas technology. In addition, renewable biomass is also a potential source of syngas though gasification [1]. Syngas-to-liquid technology has been used to produce methanol as well as diesel fuel (via Fischer-Tropsch synthesis) at an increasing rate. Despite the maturity of these syngas conversion technologies, higher alcohol synthesis from syngas also attracts intensive research interest as a promising approach to produce fuel additives and chemical feedstocks [1]. For example, although bio-ethanol has already been widely used as an additive for gasoline in the United States, an efficient chemical process to produce ethanol and higher alcohols is still desirable.

Several heterogeneous catalysts have been studied for use in higher alcohol synthesis, including Rh-based catalysts, combinations of Fischer-Tropsch catalysts and methanol synthesis catalysts (Co-Cu, for example), and Mo-based catalysts [3]. The Rhbased catalysts produce high ethanol and other C2-oxygenates [4], but the potential large scale applications of these catalysts in industry are quite limited by the high cost and limited availability of Rh. Molybdenum metal catalysts exhibit low activity for conversion of syngas and low selectivity towards alcohols, unless the Mo is bound to S, C, $\mathrm{O}$ and/or P [3]. Molybdenum-based compounds are among most promising catalysts 
for higher alcohol synthesis because of their high selectivity to linear alcohols, slow deactivation, and low sensitivity to $\mathrm{CO}_{2}$ in the syngas stream [4]. Although $\mathrm{K}-$ and Copromoted $\mathrm{MoS}_{2}$ catalysts effectively produce alcohol from syngas, with alcohol selectivity higher than $75 \%$ (on a $\mathrm{CO}_{2}$-free basis) and total alcohol yield as high as 400 $\mathrm{mg} \mathrm{g}_{\text {cat }}^{-1} \mathrm{~h}^{-1}$ [5], addition of $\mathrm{H}_{2} \mathrm{~S}$ is required to maintain the activity and higher alcohol selectivity of $\mathrm{MoS}_{2}$-based catalysts [6], which results in about 2 wt.\% sulfur in the condensed alcohol products [7]. The presence of sulfur in the products is undesirable in light of current legislation for automotive fuels in the United States and Europe, and motivates the exploration of new sulfur-free Mo-based catalysts that produce more environmentally friendly products.

Some early transition metal carbides exhibit Pt-group like catalytic activity, which suggests they may serve as alternatives to precious metals [8]. Molybdenum carbide is known to produce light hydrocarbons from syngas, with the selectivity being shifted toward alcohols after promotion by alkali metal species [9-12], and may therefore function as a non-sulfur alternative to molybdenum sulfide catalysts for higher alcohol synthesis. In addition to greater activity, improvement in product selectivity for higher alcohols is needed, especially at high CO conversion [11].

Since addition of cobalt to alkali-metal-promoted $\mathrm{MoS}_{2}$ catalysts enhanced their activity in higher alcohol synthesis from syngas [13], it is logical to explore the influence of $\mathrm{Co}$ on alkali-metal-promoted $\mathrm{Mo}_{2} \mathrm{C}$ catalysts in the reaction. In fact, Xiang et al. studied the influence of Fischer-Tropsch-active elements (Fe, Co and Ni) on unsupported $\mathrm{Mo}_{2} \mathrm{C}$ for conversion of syngas and reported that the alcohol production rate over $\mathrm{Mo}_{2} \mathrm{C}$ catalysts was promoted by added $\mathrm{Co}$ and $\mathrm{Fe}$, but not $\mathrm{Ni}$, and Co was best promoter 
among the three [14]. Lucero et al. reported that Ni enhanced the productivity and ratio of ethanol to methanol over Na-promoted bulk $\mathrm{Mo}_{2} \mathrm{C}$ catalysts [15].

In this study, $\mathrm{Co}$ and Mo precursors were supported on $\alpha-\mathrm{Al}_{2} \mathrm{O}_{3}$ via coimpregnation and calcination, and subsequently carburized to produce catalysts for syngas conversion. X-ray absorption spectroscopy was used to determine the atomic structure and chemical state of Co and Mo.

\subsection{Materials and methods}

\subsubsection{Catalyst synthesis}

The catalysts were prepared by incipient wetness co-impregnation onto the alumina support (Mager Scientific, $>99.98 \%$, predominantly $\alpha$-phase, $\mathrm{S}_{\mathrm{BET}}=27 \mathrm{~m}^{2} \mathrm{~g}^{-1}$ ) with an aqueous solution of $\left(\mathrm{NH}_{4}\right)_{6} \mathrm{Mo}_{7} \mathrm{O}_{24} \cdot 6 \mathrm{H}_{2} \mathrm{O}\left(99.98 \%\right.$, Aldrich) and $\mathrm{Co}\left(\mathrm{NO}_{3}\right)_{2} \cdot 4 \mathrm{H}_{2} \mathrm{O}$ (99.999 \%, Alfa Aesar). The samples were then dried overnight in air at $400 \mathrm{~K}$, followed by calcination at $773 \mathrm{~K}$ in flowing air for $4 \mathrm{~h}$ to produce supported molybdenum and cobalt oxide. Carburization of the catalysts was accomplished by temperatureprogrammed reaction. This step was performed in a quartz tube reactor by heating at a rate of $5 \mathrm{~K} \mathrm{~min}^{-1}$ from room temperature to $573 \mathrm{~K}$ and then at a rate of $1 \mathrm{~K} \mathrm{~min}^{-1}$ from $573 \mathrm{~K}$ to $973 \mathrm{~K}$ in a 20 vol.\% $\mathrm{CH}_{4}$ (GTS-Welco, 99.997\%) and 80 vol.\% $\mathrm{H}_{2}$ mixture (GTS-Welco, 99.999\%). The catalysts were subsequently cooled to room temperature in the same carburization gas, followed by passivation in a stream of 1.03 vol.\% $\mathrm{O}_{2} / \mathrm{N}_{2}$ mixture (GTS-Welco) at room temperature for $6 \mathrm{~h}$ before exposure to air. The catalysts were further promoted by physically mixing them with appropriate amounts of $\mathrm{Rb}_{2} \mathrm{CO}_{3}$ 
(99.975 \%, Alfa Aesar) using a mortar and pestle. The Mo loading was kept at 5 wt.\% in all the samples, with the molar ratio of Co/Mo varying from 0 to 1.0 .

An alumina-supported, "carburized" Co catalyst was synthesized by the same procedure without including the Mo precursor. The molar loading of Co in this catalyst was equivalent to that of Mo in $5 \mathrm{wt} . \%$ Mo.

\subsubsection{CO hydrogenation}

The hydrogenation of $\mathrm{CO}$ was performed in the same fixed-bed stainless steel reactor (BTRS Jr., Autoclave Engineers) used in earlier work at nominally identical conditions of $573 \mathrm{~K}, 30$ bar total pressure, and equimolar $\mathrm{H}_{2}$ (GTS-Welco, $99.999 \%$ ) and CO (GTS-Welco, $99.997 \%$ ) [11,12]. The CO was purified by passing it through a silica trap immersed in a dry ice-acetone mixture (195 K) to remove any trace iron carbonyl before introduction to the reactor. The products were analyzed by two Hewlett-Packard 5890 series II gas chromatographs on-line. The first one was equipped with a flame ionization detector and a 50 m-long HP-1 cross-linked methyl silicone gum capillary column to monitor the formation of hydrocarbons and alcohols. The second one was equipped with a thermal conductivity detector and a 6-ft long Alltech-8700 packed column and was used to monitor the formation of $\mathrm{CO}_{2}$.

The conversion of $\mathrm{CO}$ was derived from the fraction of $\mathrm{CO}$ that formed carboncontaining products [18]. The conversion of CO, if low, can be described as:

$$
\text { Conversion }(\%)=\sum n_{i} M_{i} \times 100 / M_{\mathrm{CO}} \text {, }
$$

where $n_{i}$ is the number of carbon atoms in product $i, M_{i}$ is the percentage of product $i$ detected, and $\mathrm{M}_{\mathrm{CO}}$ is the percentage of $\mathrm{CO}$ in the syngas feed. 
The selectivity to product $i$ is based on the total number of carbon atoms in the product and is therefore defined as:

$$
\text { Selectivity }(\%)=n_{i} M_{i} \times 100 / \sum n_{i} M_{i} \text {. }
$$

The conversion and selectivities were based on the identified products, which present more than $97 \%$ of the total peak area in GC chromatograms.

All the results reported here were obtained at the steady state after at least 60 hours of reaction. Syngas flow rate was adjusted to attain $~ 3 \%$ CO conversion (excluding $\left.\mathrm{CO}_{2}\right)$

\subsubsection{Characterization}

Powder X-ray diffraction (XRD) patterns of the catalysts were obtained on a PANalytical X'Pert Pro MPD Diffractometer with $\mathrm{Cu} \mathrm{K \alpha}$ radiation. Each sample was scanned at a rate of $0.05^{\circ} \mathrm{s}^{-1}$, over a range of $2 \theta$ from $10^{\circ}$ to $90^{\circ}$.

Elemental analyses of representative samples were performed at Galbraith Laboratories (Knoxville, TN). The loading of molybdenum and rubidium was determined by inductively coupled plasma atomic emission spectroscopy (ICP-AES), while the loading of carbon was evaluated by combustion and coulometric measurement.

X-ray absorption spectroscopy (XAS) was performed at beam line X18B of the National Synchrotron Light Source (NSLS), Brookhaven National Laboratory. The storage ring was typically operated at $2.8 \mathrm{GeV}$ with a ring current of about $300 \mathrm{~mA}$. The XAS data were obtained in the transmission mode at the Mo $K$ edge (20 keV) with a spot size of $0.5 \mathrm{~mm} \times 5 \mathrm{~mm}$ and at the Co $K$ edge $(7.7 \mathrm{keV})$ with a spot size of $0.5 \mathrm{~mm} \times 8 \mathrm{~mm}$. The Mo $K$ edge spectra and Co $K$ edge spectra were measured at room temperature with Mo foil (0.015 mm, 99.9\%, Goodfellow) and Co foil (0.004 mm, 99.9\%, Goodfellow) as 
energy references, respectively. The air-free handling protocol for one representative Rbpromoted $\mathrm{Co}-\mathrm{Mo}_{2} \mathrm{C} / \alpha-\mathrm{Al}_{2} \mathrm{O}_{3}$ catalyst after syngas reaction has been discussed in our previous work [12]. The XAS data were processed using the Athena software [16] for background removal, post-edge normalization, and X-ray absorption near-edge structure (XANES) analysis. Standard bulk $\mathrm{Mo}_{2} \mathrm{C}$ (Alfa Aesar, 99.5\%) was used to determine the amplitude reduction factors, $S_{0}^{2}$, for Mo-C and Mo-Mo. Cobalt foil (Goodfellow, 99.9\%) was used to determine the value of $S_{0}^{2}$ for Co-Co. The interatomic distances $(r)$, coordination numbers $(\mathrm{CN})$, Debye-Waller factors $\left(\Delta \sigma^{2}\right)$, and energy shifts $\left(\Delta E_{0}\right)$ were derived from the fitting results in the Artemis software package [16]. The EXAFS results were fitted in R-space using two shells (Mo-C \& Mo-Mo) or one shell (Co-Co) generated theoretically using FEFF 6.0 [17].

\subsection{Results and discussion}

The performance of the catalysts in the syngas reaction at $573 \mathrm{~K}$ and 30 bar is summarized in Table 5.1. Since the selectivity for alcohols on the Rb-promoted $\mathrm{Mo}_{2} \mathrm{C}$ catalysts was observed to decrease with CO conversion $[11,12]$, the results from all the catalysts in this study were compared at the same CO conversions level (about 3\%, excluding $\mathrm{CO}_{2}$ ). The $\mathrm{CO}$ conversion was adjusted by changing the syngas flow rates until the desired conversion was achieved. 
Table 5.1 Reactivity of $\mathrm{Co}-\mathrm{Mo}_{2} \mathrm{C} / \alpha-\mathrm{Al}_{2} \mathrm{O}_{3}$ and Rb-promoted $\mathrm{Co}-\mathrm{Mo}_{2} \mathrm{C} / \alpha-\mathrm{Al}_{2} \mathrm{O}_{3}$ catalysts in $\mathrm{CO}$ hydrogenation

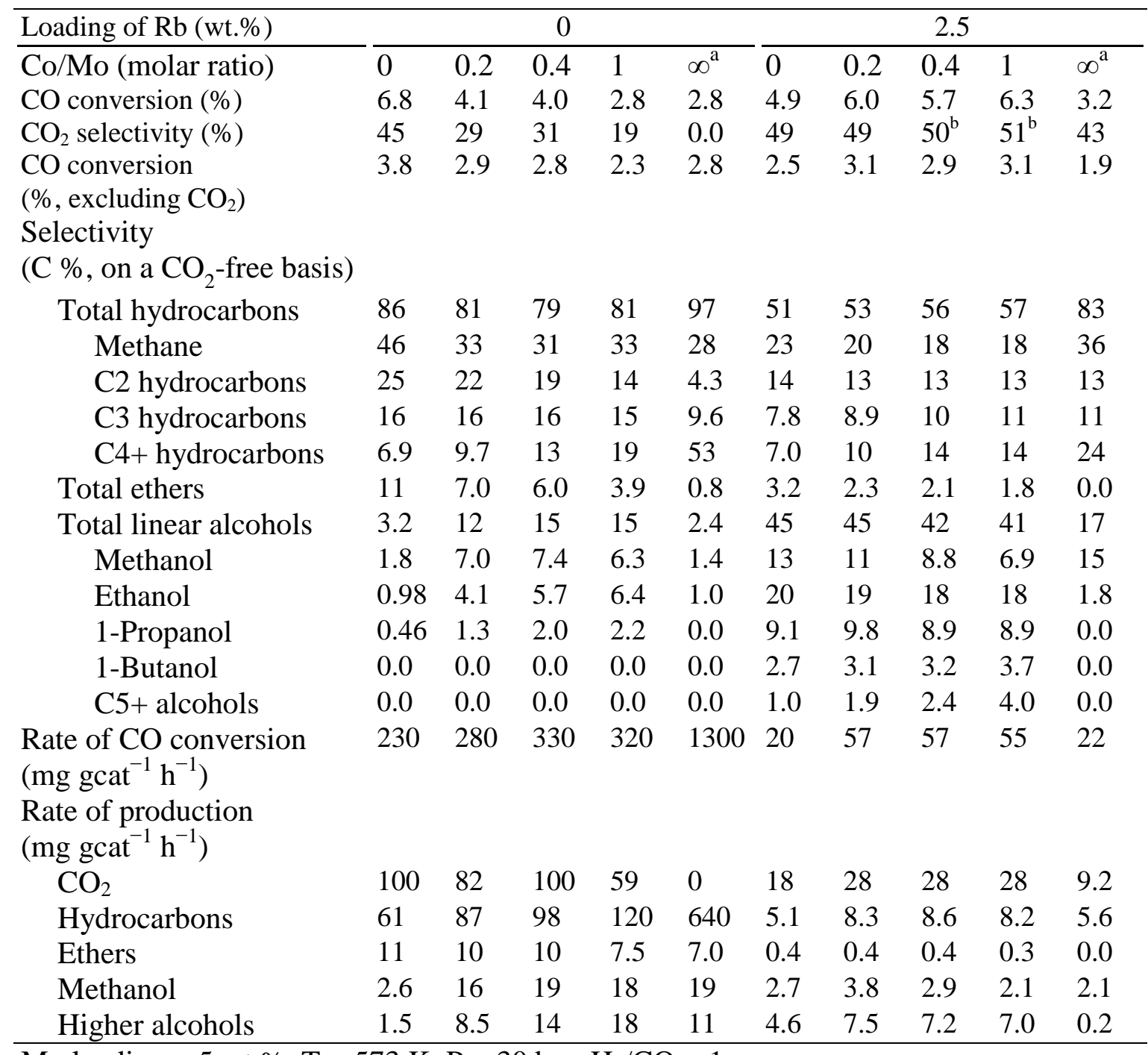

Mo loading $=5$ wt. $\%, \mathrm{~T}=573 \mathrm{~K}, \mathrm{P}=30 \mathrm{bar}, \mathrm{H}_{2} / \mathrm{CO}=1$.

Syngas flow rate was adjusted to attain $\sim 3 \% \mathrm{CO}$ conversion (excluding $\mathrm{CO}_{2}$ ).

Data were recorded after $>50 \mathrm{~h}$ on stream when the catalysts reached steady state (stable activity and product distribution).

${ }^{\text {a }}$ The molar loading of Co is equivalent to that of Mo in a $5 \mathrm{wt} . \%$ Mo sample.

b The excess beyond the theoretical limit (50\%) is likely due to experimental error in analysis.

According to Table 5.1, the unpromoted $\mathrm{Co} / \alpha-\mathrm{Al}_{2} \mathrm{O}_{3}$ catalyst produced $97 \%$ hydrocarbons (3\% alcohols) at 2.8\% CO conversion, which is consistent with the wellknown $\mathrm{CO}$ hydrogenation of Co catalysts. The unpromoted $\mathrm{Mo}_{2} \mathrm{C}$ catalyst revealed $86 \%$ hydrocarbon selectivity (on a $\mathrm{CO}_{2}$-free basis) and $11 \%$ ether selectivity. Since passivation 
can introduce surface acid sites on $\mathrm{Mo}_{2} \mathrm{C}$ catalysts [19], the alcohol products can undergo secondary dehydration reactions and form ethers [12]. When the loading of Co on $\mathrm{Mo}_{2} \mathrm{C}$ $/ \alpha-\mathrm{Al}_{2} \mathrm{O}_{3}$ increased from 0 to the molar equivalent of $\mathrm{Mo}$, the rate of hydrocarbon formation on the catalysts increased from $61 \mathrm{mg} \mathrm{gcat}^{-1} \mathrm{~h}^{-1}$ to $120 \mathrm{mg} \mathrm{gcat}^{-1} \mathrm{~h}^{-1}$, while the rate of ether formation reduced from $11 \mathrm{mg} \mathrm{gcat}^{-1} \mathrm{~h}^{-1}$ to $7.5 \mathrm{mg} \mathrm{gcat}^{-1} \mathrm{~h}^{-1}$. More importantly, the rate of methanol production increased substantially from $2.6 \mathrm{mg} \mathrm{gcat}^{-1}$ $\mathrm{h}^{-1}$ to $18 \mathrm{mg} \mathrm{gcat}^{-1} \mathrm{~h}^{-1}$ as the rate of higher alcohol production also increased from 1.5 mg gcat ${ }^{-1} \mathrm{~h}^{-1}$ to $18 \mathrm{mg}_{\text {gcat }}{ }^{-1} \mathrm{~h}^{-1}$. The presence of Co with $\mathrm{Mo}_{2} \mathrm{C}$ did not significantly influence the total rate of $\mathrm{CO}$ conversion, but it decreased the $\mathrm{CO}_{2}$ selectivity from $45 \%$ to $19 \%$, which is consistent with the negligible water-gas-shift activity observed over the $\mathrm{Co} / \alpha-\mathrm{Al}_{2} \mathrm{O}_{3}$ catalyst. It is important to note that co-existence of Co and Mo decreased the rate of hydrocarbon production by more than $82 \%$ from the $\mathrm{Co} / \alpha-\mathrm{Al}_{2} \mathrm{O}_{3}$ catalyst, which had the same amount of Co. These results indicate a clear interaction between the supported Mo and Co species.

The addition of 2.5 wt.\% $\mathrm{Rb}$ promoter to 5 wt.\% $\mathrm{Mo}_{2} \mathrm{C} / \alpha-\mathrm{Al}_{2} \mathrm{O}_{3}$ substantially inhibited the production rate of hydrocarbons by an order of magnitude and shifted the oxygenate composition from ethers to predominantly alcohols. Similarly, over the Co$\mathrm{Mo}_{2} \mathrm{C} / \alpha-\mathrm{Al}_{2} \mathrm{O}_{3}$ catalysts, the addition of $\mathrm{Rb}$ promoter also significantly reduced the production rates of hydrocarbons, ethers and methanol by about an order of magnitude, while decreasing the production rate of higher alcohols by only $30 \%-60 \%$. The lower overall activity of the Rb-promoted catalysts is consistent with the site-blockage mechanism of alkali metal promoters on Mo-based catalysts for higher alcohol synthesis suggested by Lee et al. [20, 21], which has been supported by prior works on Rb- 
promoted $\mathrm{Mo}_{2} \mathrm{C} / \mathrm{MgO}$ [11], Rb-promoted $\mathrm{Mo}_{2} \mathrm{C} / \alpha-\mathrm{Al}_{2} \mathrm{O}_{3}$ [12] and K-promoted bulk $\mathrm{Mo}_{2} \mathrm{C}$ catalysts [9]. The reduced formation of ethers is likely the result of the basic $\mathrm{Rb}$ promoter neutralizing the surface acid sites on $\mathrm{Mo}_{2} \mathrm{C}$ [19] that may catalyze the dehydration of alcohols. Although the rate of $\mathrm{CO}_{2}$ production was reduced over the Rbpromoted $\mathrm{Co}-\mathrm{Mo}_{2} \mathrm{C}$, the overall selectivity to $\mathrm{CO}_{2}$ was about $50 \%$, which is the stoichiometric maximum under our conditions. The $\mathrm{Co} / \alpha-\mathrm{Al}_{2} \mathrm{O}_{3}$ catalyst revealed very little activity for higher alcohol synthesis after the addition of Rb, which suggests that the formation of higher alcohols on Rb-promoted $\mathrm{Co}-\mathrm{Mo}_{2} \mathrm{C}$ catalysts is primarily associated with the molybdenum carbide species.

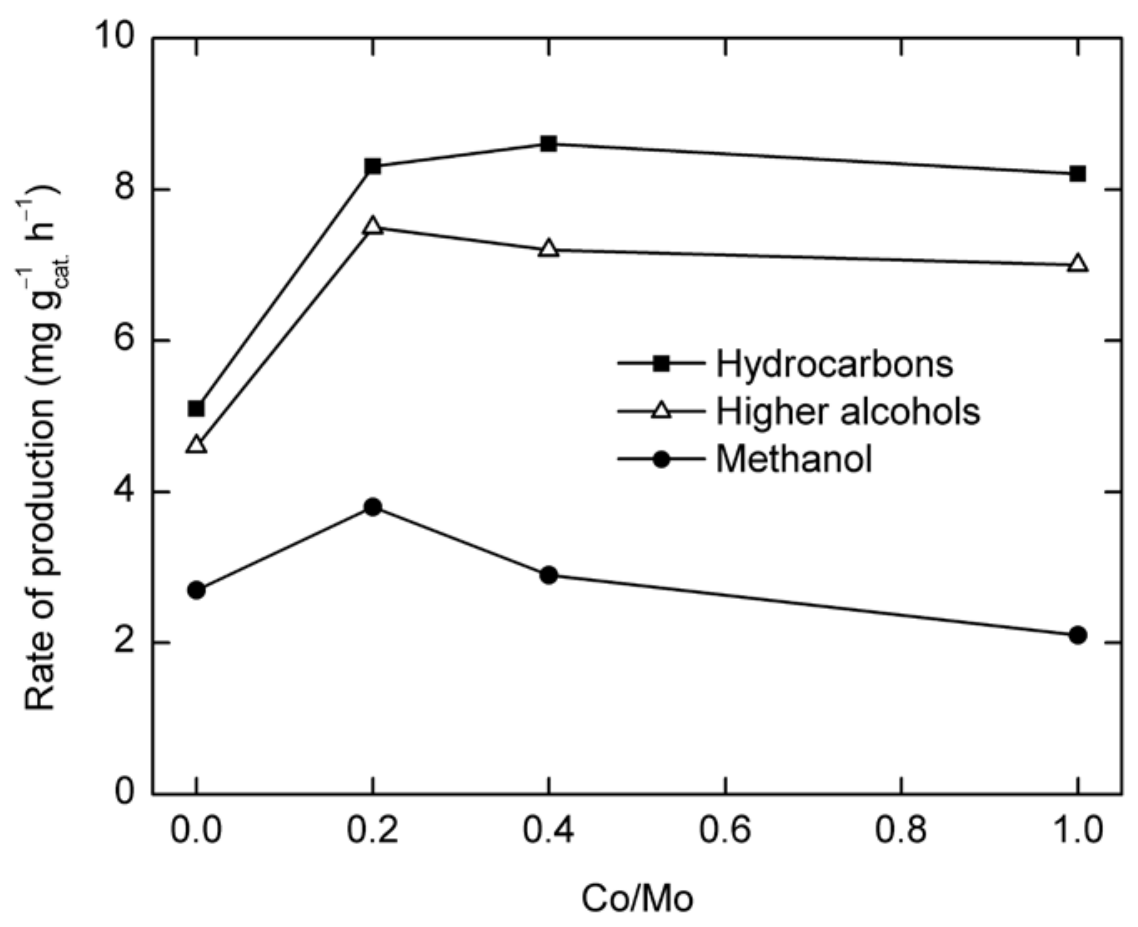

Figure 5.1 Changes in the rate of production of hydrocarbons, methanol and higher alcohols with $\mathrm{Co} / \mathrm{Mo}$ ratio over 2.5 wt.\% Rb-promoted $\mathrm{Co}-\mathrm{Mo}_{2} \mathrm{C} / \alpha-\mathrm{Al}_{2} \mathrm{O}_{3}$ catalysts in $\mathrm{CO}$ hydrogenation at $573 \mathrm{~K}$ and $30 \mathrm{bar}$

The change of production rates with Co/Mo ratio over Rb-promoted catalysts is plotted in Figure 5.1. When the Co/Mo ratio increased from 0 to 0.2 , the production rates of hydrocarbons, methanol and higher alcohols both increased by about 50\%. Increasing 
the $\mathrm{Co} / \mathrm{Mo}$ ratio from 0.2 to 1 left the production rates of hydrocarbons and higher alcohols almost unchanged, whereas that of methanol decreased to a level slightly less than that before Co promotion. As a consequence, the addition of Co ultimately promoted the formation of higher alcohols over methanol, which is consistent with the promotional effects of Co on K-promoted bulk $\mathrm{Mo}_{2} \mathrm{C}$ catalysts [22] and that of $\mathrm{Ni}$ on Na-promoted bulk $\mathrm{Mo}_{2} \mathrm{C}$ catalysts [15]. Similar trends have been observed on alkali-metal-promoted supported $\mathrm{MoS}_{2}$ catalysts as well [23, 24]. A density functional theory (DFT) study showed that Co atoms can be incorporated into the S-edge sites of $\mathrm{MoS}_{2}$, which may generate active Co-Mo-S surface species and increase the activity of the catalyst [25]. Those results are not completely analogous to $\mathrm{Mo}_{2} \mathrm{C}$-based catalysts since $\mathrm{Mo}_{2} \mathrm{C}$ is a more metal-like compound and $\mathrm{MoS}_{2}$ has a covalent layered structure.

The chain growth probability $(\alpha)$ [26] of the linear hydrocarbons produced on these catalysts was calculated from the following expression:

$$
X_{n} / n=(1-\alpha)^{2} \alpha^{n-1},
$$

where $X_{\mathrm{n}}$ is the molar fraction of carbon atoms in the hydrocarbon (or alcohol) molecules containing n carbon atoms among all the hydrocarbons considered. The expression above can be transformed to:

$$
\log \left(X_{n} / n\right)=(n-1) \log \alpha+2 \log (1-\alpha)
$$

Appropriate plots associated with the hydrocarbons and alcohols produced on the different catalysts are presented in Figure 5.2, and the corresponding values of $\alpha$ and $R^{2}$ derived from linear fits are listed in Table 5.2. 

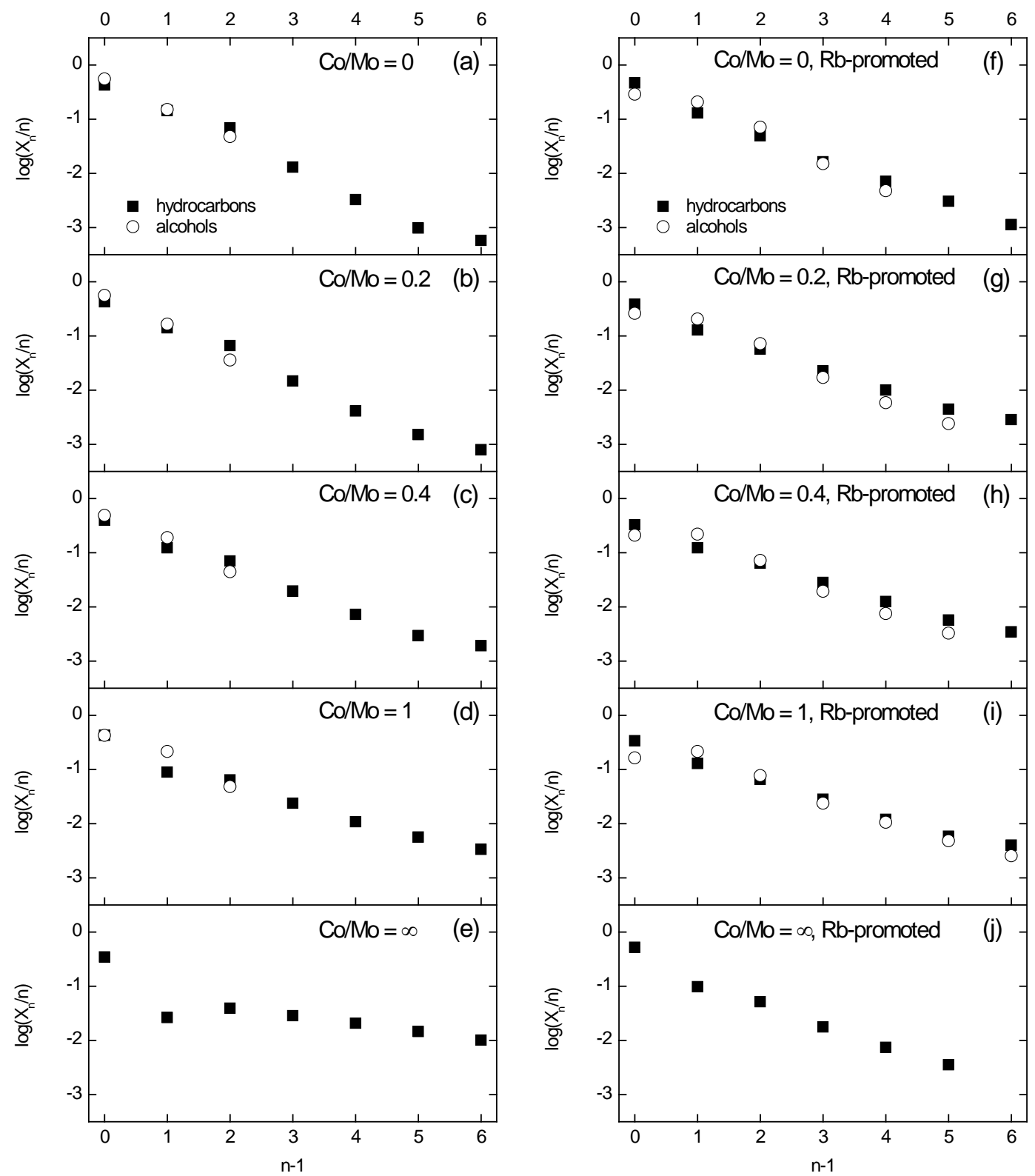

Figure 5.2 Evaluation of chain growth probability of linear hydrocarbons (paraffins and olefins combined, filled squares) and linear alcohols (open circles) over $\mathrm{Co}-\mathrm{Mo}_{2} \mathrm{C}$ catalysts with various Co/Mo ratios, without Rb promoter (a-e) and with Rb promoter (fj). 
The chain growth probability of both hydrocarbons and alcohols increased with both the Co/Mo ratio and the addition of $\mathrm{Rb}$ promoter (Table 5.2). On Rb-promoted $\mathrm{Mo}_{2} \mathrm{C}$ (Figure 5.2f) and $\mathrm{Co}-\mathrm{Mo}_{2} \mathrm{C}$ (Figure 5.2g-i) catalysts, the $R^{2}$ values for alcohols never exceeded 0.97 (Table 5.2), and were always less than the 0.99+ values for hydrocarbons (Table 5.2). The poor linear fit corresponding to the product distribution of the alcohols produced over the Rb-promoted catalysts results primarily from a low rate of methanol production and suggests that the synthesis of alcohols may not be dictated solely by the standard chain growth mechanism described by Anderson-Schulz-Flory (ASF) distribution. Secondary reactions such as coupling, dehydration, and homologation may account for the lower methanol selectivity than that expected from the ASF distribution.

Table 5.2 Chain growth probability $(\alpha)$ and $R^{2}$ derived from linear fits

\begin{tabular}{|c|c|c|c|c|}
\hline \multirow[t]{2}{*}{ Sample } & \multicolumn{2}{|c|}{ Hydrocarbons $^{\text {a }}$} & \multicolumn{2}{|c|}{ Alcohols $^{b}$} \\
\hline & $\alpha$ & $R^{2}$ & $\alpha$ & $R^{2}$ \\
\hline $\mathrm{Co} / \mathrm{Mo}=0$ & 0.31 & 0.988 & 0.29 & 0.999 \\
\hline $\mathrm{Co} / \mathrm{Mo}=0.2$ & 0.33 & 0.991 & 0.25 & 0.996 \\
\hline $\mathrm{Co} / \mathrm{Mo}=0.4$ & 0.40 & 0.989 & 0.30 & 0.986 \\
\hline $\mathrm{Co} / \mathrm{Mo}=1.0$ & 0.46 & 0.977 & 0.34 & 0.956 \\
\hline $\mathrm{Co} / \mathrm{Mo}=\infty$ & 0.65 & 0.700 & - & - \\
\hline $\mathrm{Co} / \mathrm{Mo}=0, \mathrm{Rb}$-promoted & 0.37 & 0.996 & 0.32 & 0.962 \\
\hline $\mathrm{Co} / \mathrm{Mo}=0.2, \mathrm{Rb}-$ promoted & 0.43 & 0.993 & 0.36 & 0.973 \\
\hline $\mathrm{Co} / \mathrm{Mo}=0.4, \mathrm{Rb}$-promoted & 0.43 & 0.996 & 0.40 & 0.963 \\
\hline $\mathrm{Co} / \mathrm{Mo}=1.0, \mathrm{Rb}$-promoted & 0.47 & 0.991 & 0.45 & 0.962 \\
\hline $\mathrm{Co} / \mathrm{Mo}=\infty, \mathrm{Rb}$-promoted & 0.38 & 0.982 & - & - \\
\hline
\end{tabular}

${ }^{\mathrm{a}}$ linear paraffins and olefins combined

${ }^{\mathrm{b}}$ linear alcohols 
To explore the effect of Rb loading on catalyst performance, a sample with 5 wt.\% $\mathrm{Rb}$ was also prepared and evaluated. As summarized in Table 5.3, the alcohol selectivity of the catalyst with 5 wt.\% Rb was similar to that with 2.5 wt.\% Rb, although the overall activity was lower. These results are consistent with the additional Rb blocking some of the active sites on the catalysts as suggested by Lee et al. [20, 21].

Table 5.3 Influence of $\mathrm{Rb}$ loading on the reactivity of $\mathrm{Co}-\mathrm{Mo}_{2} \mathrm{C} / \alpha-\mathrm{Al}_{2} \mathrm{O}_{3}$ (molar ratio of $\mathrm{Co} / \mathrm{Mo}=1)$ in $\mathrm{CO}$ hydrogenation

\begin{tabular}{|c|c|c|}
\hline Rb loading (\%) & 2.5 & 5.0 \\
\hline CO conversion (\%) & 6.3 & 4.7 \\
\hline $\mathrm{CO}_{2}$ selectivity (\%) & $51^{\mathrm{a}}$ & $53^{\mathrm{a}}$ \\
\hline $\mathrm{CO}$ conversion (\%, excluding $\left.\mathrm{CO}_{2}\right)$ & 3.1 & 2.2 \\
\hline \multicolumn{3}{|l|}{ Selectivity (C \%, on a $\mathrm{CO}_{2}$-free basis) } \\
\hline Total hydrocarbons & 57 & 58 \\
\hline Methane & 18 & 20 \\
\hline C2 hydrocarbons & 13 & 14 \\
\hline C3 hydrocarbons & 11 & 9.8 \\
\hline C4+ hydrocarbons & 14 & 14 \\
\hline Total ethers & 1.8 & 1.3 \\
\hline Total alcohols & 41 & 40 \\
\hline Methanol & 6.9 & 7.3 \\
\hline Ethanol & 18 & 17 \\
\hline 1-Propanol & 8.9 & 9.0 \\
\hline 1-Butanol & 3.7 & 3.4 \\
\hline C5+ linear alcohols & 4.0 & 4.0 \\
\hline Rate of CO conversion (mg gcat ${ }^{-1} \mathrm{~h}^{-1}$ ) & 55 & 40 \\
\hline \multicolumn{3}{|l|}{ Rate of production (mg gcat ${ }^{-1} \mathrm{~h}^{-1}$ ) } \\
\hline $\mathrm{CO}_{2}$ & 28 & 21 \\
\hline Hydrocarbons & 8.2 & 5.8 \\
\hline Ethers & 0.3 & 0.2 \\
\hline Methanol & 2.1 & 1.5 \\
\hline Higher alcohols & 7.0 & 4.4 \\
\hline
\end{tabular}

Mo loading $=5 \mathrm{wt} . \%, \mathrm{~T}=573 \mathrm{~K}, \mathrm{P}=30 \mathrm{bar}, \mathrm{H}_{2} / \mathrm{CO}=1$. Syngas flow rate was adjusted to attain $\sim 3 \% \mathrm{CO}$ conversion (excluding $\mathrm{CO}_{2}$ ). Data were recorded after $>60 \mathrm{~h}$ on stream when the catalysts reached steady state (stable activity and product distribution).

${ }^{\mathrm{a}}$ The excess beyond the theoretical limit (50\%) is likely due to experimental error in analysis. 
Figure 5.3 compares the alcohol selectivity over Rb-promoted $\mathrm{Mo}_{2} \mathrm{C} / \alpha-\mathrm{Al}_{2} \mathrm{O}_{3}$, with and without Co, as a function of CO conversion. As the CO conversion increased from 5 to $20 \%$ over Rb-promoted $\mathrm{Mo}_{2} \mathrm{C} / \alpha-\mathrm{Al}_{2} \mathrm{O}_{3}$, the selectivity to alcohols decreased significantly. In contrast, the alcohol selectivity was less impacted by the CO conversion when Co was added to the catalyst.

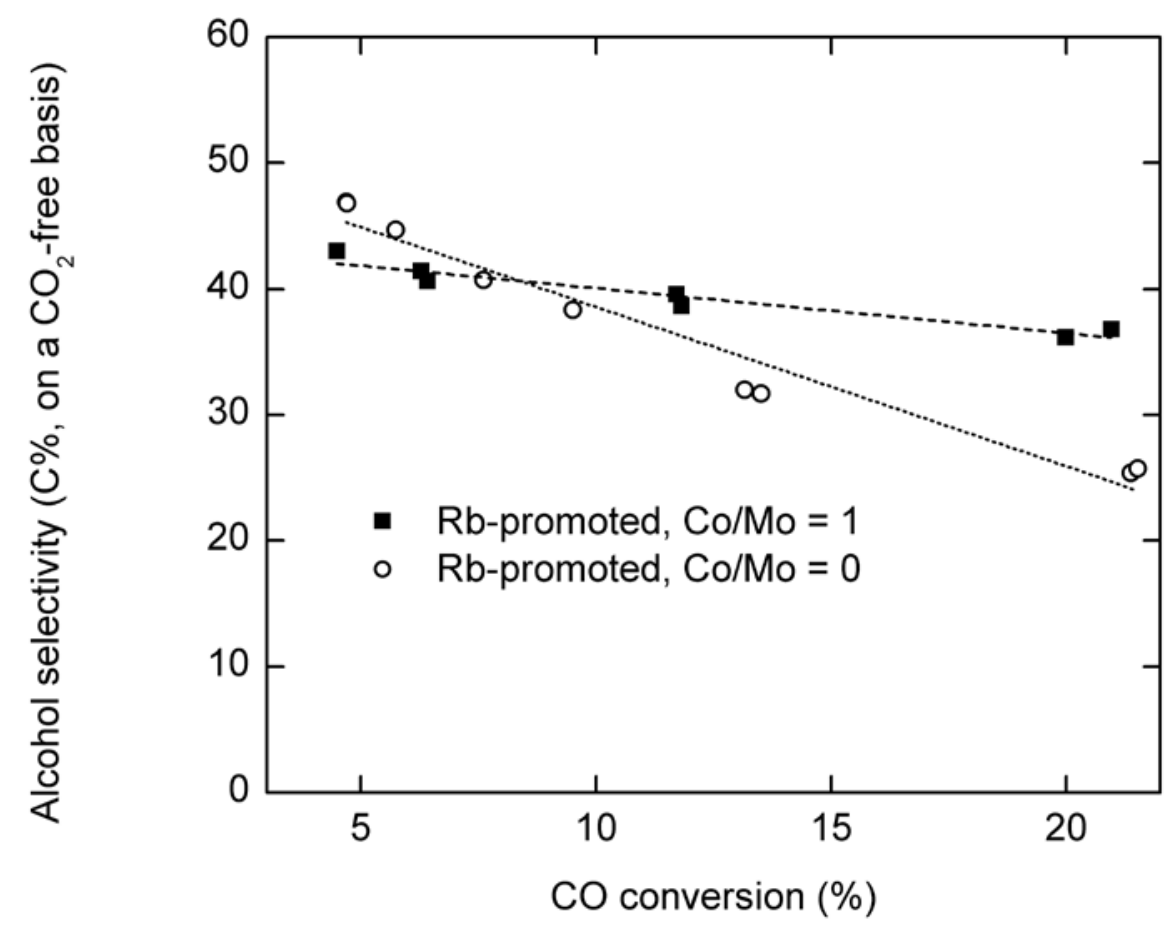

Figure 5.3 Change of alcohol selectivity with $\mathrm{CO}$ conversion over $\mathrm{Rb}$-promoted $\mathrm{Mo}_{2} \mathrm{C} / \alpha-\mathrm{Al}_{2} \mathrm{O}_{3}(\mathrm{Co} / \mathrm{Mo}=0)$ and Rb-promoted $\mathrm{Co}-\mathrm{Mo}_{2} \mathrm{C} / \alpha-\mathrm{Al}_{2} \mathrm{O}_{3}(\mathrm{Co} / \mathrm{Mo}=1)$ catalysts. The loading of $\mathrm{Mo}$ is 5 wt.\%. The loading of $\mathrm{Rb}$ is 2.5 wt.\%. Reaction conditions: $573 \mathrm{~K}, 30$ bar syngas, $\mathrm{H}_{2} / \mathrm{CO}=1$.

The X-ray diffraction patterns of the catalysts are provided in Figure 5.4. None of the Co-containing catalysts (Figure 5.4c-f) revealed XRD peaks corresponding to any Co species, suggesting that alumina-supported Co species were highly dispersed. No diffraction peaks associated with $\mathrm{Mo}_{2} \mathrm{C}$ were present in the XRD pattern of $\mathrm{Mo}_{2} \mathrm{C} / \alpha$ $\mathrm{Al}_{2} \mathrm{O}_{3}$ (Figure 5.4b), which is consistent with our previous work that identified $\sim 1 \mathrm{~nm}$ $\mathrm{Mo}_{2} \mathrm{C}$ particles on $\alpha-\mathrm{Al}_{2} \mathrm{O}_{3}$ [12]. When $\mathrm{Co}$ was added to the catalyst, the $\{101\}$ reflection 
of hexagonal $\mathrm{Mo}_{2} \mathrm{C}$ appeared at $39.4^{\circ}$ and became more intense with Co loading (Figure 5.4c-e). Liang et al. used carbothermal reduction with dihydrogen to synthesize Mobased bimetallic carbides on activated carbon support [27], and they reported that addition of a second metal component (Co, Ni) to Mo decreased the formation temperature of the carbide, presumably because the second metal facilitated the formation of $\mathrm{CH}_{\mathrm{x}}$ species that can accelerate the carburization process. A similar promotional effect of Co on the carburization of Mo may also occur in our synthesis. Thus, the high temperature used in our catalyst carburization may have exceeded the minimum temperature necessary for carburizing the Co-Mo mixed oxide precursor and may have caused growth of $\mathrm{Mo}_{2} \mathrm{C}$ domain.

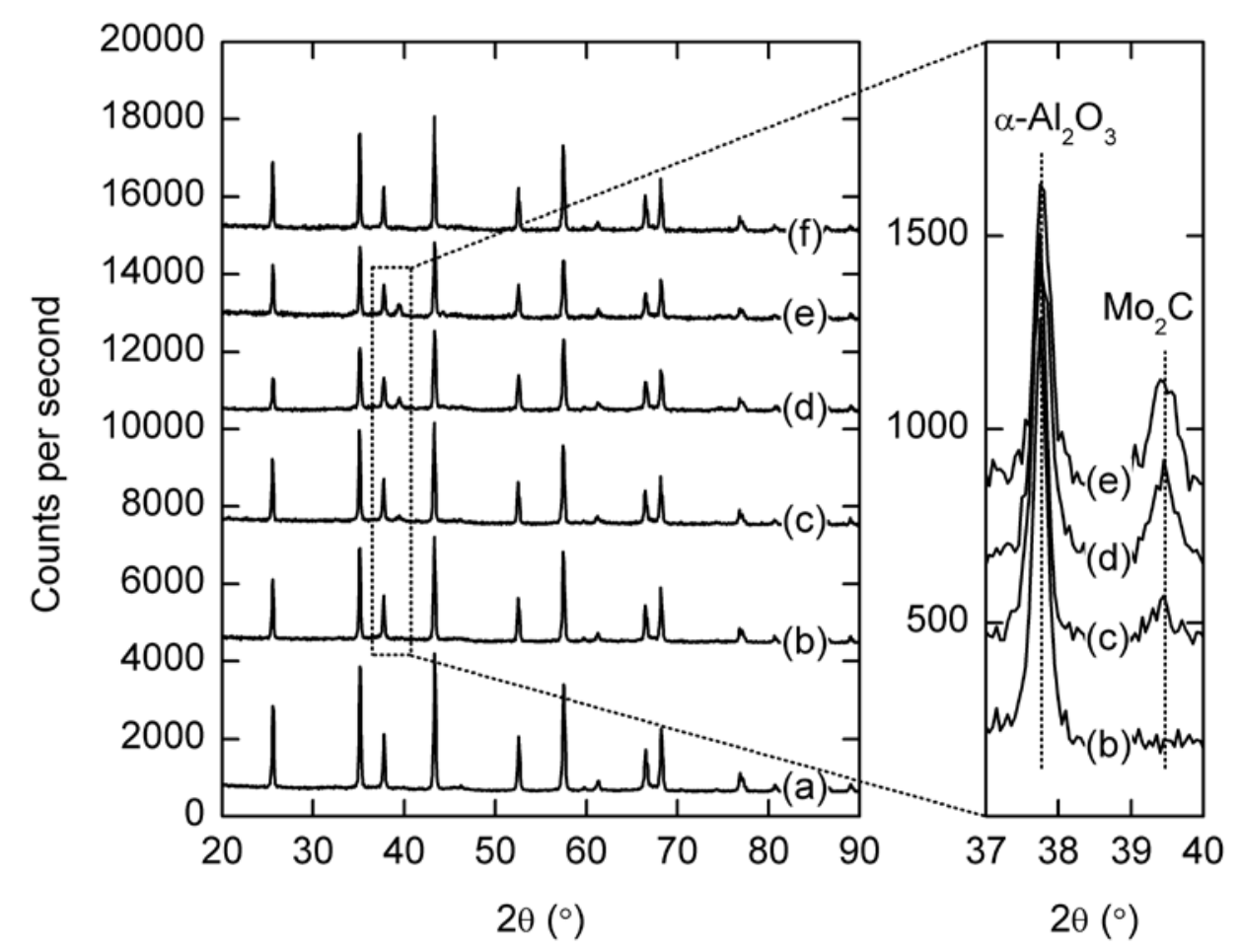

Figure 5.4 X-ray diffraction patterns of (a) $\alpha-\mathrm{Al}_{2} \mathrm{O}_{3}$ (Mager Scientific); (b) $\mathrm{Mo}_{2} \mathrm{C} / \alpha$ $\mathrm{Al}_{2} \mathrm{O}_{3}$; (c) $\mathrm{Co}-\mathrm{Mo}_{2} \mathrm{C} / \alpha-\mathrm{Al}_{2} \mathrm{O}_{3}, \mathrm{Co} / \mathrm{Mo}=0.2$; (d) $\mathrm{Co}-\mathrm{Mo}_{2} \mathrm{C} / \alpha-\mathrm{Al}_{2} \mathrm{O}_{3}, \mathrm{Co} / \mathrm{Mo}=0.4$; (e) $\mathrm{Co}-\mathrm{Mo}_{2} \mathrm{C} / \alpha-\mathrm{Al}_{2} \mathrm{O}_{3}, \mathrm{Co} / \mathrm{Mo}=1$; (f) $\mathrm{Co} / \alpha-\mathrm{Al}_{2} \mathrm{O}_{3}$. Patterns are offset for clarity. 


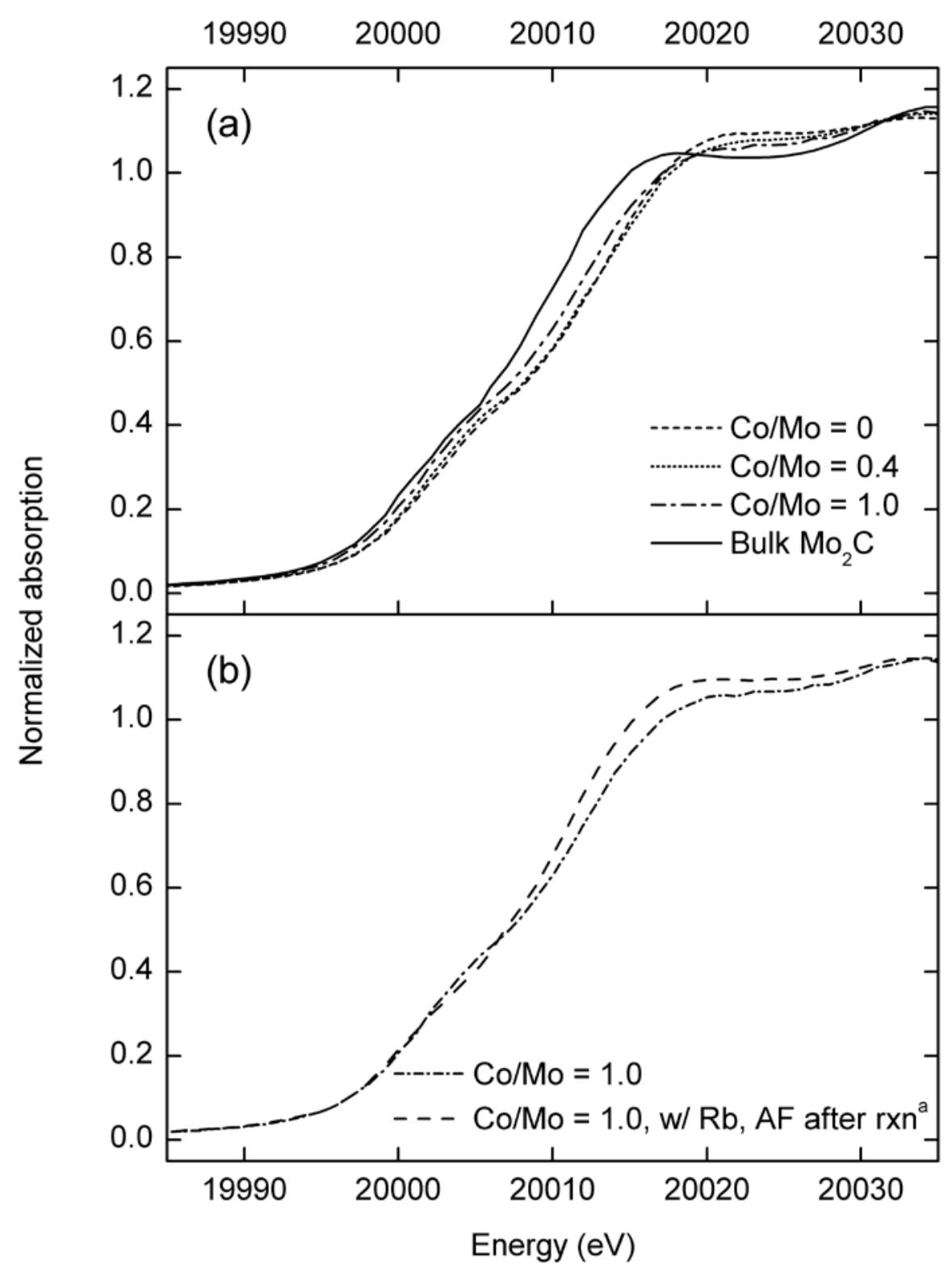

Figure 5.5 Mo $\mathrm{K}$ edge XANES of (a) bulk $\mathrm{Mo}_{2} \mathrm{C}$ and alumina-supported $\mathrm{Co}-\mathrm{Mo}_{2} \mathrm{C}$ species with various molar ratios of $\mathrm{Co} / \mathrm{Mo}$; (b) a comparison between $\mathrm{Co}-\mathrm{Mo}_{2} \mathrm{C} / \alpha-$ $\mathrm{Al}_{2} \mathrm{O}_{3}(\mathrm{Co} / \mathrm{Mo}=1.0)$ and Rb-promoted $\mathrm{Co}-\mathrm{Mo}_{2} \mathrm{C} / \alpha-\mathrm{Al}_{2} \mathrm{O}_{3}(\mathrm{Co} / \mathrm{Mo}=1.0)$ after $120 \mathrm{~h}$ syngas reaction.

${ }^{a}$ Purged in Ar after syngas reaction, air-free handling for sample preparation. 
The results from elemental analysis revealed a $\mathrm{MoC}_{0.525}$ stoichiometry for the supported molybdenum carbide sample, which is close to that of bulk $\mathrm{Mo}_{2} \mathrm{C}$. The analysis of a carburized $\mathrm{Co}-\mathrm{Mo} / \alpha-\mathrm{Al}_{2} \mathrm{O}_{3}$ sample $(\mathrm{Co} / \mathrm{Mo}=1)$ revealed a stoichiometry of $\mathrm{MoCo}_{0.96} \mathrm{C}_{1.05}$, indicating excess carbon needed for stoichiometric $\mathrm{Mo}_{2} \mathrm{C}$. Although one might propose the excess carbon to be associated with a highly-dispersed Co carbide phase, results from X-ray absorption spectroscopy discussed below were not consistent with that hypothesis.

The X-ray absorption near edge structure (XANES) of the catalyst samples at the Mo $K$ edge is summarized in Figure 5.5. The Mo species in $\mathrm{Mo}_{2} \mathrm{C} / \alpha-\mathrm{Al}_{2} \mathrm{O}_{3}(\mathrm{Co} / \mathrm{Mo}=0$, Figure 5.5a) was more oxidized than the bulk $\mathrm{Mo}_{2} \mathrm{C}$ standard, which is due to the high affinity of surface Mo for oxygen and is consistent with our previous observations on passivated $\mathrm{Mo}_{2} \mathrm{C}$ supported on $\mathrm{MgO}$ [11] and $\alpha-\mathrm{Al}_{2} \mathrm{O}_{3}$ [12]. For a carbide sample with relatively high loading of $\mathrm{Co}$, the Mo species in a Co- $-\mathrm{Mo}_{2} \mathrm{C} / \alpha-\mathrm{Al}_{2} \mathrm{O}_{3}$ sample with $\mathrm{Co} / \mathrm{Mo}$ $=1.0$ (Figure 5.5a) was more reduced than $\mathrm{Mo}_{2} \mathrm{C} / \alpha-\mathrm{Al}_{2} \mathrm{O}_{3}$, but was still more oxidized than bulk $\mathrm{Mo}_{2} \mathrm{C}$. Analysis of a sample with air-free handling after $120 \mathrm{~h}$ syngas reaction did not significantly alter the edge position of a 2.5 wt.\% Rb-promoted $\mathrm{Co}-\mathrm{Mo}_{2} \mathrm{C} / \alpha-$ $\mathrm{Al}_{2} \mathrm{O}_{3}$ sample $(\mathrm{Co} / \mathrm{Mo}=1.0$, Figure $5.5 b)$ compared to an unreacted Co- $\mathrm{Mo}_{2} \mathrm{C} / \alpha-\mathrm{Al}_{2} \mathrm{O}_{3}$ catalyst analyzed in air.

The Fourier transforms (FT) of $k^{3}$-weighted extended X-ray absorption fine structure (EXAFS) at Mo $K$ edge are shown in Figure 5.6 and the structural parameters derived from the corresponding curve fits are presented in Table 5.4. Example curve fits associated with the results in Table 5.4 are compared to the experimental EXAFS for Mo $K$ edge EXAFS of $\mathrm{Co}-\mathrm{Mo}_{2} \mathrm{C} / \alpha-\mathrm{Al}_{2} \mathrm{O}_{3}(\mathrm{Co} / \mathrm{Mo}=1.0)$ in Figure 5.7. All of the $R$-factors of 
the fits are much less than 0.1 , indicating good agreements between the experimental EXAFS and fits. In the $\mathrm{Mo}_{2} \mathrm{C} / \alpha-\mathrm{Al}_{2} \mathrm{O}_{3}$ sample (Figure 5.6a), the supported $\mathrm{Mo}_{2} \mathrm{C}$ had a Mo-Mo coordination number as low as 2.9 (Table 5.4), which is consistent with the highly-dispersed $\mathrm{Mo}_{2} \mathrm{C}$ clusters reported on $\mathrm{H}-\mathrm{ZSM}-5$ zeolite [28], $\alpha-\mathrm{Al}_{2} \mathrm{O}_{3}$ [12], $\gamma-\mathrm{Al}_{2} \mathrm{O}_{3}$ [29] and mixed-phase $\mathrm{Al}_{2} \mathrm{O}_{3}$, with Mo-Mo coordination numbers derived from EXAFS of 2.6, 2.5, 4 and 3.2, respectively. The Mo-Mo coordination number increased with Co/Mo ratio from 2.9 in $\mathrm{Mo}_{2} \mathrm{C} / \alpha-\mathrm{Al}_{2} \mathrm{O}_{3}$ to 6.9 (Table 5.4) in the $\mathrm{Co}-\mathrm{Mo}_{2} \mathrm{C} / \alpha-\mathrm{Al}_{2} \mathrm{O}_{3}$ sample with a Co/Mo ratio of 1.0 (Figure 5.6c), which is consistent with the growth of $\mathrm{Mo}_{2} \mathrm{C}$ domain suggested by EXAFS (Figure 5.6) and XRD (Figure 5.4). The growth of $\mathrm{Mo}_{2} \mathrm{C}$ domains decreased the percentage of surface Mo atoms that can be partially oxidized by $\mathrm{O}_{2}$, resulting in a lower average oxidation state of Mo, which is in good agreement with the observation in Mo $K$ edge XANES (Figure 5.5a). After 3 days of syngas reaction, the coordination number of Mo-Mo in a Rb-promoted $\mathrm{Co}-\mathrm{Mo}_{2} \mathrm{C} / \alpha-$ $\mathrm{Al}_{2} \mathrm{O}_{3}$ sample $(\mathrm{Co} / \mathrm{Mo}=1.0)$ increased slightly from 6.9 to 7.7 , which suggests that sintering of $\mathrm{Mo}_{2} \mathrm{C}$ domain during reaction was relatively minor. However, no clear evidence of Mo-Co interactions was found in the supported $\mathrm{Co}-\mathrm{Mo}_{2} \mathrm{C}$ samples (Figure 5.6b-c). Efforts were made to fit the second shell in Figure 5.6 as Mo-Co, but none of the fits were physically realistic $\left(\left|\Delta E_{0}\right|>30 \mathrm{eV}, \Delta \sigma^{2}>0.03\right.$ or $\left.\Delta \sigma^{2}<0\right)$. 

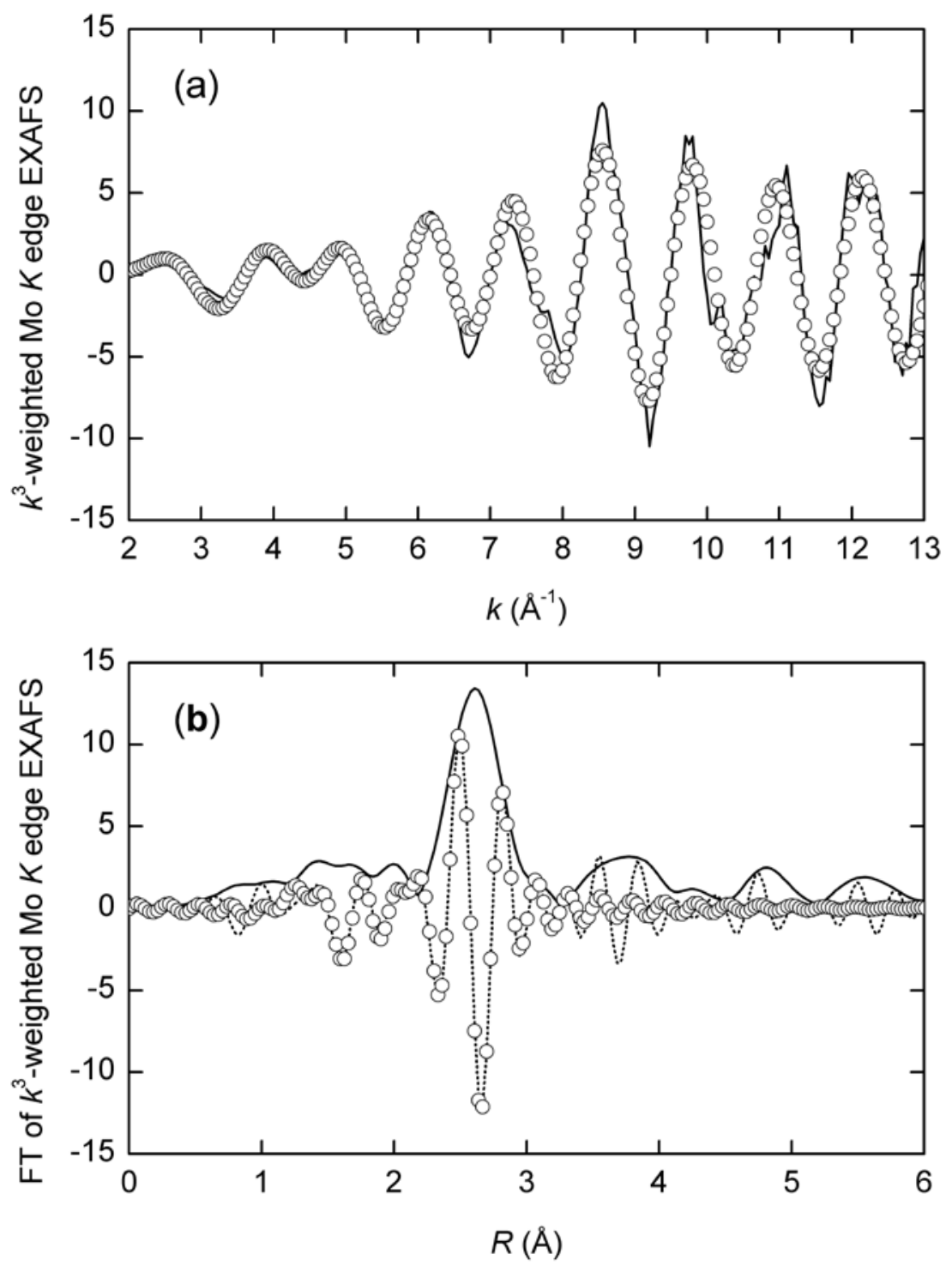

Figure 5.7 Comparison of the curve fit to experimental Mo $K$ edge EXAFS of Co$\mathrm{Mo}_{2} \mathrm{C} / \alpha-\mathrm{Al}_{2} \mathrm{O}_{3}(\mathrm{Co} / \mathrm{Mo}=1.0)$ : (a) $k^{3}$-Weighted Mo $K$ edge EXAFS (solid line) and the result from curve fit (circles); (b) magnitude (solid line) and the imaginary part (dashed line) of the Fourier transform of EXAFS compared with the result from the curve fit (circles).

The XANES spectra at the Co $K$ edge of bulk Co standards and aluminasupported Co samples are summarized in Figure 5.8. The FT of $k^{3}$-weighted Co $K$ edge EXAFS are shown in Figure 5.9 and the structural parameters derived from the corresponding curve fits are presented in Table 5.5. Example curve fits associated with the results in Table 5.5 are compared to the experimental EXAFS for Mo $K$ edge EXAFS 
of $\mathrm{Co}-\mathrm{Mo}_{2} \mathrm{C} / \alpha-\mathrm{Al}_{2} \mathrm{O}_{3}(\mathrm{Co} / \mathrm{Mo}=1.0)$ in Figure 5.9. All of the $R$-factors of the fits are much less than 0.1, indicating good agreements between the experimental EXAFS and fits. The XANES spectra suggest that the Co species in "carburized" $\mathrm{Co} / \alpha-\mathrm{Al}_{2} \mathrm{O}_{3}(\mathrm{Co} / \mathrm{Mo}$ $=\infty$, Figure 5.8b) was severely oxidized after exposure to air, which is even more oxidized than the $\mathrm{CoO}$ standard (Figure 5.8a). The FT of Co $K$ edge EXAFS showed that alumina-supported "carburized" Co (Figure 5.9a) possessed a similar structure to bulk $\mathrm{Co}_{3} \mathrm{O}_{4}$ (Figure 5.9b). These results are in good agreement with the high dispersion of Co species suggested by the corresponding XRD pattern (Figure 5.4f), given that the reduction of silica-supported $\mathrm{Co}_{3} \mathrm{O}_{4}$ is difficult when the diameter of the cluster is below $6 \mathrm{~nm}$ [31]. Strong interactions of Co oxide nanoparticles with a silica support were thought to inhibit their reduction [31]. However, the bimetallic samples with a Co/Mo ratio of 0.4 or 1.0 exhibited a lower white line intensity and a lower edge energy in XANES (Figure 5.8b) compared to the supported Co sample. The peak positions in the Fourier transforms of the EXAFS (Figure 5.9d-e) associated with the Co- $\mathrm{Mo}_{2} \mathrm{C} / \alpha-\mathrm{Al}_{2} \mathrm{O}_{3}$ samples suggest that the Co likely remained in a metallic form when Mo was present. The fits of the EXAFS gave Co-Co coordination numbers in $\mathrm{Co}-\mathrm{Mo}_{2} \mathrm{C} / \alpha-\mathrm{Al}_{2} \mathrm{O}_{3}$ less than 8 (Table 5.5), which corresponds to $>75 \%$ dispersion of Co [32], or particles with an average diameter less than $1.4 \mathrm{~nm}$. Clearly, the supported Mo carbide species assisted the Co clusters to form reduced particles. However, no clear evidence of Co-Mo interactions was found in the Co EXAFS of the supported Co- $\mathrm{Mo}_{2} \mathrm{C}$ samples (Figure 5.9d-e). Efforts were made to fit the large peak in Figure 5.9d-e as Co-Mo or a mixture of Co-Mo and Co-Co, but none of the fits was realistic $\left(\left|\Delta E_{0}\right|>30 \mathrm{eV}\right.$ or $\left.\mathrm{CN}<0\right)$. A phase separation involving $\mathrm{Co}$ and $\mathrm{Mo}_{2} \mathrm{C}$ has been also reported by Xiao et al. who used a similar 
carburization method from a Co-Mo mixed oxide precursor [33]. Moreover, no evidence for a Co carbide species was revealed by EXAFS of the supported $\mathrm{Co}-\mathrm{Mo}_{2} \mathrm{C}$ samples, since there was no apparent Co-C interaction present in Figure 5.9d-e and the Co-Co distance in $\mathrm{Co}_{2} \mathrm{C}(2.62 \AA$, [34]) is much longer than that in Co metal (observed in this work).

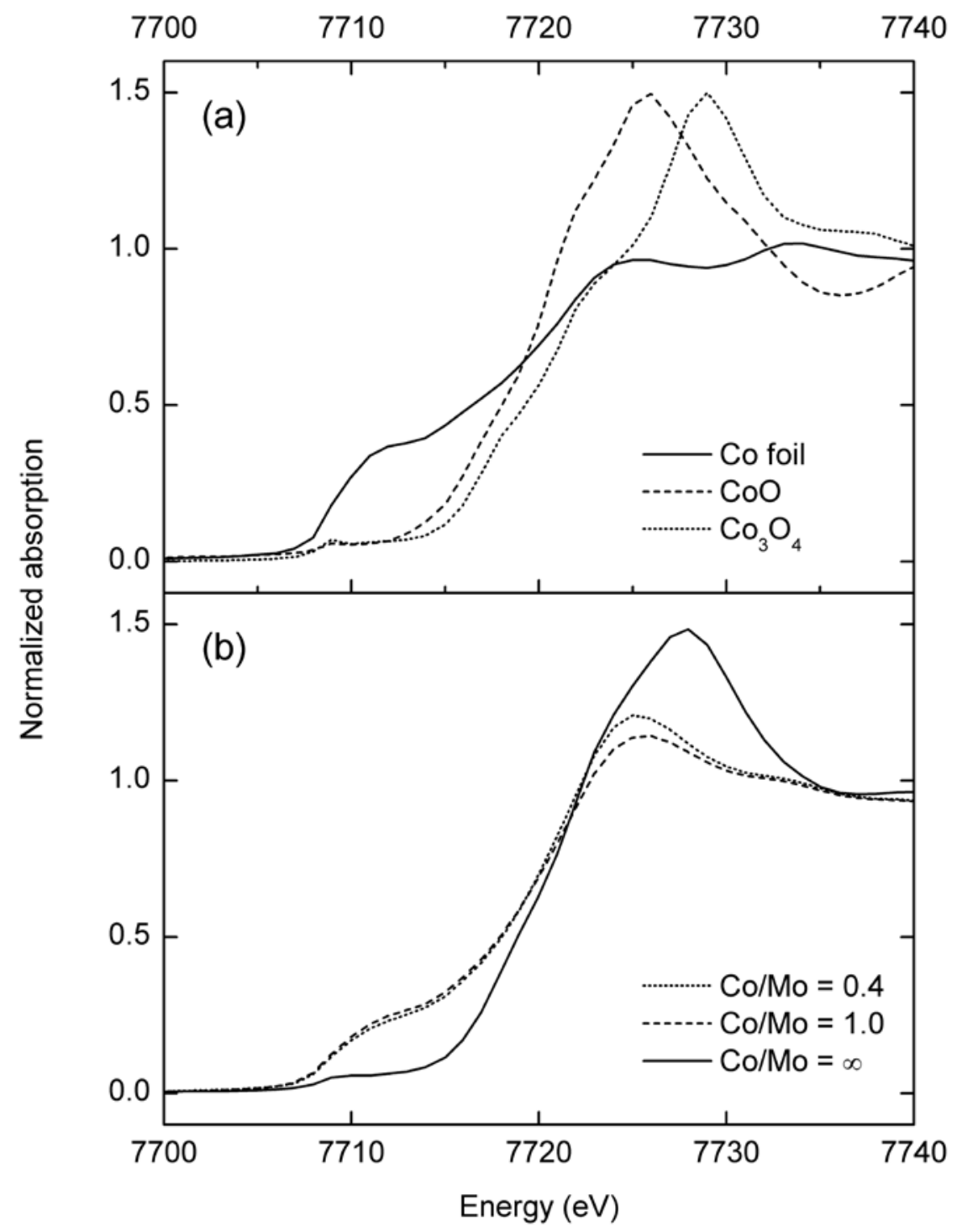

Figure 5.8 Co $K$ edge XANES of (a) Co reference standards; (b) Co- $\mathrm{Mo}_{2} \mathrm{C} / \alpha-\mathrm{Al}_{2} \mathrm{O}_{3}$ catalysts with various molar ratios of $\mathrm{Co} / \mathrm{Mo}$. The loading of Mo is $5 \mathrm{wt} . \%$. The molar loading of $\mathrm{Co}$ in the sample "Co/Mo $=\infty$ " $\left(\mathrm{Co}\right.$ supported on $\left.\alpha-\mathrm{Al}_{2} \mathrm{O}_{3}\right)$ is equivalent to that of Mo in a 5 wt.\% Mo sample. 


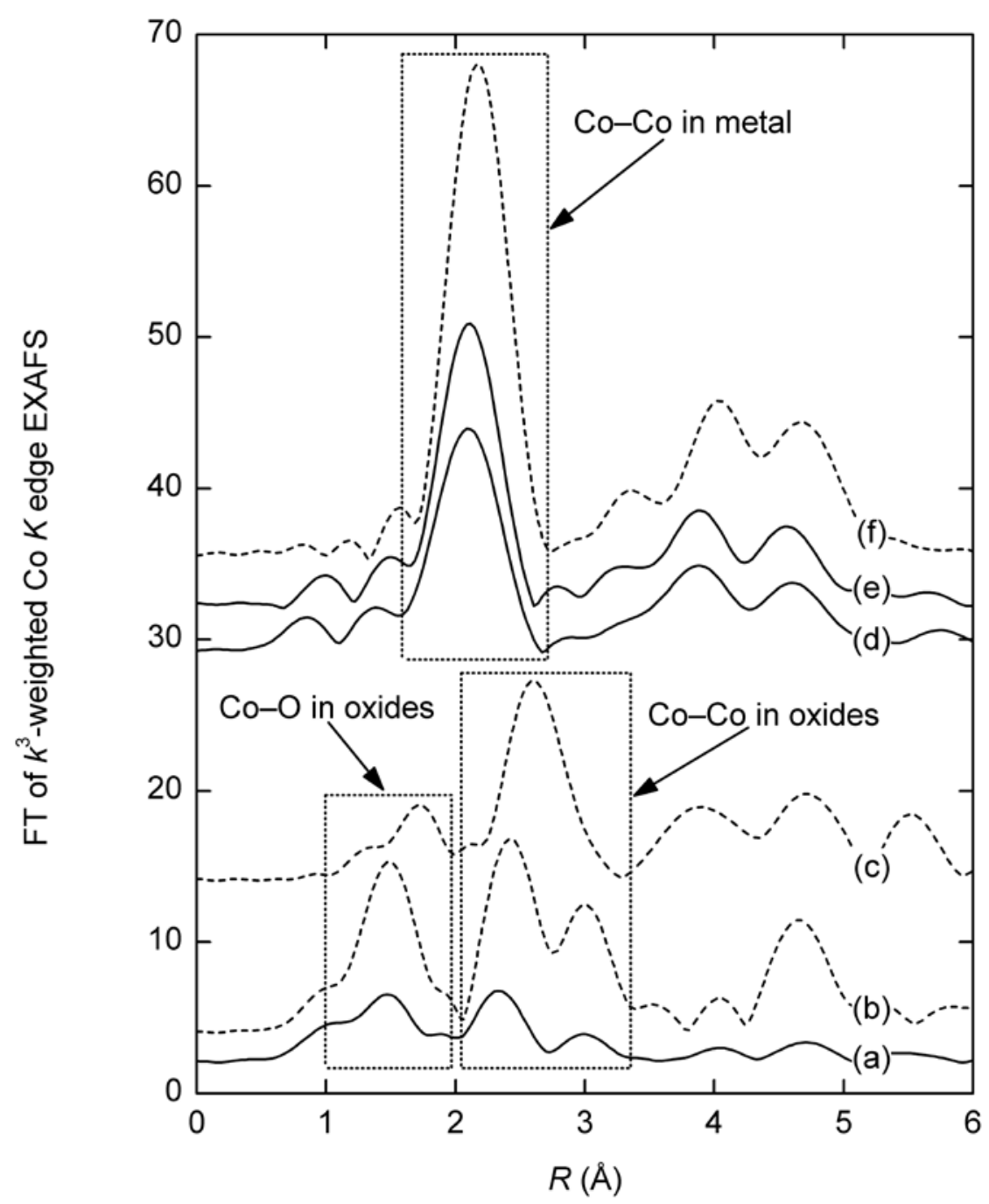

Figure 5.9 FT (not phase-shift-corrected) of $k^{3}$-weighted Co $K$ edge EXAFS: (a) 3.1 wt. \% Co/ $\alpha-\mathrm{Al}_{2} \mathrm{O}_{3}$; (b) $\mathrm{Co}_{3} \mathrm{O}_{4}$; (c) $\mathrm{CoO}$; (d) $\mathrm{Co}-\mathrm{Mo}_{2} \mathrm{C} / \alpha-\mathrm{Al}_{2} \mathrm{O}_{3}, \mathrm{Co} / \mathrm{Mo}=0.4$; (e) $\mathrm{Co}-$ $\mathrm{Mo}_{2} \mathrm{C} / \alpha-\mathrm{Al}_{2} \mathrm{O}_{3}, \mathrm{Co} / \mathrm{Mo}=1.0$; (f) Co foil. Spectra are offset for clarity. The loading of $\mathrm{Mo}$ is 5 wt.\%. The $\mathrm{Co} / \mathrm{Mo}$ ratio is mole-based. The molar loading of Co corresponding to $3.1 \mathrm{wt}$ \% Co is equivalent to that of Mo in a 5 wt.\% Mo sample.

Table 5.5 Results from the Analysis of Co $K$ edge EXAFS

\begin{tabular}{lllllll}
\hline Sample & Shell & $\mathrm{CN}$ & $r(\AA)$ & $\Delta \sigma^{2}\left(10^{-3} \AA^{2}\right)$ & $\Delta E_{0}(\mathrm{eV})$ & $R$-factor \\
\hline Co foil & Co-Co & $12^{\mathrm{a}}$ & $2.49 \pm 0.00$ & $5.9 \pm 0.4$ & $5.5 \pm 0.4$ & 0.004 \\
Co/Mo $=0.4$ & Co-Co & $5.8 \pm 1.4$ & $2.50 \pm 0.02$ & $5.3 \pm 2.1$ & $-4.7 \pm 2.5$ & 0.086 \\
Co/Mo = 1 & Co-Co & $7.0 \pm 1.2$ & $2.50 \pm 0.01$ & $5.8 \pm 1.4$ & $-5.3 \pm 1.7$ & 0.042 \\
\hline
\end{tabular}

Fitting parameters: Fourier transform range, $\Delta k, 2-12 \AA^{-1}$; fitting range, $\Delta R, 1-3 \AA$; weighting, $k^{1} \& k^{3} ; S_{0}^{2}(\mathrm{Co}-\mathrm{Co})=0.69$.

${ }^{\mathrm{a}}$ Value was assigned in curving-fitting on the basis of standard structure. 

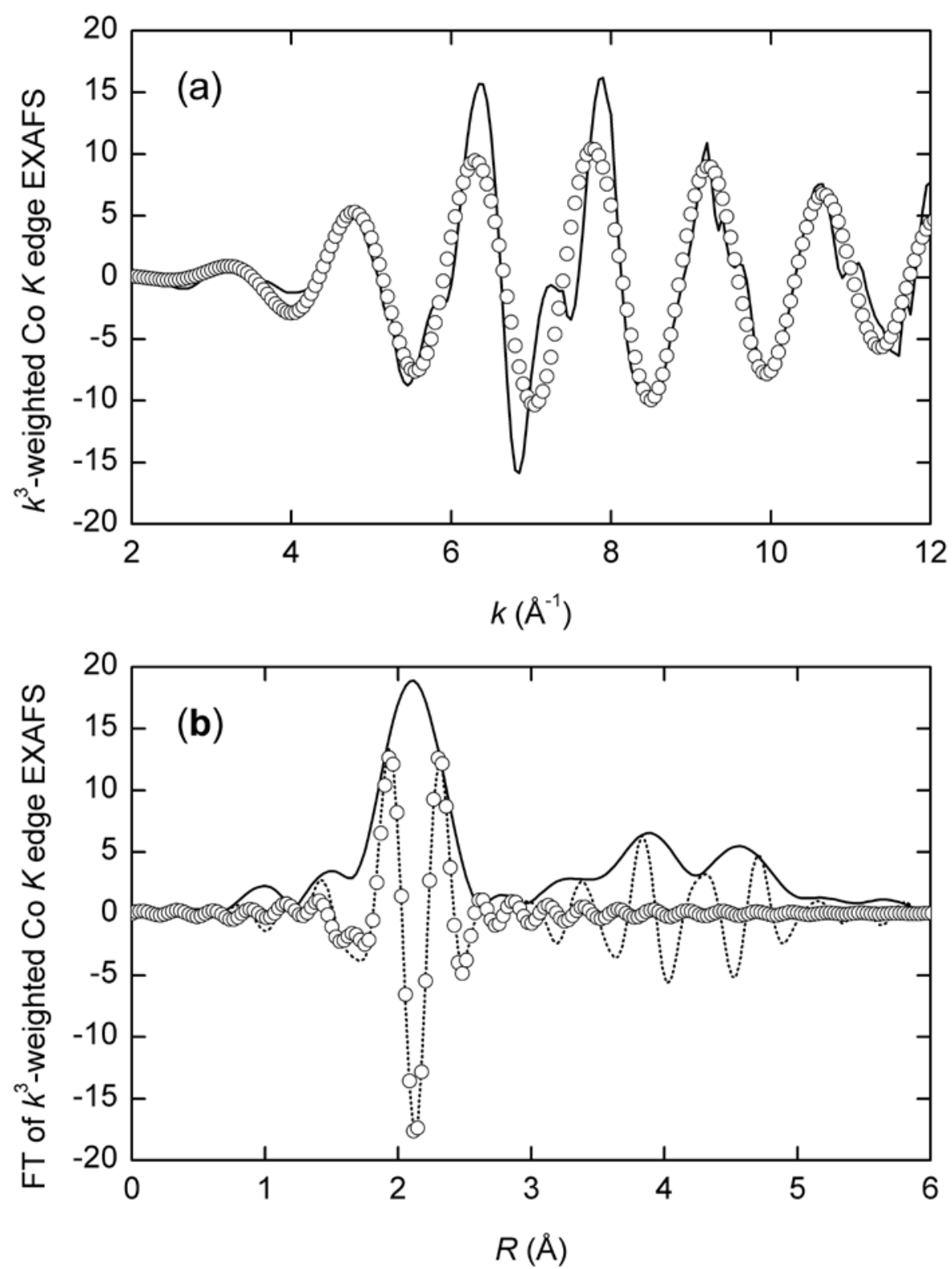

Figure 5.10 Comparison of the curve fit to experimental Co $K$ edge EXAFS of Co$\mathrm{Mo}_{2} \mathrm{C} / \alpha-\mathrm{Al}_{2} \mathrm{O}_{3}(\mathrm{Co} / \mathrm{Mo}=1.0)$ : (a) $k^{3}$-Weighted Mo $K$ edge EXAFS (solid line) and the result from curve fit (circles); (b) magnitude (solid line) and the imaginary part (dashed line) of the Fourier transform of EXAFS compared with the result from the curve fit (circles).

The evidence for metallic Co co-existing with $\mathrm{Mo}_{2} \mathrm{C}$, as well as lack of a $\mathrm{Co}-\mathrm{C}$ interaction in Co EXAFS, seems to contradict the excessive carbon found in the $\mathrm{MoCo}_{0.96} \mathrm{C}_{1.05}$ sample revealed by elemental analysis. However, the extra carbon may result from the residual $\mathrm{CH}_{\mathrm{x}}$ species produced during the carburization of Mo assisted by 
Co [27], or by the adsorption of atmospheric $\mathrm{CO}_{2}$ on a partially oxidized Co surface (Figure 5.8b), forming a carbonate surface species.

It has been shown that $\mathrm{Ru}, \mathrm{Rh}, \mathrm{Re}$ and $\mathrm{Pt}$, even in very small amounts (0.05-0.1 wt.\%), are able to enhance the reducibility of Co catalysts on various supports $\left(\mathrm{Al}_{2} \mathrm{O}_{3}\right.$, $\mathrm{SiO}_{2}, \mathrm{TiO}_{2}, \mathrm{ZrO}_{2}$, etc.) for Fischer-Tropsch synthesis [35-43]. This improvement in Co reducibility is not likely the result of differences in the Co particle size, as observed by Das et al. on $\mathrm{Co}-\mathrm{Re} / \mathrm{Al}_{2} \mathrm{O}_{3}$ catalysts [44].

In alumina-supported Pt-Co catalysts, Jacobs et al. [45] showed that Pt may locate on the edge of the Co metal clusters without forming Pt-Pt aggregates. The same model may also be applied to the Pt-Co catalysts supported on $\mathrm{Al}_{2} \mathrm{O}_{3}$ and on $\mathrm{NaY}$ zeolite reported by Guczi et al. [46]. Even if there is phase segregation of components in a bimetallic catalyst, a hydrogen spillover mechanism can still account for the influence of $\mathrm{Pt}, \mathrm{Rh}$ or $\mathrm{Ru}$ on the reducibility of Co catalysts $[47,48]$. In this mechanism, the oxide precursor of $\mathrm{Pt}, \mathrm{Rh}$ or $\mathrm{Ru}$ is reduced to the metallic state at a much lower temperature than Co oxide. Once the non-cobalt metal is reduced, it facilitates the dissociation of $\mathrm{H}_{2}$ and the spillover of $\mathrm{H}$ atoms, thus enhancing the reduction of Co oxide. It has also been shown that for a zeolite-supported Pt-Co catalyst, once the metallic Co was formed, it remained metallic in air with co-existing Pt [46]. However, the Co in analogous aluminasupported bimetallic Pt-Co particles was readily oxidized in air [46]. Since our catalysts are supported on alumina, we do not have a good explanation at this time for the stability of metallic Co in our $\mathrm{Co}-\mathrm{Mo}_{2} \mathrm{C} / \alpha-\mathrm{Al}_{2} \mathrm{O}_{3}$ catalysts in air.

According to the similarity in reactivity between $\mathrm{Mo}_{2} \mathrm{C}$ and certain Pt-group metals [49], the enhancement of Co reducibility demonstrated with Co-M catalysts ( $\mathrm{M}=$ 
$\mathrm{Ru}$, Rh or Pt) may be also applicable to the $\mathrm{Co}-\mathrm{Mo}_{2} \mathrm{C} / \alpha-\mathrm{Al}_{2} \mathrm{O}_{3}$ catalysts in this study. Since we have not observed a direct interaction between Co and Mo atoms by X-ray absorption spectroscopy, an interaction may exist at the boundary between a Co domain and a $\mathrm{Mo}_{2} \mathrm{C}$ domain. The lack of an obvious Co-Mo interaction in EXAFS likely results from the small fraction of atoms at the interface between the phases. Nevertheless, according to the reactivity results (Table 5.1), a Co- $\mathrm{Mo}_{2} \mathrm{C} / \alpha-\mathrm{Al}_{2} \mathrm{O}_{3}$ catalyst as prepared in this study cannot be treated as a simple superposition of $\mathrm{Co} / \alpha-\mathrm{Al}_{2} \mathrm{O}_{3}$ and $\mathrm{Mo}_{2} \mathrm{C} / \alpha-\mathrm{Al}_{2} \mathrm{O}_{3}$, which also suggests a molecular level interaction between Co and Mo species.

\subsection{Conclusions}

Bimetallic Co- $\mathrm{Mo}_{2} \mathrm{C} / \alpha-\mathrm{Al}_{2} \mathrm{O}_{3}$ catalysts were prepared by co-impregnating the Co and Mo precursors, followed by calcination, carburization and passivation. The addition of Co to $\mathrm{Rb}$-promoted $\mathrm{Mo}_{2} \mathrm{C} / \alpha-\mathrm{Al}_{2} \mathrm{O}_{3}$ enhanced the overall reactivity of $\mathrm{Mo}_{2} \mathrm{C}$ catalysts, promoted the formation of higher alcohols over methanol, and effectively reduced the loss of alcohol selectivity at high CO conversion. The results from X-ray absorption spectroscopy revealed that the Co metal and Mo carbide domains on alumina, although very highly dispersed, were capable to keep each other more reduced than their corresponding monometallic samples. Although direct interactions between Co and Mo were not observed spectroscopically, the reactivity patterns reported here clearly suggest a molecular-level interaction between Co and Mo.

\subsection{Acknowledgements}

The authors acknowledge financial support from The Dow Chemical Company and helpful discussions with Dr. David Barton and Dr. Gerolamo Budroni at The Dow 
Chemical Company, and Dr. Pradeep Agrawal, Dr. David Sholl, Mr. Michael Morrill and Mr. Liwei Li at the Georgia Institute of Technology. The authors also acknowledge Dr. Gary Koenig and Ms. Yue Huang at University of Virginia for the use of their glovebox for air-free sample preparation. Use of the NSLS was supported by the US Department of Energy, Office of Science, Office of Basic Energy Sciences, under Contract No. DEAC02-98CH10886. Beamline X18B at the NSLS is supported in part by the Synchrotron Catalysis Consortium, US Department of Energy Grant No. DE-FG02-05ER15688. The authors acknowledge with gratitude the invaluable assistance received from the $\mathrm{X}-18 \mathrm{~B}$ beam line personnel, Dr. Nebojsa Marinkovic and Dr. Syed Khalid.

\section{References of Chapter 5}

[1] G.W. Huber, S. Iborra, A. Corma, "Synthesis of transportation fuels from biomass: Chemistry, catalysts, and engineering,” Chemical Reviews 106 (2006) 4044-4098.

[2] K. Fang, D. Li, M. Lin, M. Xiang, W. Wei, Y. Sun, “A short review of heterogeneous catalytic process for mixed alcohols synthesis via syngas,” Catalysis Today 147 (2009) 133-138.

[3] S. Zaman, K.J. Smith, "A review of molybdenum catalysts for synthesis gas conversion to alcohols: Catalysts, mechanisms and kinetics," Catalysis Reviews: Science and Engineering 54 (2012) 41-132.

[4] V. Subramani, S.K. Gangwal, A review of recent literature to search for an efficient catalytic process for the conversion of syngas to ethanol, Energy \& Fuels 22 (2008) 814-839.

[5] R.R. Stevens, Process for producing alcohols from synthesis gas, U.S. Patent 4752622, 1988, to The Dow Chemical Company.

[6] M.M. Conway, C.B. Murchison, R.R. Stevens, "Method for adjusting methanol to higher alcohol ratios,” U.S. Patent 4675344, 1987 to The Dow Chemical Company.

[7] J.M. Christensen, P.M. Mortensen, R. Trane, P.A. Jensen, A.D. Jensen, "Effects of $\mathrm{H}_{2} \mathrm{~S}$ and process conditions in the synthesis of mixed alcohols from syngas over alkali promoted cobalt-molybdenum sulfide,” Applied Catalysis A: General 366 (2009) 29-43. 
[8] J.G. Chen, Carbide and nitride overlayers on early transition metal surfaces: Preparation, characterization, and reactivities, Chemical Reviews 96 (1996) 14771498.

[9] H.C. Woo, K.Y. Park, Y.G. Kim, I.S. Nam, J.S. Chung, J.S. Lee, "Mixed alcohol synthesis from carbon monoxide and dihydrogen over potassium-promoted molybdenum carbide catalysts,” Applied Catalysis 75 (1991) 267-280.

[10] M. Xiang, D. Li, W. Li, B. Zhong, Y. Sun, "Performances of mixed alcohols synthesis over potassium promoted molybdenum carbides,” Fuel 85 (2006) 26622665.

[11] H. Shou, R.J. Davis, "Reactivity and in situ X-ray absorption spectroscopy of Rbpromoted $\mathrm{Mo}_{2} \mathrm{C} / \mathrm{MgO}$ catalysts for higher alcohol synthesis," Journal of Catalysis 282 (2011) 83-93.

[12] H. Shou, D. Ferrari, D.G. Barton, C.W. Jones, R.J. Davis, "Influence of passivation on the reactivity of unpromoted and Rb-promoted $\mathrm{Mo}_{2} \mathrm{C}$ nanoparticles for $\mathrm{CO}$ hydrogenation,” ACS Catalysis 2 (2012) 1408-1416.

[13] Z. Li, Y. Fu, J. Bao, M. Jiang, T. Hu, T. Liu, Y. Xie, "Effect of cobalt promoter on Co-Mo-K/C catalysts used for mixed alcohol synthesis,” Applied Catalysis A: General 220 (2001) 21-30.

[14] M. Xiang, D. Li, H. Xiao, J. Zhang, H. Qi, W. Li, B. Zhong, Y. Sun, "Synthesis of higher alcohols from syngas over Fischer-Tropsch elements modified $\mathrm{K} / \beta-\mathrm{Mo}_{2} \mathrm{C}$ catalysts,” Fuel 87 (2008) 599-603.

[15] A.J. Lucero, V.K. Sethi, W.H. Tuminello, "Process and catalyst for production of mixed alcohols from synthesis gas,” U.S. Patent 8048933, 2011, to University of Wyoming Research Corporation.

[16] B. Ravel, M. Newville, “ATHENA, ARTEMIS, HEPHAESTUS: Data analysis for X-ray absorption spectroscopy using IFEFFIT,” Journal of Synchrotron Radiation 12 (2005) 537-541.

[17] S.I. Zabinsky, J.J. Rehr, A. Ankudinov, R.C. Albers, M.J. Eller, "Multiplescattering calculations of x-ray-absorption spectra,” Physical Review B 52 (1995) 2995-3009.

[18] R. Burch, M.I. Petch, "Investigation of the synthesis of oxygenates from carbon monoxide/hydrogen mixtures on supported rhodium catalysts," Applied Catalysis A: General 88 (1992) 39-60.

[19] S.K. Bej, C.A. Bennett, L.T. Thompson, "Acid and base characteristics of molybdenum carbide catalysts,” Applied Catalysis A: General 250 (2003) 197-208. 
[20] J.S. Lee, S. Kim, K.H. Lee, I.-S. Nam, J.S. Chung, Y.G. Kim, H.C. Woo, "Role of alkali promoters in $\mathrm{K} / \mathrm{MoS}_{2}$ catalysts for $\mathrm{CO}-\mathrm{H}_{2}$ reactions," Applied Catalysis A: General 110 (1994) 11-25.

[21] J.S. Lee, S. Kim, Y.G. Kim, "Electronic and geometric effects of alkali promoters in CO hydrogenation over K/Mo ${ }_{2} \mathrm{C}$ catalysts," Topics in Catalysis 2 (1995) 127140.

[22] M. Xiang, D. Li, W. Li, B. Zhong, Y. Sun, "Synthesis of higher alcohols from syngas over $\mathrm{K} / \mathrm{Co} / \beta-\mathrm{Mo}_{2} \mathrm{C}$ catalysts," Catalysis Communications 8 (2007) 503507.

[23] V.R. Surisetty, I. Eswaramoorthi, A.K. Dalai, "Comparative study of higher alcohols synthesis over alumina and activated carbon-supported alkali-modified MoS2 catalysts promoted with group VIII metals,” Fuel 96 (2012) 77-84.

[24] V.R. Surisetty, A.K. Dalai, J. Kozinski, "Synthesis of higher alcohols from synthesis gas over Co-promoted alkali-modified $\mathrm{MoS}_{2}$ catalysts supported on MWCNTs,” Applied Catalysis A: General 385 (2010) 153-162.

[25] M. Sun, A.E. Nelson, J. Adjaye, "On the incorporation of nickel and cobalt into $\mathrm{MoS}_{2}$-edge structures,” Journal of Catalysis 226 (2004) 32-40.

[26] P.L. Spath, D.C. Dayton, Preliminary Screening - Technical and economic assessment of synthesis gas to fuels and chemicals with emphasis on the potential for biomass-derived syngas, U.S. Department of Energy Report, Oak Ridge, TN, 2003.

[27] C. Liang, W. Ma, Z. Feng, C. Li, “Activated carbon supported bimetallic CoMo carbides synthesized by carbothermal hydrogen reduction,” Carbon 41 (2003) 1833-1839.

[28] W. Ding, S. Li, G.D. Meitzner, E. Iglesia, "Methane conversion to aromatics on Mo/H-ZSM5: Structure of molybdenum species in working catalysts," The Journal Physical Chemistry B 105 (2001) 506-513.

[29] J.S. Lee, M. Boudart, "In situ carburization of metallic molybdenum during catalytic reactions of carbon-containing gases,” Catalysis Letter 20 (1993) 97-106.

[30] H. Shou, L. Li, D. Ferrari, D.S. Sholl, R.J. Davis, "Use of infrared spectroscopy and density functional theory to study the influence of rubidium on aluminasupported molybdenum carbide catalyst for higher alcohol synthesis from syngas," Journal of Catalysis 299 (2013) 150-161.

[31] A.Y. Khodakov, J. Lynch, D. Bazin, B. Rebours, N. Zanier, B. Moisson, P. Chaumette, "Reducibility of cobalt species in silica-supported Fischer-Tropsch catalysts,” Journal of Catalysis 168 (1997) 16-25. 
[32] A. Jentys, "Estimation of mean size and shape of small metal particles by EXAFS," Physical Chemistry Chemical Physics 1 (1999) 4059-4063.

[33] T. Xiao, A.P.E. York, K.S. Coleman, J.B. Claridge, J. Sloan, J. Charnock, M.L.H. Green, "Effect of carburising agent on the structure of molybdenum carbides," Journal of Materials Chemistry 11 (2001) 3094-3098.

[34] Y.-H. Zhao, H.-Y. Su, K. Sun, J. Liu, W.-X. Li, "Structural and electronic properties of cobalt carbide $\mathrm{Co}_{2} \mathrm{C}$ and its surface stability: Density functional theory study,” Surface Science 606 (2012) 598-604.

[35] K. Takeuchi, T. Matsukaki, H. Arakawa, Y. Sugi, "Synthesis of ethanol from syngas over Co-Re-Sr/SiO 2 catalysts,” Applied Catalysis 18 (1985) 325-334.

[36] K. Takeuchi, T. Matsuzaki, H. Arakawa, T. Hanaoka, Y. Sugi, "Synthesis of C2oxygenates from syngas over cobalt catalysts promoted by ruthenium and alkaline earths,” Applied Catalysis 48 (1989) 149-157.

[37] S. Vada, A. Hoff, E. Ådnanes, D. Schanke, A. Holmen, "Fischer-Tropsch synthesis on supported cobalt catalysts promoted by platinum and rhenium," Topics in Catalysis 2 (1995) 155-162.

[38] A. Feller, M. Claeys, E. van Steen, "Cobalt cluster effects in zirconium promoted Co/SiO 2 Fischer-Tropsch catalysts,” Journal of Catalysis 185 (1999) 120-130.

[39] C.L. Bianchi, "TPR and XPS Investigations of $\mathrm{Co} / \mathrm{Al}_{2} \mathrm{O}_{3}$ Catalysts Promoted with Ru, Ir and Pt,” Catalysis Letters 76 (2001) 155-159.

[40] A. Martínez, C. López, F. Márquez, I. Díaz, "Fischer-Tropsch synthesis of hydrocarbons over mesoporous Co/SBA-15 catalysts: The influence of metal loading, cobalt precursor, and promoters,” Journal of Catalysis 220 (2003) 486499.

[41] C.J. Bertole, C.A. Mims, G. Kiss, "Support and rhenium effects on the intrinsic site activity and methane selectivity of cobalt Fischer-Tropsch catalysts," Journal of Catalysis 221 (2004) 191-203.

[42] W. Chu, P.A. Chernavskii, L. Gengembre, G.A. Pankina, P. Fongarland, A.Y. Khodakov, "Cobalt species in promoted cobalt alumina-supported Fischer-Tropsch catalysts,” Journal of Catalysis 252 (2007) 215-230.

[43] J. Hong, P.A. Chernavskii, A.Y. Khodakov, W. Chu, "Effect of promotion with ruthenium on the structure and catalytic performance of mesoporous silica (smaller and larger pore) supported cobalt Fischer-Tropsch catalysts," Catalysis Today 140 (2009) 135-141. 
[44] T.K. Das, G. Jacobs, P.M. Patterson, W.A. Conner, J. Li, B.H. Davis, "FischerTropsch synthesis: Characterization and catalytic properties of rhenium promoted cobalt alumina catalysts,” Fuel 82 (2003) 805-815.

[45] G. Jacobs, J.A. Chaney, P.M. Patterson, T.K. Das, J.C. Maillot, B.H. Davis, "Fischer-Tropsch synthesis: Study of the promotion of Pt on the reduction property of $\mathrm{Co} / \mathrm{Al}_{2} \mathrm{O}_{3}$ catalysts by in situ EXAFS of Co $K$ and Pt $L_{\mathrm{III}}$ edges and XPS," Journal of Synchrotron Radiation 11 (2004) 414-422.

[46] L. Guczi, D. Bazin, I. Kovács, L. Borkó, Z. Schay, J. Lynch, P. Parent, C. Lafon, G. Stefler, Zs. Koppány, I. Sajó, “Structure of Pt-Co/ $\mathrm{Al}_{2} \mathrm{O}_{3}$ and $\mathrm{Pt}-\mathrm{Co} / \mathrm{NaY}$ bimetallic catalysts: Characterization by in situ EXAFS, TPR, XPS and by activity in CO (carbon monoxide) hydrogenation,” Topics in Catalysis 20 (2002) 129-139.

[47] A.M. Hilmen, D. Schanke, A. Holmen, "TPR study of the mechanism of rhenium promotion of alumina-supported cobalt Fischer-Tropsch catalysts, Catalysis Letters 38 (1996) 143-147.

[48] F. Diehl, A.Y. Khodakov, "Promotion of Cobalt Fischer-Tropsch catalysts with noble metals: A review," Oil \& Gas Science and Technology - Revue de l"IFP 64 (2008) 11-24.

[49] H.H. Hwu, J.G. Chen, "Surface Chemistry of Transition Metal Carbides,” Chemical Reviews 105 (2005) 185-212. 


\title{
Chapter 6. Multi-product steady-state isotopic transient kinetic analysis of CO hydrogenation over supported molybdenum carbide
}

Modified with permission from Heng Shou and Robert J. Davis, "Multi-product steady state isotopic transient kinetic analysis of CO hydrogenation over supported molybdenum carbide," to submitted to Journal of Catalysis.

\begin{abstract}
Isotopic transient analysis of steady state of CO hydrogenation catalyzed by alumina-supported $\mathrm{Mo}_{2} \mathrm{C}$ nanoclusters was performed at $573 \mathrm{~K}, 1.2$ bar syngas with $\mathrm{H}_{2} / \mathrm{CO}=1$. An isotope switch from ${ }^{12} \mathrm{CO}$ to ${ }^{13} \mathrm{CO}$ during the steady-state reaction produced a rapid transient associated with CO hydrogenation and a very slow transient associated with turnover of ineffective catalytic sites or exchange of carbidic carbon with reaction intermediates. Although the intrinsic turnover frequency for hydrocarbon formation was similar to that observed on late transition metals, the coverage of reaction intermediates on the $\mathrm{Mo}_{2} \mathrm{C}$ clusters was very low ( $\left.\ll 1 \%\right)$, which accounts for the overall low activity of $\mathrm{Mo}_{2} \mathrm{C}$. Promotion of $\mathrm{Mo}_{2} \mathrm{C}$ with $\mathrm{Rb}_{2} \mathrm{CO}_{3}$ lowered the coverage of intermediates even further, but increased the selectivity towards alcohols. Very strong interaction of the alcohols with the promoter suggests that Rb may form alkoxides at reaction conditions.
\end{abstract}




\subsection{Introduction}

Early transition metal carbides (e.g., molybdenum carbide, $\mathrm{Mo}_{2} \mathrm{C}$ ) are potentially alternative catalysts to Pt-group metals [1] and are catalytically active in a variety of reactions, such as hydrogenolysis [2], isomerization [3,4], dehydrogenation [5,6], condensation [6,7], water-gas shift [8] and CO hydrogenation [9-20]. Molybdenum carbide catalysts are well-known to produce light hydrocarbons from syngas [15,21,22], but the selectivity of the reaction can be shifted from hydrocarbons to alcohols when appropriate promoters (i.e. alkali metal salts of weak acids [12,18]) and reaction conditions are used [11,14]. Unfortunately, the specific activity of the $\mathrm{Mo}_{2} \mathrm{C}$-based catalysts in CO hydrogenation is very low compared to other catalysts. For example, the apparent turnover frequency, or TOF, of $\mathrm{CO}$ on $\mathrm{Mo}_{2} \mathrm{C} / \alpha-\mathrm{Al}_{2} \mathrm{O}_{3}$ catalysts [17] (normalized by the amount of surface metal atoms) was approximately two orders of magnitude lower than that on an iron-promoted, titania-supported rhodium catalyst under similar conditions [23]. The very low apparent activity of molybdenum carbide can be attributed to either an intrinsically slow rate of catalytic turnover, or to a very small number of the active sites that accomplish the catalytic cycle related to the amount of Mo at the surface. Due to the high oxophilicity of $\mathrm{Mo}_{2} \mathrm{C}$, it is not straightforward to count the active sites that participate in the CO hydrogenation reaction. We therefore used isotopic transient kinetic analysis to probe the kinetics of $\mathrm{CO}$ hydrogenation catalyzed by supported molybdenum carbide.

Steady-state isotopic transient kinetic analysis (SSITKA), as developed by Happel [24], Bennett [25], and Biloen [26], is very useful for evaluating fundamental kinetic parameters of operating solid catalysts, including surface coverages of reaction 
intermediates, surface residence times, and active site heterogeneities. In addition, the technique can help identify possible mechanisms [27]. For CO hydrogenation, SSITKA has been employed on various metal catalysts including Fe [28-33], Pd [34-37], Co [28,29,38-42], Ru [43], Ni [44,45] and Rh [46,47]. For a complete discussion of SSITKA, please see the review by Shannon and Goodwin [27].

In the current work, we have used SSITKA to probe the kinetics of CO hydrogenation over alumina-supported $\mathrm{Mo}_{2} \mathrm{C}$ nanoclusters, with and without $\mathrm{Rb}$ promoters. As discussed above, the unpromoted $\mathrm{Mo}_{2} \mathrm{C}$ catalyst functioned primarily as a hydrocarbon formation catalyst with a standard Anderson-Schultz-Flory distribution $[15,21,22]$. Addition of alkali metal promoters to $\mathrm{Mo}_{2} \mathrm{C}$ allowed alcohols to be produced in addition to hydrocarbons [11-14,16-18].

\subsection{Experimental methods}

\subsubsection{Catalyst synthesis}

The $\mathrm{Mo}_{2} \mathrm{C}$ nanoclusters were prepared on $\alpha-\mathrm{Al}_{2} \mathrm{O}_{3}$ by incipient wetness impregnation of an aqueous solution of $\left(\mathrm{NH}_{4}\right)_{6} \mathrm{Mo}_{7} \mathrm{O}_{24}$ followed by drying, calcination, reduction and temperature-programmed carburization up to $900 \mathrm{~K}$ (with a mixture of $\mathrm{C}_{2} \mathrm{H}_{6}$ and $\mathrm{H}_{2}$ ) as described in detail in previous work [17]. The addition of $\mathrm{Rb}_{2} \mathrm{CO}_{3}$ promoter was performed between reduction and carburization, by physically mixing $\mathrm{Rb}_{2} \mathrm{CO}_{3}$ with the supported suboxide precursor in a mortar and pestle [17]. After carburization, the catalysts were cooled to room temperature in flowing He before being passivated in a stream of 1 vol.\% $\mathrm{O}_{2} / \mathrm{N}_{2}$ mixture at room temperature for $12 \mathrm{~h}$. The nominal loading of $\mathrm{Mo}_{2} \mathrm{C}$ and $\mathrm{Rb}$ on alumina was $5 \mathrm{wt} . \%$ and $1.5 \mathrm{wt} . \%$, respectively. 
According the characterization results presented previously [17], the 5 wt.\% $\mathrm{Mo}_{2} \mathrm{C} / \mathrm{Al}_{2} \mathrm{O}_{3}$ catalyst showed a $4.7 \mathrm{wt}$.\% Mo loading and a C/Mo molar ratio of 0.39 . The results from extended X-ray absorption fine-structure (EXAFS) spectroscopy and electron microscopy confirmed the formation of highly dispersed molybdenum carbide on alumina support, with the particle size of $1 \mathrm{~nm}$. The $1.5 \mathrm{wt} . \% \mathrm{Rb}-5 \mathrm{wt} . \% \mathrm{Mo}_{2} \mathrm{C} / \mathrm{Al}_{2} \mathrm{O}_{3}$ catalyst revealed a $\mathrm{Rb} / \mathrm{Mo}$ molar ratio of 0.31 , which was close to the nominal value (0.34). After passivation of the molybdenum carbide catalysts, the surface was partially oxidized [17].

\subsubsection{Hydrogenation of carbon monoxide}

Hydrogenation of CO was conducted in a fixed-bed stainless steel reactor (3/8 inch OD) with $0.5 \mathrm{~g}$ of $5 \mathrm{wt} . \% \mathrm{Mo}_{2} \mathrm{C} / \alpha-\mathrm{Al}_{2} \mathrm{O}_{3}$ or $2.0 \mathrm{~g}$ of $1.5 \mathrm{wt} . \% \mathrm{Rb}-5 \mathrm{wt} . \% \mathrm{Mo}_{2} \mathrm{C} / \alpha-$ $\mathrm{Al}_{2} \mathrm{O}_{3}$. The catalysts were tested at nominally identical conditions of $573 \mathrm{~K}, 1.2$ bar total pressure with equivalent partial pressure of $\mathrm{H}_{2}$ (GTS-Welco, 99.999\%) and CO (GTSWelco, 99.997\%).

The products were analyzed by an on-line SRI 8610C gas chromatograph equipped with a flame ionization detector (FID) and a thermal conductivity detector (TCD). A Restek MXT ${ }^{\circledR}$-Q-Bond column (0.53 mm I.D., $30 \mathrm{~m}$ length) connected to an FID was used to quantify hydrocarbons and alcohols, while a HayeSep-D column (3.2 mm I.D., $1.8 \mathrm{~m}$ length) connected to a TCD was used to analyze $\mathrm{CO}$ and $\mathrm{CO}_{2}$.

The conversion of $\mathrm{CO}$ was derived from the fraction of $\mathrm{CO}$ that formed carboncontaining products [48]. The conversion of $\mathrm{CO}$, if low, can be described as:

$$
\text { Conversion }(\%)=\sum n_{i} M_{i} \times 100 / M_{\mathrm{CO}} \text {, }
$$


where $n_{i}$ is the number of carbon atoms in product $i, M_{i}$ is the percentage of product $i$ detected, and $M_{\mathrm{CO}}$ is the percentage of $\mathrm{CO}$ in the syngas feed.

The selectivity towards product $i$ is based on the total number of carbon atoms in the product and is therefore defined as:

$$
\text { Selectivity }(\%)=n_{i} M_{i} \times 100 / \sum n_{i} M_{i} \text {. }
$$

The conversion and selectivities were based on the identified products, which present more than $97 \%$ of the total peak area in GC chromatograms.

\subsubsection{Multi-product SSITKA}

Our lab has used SSITKA to study a variety of reactions on solid catalysts such as ammonia synthesis on $\mathrm{Ru}[49,50]$, CO hydrogenation on $\mathrm{Au}[51,52]$, and ethanol coupling on MgO [53]. Our reactor system in previous works analyzed for only one product of the reaction. We therefore needed to make substantial changes to our reactor system to analyze the multiple products formed during $\mathrm{CO}$ hydrogenation.

The system used for the multi-product SSITKA experiments is based on the design reported by Goodwin and co-workers [42,46,54] and is shown in Figure 6.1. The isotopic switch from ${ }^{12} \mathrm{CO}$ to ${ }^{13} \mathrm{CO}$ was carried out after the reaction achieved steady state (typically more than 72 hours on stream) at $573 \mathrm{~K}, 1.2$ bar and $\mathrm{H}_{2} / \mathrm{CO}=1$. Although higher pressures were utilized in our previous works with supported $\mathrm{Mo}_{2} \mathrm{C}$ catalysts (30 bar) [16-18], our SSITKA experiments required us to minimize both gas phase hold-up in the system as well as adsorption on the support. The syngas flow rate was varied from 10.8 to $15.6 \mathrm{~cm}^{3} \mathrm{~min}^{-1}$ and the Ar flow rate was maintained at $0.2 \mathrm{~cm}^{3} \mathrm{~min}^{-1}$. During an 
isotopic transient experiment, a switch between naturally abundant ${ }^{12} \mathrm{CO}$ (GTS-Welco, 99.997\%) with Ar tracer (GTS-Welco, 99.999\%) and ${ }^{13} \mathrm{CO}$ (Cambridge Isotopes, 99.5\% CO, $98+\%{ }^{16} \mathrm{O}, 99+\%{ }^{13} \mathrm{C}$ ) was made using a Valco 2-position valve with an electric actuator. All of the reaction conditions remained undisturbed during the switch, including flow rates, partial pressures and reaction temperature. Backpressure regulators were used to minimize the pressure disturbance during the switch. The gas-phase hold-up of the system was determined by using an Ar tracer fed with the ${ }^{12} \mathrm{CO}$ stream. The multiple products formed during CO hydrogenation created a complex fragmentation pattern in the mass spectrometer. To simplify the product analysis, we first separated the products by gas chromatography, then converted the $\mathrm{C} 2+$ products to $\mathrm{CH}_{4}$ prior to admission to the mass spectrometer. This methodology was used previously by Bennett and co-workers $[44,45]$ and recently by Goodwin and co-workers $[42,46,54]$ to study the kinetics of CO hydrogenation.

In our transient reactor system, a Valco 34-port auto-sampling valve was employed to collect 16 samples during the isotopic transients. The collected effluent samples were separated in a Restek $\mathrm{MXT}^{\circledR}$-Q-Bond column (0.53 mm I.D., $30 \mathrm{~m}$ length) placed in the same GC oven used for steady-state product analysis. Dihydrogen was used as the carrier gas and as a reactant for the subsequent hydrogenolysis reaction. After separation, the products were fed into a hydrogenolysis reactor containing $5 \mathrm{~g}$ of $5 \mathrm{wt} . \%$ $\mathrm{Pt} / \mathrm{Al}_{2} \mathrm{O}_{3}$ (Sigma-Aldrich) held at $673 \mathrm{~K}$ to convert $\mathrm{CO}$ and all the products to $\mathrm{CH}_{4}$. The resulting $\mathrm{CH}_{4}$ was subsequently fed to the mass spectrometer (Pfeiffer Vacuum) to measure the isotope content of the products. The signal for $\mathrm{m} / \mathrm{z}=15$ and 17 were monitored for ${ }^{12} \mathrm{CH}_{4}$ and ${ }^{13} \mathrm{CH}_{4}$, respectively. Since the fragmentation of ${ }^{13} \mathrm{CH}_{4}$ also 
contributes to the signal for ${ }^{12} \mathrm{CH}_{4}$ (14\% of the ${ }^{13} \mathrm{CH}_{4}$ signal according to calibration), the ${ }^{12} \mathrm{CH}_{4}$ responses $(\mathrm{m} / \mathrm{z}=15)$ were all corrected by subtracting the fragment from ${ }^{13} \mathrm{CH}_{4}$.

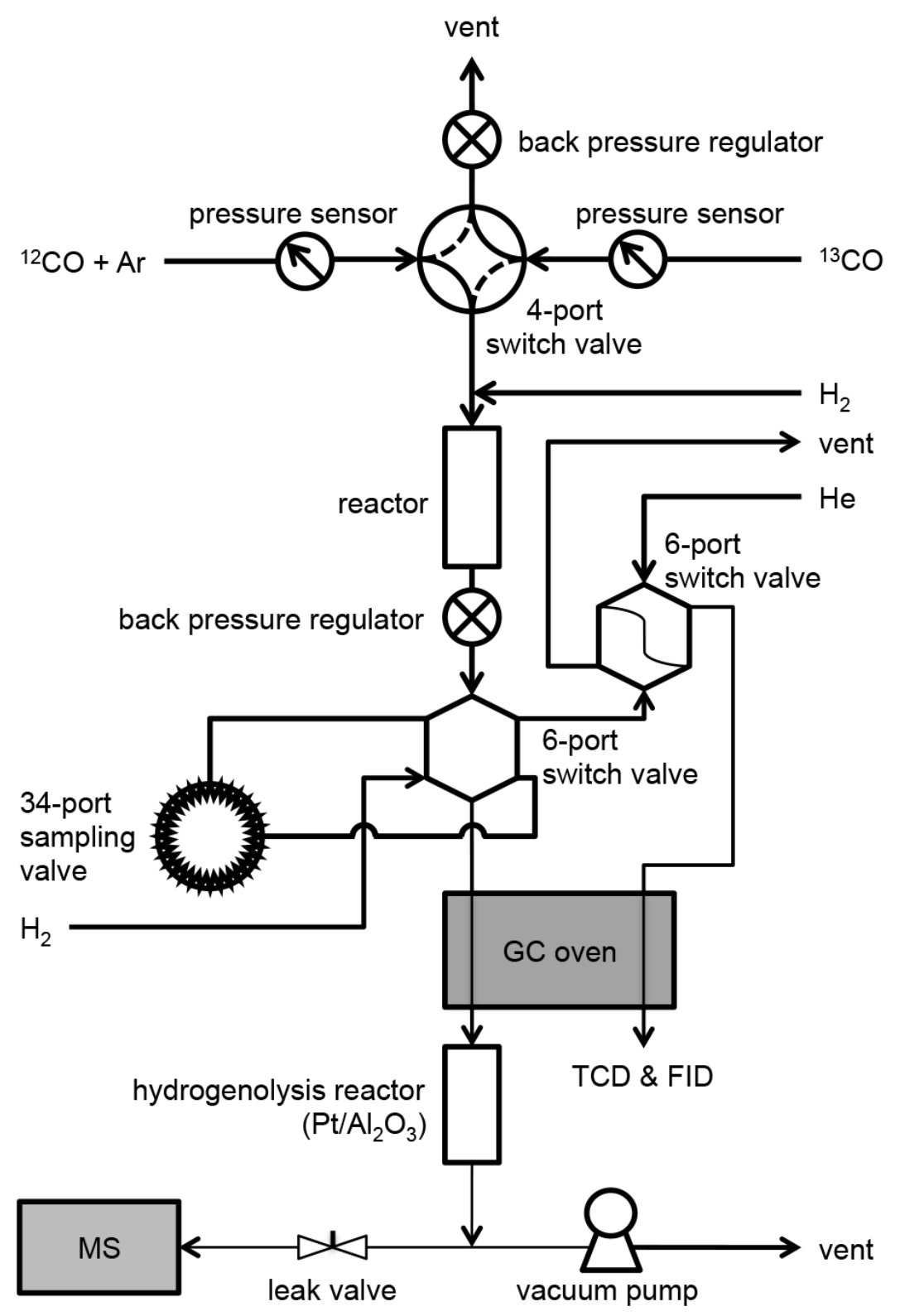

Figure 6.1 The reaction system for multi-product SSITKA

Because the Restek GC column was unable to separate $\mathrm{CO}_{2}$ and $\mathrm{CH}_{4}$ from $\mathrm{CO}$, another series of transient experiments had to be performed. To analyze $\mathrm{CH}_{4}$ and $\mathrm{CO}_{2}$, the hydrogenolysis reactor prior to the MS was bypassed and the responses for $\mathrm{CH}_{4}, \mathrm{CO}_{2}$ and the Ar tracer were monitored directly by MS. 


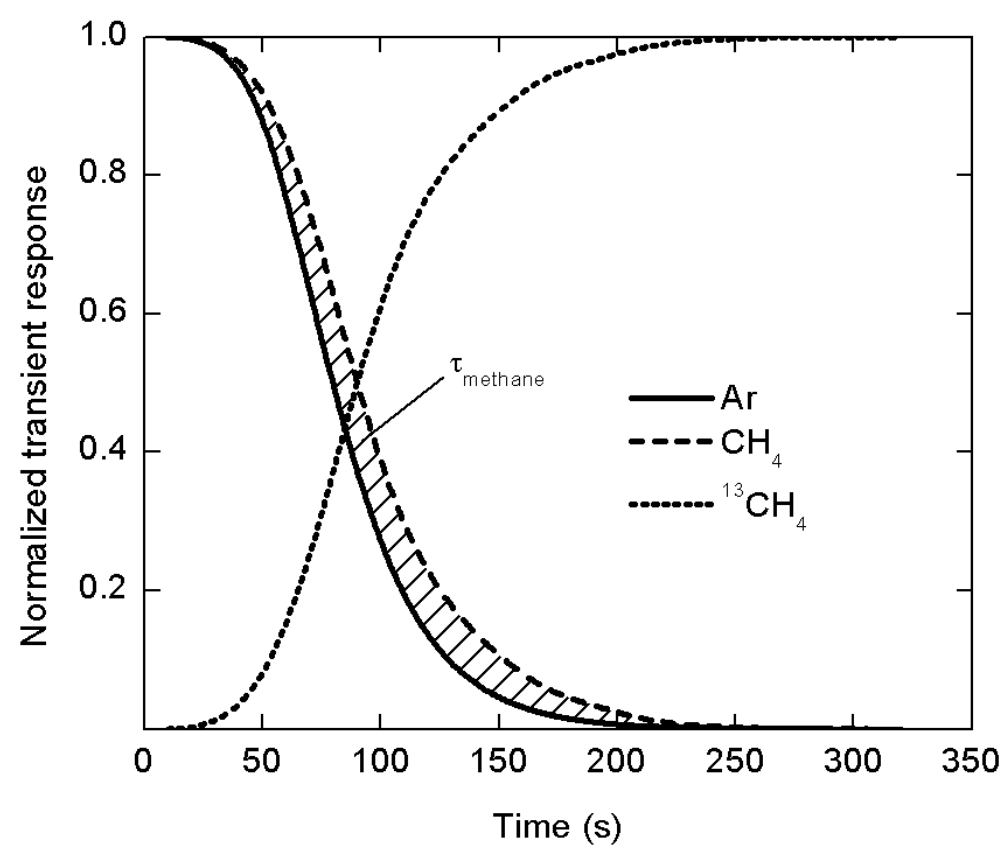

Figure 6.2 Example of normalized transient responses for $\mathrm{Ar},{ }^{12} \mathrm{CH}_{4}$ and ${ }^{13} \mathrm{CH}_{4}$ following a ${ }^{12} \mathrm{CO} /{ }^{13} \mathrm{CO}$ switch during steady state $\mathrm{CO}$ hydrogenation. The Ar transient was used to evaluate the gas phase hold-up of the system. The shaded area represents the surface mean residence time of reaction intermediates that lead to $\mathrm{CH}_{4}\left(\tau_{\text {methane }}\right)$.

Figure 6.2 shows the normalized steady-state transient responses of the ${ }^{12} \mathrm{CH}_{4}$ and

${ }^{13} \mathrm{CH}_{4}$ produced over 5 wt. $\% \mathrm{Mo}_{2} \mathrm{C} / \alpha-\mathrm{Al}_{2} \mathrm{O}_{3}$ during $\mathrm{CO}$ hydrogenation after a switch from ${ }^{12} \mathrm{CO}$ to ${ }^{13} \mathrm{CO}$. The mean surface residence time of the reaction intermediates leading to a certain product $\left(\tau_{i}\right)$ was determined by integrating the area between the normalized transient response of the ${ }^{12} \mathrm{C}$ portion in the corresponding product $\left(F_{i}\right)$ and that of the inert tracer $\operatorname{Ar}\left(F_{\mathrm{Ar}}\right)$ :

$$
\tau_{i}=\int\left(F_{i}-F_{\mathrm{Ar}}\right) d t
$$

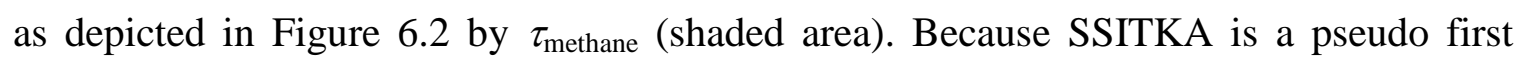
order analysis, the corresponding turnover frequency (TOF) to produce a specific product is simply: 


$$
\mathrm{TOF}_{i}=\tau_{i}^{-1}
$$

The amount of active surface intermediates leading to a specific product (i) can be determined by a straightforward material balance on the reactor:

$$
N_{i}=\tau_{i} R_{i} X_{i},
$$

where $R_{i}$ is the rate of formation of product $i$ at steady state reaction, and $X_{\mathrm{i}}$ refers to the fractional change in ${ }^{12} \mathrm{C}$ response (after the switch to ${ }^{13} \mathrm{CO}$ ) from the initial value. The corresponding surface coverage $\left(\theta_{i}\right)$ is thus:

$$
\theta_{i}=N_{i} / \text { (amount of surface Mo atoms). }
$$

Given the nearly $100 \%$ dispersion of $\mathrm{Mo}$ in the $\mathrm{Mo}_{2} \mathrm{C}$ nanoclusters as indicated by transmission electron microscopy (TEM) and extended X-ray absorption fine structure (EXAFS) [17],

$$
\theta_{i}=N_{i} /(\text { amount of Mo atoms }) \text {. }
$$

We perfromed this simplified analysis of the transient results (simple carbon material balance) because all of the experimenes were perfomed at identical conditions of pressure and temperature.

In another series of experiments, the desorption of the surface intermediates leading to different products in CO hydrogenation was studied after the CO flow was halted. A switch between CO (GTS-Welco, 99.997\%) and Ar (GTS-Welco, 99.999\%) was made using the Valco 2-position valve with an electric actuator at the steady state of reaction while the $\mathrm{H}_{2}$ (GTS-Welco, 99.999\%) flow was maintained. The Valco 34-port auto-sampling valve was employed to collect 16 samples of product gas during desorption. The downstream setup (GC column, hydrogenolysis reactor, MS, etc.) was the same as that used for the SSITKA experiments. 
Table 6.1 Performance of unpromoted and Rb-promoted 5 wt. $\% \mathrm{Mo}_{2} \mathrm{C} / \alpha-\mathrm{Al}_{2} \mathrm{O}_{3}$ catalysts in CO hydrogenation at near ambient pressure

\begin{tabular}{|c|c|c|}
\hline Rb loading (wt.\%) & $0^{\mathrm{a}}$ & $1.5^{b}$ \\
\hline CO conversion $(\%)$ & 0.72 & 0.37 \\
\hline Apparent TOF of CO hydrogenation $\left(\mathrm{s}^{-1}\right)^{\mathrm{c}}$ & 0.00008 & 0.00001 \\
\hline $\mathrm{CO}_{2}$ selectivity (\%) & $53^{d}$ & $52^{d}$ \\
\hline \multicolumn{3}{|l|}{ Selectivity (C\%, on a $\mathrm{CO}_{2}$-free basis) } \\
\hline Paraffins & 82 & 43 \\
\hline Methane & 54 & 33 \\
\hline Ethane & 25 & 5.4 \\
\hline Propane & 2.6 & 2.9 \\
\hline Butane & 0.0 & 2.1 \\
\hline Olefins & 18 & 36 \\
\hline Ethene & 11 & 21 \\
\hline Propene & 7.4 & 9.4 \\
\hline 1-Butene & 0.0 & 5.0 \\
\hline Alcohols & 0.0 & 21 \\
\hline Methanol & 0.0 & 11 \\
\hline Ethanol & 0.0 & 5.9 \\
\hline 1-Propanol & 0.0 & 3.6 \\
\hline \multicolumn{3}{|c|}{$\begin{array}{l}T=573 \mathrm{~K}, p=1.2 \text { bar, } \mathrm{H}_{2} / \mathrm{CO}=1 \text {, syngas flow rate }=15.6 \mathrm{~cm}^{3} \mathrm{~min}^{-1} \text {, Ar flow rate }=0.2 \\
\mathrm{~cm}^{3} \mathrm{~min}^{-1} \text {. Results were reported after at least } 72 \mathrm{~h} \text { on stream, after steady state was } \\
\text { achieved. } \\
\text { a } 0.5 \mathrm{~g} \text { catalyst } \\
\text { b } 2.0 \text { g catalyst } \\
{ }^{\mathrm{c}} \text { Apparent TOF of CO hydrogenation was calculated with the assumption that every } \\
\text { metal atom is a potential active site, given the nearly } 100 \% \text { dispersion of Mo } \\
\text { determined by TEM and EXAFS [17]. }\end{array}$} \\
\hline
\end{tabular}

\subsection{Results and discussion}

Table 6.1 summarizes the performance of unpromoted and Rb-promoted aluminasupported $\mathrm{Mo}_{2} \mathrm{C}$ catalysts in the reaction of syngas $\left(\mathrm{H}_{2} / \mathrm{CO}=1\right)$ at $573 \mathrm{~K}$ and 1.2 bar. The unpromoted 5 wt.\% $\mathrm{Mo}_{2} \mathrm{C} / \alpha-\mathrm{Al}_{2} \mathrm{O}_{3}$ catalyst produced only hydrocarbons (82\% paraffins and $18 \%$ olefins) and $\mathrm{CO}_{2}$ at these conditions. The selectivity towards alcohols increased to $21 \%$ after addition of $1.5 \mathrm{wt} . \% \mathrm{Rb}$, which is in good agreement with the earlier works on the catalytic performance of $\mathrm{Mo}_{2} \mathrm{C}$ promoted by alkali metal species in $\mathrm{CO}$ 
hydrogenation [11,14-19]. It should be noted that the alcohol selectivity during our ambient-pressure CO hydrogenation studies was not as high as that observed at elevated pressure [17]. Nevertheless, the relatively high selectivity towards olefins (36\% on a $\mathrm{CO}_{2}$-free basis) observed at ambient pressure over $1.5 \mathrm{wt} . \% \mathrm{Rb}-5 \mathrm{wt} . \% \mathrm{Mo}_{2} \mathrm{C} / \alpha-\mathrm{Al}_{2} \mathrm{O}_{3}$ is consistent with the findings by Park et al. [21] As shown in Table 6.1, the CO conversion was kept below 1\%, thus ensuring differential reaction conditions. Figure 6.3 shows that the CO conversion was strictly linear with respect the inverse of the gas flow rate, confirming the differential behavior of the reactor system.

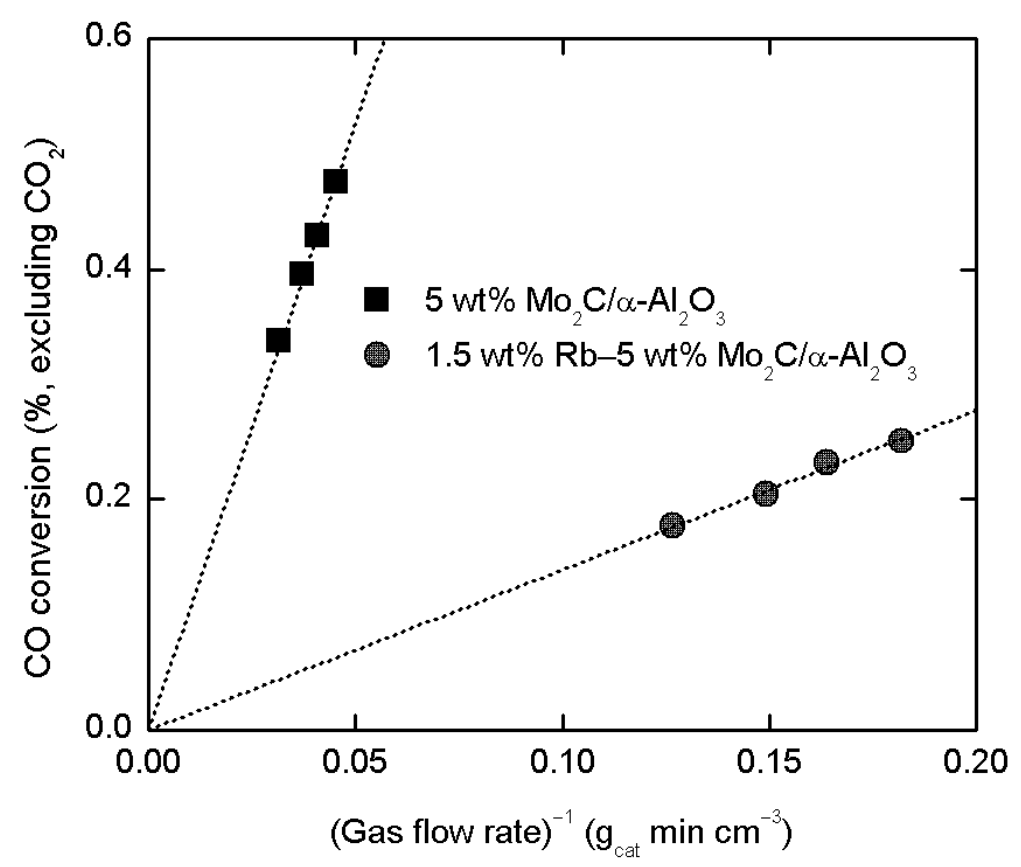

Figure 6.3 Influence of syngas flow rate on the observed conversion of $\mathrm{CO}$, excluding $\mathrm{CO}_{2}$, over $\mathrm{Mo}_{2} \mathrm{C} / \alpha-\mathrm{Al}_{2} \mathrm{O}_{3}$ catalysts at steady state. Reaction conditions: $573 \mathrm{~K}, 1.2 \mathrm{bar}$, $\mathrm{H}_{2} / \mathrm{CO}=1$.

\subsubsection{Transient analysis of $\mathrm{CO}$ hydrogenation over $\mathrm{Mo}_{2} \mathrm{C} / \alpha-\mathrm{Al}_{2} \mathrm{O}_{3}$}

Multi-product SSITKA allows the determination of the surface reaction parameters, including the surface residence times of reaction intermediates $(\tau)$ and 
amount of intermediates $(N)$ leading to different products. Figure 6.4 presents the transient responses of various products formed over a 5 wt. $\% \mathrm{Mo}_{2} \mathrm{C} / \alpha-\mathrm{Al}_{2} \mathrm{O}_{3}$ catalyst up to $1 \mathrm{~h}$ after an isotope switch. All the transient responses were normalized by the steady state signal of ${ }^{12} \mathrm{C}$ before the transient occurred. The ${ }^{12} \mathrm{C}$ transient response over a $\mathrm{Mo}_{2} \mathrm{C}$ catalyst typically included a rapid decay, a slow decay, and a persistent background signal of ${ }^{12} \mathrm{C}$. In other words, the ${ }^{12} \mathrm{C}$ signal did not decay completely to the background level, even after $1 \mathrm{~h}$. The major fraction of the transient response happened quickly and is attributed to a catalytic turnover on sites denoted as Pool A. The origin of the slow decay on sites denoted as Pool B and the background ${ }^{12} \mathrm{C}$ signal are unclear. It has been reported previously that the species adsorbed on the $\mathrm{Mo}_{2} \mathrm{C}$ surface can have a fairly high adsorption energy [18,55-57], and that activation of adsorbed CO may involve the formation or participation of the carbidic carbon [18,58-60]. Because $\alpha-\mathrm{Al}_{2} \mathrm{O}_{3}$ has been used previously in SSITKA experiments as an inert agent during CO hydrogenation experiments [42], we suspect that re-adsorption of products on the $\alpha-\mathrm{Al}_{2} \mathrm{O}_{3}$ support was unlikely to cause the slow transient response. Therefore, we attribute the slow decay in the ${ }^{12} \mathrm{C}$ transient response to either a strong interaction between the adsorbed reaction intermediates and the $\mathrm{Mo}_{2} \mathrm{C}$ surface (which may be catalytically relevant), or to the exchange of carbon between the adsorbed reaction intermediates and the underlying carbidic carbon (which is likely to be catalytically irrelevant). The background incorporation of ${ }^{12} \mathrm{C}$ into products after $1 \mathrm{~h}$ was presumably due to the very slow exchange of unlabeled carbidic carbon with labeled reactive carbon. 

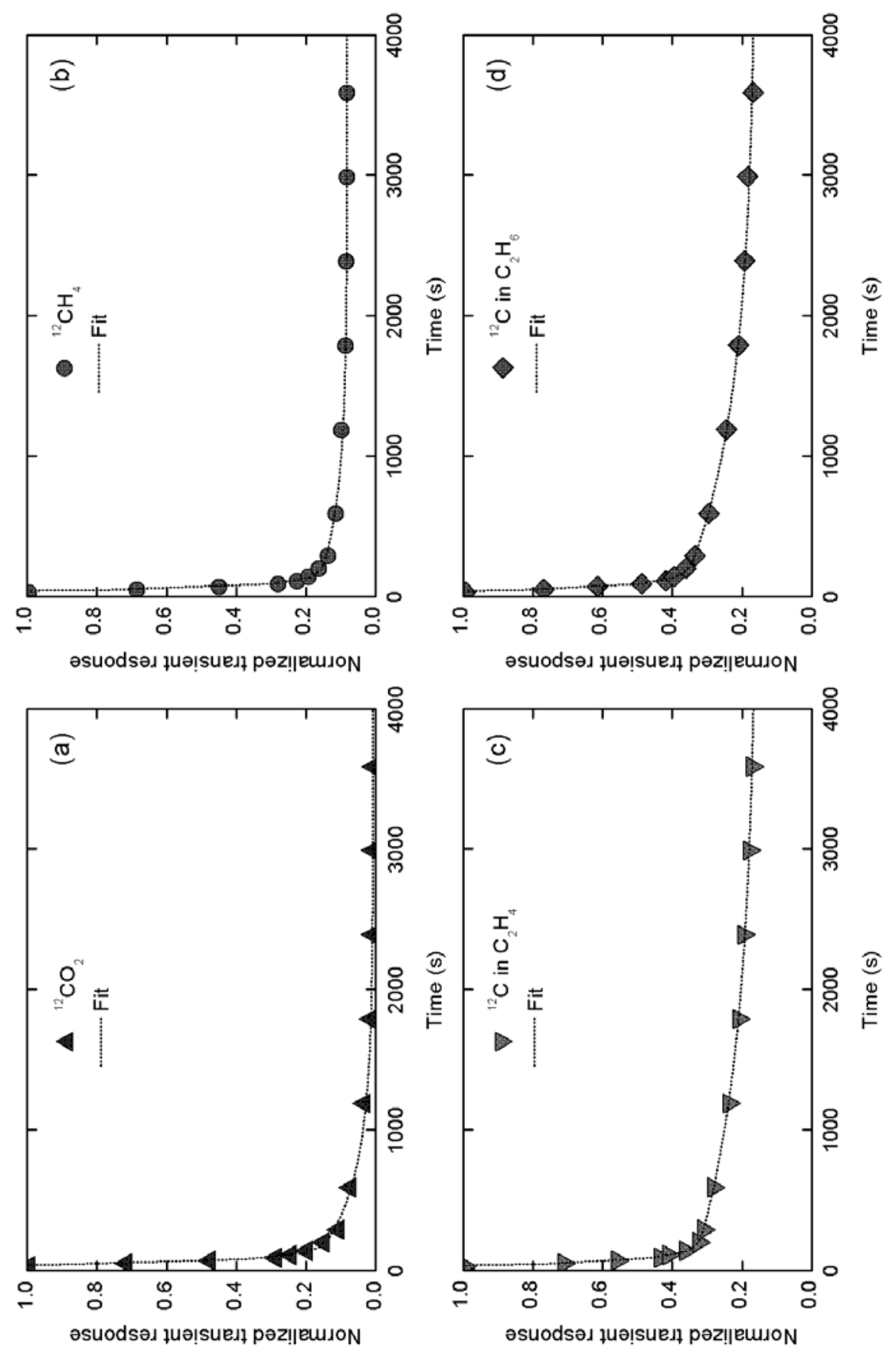

음

웅

वे

ฮี่

o 的.

艺

8

ㄱ. 믈

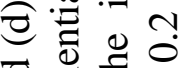

픙

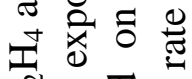

U च्य

(บ)

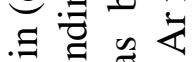

क क .

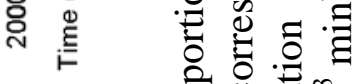
บ $8 . \mathbb{\pi}^{\mathrm{N}}$

들

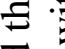

䒠

०0

声

บ

อิ

$\hat{\imath} \cdot{ }^{\infty}$

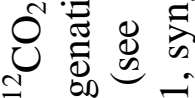

(త)

0
0
0

- $+\stackrel{\text { I }}{-1}$

ㅇำ

₹ ใิ

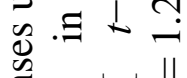

Оै च

कैत बै

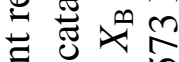

$\stackrel{5}{\infty}+1$

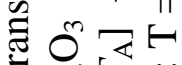

娄实药

.

ত্রิ

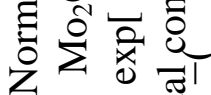

す⿺辶一

䒓 11

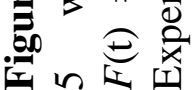


Since the isotopic transient responses in Figure 6.4 appear to be composed by two different exponential functions, we fit the curves with the following expression:

$$
F(t)=X_{\mathrm{A}} \exp \left(-\frac{t-t_{0}}{T_{\mathrm{A}}}\right)+X_{\mathrm{B}} \exp \left(-\frac{t-t_{0}}{T_{\mathrm{B}}}\right)+X_{\mathrm{bkg}},
$$

where A, B and bkg stand for the fraction of sites associated with Pool A (rapid turnover), Pool B (slow turnover) and background exchange, respectively. The results of the curve fits are summarized in Table 6.2. The sites associated with Pool A account for about 80\% of the $\mathrm{C} 1$ products and about $65 \%$ of the $\mathrm{C} 2$ products formed over 5 wt. $\% \mathrm{Mo}_{2} \mathrm{C} / \alpha-\mathrm{Al}_{2} \mathrm{O}_{3}$. This rapid transient associated with Pool A is nearly complete by $200 \mathrm{~s}$ at a flow rate of $15.6 \mathrm{~cm}^{3} \mathrm{~min}^{-1}$, so we repeated the transient experiment to collect more samples during the rapid transient. Because our sampling system allowed only 15 samples to be collected after the change in feed, shortening the total collection time allowed us to acquire more points throughout the rapid transient. Table 6.3 compares the fraction of the transients responsible for Pool A derived from both short (measured) and long (fitted) collection times and confirms that our acquisition of rapid transient results (290-430 s) reproduce well the conclusion obtained from the long time transient experiment (3600 s).

The typical transient responses of hydrocarbons and $\mathrm{CO}_{2}$ associated with Pool $\mathrm{A}$ are shown in Figure 6.5, and the calculated values of mean surface residence time $(\tau)$ of various hydrocarbons and $\mathrm{CO}_{2}$ on unpromoted and $\mathrm{Rb}$-promoted $\mathrm{Mo}_{2} \mathrm{C}$ at different syngas flow rates are displayed in Figure 6.6. The $\tau$ values for the various products in Figure 6.6 were fairly independent of flow rate over the range investigated, indicating that product re-adsorption on the catalyst or support was negligible. Therefore, $\tau$ values for each product were averaged and the results are summarized in Table 6.4. The corresponding reaction parameters such as intrinsic TOF and coverage of reaction 
intermediate were subsequently calculated from those values. It should be noted that two types of $N$ and $\theta$ are shown in Table 6.4, namely "fractional” and "max," respectively. The "fractional" values were based on the potential existence of catalytically active sites in Pool B, on which reaction intermediates turn over at low rates. On the other hand, the “max" values were calculated assuming the slow transients resulted solely from exchange of carbon between the reaction intermediates and the carbidic carbon of the catalyst, which is not directly involved in the steady state reaction rate. Since neither of the two mechanisms can be excluded, both types of coverages are reported.

Table 6.2 Fractional contribution of different sites on unpromoted $\mathrm{Mo}_{2} \mathrm{C}$ catalyst in $\mathrm{CO}$ hydrogenation

\begin{tabular}{|c|c|c|c|c|c|c|}
\hline \multirow{2}{*}{ Product } & \multicolumn{2}{|c|}{ Pool A (rapid turnover) } & \multicolumn{2}{|c|}{ Pool B (slow turnover) } & \multirow{2}{*}{$\frac{\text { Background }}{X_{\text {bkg }}}$} & \multirow{2}{*}{$\begin{array}{l}\text { Adjusted } \\
R^{2}\end{array}$} \\
\hline & $X_{\mathrm{A}}$ & $T_{\mathrm{A}}(\mathrm{s})$ & $X_{\mathrm{B}}$ & $T_{\mathrm{B}}(\mathrm{s})$ & & \\
\hline $\mathrm{CO}_{2}$ & 0.81 & 37 & 0.18 & 520 & 0.01 & 0.995 \\
\hline $\mathrm{CH}_{4}$ & 0.82 & 29 & 0.08 & 410 & 0.10 & 0.995 \\
\hline $\mathrm{C}_{2} \mathrm{H}_{4}$ & 0.66 & 35 & 0.18 & 1400 & 0.16 & 0.996 \\
\hline $\mathrm{C}_{2} \mathrm{H}_{6}$ & 0.62 & 35 & 0.22 & 1200 & 0.16 & 0.996 \\
\hline
\end{tabular}

Experimental conditions: 0.5 g 5 wt. $\% \mathrm{Mo}_{2} \mathrm{C} / \alpha-\mathrm{Al}_{2} \mathrm{O}_{3}, 573 \mathrm{~K}, 1.2 \mathrm{bar}, \mathrm{H}_{2} / \mathrm{CO}=1$, syngas flow rate $=15.6 \mathrm{~cm}^{3} \mathrm{~min}^{-1}$, Ar flow rate $=0.2 \mathrm{~cm}^{3} \mathrm{~min}^{-1}$. Parameters were derived from the fits of $F(t)=X_{\mathrm{A}} \exp \left(-\frac{t-t_{0}}{T_{\mathrm{A}}}\right)+X_{\mathrm{B}} \exp \left(-\frac{t-t_{0}}{T_{\mathrm{B}}}\right)+X_{\mathrm{bkg}}$, where $X_{\mathrm{A}}+X_{\mathrm{B}}+X_{\mathrm{bkg}}=1$.

$F(t)$ : normalized transient response

$X_{\mathrm{A}}\left(X_{\mathrm{B}}\right)$ : the fraction of a complete transient contributed by Pool A (B)

$X_{\text {bkg: }}$ the fraction of a complete transient contributed by background conversion $t_{0}$ : delay of the signal in the system

$T_{\mathrm{A}}\left(T_{\mathrm{B}}\right)$ : the system hold-up time corresponding to Pool A (B)

Table 6.3 Comparison of the fraction of transient $\left(X_{\mathrm{A}}\right)$ associated with Pool A on 5 wt.\% $\mathrm{Mo}_{2} \mathrm{C} / \alpha-\mathrm{Al}_{2} \mathrm{O}_{3}$ : fit of exponential decay vs. absolute changes in transient responses

\begin{tabular}{|c|c|c|c|c|c|}
\hline Product & \multirow{2}{*}{$\frac{\text { Fitted } X_{\mathrm{A}}}{0.81}$} & \multicolumn{4}{|c|}{ Measured $X_{\mathrm{A}}$} \\
\hline $\mathrm{CO}_{2}$ & & $\overline{0.89}$ & 0.90 & 0.88 & 0.90 \\
\hline $\mathrm{CH}_{4}$ & 0.82 & 0.84 & 0.84 & 0.82 & 0.87 \\
\hline $\mathrm{C}_{2} \mathrm{H}_{4}$ & 0.66 & 0.65 & 0.67 & 0.65 & 0.68 \\
\hline $\mathrm{C}_{2} \mathrm{H}_{6}$ & 0.62 & 0.69 & 0.68 & 0.67 & 0.70 \\
\hline \multicolumn{6}{|l|}{ Condition } \\
\hline Syngas flow rate $\left(\mathrm{cm}^{3} \mathrm{~min}^{-1}\right)$ & 15.6 & 15.6 & 13.2 & 12.0 & 10.8 \\
\hline Time of transient (s) & 3600 & 290 & 350 & 350 & 430 \\
\hline
\end{tabular}



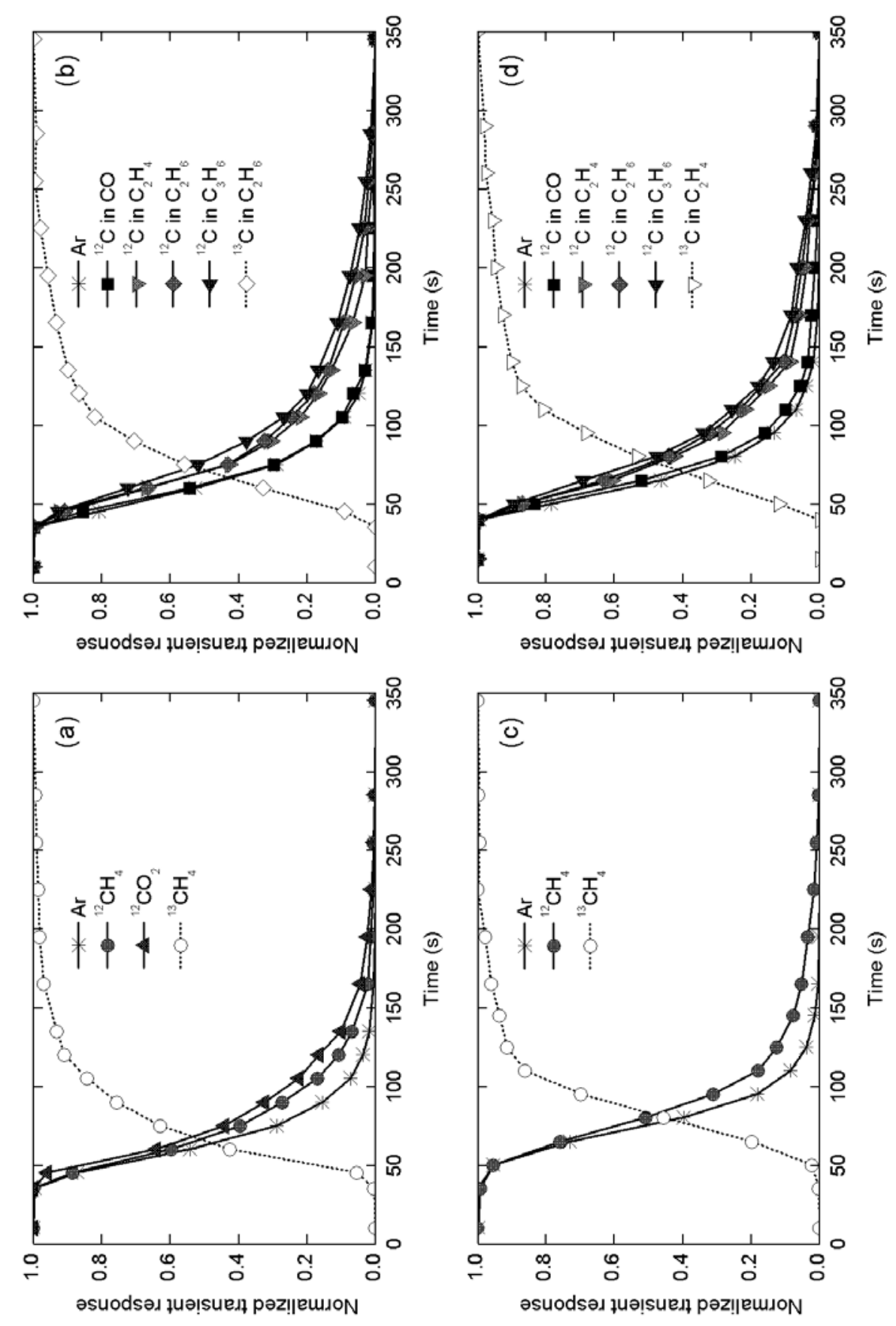

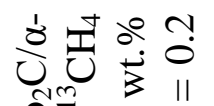

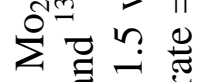

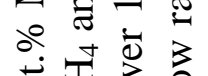

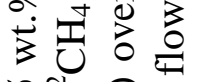

ᄂ

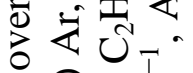

式记芯自

o

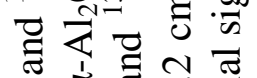

잉

ป

马을

岁元萿

西的鹀은

눠

运字舟券

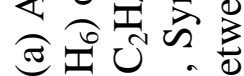

तิ

$<011$

$\circ: \exists \cup 0$

○ $\Xi \cup$

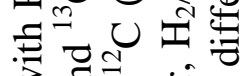

题司

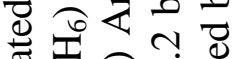

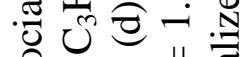

पू

व 이요

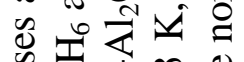

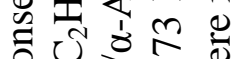

엉

की 11

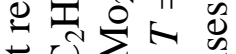

பํ.

जै

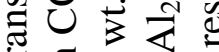

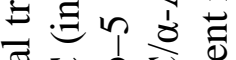

तु 0 0 ठ

궁

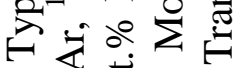

응.

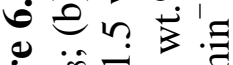

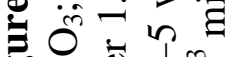

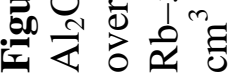



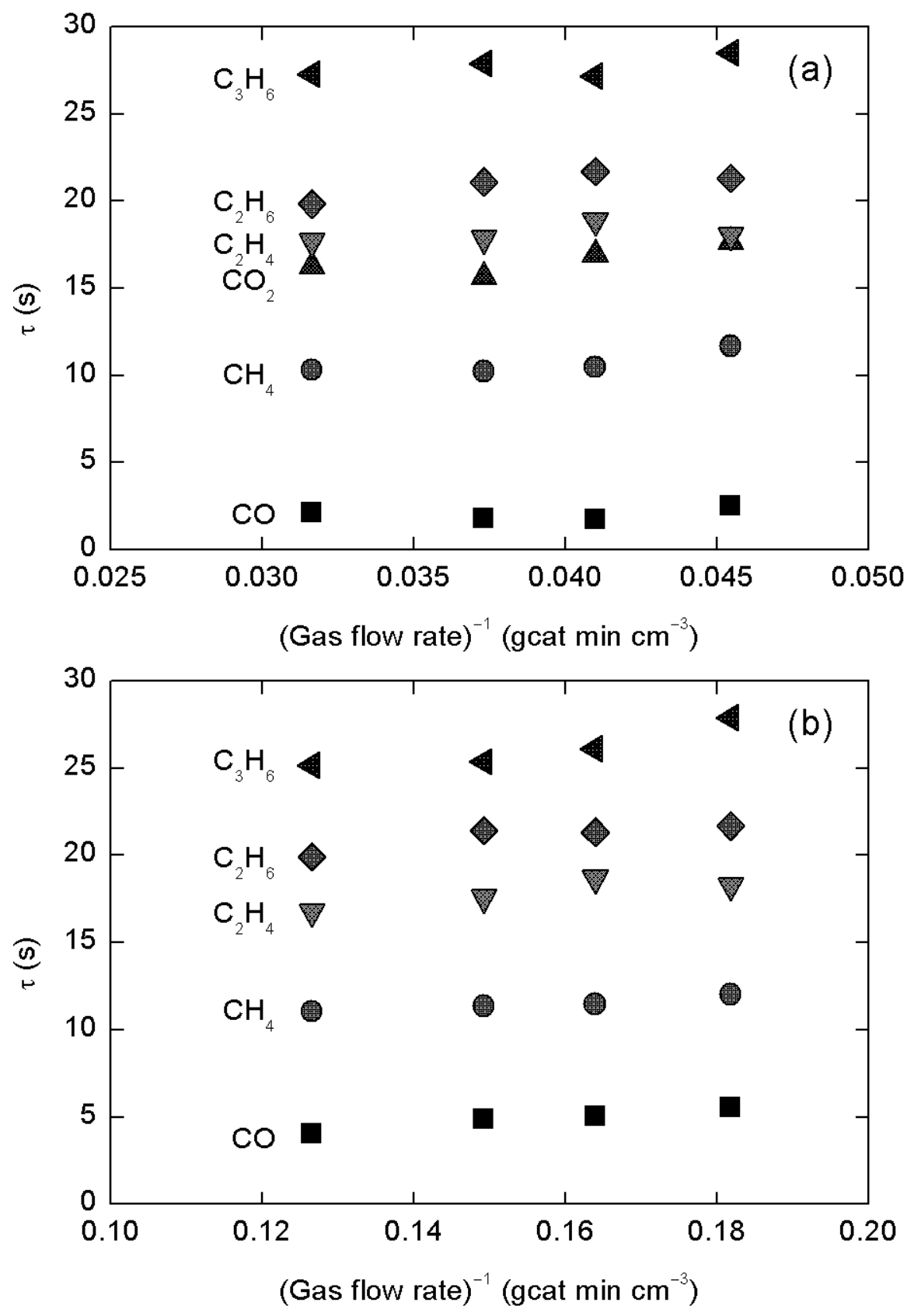

Figure 6.6 Mean surface residence time $(\tau)$ of $\mathrm{CO}$ (square), and intermediates leading to $\mathrm{CO}_{2}$ (up triangle), $\mathrm{CH}_{4}$ (circle), $\mathrm{C}_{2} \mathrm{H}_{4}$ (down triangle), $\mathrm{C}_{2} \mathrm{H}_{6}$ (diamond) and $\mathrm{C}_{3} \mathrm{H}_{6}$ (left triangle) vs. the reciprocal of gas flow rate during steady state of $\mathrm{CO}$ hydrogenation over (a) 5 wt. $\% \mathrm{Mo}_{2} \mathrm{C} / \alpha-\mathrm{Al}_{2} \mathrm{O}_{3}$ and (b) 1.5 wt. $\% \mathrm{Rb}-5$ wt. $\% \mathrm{Mo}_{2} \mathrm{C} / \alpha-\mathrm{Al}_{2} \mathrm{O}_{3}$ 
Table 6.4 Surface reaction parameters for $\mathrm{CO}$ hydrogenation on Pool A over 5 wt.\% $\mathrm{Mo}_{2} \mathrm{C} / \alpha-\mathrm{Al}_{2} \mathrm{O}_{3}$ and $1.5 \mathrm{wt} . \% \mathrm{Rb}-5 \mathrm{wt} . \% \mathrm{Mo}_{2} \mathrm{C} / \alpha-\mathrm{Al}_{2} \mathrm{O}_{3}$ catalysts estimated by SSITKA

\begin{tabular}{|c|c|c|c|c|c|c|c|c|}
\hline \multirow[t]{2}{*}{ Molecule } & \multirow{2}{*}{$\begin{array}{c}\tau_{\mathrm{A}} \\
(\mathrm{s})\end{array}$} & \multirow{2}{*}{$\begin{array}{l}\mathrm{TOF}_{\mathrm{A}} \\
\left(\mathrm{s}^{-1}\right)\end{array}$} & \multirow{2}{*}{$\begin{array}{c}R \\
\left(\operatorname{nmol}_{\mathrm{C}} \mathrm{g}_{\text {cat }}^{-1} \mathrm{~s}^{-1}\right)\end{array}$} & \multirow{2}{*}{$X_{\mathrm{A}}{ }^{\mathrm{a}}$} & \multicolumn{2}{|c|}{$\begin{array}{c}N_{\mathrm{A}}^{\mathrm{b}} \\
\left(\mu \mathrm{mol}_{\mathrm{C}} \mathrm{g}_{\text {cat }}^{-1}\right)\end{array}$} & \multicolumn{2}{|c|}{$\begin{array}{c}\theta_{\mathrm{A}}{ }^{\mathrm{c}} \\
\left(\mathrm{mmol}_{\mathrm{C}} \mathrm{mol}_{\mathrm{Mo}}^{-1}\right)\end{array}$} \\
\hline & & & & & fractional & $\max$ & fractional & $\max$ \\
\hline \multicolumn{9}{|l|}{$5 \% \mathrm{Mo}_{2} \mathrm{C}$} \\
\hline $\mathrm{CO}$ & 2.1 & - & - & - & - & - & - & - \\
\hline $\mathrm{CO}_{2}$ & 17 & - & 38 & 0.90 & 0.57 & 0.64 & 1.2 & 1.3 \\
\hline Overall $\mathrm{CH}^{\mathrm{d}}$ & 15 & 0.067 & 34 & 0.77 & 0.40 & 0.53 & 0.81 & 1.1 \\
\hline $\mathrm{CH}_{4}$ & 11 & 0.094 & 19 & 0.84 & 0.18 & 0.21 & 0.36 & 0.42 \\
\hline $\mathrm{C}_{2} \mathrm{H}_{4}$ & 18 & 0.055 & 3.3 & 0.67 & 0.04 & 0.06 & 0.08 & 0.12 \\
\hline $\mathrm{C}_{2} \mathrm{H}_{6}$ & 21 & 0.048 & 9.1 & 0.68 & 0.13 & 0.19 & 0.27 & 0.39 \\
\hline $\mathrm{C}_{3} \mathrm{H}_{6}$ & 28 & 0.036 & 2.5 & 0.71 & 0.05 & 0.07 & 0.10 & 0.14 \\
\hline $\begin{array}{l}\text { Total carbon } \\
\text { intermediates }\end{array}$ & - & - & - & - & 1.0 & 1.2 & 2.0 & 2.4 \\
\hline \multicolumn{9}{|l|}{$1.5 \% \mathrm{Rb}-5 \% \mathrm{Mo}_{2} \mathrm{C}$} \\
\hline $\mathrm{CO}$ & 4.9 & - & - & - & - & - & - & - \\
\hline Overall $\mathrm{CH}^{\mathrm{d}}$ & 16 & 0.062 & 3.3 & 0.69 & 0.035 & 0.053 & 0.071 & 0.11 \\
\hline $\mathrm{CH}_{4}$ & 12 & 0.087 & 1.5 & 0.80 & 0.014 & 0.018 & 0.029 & 0.036 \\
\hline $\mathrm{C}_{2} \mathrm{H}_{4}$ & 18 & 0.056 & 1.0 & 0.71 & 0.013 & 0.018 & 0.026 & 0.036 \\
\hline $\mathrm{C}_{2} \mathrm{H}_{6}$ & 21 & 0.047 & 0.3 & 0.34 & 0.002 & 0.006 & 0.004 & 0.012 \\
\hline $\mathrm{C}_{3} \mathrm{H}_{6}$ & 26 & 0.038 & 0.4 & 0.53 & 0.006 & 0.012 & 0.013 & 0.024 \\
\hline
\end{tabular}

Experimental conditions: $0.5 \mathrm{~g} 5$ wt. $\% \mathrm{Mo}_{2} \mathrm{C} / \alpha-\mathrm{Al}_{2} \mathrm{O}_{3}$ or $2.0 \mathrm{~g} 1.5$ wt. $\%-5$ wt. $\% \mathrm{Mo}_{2} \mathrm{C} / \alpha-$ $\mathrm{Al}_{2} \mathrm{O}_{3}$; $573 \mathrm{~K}, 1.2 \mathrm{bar}, \mathrm{H}_{2} / \mathrm{CO}=1$; syngas flow rate: $10.8,12.0,13.2$ or $15.6 \mathrm{~cm}^{3} \mathrm{~min}^{-1}$; Ar flow rate $=0.2 \mathrm{~cm}^{3} \mathrm{~min}^{-1}$.

Results were reported after $72 \mathrm{~h}$ on time when the catalysts were at steady state. Values of $\tau_{\mathrm{A}}, R$ and $X_{\mathrm{A}}$ were the average of the corresponding results at the 4 syngas flow rates.

${ }^{\mathrm{a}}$ The fraction of the rate contributed by Pool A $\left(X_{\mathrm{A}}\right)$ was determined by the change of corresponding response in MS.

${ }^{\mathrm{b}} N_{\mathrm{A}}$ represents the amount of reaction intermediate in Pool A: $N_{\mathrm{A}}($ fractional $)=\tau_{\mathrm{A}} R_{\mathrm{A}} X_{\mathrm{A}}$, assuming the slow turnovers involve strongly adsorbed intermediates; $N_{\mathrm{A}}$ (maximum) $=\tau_{\mathrm{A}} R_{\mathrm{A}}$, assuming all the slow turnovers are from the carbon exchange with the carbidic carbon.

c The carbon in the unit " $\mathrm{mmol}_{\mathrm{C}} \mathrm{mol}_{\mathrm{Mo}}^{-1}$ " refers to those participating in the turnovers on Pool A.

${ }^{\mathrm{d}}$ Overall CO hydrogenation (CH): $\tau_{\mathrm{A}, \mathrm{CH}}=N_{\mathrm{A}, \mathrm{CH}} / R_{\mathrm{CH}} X_{\mathrm{A}, \mathrm{CH}}, R_{\mathrm{CH}}=\sum R_{i}, N_{\mathrm{A}, \mathrm{CH}}=\sum N_{\mathrm{A}, i}$, $X_{\mathrm{A}, \mathrm{CH}}=\sum R_{i} X_{\mathrm{A} i} / \sum R_{i}, \theta_{\mathrm{A}, \mathrm{CH}}=\sum \theta_{\mathrm{A}, i}$. The letter " $i$ " refers to a non- $\mathrm{CO}_{2}$ product.

${ }^{\text {e }} N_{\mathrm{A}, \text { total }}=\sum N_{\mathrm{A}, i}, \theta_{\mathrm{A}, \text { total }}=\sum \theta_{\mathrm{A}, i}$. The letter “i” refers to a product (including $\mathrm{CO}_{2}$ ). 
The very low apparent TOF of $\mathrm{CO}$ hydrogenation over $\mathrm{Mo}_{2} \mathrm{C}$ catalysts, as reported in Table 6.1, was very different from the intrinsic TOF $\left(\tau^{-1}\right)$ determined by SSITKA. The intrinsic TOF for CO hydrogenation associated with Pool A on 5 wt.\% $\mathrm{Mo}_{2} \mathrm{C} / \alpha-\mathrm{Al}_{2} \mathrm{O}_{3}\left(0.067 \mathrm{~s}^{-1}\right.$, Table 6.4$)$ was nearly three orders of magnitude higher than the corresponding apparent one $\left(0.00008 \mathrm{~s}^{-1}\right.$, Table 6.1), and is comparable to the intrinsic TOF of CO hydrogenation derived from SSITKA on a bulk Fe catalyst [54] $\left(0.15 \mathrm{~s}^{-1}\right.$, at $553 \mathrm{~K}, 1.8 \mathrm{bar}$ and $\left.\mathrm{H}_{2} / \mathrm{CO}=20\right)$ and a $\mathrm{Rh} / \mathrm{SiO}_{2}$ catalyst [46] $\left(0.1 \mathrm{~s}^{-1}\right.$, at 553 $\mathrm{K}, 1.8$ bar and $\mathrm{H}_{2} / \mathrm{CO}=20$ ). Likewise, the apparent TOF on a $\mathrm{Fe}-\mathrm{Rh} / \mathrm{TiO}_{2}$ catalyst [23] was $0.1 \mathrm{~s}^{-1}$, at $567 \mathrm{~K}, 20$ bar and $\mathrm{H}_{2} / \mathrm{CO}=1$. Nørskov and co-workers used a firstprinciples approach to compare the Brønsted-Evans-Polanyi (BEP) relationship of a variety of adsorbed species on the (211) surfaces of various late transition metals $(\mathrm{Ru}, \mathrm{Ir}$, Fe, Co, Rh, Ni and Pd) [61] with a representative $\mathrm{Mo}_{2} \mathrm{C}(001)$ surface [57]. The authors concluded the chemistry of carbon on Mo-terminated $\mathrm{Mo}_{2} \mathrm{C}(001)$ was indeed similar to that on the late transition metals and suggested $\mathrm{Mo}_{2} \mathrm{C}$ should exhibit similar activity to these metals for reactions where hydrocarbons are the main intermediates [57]. Thus, our SSITKA results are in good agreement with the theoretical prediction.

A high intrinsic TOF for CO hydrogenation over $\mathrm{Mo}_{2} \mathrm{C}\left(0.067 \mathrm{~s}^{-1}\right)$ relative to a low apparent TOF $\left(0.00008 \mathrm{~s}^{-1}\right.$, Table 6.1) must necessarily correspond to a very low coverage of carbon-containing intermediates. As summarized in Table 6.4, the coverage of carbon-containing reaction intermediates leading to hydrocarbons was 8.4 $\mathrm{mmol}_{\mathrm{C}} \mathrm{mol}_{\mathrm{Mo}}^{-1}$, which is far lower than the coverage of species observed on Fe- [33] and Rh-based [47] catalysts. The low surface coverage of adsorbed species is consistent with a very weak IR band of adsorbed $\mathrm{CO}$ on $\mathrm{Mo}_{2} \mathrm{C}$ [18,62-64], and might be attributed to 
adsorbed oxygen on the molybdenum carbide surface due to the strong oxophilicity of $\mathrm{Mo}_{2} \mathrm{C}[16,70-72]$, or to graphitization during reaction [60,73]. The values of $\tau$ for hydrocarbons associated with Pool A (Table 6.4) follow the trend, $\tau_{\mathrm{C} 3}>\tau_{\mathrm{C} 2}>\tau_{\mathrm{C} 1}$, which results from the elementary reactions needed to grow the carbon chain. Similarly, unsaturated hydrocarbon $\left(\mathrm{C}_{2} \mathrm{H}_{4}\right)$ showed slightly shorter residence time than the corresponding saturated one $\left(\mathrm{C}_{2} \mathrm{H}_{6}\right)$, which is related to the time needed for chain termination via hydrogenation. According to Lohitharn and Goodwin [54], the maximum reaction time of carbon chain growth and chain termination via hydrogenation can be estimated by $\tau_{\mathrm{C}_{3} \mathrm{H}_{6}}-\tau_{\mathrm{C}_{2} \mathrm{H}_{4}} \approx 9 \mathrm{~s}$ and by $\tau_{\mathrm{C}_{2} \mathrm{H}_{6}}-\tau_{\mathrm{C}_{2} \mathrm{H}_{4}} \approx 3 \mathrm{~s}$, respectively, and both are slightly longer times than those values on Fe-based catalysts (1.7 s and 0.9 s, respectively) revealed by SSITKA [54].

The mean residence time for $\mathrm{CO}_{2}$ on 5 wt.\% $\mathrm{Mo}_{2} \mathrm{C} / \alpha-\mathrm{Al}_{2} \mathrm{O}_{3}$ was approximately the same as that for overall CO hydrogenation, indicating water produced in the reaction rapidly consumed $\mathrm{CO}$ in the water-gas shift (WGS) reaction. In fact, $\mathrm{Mo}_{2} \mathrm{C}$ is known as a good catalyst/catalytic component in WGS [8,65-68].

The corresponding overall surface coverages of reaction intermediates (Pool A and the potentially existing Pool B combined) were derived from the isotopic transient experiment up to $1 \mathrm{~h}$ (see Figure 6.4 for example curves) by subtracting the background signal, and the results are summarized in Table 6.5. With Pool B being considered, the residence times for hydrocarbons were increased by an order of magnitude. Nørskov and co-workers used a first-principles approach to predict that if oxygen is a key intermediate on the surface of oxophilic $\mathrm{Mo}_{2} \mathrm{C}$ during $\mathrm{CO}$ hydrogenation, the activity of $\mathrm{CO}$ hydrogenation can be much lower than when hydrocarbons are the main intermediates 
[57]. Therefore, Pool B might be composed of those reaction intermediates that have oxygen strongly interacting with the $\mathrm{Mo}_{2} \mathrm{C}$ surface. The inclusion of Pool $\mathrm{B}$ in the analysis increased the total coverage of reaction intermediates by a factor of $8\left(\theta_{\mathrm{A}+\mathrm{B}}=16\right.$ $\left.\operatorname{mmol}_{\mathrm{C}} \operatorname{mol}_{\mathrm{Mo}}^{-1}, \theta_{\mathrm{A}}=2 \mathrm{mmol}_{\mathrm{C}} \operatorname{mol}_{\mathrm{Mo}}^{-1}\right)$.

Table 6.5 Time constants and surface coverages during $\mathrm{CO}$ hydrogenation over unpromoted 5 wt.\% $\mathrm{Mo}_{2} \mathrm{C} / \alpha-\mathrm{Al}_{2} \mathrm{O}_{3}$ catalysts estimated by SSITKA (transient response measured up to $1 \mathrm{~h}$, corresponding to Figure 6.4)

\begin{tabular}{lccccc}
\hline Product & $\begin{array}{c}\tau_{\mathrm{A}+\mathrm{B}} \\
(\mathrm{s})\end{array}$ & $\begin{array}{c}R \\
\left(\mathrm{nmol}_{\mathrm{C}} \mathrm{g}_{\mathrm{cat}}^{-1} \mathrm{~s}^{-1}\right)\end{array}$ & $X_{\mathrm{A}+\mathrm{B}}{ }^{\mathrm{a}}$ & $\begin{array}{c}N_{\mathrm{A}+\mathrm{B}}{ }^{\mathrm{b}} \\
\left(\mu \mathrm{mol}_{\mathrm{C}} \mathrm{g}_{\mathrm{cat}}^{-1}\right)\end{array}$ & $\begin{array}{c}\theta_{\mathrm{A}+\mathrm{B}}{ }^{\mathrm{c}} \\
\left(\mathrm{mmol}_{\mathrm{C}} \mathrm{mol}_{\mathrm{Mo}}^{-1}\right)\end{array}$ \\
\hline $\mathrm{CO}_{2}$ & 97 & 42 & 1 & 3.9 & 8.0 \\
Overall CH $^{\mathrm{d}}$ & 130 & 35 & 0.88 & 4.1 & 8.4 \\
$\quad \mathrm{CH}_{4}$ & 57 & 20 & 0.91 & 0.9 & 2.1 \\
$\quad \mathrm{C}_{2} \mathrm{H}_{4}$ & 220 & 3.9 & 0.83 & 0.71 & 1.5 \\
$\quad \mathrm{C}_{2} \mathrm{H}_{6}$ & 250 & 8.9 & 0.83 & 1.9 & 4.0 \\
$\quad \mathrm{C}_{3} \mathrm{H}_{6}$ & 190 & 2.7 & 0.85 & 0.43 & 0.9 \\
Total carbon & - & 77 & 0.95 & 8.1 & 16 \\
intermediates & & & & $0.47^{\mathrm{f}}$ & 1.0 \\
Background carbon (bkg) & & & & $210^{\mathrm{g}}$ & \\
Total carbidic carbon & & & & &
\end{tabular}

Experimental conditions: 0.5 g 5 wt. $\% \mathrm{Mo}_{2} \mathrm{C} / \alpha-\mathrm{Al}_{2} \mathrm{O}_{3} ; T=573 \mathrm{~K}, p=1.2$ bar, $\mathrm{H}_{2} / \mathrm{CO}=1$; syngas flow rate $=15.6 \mathrm{~cm}^{3} \mathrm{~min}^{-1}$, Ar flow rate $=0.2 \mathrm{~cm}^{3} \mathrm{~min}^{-1}$.

${ }^{\mathrm{a}}$ The fraction of the rate $(X)$ was determined by the change of corresponding response in MS.

b The concentration of reaction intermediate: $N=\tau_{\mathrm{A}+\mathrm{B}} R X_{\mathrm{A}+\mathrm{B}}$.

c In the unit " $\mathrm{mmol}_{\mathrm{C}} \mathrm{mol}_{\mathrm{Mo}}^{-1}$," carbon refers to those participating in the turnovers.

${ }^{\mathrm{d}} \tau_{\mathrm{CH}}=N_{\mathrm{CH}} /\left(R_{\mathrm{CH}} X_{\mathrm{CH}}\right), N_{\mathrm{CH}}=\sum N_{i}, R_{\mathrm{CH}}=\sum R_{i}, X_{\mathrm{CH}}=\sum R_{i} X_{i} / \sum R_{i}, \theta_{\mathrm{CH}}=\sum \theta_{i}$. The letter " $i$ ” refers to a product (including $\mathrm{CO}_{2}$ ).

e Overall CO hydrogenation $(\mathrm{CH}): \quad R_{\text {total }}=\sum R_{i}, \quad X_{\mathrm{A}+\mathrm{B}, \text { total }}=\sum R_{i} X_{\mathrm{A}+\mathrm{B}, i} / \sum R_{i}$, $N_{\mathrm{A}+\mathrm{B}, \text { total }}=\sum N_{\mathrm{A}+\mathrm{B},}, \theta_{\mathrm{A}+\mathrm{B}, \text { total }}=\sum \theta_{\mathrm{A}+\mathrm{B},}$. The letter “ $i$ ” refers to a product (including $\left.\mathrm{CO}_{2}\right)$.

${ }^{\mathrm{f}} N_{\mathrm{bkg}}=N_{\mathrm{A}+\mathrm{B} \text {, total }}\left(1-X_{\mathrm{A}+\mathrm{B}, \text { total }}\right) / X_{\mathrm{A}+\mathrm{B} \text {, total }}$.

$\mathrm{g}$ The amount of carbidic carbon is derived from elemental analysis [17]. 


\subsubsection{Transient analysis of $\mathrm{CO}$ hydrogenation over $\mathrm{Rb}$-promoted $\mathrm{Mo}_{2} \mathrm{C} / \alpha$ -} $\mathrm{Al}_{2} \mathrm{O}_{3}$

With the addition of $\mathrm{Rb}$ promoter, the time constants for the hydrocarbons associated with Pool A were almost the same as those measured on the unpromoted $\mathrm{Mo}_{2} \mathrm{C}$ catalyst, but the surface coverages of carbon-containing reaction intermediates were lowered by an order of magnitude (Table 6.4). These results provide direct evidence for the site-blocking mechanism of alkali metal promotion on Mo-based catalysts for the enhancement of alcohol selectivity suggested by Lee and co-workers [12,69] and by our previous studies [16-18].

It should be noted that the $\mathrm{CO}_{2}$ transient on the $\mathrm{Rb}$-promoted $\mathrm{Mo}_{2} \mathrm{C}$ catalyst was not complete after 290-430 s, and labeled alcohols were never observed over that time frame.

Since labeled alcohols were not detected in the effluent of the reactor containing 1.5 wt.\% Rb-5 wt.\% $\mathrm{Mo}_{2} \mathrm{C} / \alpha-\mathrm{Al}_{2} \mathrm{O}_{3}$ even after sampling for $2 \mathrm{~h}$ beyond the switch to labeled ${ }^{13} \mathrm{CO}$, SSITKA could not be used to quantify the surface coverage of intermediates leading to alcohols. Evidently, the alcohols were strongly retained by the catalyst. To overcome this problem, we decided to perform a long-term transient experiment in which the steady-state CO flow was simply replaced with Ar so that we could follow the desorption of the products formed into a stream of $\mathrm{H}_{2}$ and Ar. The profiles of normalized desorption rates over 5 wt. $\% \mathrm{Mo}_{2} \mathrm{C} / \alpha-\mathrm{Al}_{2} \mathrm{O}_{3}$ and 1.5 wt.\% $\mathrm{Rb}-5$ wt.\% $\mathrm{Mo}_{2} \mathrm{C} / \alpha-\mathrm{Al}_{2} \mathrm{O}_{3}$ are shown in Figure 6.7, and the amount of the reaction intermediates $(N)$ and the corresponding surface coverages $(\theta)$ determined from the material balance are summarized in Table 6.6. 

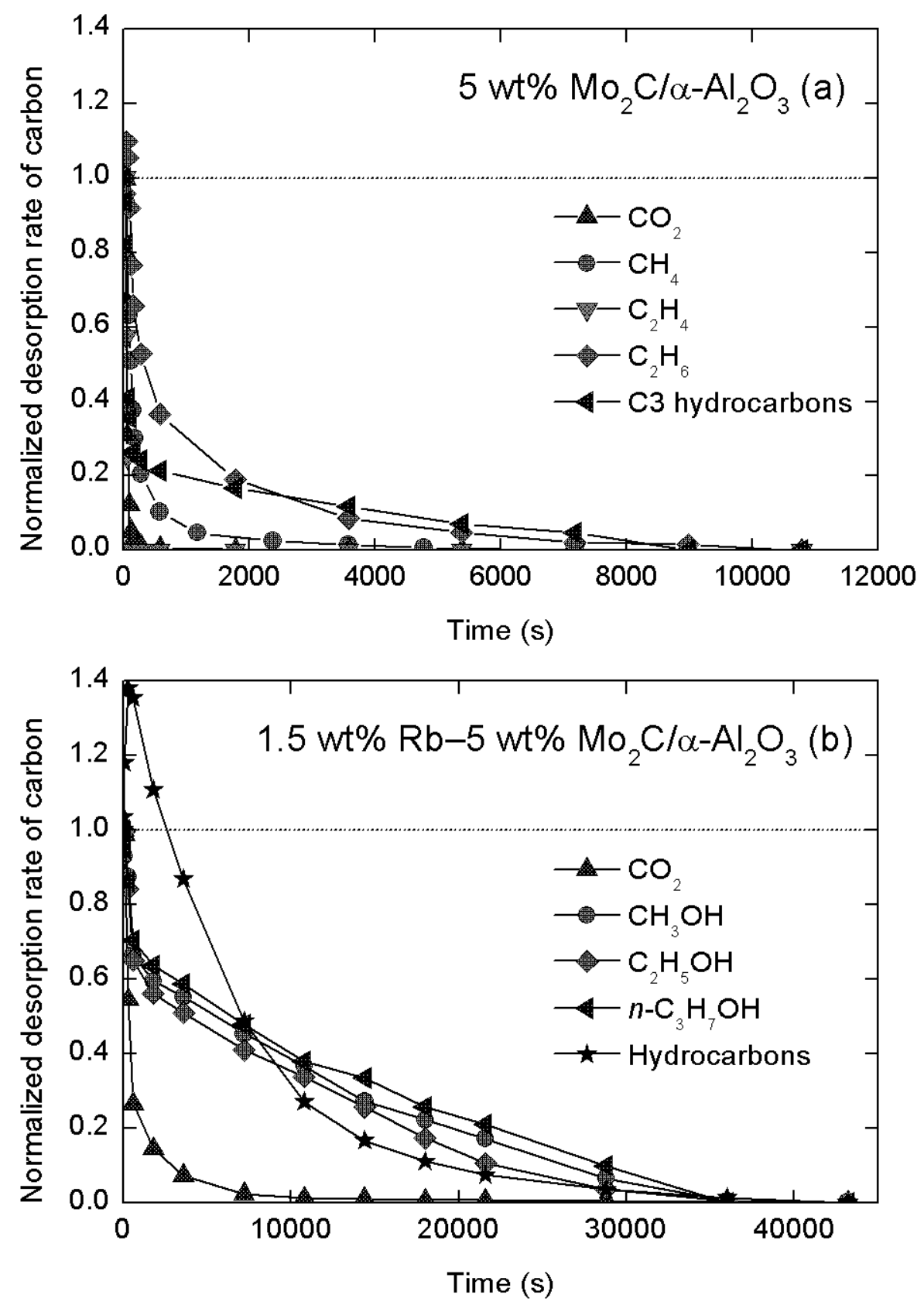

Figure 6.7 Transient desorption rates of carbon in various products associated with (a) 5 wt.\% $\mathrm{Mo}_{2} \mathrm{C} / \alpha-\mathrm{Al}_{2} \mathrm{O}_{3}$, and (b) 1.5 wt.\% Rb-5 wt. $\% \mathrm{Mo}_{2} \mathrm{C} / \alpha-\mathrm{Al}_{2} \mathrm{O}_{3}$ in steady-state CO hydrogenation. Results were normalized by the difference between the initial and final desorption rates. 
Table 6.6 Coverage of reaction intermediates in CO hydrogenation over 5 wt. $\% \mathrm{Mo}_{2} \mathrm{C} / \alpha$ $\mathrm{Al}_{2} \mathrm{O}_{3}$ and 1.5 wt.\% Rb-5 wt.\% $\mathrm{Mo}_{2} \mathrm{C} / \alpha-\mathrm{Al}_{2} \mathrm{O}_{3}$ catalysts estimated by the interruption of $\mathrm{CO}$ flow and subsequent desorption of products (see Figure 6.7)

\begin{tabular}{|c|c|c|}
\hline Product & $\begin{array}{l}\tau^{\mathrm{a}} \\
(\mathrm{s})\end{array}$ & $\left.\underset{\left(\mathrm{nmol} \mathrm{g}^{-1} \mathrm{~s}^{-1}\right) X_{(}^{\mathrm{b}} N^{\mathrm{c}}}{\left.\mathrm{mol} \mathrm{g}^{-1}\right)\left(\mathrm{mmol} \mathrm{mol}^{-1}\right)} \theta^{\mathrm{d}}\right)$ \\
\hline
\end{tabular}

5 wt. $\% \mathrm{Mo}_{2} \mathrm{C}$

$\mathrm{CH}_{4}$

20

260

C2 hydrocarbons

340

C3 hydrocarbons

920

Total carbon intermediates ${ }^{\mathrm{e}}$

-

Background carbon

\section{5 wt.\% Rb-5 wt. $\% \mathrm{Mo}_{2} \mathrm{C}$}

$\mathrm{CO}_{2}$

\section{1}

0.99

5.6

11

Hydrocarbons ${ }^{\text {g }}$

10000

3.2

0.87

30

61

$\mathrm{CH}_{3} \mathrm{OH}$

9400

0.54

0.81

4.1

8.3

$\mathrm{C}_{2} \mathrm{H}_{5} \mathrm{OH}$

8200

0.28

0.82

1.8

3.7

$n-\mathrm{C}_{3} \mathrm{H}_{7} \mathrm{OH}$

10000

0.17

1

1.8

3.7

Total carbon intermediates ${ }^{\mathrm{e}}$

9.3

0.94

43

88

Background carbon

Total Rb

$2.9^{\mathrm{f}}$

$180^{\mathrm{h}}$

Total carbidic carbon

$210^{\mathrm{i}}$

Experimental conditions: 0.5 g 5 wt. $\% \mathrm{Mo}_{2} \mathrm{C} / \alpha-\mathrm{Al}_{2} \mathrm{O}_{3}$ or 2.0 g 1.5 wt. $\%-5$ wt. $\% \mathrm{Mo}_{2} \mathrm{C} / \alpha-$ $\mathrm{Al}_{2} \mathrm{O}_{3} ; T=573 \mathrm{~K}, p=1.2$ bar, $\mathrm{H}_{2} / \mathrm{CO}=1$ before switch, $\mathrm{H}_{2} / \mathrm{Ar}=1$ after switch; total flow rate $=15.6 \mathrm{~cm}^{3} \mathrm{~min}^{-1}$.

${ }^{\text {a }}$ Gas phase hold-up of the system was subtracted.

b The fraction of the rate $(X)$ was determined by the change of corresponding response in MS.

c The concentration of reaction intermediate: $N=\tau R X$.

d In the unit " $\mathrm{mmol}_{\mathrm{C}} \mathrm{mol}_{\mathrm{Mo}}^{-1}$," carbon refers to those participate in the turnovers.

e $R_{\text {total }}=\sum R_{i}, X_{\text {total }}=\sum R_{i} X_{i} / \sum R_{i}, N_{\text {total }}=\sum N_{i}, \theta_{\text {toal }}=\sum \theta_{i}$. The letter " $i$ " refers to a product (including $\mathrm{CO}_{2}$ ).

f $N_{\text {bkg }}=\tau_{\text {total }} R_{\text {total }}\left(1-X_{\text {total }}\right)$.

g The sum of $\mathrm{CH}_{4}, \mathrm{C}_{2} \mathrm{H}_{4}, \mathrm{C}_{2} \mathrm{H}_{6}$ and $\mathrm{C}_{3} \mathrm{H}_{6}$, which represents $87 \%$ of the total hydrocarbons.

$\mathrm{h}$ The unit of the total $\mathrm{Rb}$ concentration is $\mu \mathrm{mol}_{\mathrm{Rb}} \mathrm{g}_{\text {cat }}^{-1}$.

${ }^{\mathrm{i}}$ The amount of carbidic carbon is derived from elemental analysis [17]. 
The values of $N$ and $\theta$ for the total carbon intermediates on 5 wt.\% $\mathrm{Mo}_{2} \mathrm{C} / \alpha-\mathrm{Al}_{2} \mathrm{O}_{3}$ measured by the desorption experiment $\left(N=13 \mu \mathrm{mol}_{\mathrm{C}} \mathrm{g}_{\text {cat }}^{-1}, \theta=27 \mathrm{mmol}_{\mathrm{C}} \mathrm{mol}_{\mathrm{Mo}}^{-1}\right.$, in Table 6.6) are comparable to those derived from SSITKA ( $N=8.1 \mu \mathrm{mol}_{\mathrm{C}} \mathrm{g}_{\text {cat }}^{-1}, \theta=16$ $\mathrm{mmol}_{\mathrm{C}} \mathrm{mol}_{\mathrm{Mo}}^{-1}$, in Table 6.5), which suggests that desorption experiments with flowing $\mathrm{H}_{2}$ and Ar provide reasonable estimations of $N$ and $\theta$. Interestingly, increases in the desorption rates of hydrocarbons were observed in the first several minutes of the desorption experiments under flowing $\mathrm{H}_{2}$ and $\mathrm{Ar}$ (the portions exceeding 1 in Figure 6.7), and the effluent $\mathrm{CO}_{2}$ from 5 wt.\% $\mathrm{Mo}_{2} \mathrm{C} / \alpha-\mathrm{Al}_{2} \mathrm{O}_{3}$ in the desorption experiment (0.8 $\mu \mathrm{mol}_{\mathrm{C}} \mathrm{g}_{\text {cat }}^{-1}$, in Table 6.6) was much less than the value measured by SSITKA (3.9 $\mu \mathrm{mol}_{\mathrm{C}} \mathrm{g}_{\text {cat }}^{-1}$, in Table 6.5). These results suggest that the carbon intermediates leading to $\mathrm{CO}_{2}$ formation during steady-state syngas reaction (presumably associatively adsorbed CO) may undergo hydrogenation to hydrocarbons instead. Additionally, halting the flow of CO may facilitate rapid hydrogenation of adsorbed hydrocarbon fragments thus resulting in a rapid desorption at short times. Nevertheless, these changes in specific products did not significantly affect the overall decay in the overall desorption rate of the carbon intermediates with time on stream, and should not affect the quantification of the total amount of carbon intermediates on the surface at the time of the transient. With added 1.5 wt.\% Rb, the mean residence time of $\mathrm{CO}_{2}$ on 5 wt. $\% \mathrm{Mo}_{2} \mathrm{C} / \alpha-\mathrm{Al}_{2} \mathrm{O}_{3}$ was significantly increased (noted the change in scale of the x-axis in Figure 6.7), indicating a strong affinity between $\mathrm{CO}_{2}$ and the basic $\mathrm{Rb}$ species, which is to be expected. The amount of the total carbon desorbed from the $5 \mathrm{wt} . \% \mathrm{Mo}_{2} \mathrm{C} / \alpha-\mathrm{Al}_{2} \mathrm{O}_{3}$ catalyst increased by a factor of 3 after adding $\mathrm{Rb}$ (see Table 6.6), among which $8 \mu \mathrm{mol}_{\mathrm{C}} \mathrm{g}_{\text {cat }}^{-1}$ was associated 
with alcohols. Evidently, the presence of $\mathrm{Rb}$ on the catalyst increased the retention of products on the surface during CO hydrogenation. Since the total amount of carbon desorbed from the promoted catalyst ( $43 \mu \mathrm{mol}_{\mathrm{C}} \mathrm{g}_{\text {cat }}^{-1}$ ) was much less than the amount of $\mathrm{Rb}\left(180 \mu \mathrm{mol}_{\mathrm{C}} \mathrm{g}_{\mathrm{cat}}^{-1}\right)$ in the catalyst, we concluded that interactions of products and/or reaction intermediates with the Rb promoter is significant. It is possible that $\mathrm{Rb}$ alkoxides is one form of the Rb species present during reaction, as suggested by Woo et al. [74] Also, given the total amount of the carbidic carbon $\left(210 \mu \mathrm{mol}_{\mathrm{C}} \mathrm{g}_{\text {cat }}^{-1}\right)$ exceeded the measured amount of carbon-containing intermediates formed on $5 \mathrm{wt}$. $\% \mathrm{Mo}_{2} \mathrm{C} / \alpha-\mathrm{Al}_{2} \mathrm{O}_{3}$ $\left(13 \mu \mathrm{mol}_{\mathrm{C}} \mathrm{g}_{\text {cat }}^{-1}\right)$ and on 1.5 wt.\% Rb-5 wt.\% $\mathrm{Mo}_{2} \mathrm{C} / \alpha-\mathrm{Al}_{2} \mathrm{O}_{3}\left(43 \mu \mathrm{mol}_{\mathrm{C}} \mathrm{g}_{\text {cat }}^{-1}\right)$, the slow exchange of carbon between the reaction intermediates and the carbidic carbon cannot be completed during the time of measurements.

\subsection{Conclusions}

The isotopic transient analysis revealed that although the catalytically-relevant pool on $\mathrm{Mo}_{2} \mathrm{C}$ catalysts was capable of relatively rapid turnovers in $\mathrm{CO}$ hydrogenation ( $0.067 \mathrm{~s}^{-1}$ at $573 \mathrm{~K}$ in 1.2 bar syngas), the surface coverage of reaction intermediates was extremely low, resulting in a low apparent activity of the $\mathrm{Mo}_{2} \mathrm{C}$-based catalysts in the $\mathrm{CO}$ hydrogenation reaction. The low surface coverage of the reaction intermediates was decreased even further by adding $\mathrm{Rb}$ promoter. The added $\mathrm{Rb}$ promoter interacted strongly with the alcohols formed during $\mathrm{CO}$ hydrogenation, suggesting that $\mathrm{Rb}$ alkoxides may be one form of the $\mathrm{Rb}$ species present during reaction. Exchange of carbon between the adsorbed reaction intermediates during CO hydrogenation and the carbidic 
carbon in the carbide catalysts likely accounted for the long transient response and background level of signal after an isotopic switch.

The results of this work show that appropriately active sites, typical of late transition metals, do indeed exist on supported $\mathrm{Mo}_{2} \mathrm{C}$ catalysts for $\mathrm{CO}$ hydrogenation, but the number of those sites is very low compare to the total amount of Mo at the surface. Future work with $\mathrm{Mo}_{2} \mathrm{C}$ catalysts for $\mathrm{CO}$ hydrogenation should involve identification of those sites and optimization of their number density.

\subsection{Acknowledgements}

We acknowledge financial support from The Dow Chemical Company and helpful discussions on the installation of the experimental setup for multi-product SSITKA with Prof. James Goodwin (Clemson University) and Dr. Yu-Tung Tsai (Oak Ridge National Laboratory). We thank our collaborators at The Dow Chemical Company and Georgia Institute of Technology who were involved in this project, Dr. Daniela Ferrari, Dr. David Barton, Prof. Christopher Jones, Prof. David Sholl, Prof. Pradeep Agrawal, Mr. Liwei Li and Mr. Michael Morrill.

\section{References of Chapter 6}

[1] R.B. Levy, M. Boudart, "Platinum-like behavior of tungsten carbide in surface catalysis,” Science 181 (1973) 547-549.

[2] J.S. Lee, S. Locatelli, S.T. Oyama, M. Boudart, "Molybdenum carbide catalysts 3. Turnover rates for the hydrogenolysis of $n$-butane,” Journal of Catalysis 125 (1990) 157-170.

[3] E.A. Blekkan, C. Pham-Huu, M.J. Ledoux, J. Guille, "Isomerization of $n$-heptane on an oxygen-modified molybdenum carbide catalyst," Industrial \& Engineering Chemistry Research 33 (1994) 1657-1664.

[4] M.J. Ledoux, C. Pham-Huu, R.R. Chianelli, “Catalysis with carbides,” Current Opinion in Solid State and Materials Science 1 (1996) 96-100. 
[5] T. Hyeon, M. Fang, K.S. Suslick, "Nanostructured molybdenum carbide: sonochemical synthesis and catalytic properties," Journal of the American Chemical Society 118 (1996) 5492-5493.

[6] S.K. Bej, C.A. Bennett, L.T. Thompson, "Acid and base characteristics of molybdenum carbide catalysts,” Applied Catalysis A: General 250 (2003) 197-208.

[7] S.K. Bej, L.T. Thompson, “Acetone condensation over molybdenum nitride and carbide catalysts,” Applied Catalysis A: General 264 (2004) 141-150.

[8] J. Patt, D.J. Moon, C. Phillips, L. Thompson, "Molybdenum carbide catalysts for water-gas shift,” Catalysis Letters 65 (2000) 193-195.

[9] I. Kojima, E. Miyazaki, I. Yasumori, "Synthesis of hydrocarbons from $\mathrm{CO}$ and $\mathrm{H}_{2}$ over metal carbide catalysts," Journal of the Chemical Society, Chemical Communications (1980) 573-574.

[10] I. Kojima, E. Miyazaki, "Catalysis by transition metal carbides: V. Kinetic measurements of hydrogenation of $\mathrm{CO}$ over $\mathrm{TaC}$, TiC, and $\mathrm{Mo}_{2} \mathrm{C}$ catalysts," Journal of Catalysis 89 (1984) 168-171.

[11] H.C. Woo, K.Y. Park, Y.G. Kim, I.S. Nam, J.S. Chung, J.S. Lee, "Mixed alcohol synthesis from carbon monoxide and dihydrogen over potassium-promoted molybdenum carbide catalysts,” Applied Catalysis 75 (1991) 267-280.

[12] J.S. Lee, S. Kim, Y.G. Kim, "Electronic and geometric effects of alkali promoters in CO hydrogenation over K/Mo2C catalysts,” Topics in Catalysis 2 (1995) 127140.

[13] H.G. Kim, K.H. Lee, J.S. Lee, "Carbon monoxide hydrogenation over molybdenum carbide catalysts,” Research on Chemical Intermediates 26 (2000) 427-443.

[14] M. Xiang, D. Li, W. Li, B. Zhong, Y. Sun, "Performances of mixed alcohols synthesis over potassium promoted molybdenum carbides,” Fuel 85 (2006) 26622665.

[15] D.-V.N. Vo, A.A. Adesina, "Fischer-Tropsch synthesis over alumina-supported molybdenum carbide catalyst,” Applied Catalysis A: General 399 (2011) 221-232.

[16] H. Shou, R.J. Davis, "Reactivity and in situ X-ray absorption spectroscopy of Rbpromoted $\mathrm{Mo}_{2} \mathrm{C} / \mathrm{MgO}$ catalysts for higher alcohol synthesis,” Journal of Catalysis 282 (2011) 83-93.

[17] H. Shou, D. Ferrari, D.G. Barton, C.W. Jones, R.J. Davis, "Influence of passivation on the reactivity of unpromoted and Rb-promoted $\mathrm{Mo}_{2} \mathrm{C}$ nanoparticles for $\mathrm{CO}$ hydrogenation,” ACS Catalysis 2 (2012) 1408-1416. 
[18] H. Shou, L. Li, D. Ferrari, D.S. Sholl, R.J. Davis, "Use of infrared spectroscopy and density functional theory to study the influence of rubidium on aluminasupported molybdenum carbide catalyst for higher alcohol synthesis from syngas," Journal of Catalysis 299 (2013) 150-161.

[19] J.M. Christensen, L.D.L. Duchstein, J.B. Wagner, P.A. Jensen, B. Temel, A.D. Jensen, "Catalytic conversion of syngas into higher alcohols over carbide catalysts," Industrial \& Engineering Chemistry Research 51 (2012) 4161-4172.

[20] S.-H. Chai, V. Schwartz, J.Y. Howe, X. Wang, M. Kidder, S.H. Overbury, S. Dai, D. Jiang, "Graphitic mesoporous carbon-supported molybdenum carbides for catalytic hydrogenation of carbon monoxide to mixed alcohols," Microporous and Mesoporous Materials 170 (2013) 141-149.

[21] K.Y. Park, W.K. Seo, J.S. Lee, "Selective synthesis of light olefins from syngas over potassium-promoted molybdenum carbide catalysts," Catalysis Letters 11 (1991) 349-356.

[22] D.-V.N. Vo, T.-H. Nguyen, E.M. Kennedy, B.Z. Dlugogorski, A.A. Adesina, "Fischer-Tropsch synthesis: Effect of promoter type on alumina-supported Mo carbide catalysts,” Catalysis Today 175 (2011) 450-459.

[23] M.A. Haider, M.R. Gogate, R.J. Davis, "Fe-promotion of supported Rh catalysts for direct conversion of syngas to ethanol,” Journal of Catalysis 261 (2009) 9-16.

[24] J. Happel, “Transient tracing,” Chemical Engineering Science 33 (1978) 1567.

[25] C.O. Bennett, "Understanding heterogeneous catalysis through the transient method,” ACS Symposium Series 1 (1982) 1-32.

[26] P. Biloen, “Transient kinetic methods,” Journal of Molecular Catalysis 21 (1993) 17-24.

[27] S.L. Shannon, J.G. Goodwin, "Characterization of Catalytic Surfaces by IsotopicTransient Kinetics during Steady-State Reaction,” Chemical Reviews 95 (1995) 677-695.

[28] C.A. Mims, L.E. McCandlish, "Chain growth rates in Fischer-Tropsch synthesis on an iron catalyst: an isotopic transient study," Journal of the American Chemical Society 107 (1985) 696-697.

[29] C.A. Mims, L.E. McCandlish, "Evidence for rapid chain growth in the FischerTropsch synthesis over iron and cobalt catalysts," The Journal of Physical Chemistry 91 (1987) 929-937.

[30] D.M. Stockwell, D. Bianchi, C.O. Bennett, "Carbon pathways in methanation and chain growth during the Fischer-Tropsch synthesis on $\mathrm{Fe} / \mathrm{Al}_{2} \mathrm{O}_{3}$," Journal of Catalysis 113 (1988) 13-24. 
[31] K. Sudsakorn, J.G. Goodwin, A.A. Adeyiga, "Effect of activation method on Fe FTS catalysts: investigation at the site level using SSITKA," Journal of Catalysis 213 (2003) 204-210.

[32] N. Lohitharn, J.G. Goodwin, "Impact of Cr, Mn and Zr addition on Fe FischerTropsch synthesis catalysis: Investigation at the active site level using SSITKA,” Journal of Catalysis 257 (2008) 142-151.

[33] N. Lohitharn, J.G. Goodwin, "Effect of K promotion of Fe and FeMn FischerTropsch synthesis catalysts: Analysis at the site level using SSITKA," Journal of Catalysis 260 (2008) 7-16.

[34] S.H. Ali, J.G. Goodwin, "Isotopic transient kinetic Analysis of the induction phenomenon for methanol synthesis on $\mathrm{Pd} / \mathrm{SiO}_{2}$," Journal of Catalysis 170 (1997) 265-274.

[35] S.H. Ali, J.G. Goodwin, "Analysis of sequential reactions in bifunctional catalyst systems using isotopic transient kinetics: methanol synthesis on $\mathrm{Pd} / \mathrm{SiO}_{2}+\mathrm{Al}_{2} \mathrm{O}_{3}$," Journal of Catalysis 171 (1997) 333-338.

[36] S.H. Ali, J.G. Goodwin, "Impact of readsorption effects and their removal from surface reaction parameters obtained by isotopic transient kinetic analysis: Methanol synthesis on $\mathrm{Pd} / \mathrm{SiO}_{2}$," Journal of Catalysis 171 (1997) 339-344.

[37] S.H. Ali, J.G. Goodwin, "SSITKA Investigation of palladium precursor and support effects on CO hydrogenation over supported Pd catalysts," Journal of Catalysis 176 (1998) 3-13.

[38] C.A. Mims, "An oxygenated C1 intermediate in the Fischer-Tropsch synthesis on cobalt," Catalysis Letters 1 (1988) 293-298.

[39] S. Vada, B. Chen, J.G. Goodwin, "Isotopic transient study of La promotion of $\mathrm{Co} / \mathrm{Al}_{2} \mathrm{O}_{3}$ for CO hydrogenation," Journal of Catalysis 153 (1995) 224-231.

[40] V. Frøseth, S. Storsæter, Ø. Borg, E.A. Blekkan, M. Rønning, A. Holmen, "Steady state isotopic transient kinetic analysis (SSITKA) of CO hydrogenation on different Co catalysts," Applied Catalysis A: General 289 (2005) 10-15.

[41] J. Yang, D. Chen, A. Holmen, "Understanding the kinetics and Re promotion of carbon nanotube supported cobalt catalysts by SSITKA," Catalysis Today 186 (2012) 99-108.

[42] Y.-T. Tsai, X. Mo, J.G. Goodwin, "The synthesis of hydrocarbons and oxygenates during $\mathrm{CO}$ hydrogenation on CoCuZnO catalysts: Analysis at the site level using multiproduct SSITKA,” Journal of Catalysis 285 (2012) 242-250.

[43] B. Chen, J.G. Goodwin, "Isotopic transient kinetic analysis of CO hydrogenation on $\mathrm{Cu}$-modified $\mathrm{Ru} / \mathrm{SiO}_{2}$, Journal of Catalysis 158 (1996) 511-520. 
[44] D.M. Stockwell, C.O. Bennett, "An isotopic study of chain growth during the $\mathrm{CO} / \mathrm{H}_{2}$ reaction over $\mathrm{Ni} / \mathrm{Al}_{2} \mathrm{O}_{3}$,” Journal of Catalysis 110 (1988) 354-363.

[45] D.M. Stockwell, J.S. Chung, C.O. Bennett, “A transient infrared and isotopic study of methanation over $\mathrm{Ni} / \mathrm{Al}_{2} \mathrm{O}_{3}$,” Journal of Catalysis 112 (1988) 135-144.

[46] J. Gao, X. Mo, J.G. Goodwin, "Relationships between oxygenate and hydrocarbon formation during $\mathrm{CO}$ hydrogenation on $\mathrm{Rh} / \mathrm{SiO}_{2}$ : Use of multiproduct SSITKA," Journal of Catalysis 275 (2010) 211-217.

[47] J. Gao, X. Mo, J.G. Goodwin, "Evidence of strong metal-oxide interactions in promoted $\mathrm{Rh} / \mathrm{SiO}_{2}$ on CO hydrogenation: Analysis at the site level using SSITKA," Catalysis Today 160 (2011) 44-49.

[48] R. Burch, M.I. Petch, "Investigation of the synthesis of oxygenates from carbon monoxide/hydrogen mixtures on supported rhodium catalysts," Applied Catalysis A: General 88 (1992) 39-60.

[49] B.C. McClaine, R.J. Davis, "Isotopic transient kinetic analysis of Cs-promoted Ru/MgO during ammonia synthesis,” Journal of Catalysis 210 (2002) 387-396.

[50] B.C. McClaine, R.J. Davis, "Importance of product readsorption during isotopic transient analysis of ammonia synthesis on Ba-promoted Ru/BaX catalyst,” Journal of Catalysis 211 (2002) 379-386.

[51] J.T. Calla, M.T. Bore, A.K. Datye, R.J. Davis, "Effect of alumina and titania on the oxidation of CO over Au nanoparticles evaluated by ${ }^{13} \mathrm{C}$ isotopic transient analysis," Journal of Catalysis 238 (2006) 458-467.

[52] J.T. Calla, R.J. Davis, “Oxygen-exchange reactions during CO oxidation over titania- and alumina-supported Au nanoparticles,” Journal of Catalysis 241 (2006) 407-416.

[53] T.W. Birky, J.T. Kozlowski, R.J. Davis, "Isotopic transient analysis of the ethanol coupling reaction over magnesia,” Journal of Catalysis 298 (2013) 130-137.

[54] N. Lohitharn, J.G. Goodwin, "An investigation using SSITKA of chain growth on Fe and FeMnK Fischer-Tropsch synthesis catalysts," Catalysis Communications 10 (2009) 758-762.

[55] X.-R. Shi, J. Wang, K. Hermann, "CO and NO adsorption and dissociation at the $\beta$ $\mathrm{Mo}_{2} \mathrm{C}(0001)$ surface: A density functional theory study,” The Journal of Physical Chemistry C 114 (2010) 13630-13641.

[56] J.W. Han, L. Li, D.S. Sholl, "Density functional theory study of H and CO adsorption on alkali-promoted $\mathrm{Mo}_{2} \mathrm{C}$ Surfaces,” The Journal of Physical Chemistry C 115 (2011) 6870-6876. 
[57] A.J. Medford, A. Vojvodic, F. Studt, F. Abild-Pedersen, J.K. Nørskov, “Elementary steps of syngas reactions on $\mathrm{Mo}_{2} \mathrm{C}\left(\begin{array}{lll}0 & 0 & 1\end{array}\right)$ : Adsorption thermochemistry and bond dissociation,” Journal of Catalysis (2012).

[58] J. Ren, C.-F. Huo, J. Wang, Y.-W. Li, H. Jiao, "Surface structure and energetics of oxygen and CO adsorption on $\alpha-\mathrm{Mo}_{2} \mathrm{C}(0) 00$ 1)," Surface Science 596 (2005) 212221.

[59] J.R. Kitchin, J.K. Nørskov, M.A. Barteau, J.G. Chen, "Trends in the chemical properties of early transition metal carbide surfaces: A density functional study," Catalysis Today 105 (2005) 66-73.

[60] J.A. Schaidle, "carbide and nitride based catalysts for synthesis gas conversion," Ph.D., University of Michigan, 2011.

[61] S. Wang, B. Temel, J. Shen, G. Jones, L.C. Grabow, F. Studt, T. Bligaard, F. AbildPedersen, C.H. Christensen, J.K. Nørskov, "Universal Brønsted-Evans-Polanyi relations for $\mathrm{C}-\mathrm{C}, \mathrm{C}-\mathrm{O}, \mathrm{C}-\mathrm{N}, \mathrm{N}-\mathrm{O}, \mathrm{N}-\mathrm{N}$, and $\mathrm{O}-\mathrm{O}$ dissociation reactions," Catalysis Letters 141 (2011) 370-373.

[62] J. Raskó, J. Kiss, "Infrared study of the adsorption of $\mathrm{CO}$ and $\mathrm{CH}_{3}$ on silicasupported $\mathrm{MoO}_{3}$ and $\mathrm{Mo}_{2} \mathrm{C}$ catalysts,” Applied Catalysis A: General 253 (2003) 427-436.

[63] W. Wu, Z. Wu, C. Liang, X. Chen, P. Ying, C. Li, “In Situ FT-IR spectroscopic studies of $\mathrm{CO}$ adsorption on fresh $\mathrm{Mo}_{2} \mathrm{C} / \mathrm{Al}_{2} \mathrm{O}_{3}$ catalyst," The Journal of Physical Chemistry B 107 (2003) 7088-7094.

[64] W. Wu, Z. Wu, C. Liang, P. Ying, Z. Feng, C. Li, “An IR study on the surface passivation of $\mathrm{Mo}_{2} \mathrm{C} / \mathrm{Al}_{2} \mathrm{O}_{3}$ catalyst with $\mathrm{O}_{2}, \mathrm{H}_{2} \mathrm{O}$ and $\mathrm{CO}_{2}$," Physical Chemistry Chemical Physics 6 (2004) 5603-5608.

[65] H. Tominaga, M. Nagai, "Density functional theory of water-gas shift reaction on molybdenum carbide,” The Journal of Physical Chemistry B 109 (2005) 2041520423.

[66] M. Nagai, K. Matsuda, "Low-temperature water-gas shift reaction over cobaltmolybdenum carbide catalyst,” Journal of Catalysis 238 (2006) 489-496.

[67] J.A. Schaidle, A.C. Lausche, L.T. Thompson, "Effects of sulfur on $\mathrm{Mo}_{2} \mathrm{C}$ and $\mathrm{Pt} / \mathrm{Mo}_{2} \mathrm{C}$ catalysts: Water gas shift reaction,” Journal of Catalysis 272 (2010) 235245.

[68] N.M. Schweitzer, J.A. Schaidle, O.K. Ezekoye, X. Pan, S. Linic, L.T. Thompson, "High activity carbide supported catalysts for water gas shift," Journal of the American Chemical Society 133 (2011) 2378-2381. 
[69] J.S. Lee, S. Kim, K.H. Lee, I.-S. Nam, J.S. Chung, Y.G. Kim, H.C. Woo, "Role of alkali promoters in $\mathrm{K} / \mathrm{MoS}_{2}$ catalysts for $\mathrm{CO}-\mathrm{H}_{2}$ reactions," Applied Catalysis A: General 110 (1994) 11-25.

[70] J.S. Lee, S.T. Oyama, M. Boudart, "Molybdenum carbide catalysts: I. Synthesis of unsupported powders,” Journal of Catalysis 106 (1987) 125-133.

[71] H.H. Hwu, J.G. Chen, "Surface Chemistry of Transition Metal Carbides,” Chemical Reviews 105 (2005) 185-212.

[72] J.A. Schaidle, N.M. Schweitzer, O.T. Ajenifujah, L.T. Thompson, "On the preparation of molybdenum carbide-supported metal catalysts," Journal of Catalysis 289 (2012) 210-217.

[73] J. Sehested, C.J.H. Jacobsen, S. Rokni, J.R. Rostrup-Nielsen, “Activity and stability of molybdenum carbide as a catalyst for $\mathrm{CO}_{2}$ reforming," Journal of Catalysis 201 (2001) 206-212.

[74] H.C. Woo, I.S. Nam, J.S. Lee, J.S. Chung, Y.G. Kim, "Structure and Distribution of Alkali Promoter in K/MoS2 Catalysts and Their Effects on Alcohol Synthesis from Syngas," Journal of Catalysis 142 (1993) 672-690. 


\section{Chapter 7. \\ Conclusions and future work}

\subsection{Conclusions}

Molybdenum carbide nanoclusters (1-3 nm) were synthesized on various supports (MgO, $\alpha-\mathrm{Al}_{2} \mathrm{O}_{3}$ and $\gamma-\mathrm{Al}_{2} \mathrm{O}_{3}$ ) using incipient wetness impregnation, followed by drying, calcination and temperature-programmed carburization with a mixture of $\mathrm{H}_{2}$ and $\mathrm{CH}_{4}$ (or $\mathrm{C}_{2} \mathrm{H}_{6}$ ). The high dispersion of the molybdenum carbide domains was verified by the lack of a diffraction pattern in XRD, the direct observation in electron microscopy and the coordination number of Mo-Mo derived from EXAFS.

The CO hydrogenation reactions were conducted in a fixed-bed reactor at typical conditions of $573 \mathrm{~K}, 30$ bar and $\mathrm{H}_{2} / \mathrm{CO}=1$. The supported- $\mathrm{Mo}_{2} \mathrm{C}$ catalysts without coexisting $\mathrm{Rb}$ promoter typically demonstrated high selectivity towards hydrocarbons in $\mathrm{CO}$ hydrogenation. If not passivated, the unpromoted $\mathrm{Mo}_{2} \mathrm{C} / \alpha-\mathrm{Al}_{2} \mathrm{O}_{3}$ catalyst also demonstrated the capacity for alcohol formation, the rate of which was comparable to those on Rb-promoted $\mathrm{Mo}_{2} \mathrm{C} / \alpha-\mathrm{Al}_{2} \mathrm{O}_{3}$. Passivation with dilute $\mathrm{O}_{2}$ introduced surface acidity on $\mathrm{Mo}_{2} \mathrm{C}$ and decreased the activity of unpromoted $\mathrm{Mo}_{2} \mathrm{C} / \alpha-\mathrm{Al}_{2} \mathrm{O}_{3}$ in $\mathrm{CO}$ hydrogenation by about $40 \%$. Passivation did not significantly affect the activity of the Rb-promoted $\mathrm{Mo}_{2} \mathrm{C} / \alpha-\mathrm{Al}_{2} \mathrm{O}_{3}$ catalyst. The acidity on the $\mathrm{Mo}_{2} \mathrm{C}$ catalyst (introduced by the surface passivation) or on the support (like $\gamma-\mathrm{Al}_{2} \mathrm{O}_{3}$ ) substantially decreased the apparent alcohol formation rate on $\mathrm{Mo}_{2} \mathrm{C}$ by catalyzing secondary dehydration reactions of alcohols to form ethers or hydrocarbons. The addition of Rb promoter to $\mathrm{Mo}_{2} \mathrm{C} / \mathrm{Al}_{2} \mathrm{O}_{3}$ gradually shifted the selectivity of the syngas reaction toward alcohols, primarily by 
inhibiting hydrocarbon and ether formation. In addition, the added $\mathrm{Rb}$ promoted the formation of higher alcohols over methanol. Due to its basicity, MgO support also increased the alcohol selectivity on $\mathrm{Mo}_{2} \mathrm{C}$ to some extent. Moreover, the alcohol selectivity over $\mathrm{Mo}_{2} \mathrm{C}$ catalysts decreased significantly with $\mathrm{CO}$ conversion, suggesting that alcohols were probably the primary products in CO hydrogenation. In all cases, the selectivity of $\mathrm{CO}_{2}$ was nearly the stoichiometric maximum, indicating the water-gas shift reaction is very favored at syngas reaction conditions.

X-ray absorption near edge spectroscopy followed the partial reduction of passivated supported $\mathrm{Mo}_{2} \mathrm{C}$ at reaction conditions (573 K, 30 bar), confirmed the presence of partially oxidized Mo during reaction and observed structural modification of $\mathrm{Rb}_{2} \mathrm{CO}_{3}$ caused by $\mathrm{Mo}_{2} \mathrm{C}$. Also, the ex situ XANES of air-free $\mathrm{Mo}_{2} \mathrm{C} / \alpha-\mathrm{Al}_{2} \mathrm{O}_{3}$ samples (prepared in glovebox) directly confirm the partial oxidation of oxophilic $\mathrm{Mo}_{2} \mathrm{C}$ caused by passivation with $1 \% \mathrm{O}_{2}$.

The IR spectrum of adsorbed CO revealed features at $2105 \mathrm{~cm}^{-1}$ and $2014 \mathrm{~cm}^{-1}$ on the unpromoted 2 wt.\% $\mathrm{Mo}_{2} \mathrm{C} / \gamma-\mathrm{Al}_{2} \mathrm{O}_{3}$ catalyst pretreated by 30 bar syngas at $573 \mathrm{~K}$. With added $\mathrm{Rb}_{2} \mathrm{CO}_{3}$, the IR features of adsorbed $\mathrm{CO}$ on $\mathrm{Mo}_{2} \mathrm{C}$ nanoclusters shifted substantially to lower frequencies $\left(\sim 200 \mathrm{~cm}^{-1}\right.$ shift from an unpromoted sample to a 10 wt.\% Rb-promoted sample), which correlated with the enhanced alcohol selectivity. Results from DFT qualitatively reproduced the trends observed by IR spectroscopy and were used to interpret the various features (Mo-top and C-top CO adsorption). The interaction of the $\mathrm{Rb}$ promoter and the $\mathrm{Mo}_{2} \mathrm{C}$ catalyst was facilitated by $\mathrm{H}_{2} \mathrm{O}$ added during catalyst pretreatment, and presumably by in situ formation of $\mathrm{H}_{2} \mathrm{O}$ during syngas reaction. According to DFT calculation, water can easily dissociate on the representative 
$\mathrm{Mo}_{2} \mathrm{C}$ surface, forming $\mathrm{OH}$ groups, which probably possess decent acidity. The basic $\mathrm{Rb}_{2} \mathrm{CO}_{3}$ promoter may interact with $\mathrm{Mo}_{2} \mathrm{C}$ by neutralizing the surface acidity, and hence preventing the potential secondary reaction paths and preserving the alcohols as primary products in CO hydrogenation, which can be reflected in the corresponding changes of product distribution in catalytic syngas conversion.

Bimetallic Co- $\mathrm{Mo}_{2} \mathrm{C} / \alpha-\mathrm{Al}_{2} \mathrm{O}_{3}$ catalysts were prepared by co-precipitation of the Co and Mo precursors, followed by drying, calcination, carburization and passivation. The addition of Co to Rb-promoted $\mathrm{Mo}_{2} \mathrm{C} / \alpha-\mathrm{Al}_{2} \mathrm{O}_{3}$ enhanced the overall reactivity of $\mathrm{Mo}_{2} \mathrm{C}$ catalysts, promoted the formation of higher alcohols over methanol, and effectively reduced the loss of alcohol selectivity at high CO conversion. The results from X-ray absorption spectroscopy revealed that the Co metal and Mo carbide domains on alumina, although very highly dispersed, were more reduced than their corresponding monometallic samples. Although direct interactions between Co and Mo were not observed spectroscopically, the reactivity patterns reported here clearly suggest a molecular-level interaction between Co and Mo.

The multi-product SSITKA revealed that the intrinsic TOF on the relatively "slow" $\mathrm{Mo}_{2} \mathrm{C}$ catalysts was in fact comparable to those on other active elements in $\mathrm{CO}$ hydrogenation such as Fe and $\mathrm{Rh}$. Consequently, the small coverage of the reactive intermediates on $\mathrm{Mo}_{2} \mathrm{C}$ surface was found to be the reason for its low apparent activity in $\mathrm{CO}$ hydrogenation. The addition of $\mathrm{Rb}_{2} \mathrm{CO}_{3}$ did not change the intrinsic rate of $\mathrm{CO}$ hydrogenation on $\mathrm{Mo}_{2} \mathrm{C}$, but substantially reduced the coverage of the reactive intermediates, which provided direct evidence for the previously-speculated site-blockage mechanism of the alkali metal promoter on the $\mathrm{Mo}_{2} \mathrm{C}$ catalyst. The SSITKA also 
demonstrated that the rate of the water-gas shift reaction on $\mathrm{Mo}_{2} \mathrm{C}$ was naturally faster than that of $\mathrm{CO}$ hydrogenation, which is consistent with the ever-present $\mathrm{CO}_{2}$ selectivity that was close to the stoichiometric maximum in $\mathrm{Mo}_{2} \mathrm{C}$-catalyzed syngas reaction.

In summary, given the abundant fundamental understanding on the nature of $\mathrm{Mo}_{2} \mathrm{C}$ catalyst obtained from this study, promoted $\mathrm{Mo}_{2} \mathrm{C}$ is perhaps not among the optimal choices for catalytic conversion of syngas towards higher alcohols because of:

1. Limited higher alcohol selectivity ( $<50 \%$ on a $\mathrm{CO}_{2}$-free basis);

2. A low coverage of active sites in CO hydrogenation;

3. Rapid water-gas shift compared to CO hydrogenation (which unproductively consumes $\mathrm{CO}$ )

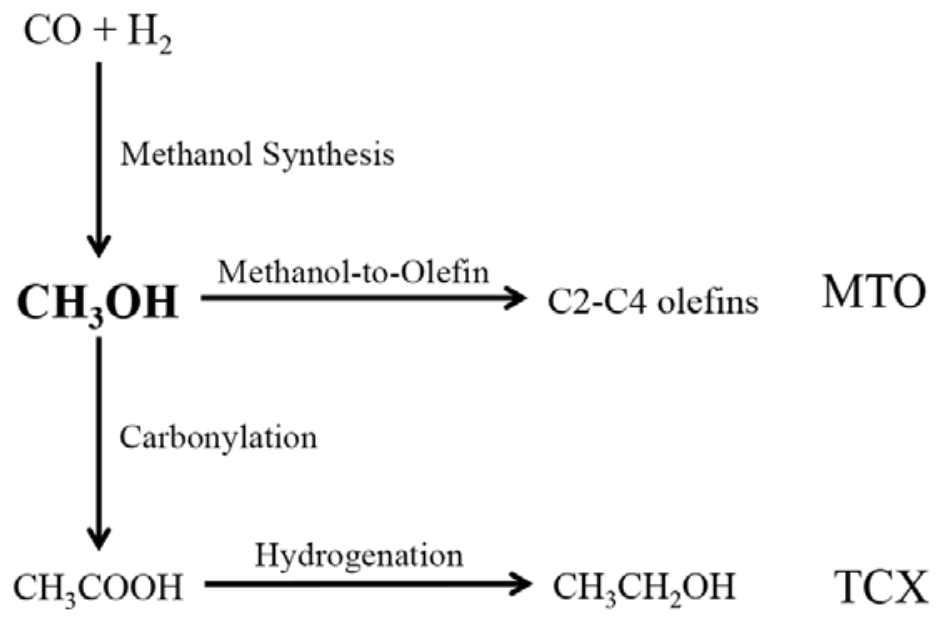

Figure 7.1 Syngas conversion (via methanol) towards C2-C4 olefins and ethanol.

\subsection{Future Work}

Given the difficulty in suppressing methanation and water-gas shift reactions, the direct syngas conversion towards desirable C2+ products on Mo-based catalysts is still problematic. In fact, the competitive processes via a methanol intermediate, although multi-step, are able to give almost 100\% carbon efficiency from syngas, such as UOP’s MTO [1] and Celanese's TCX [2], as shown in Figure 7.1. 
Indeed, it is difficult to obtain an as high carbon efficiency in an alternative process, but there is room to improve the design of the Mo-based catalysts for selective conversion of syngas, as are suggested below.

\subsubsection{Single-phase molybdenum-based bimetallic carbide catalysts for CO hydrogenation}

Since the mixed-phase $\mathrm{Co}-\mathrm{Mo}_{2} \mathrm{C}$ did not significantly improve $\mathrm{Mo}_{2} \mathrm{C}$ in higher alcohol synthesis [1], a reasonable alternative would be to use $\mathrm{Mo}_{2} \mathrm{C}$ as catalyst support for selective syngas conversion. In fact, $\mathrm{Mo}_{2} \mathrm{C}$-supported $\mathrm{Co}$ and $\mathrm{Ru}$ catalysts have been explored for Fischer-Tropsch synthesis [3]. Since Thompson and co-workers had reported superior activity of $\mathrm{Pt} / \mathrm{Mo}_{2} \mathrm{C}$ in the water-gas shift reaction compared to $\mathrm{Mo}_{2} \mathrm{C}$ [4], such synergy may also occur in CO hydrogenation. Unfortunately, according to Schaidle [5], $\mathrm{Mo}_{2} \mathrm{C}$-supported metal catalysts were not bifunctional in nature for $\mathrm{CO}$ hydrogenation, where the reaction seemed to take place on the supported metal sites and $\mathrm{Mo}_{2} \mathrm{C}$ sites independently.

Single-phase Co-Mo and Fe-Mo bimetallic carbides, however, may be worth exploring. The phase-pure bulk and supported $\mathrm{Co}_{3} \mathrm{Mo}_{3} \mathrm{C}\left(\mathrm{Fe}_{3} \mathrm{Mo}_{3} \mathrm{C}\right)$ can be synthesized by one-step [6,7] or two-step [8,9] topotactic methods from the mixed oxide via $\mathrm{Co}_{3} \mathrm{Mo}_{3} \mathrm{~N}\left(\mathrm{Fe}_{3} \mathrm{Mo}_{3} \mathrm{~N}\right)$, or by carbothermal hydrogen reduction from carbon-supported mixed oxide [10]. The catalytic conversion of syngas on alkali-metal-promoted $\mathrm{Mo}_{2} \mathrm{C}$ always produces substantial undesired $\mathrm{C} 1$ products $\left(\mathrm{CH}_{4}, \mathrm{CH}_{3} \mathrm{OH}\right.$ and $\left.\mathrm{CO}_{2}\right)$. The Co (or Fe) component may shift the selectivity towards $\mathrm{C} 2+$ products, given its stronger chain growth capacity and lower water-gas-shift activity than $\mathrm{Mo}_{2} \mathrm{C}$. Also, the phase uniformity may bring the synergetic effect between the two metals. 


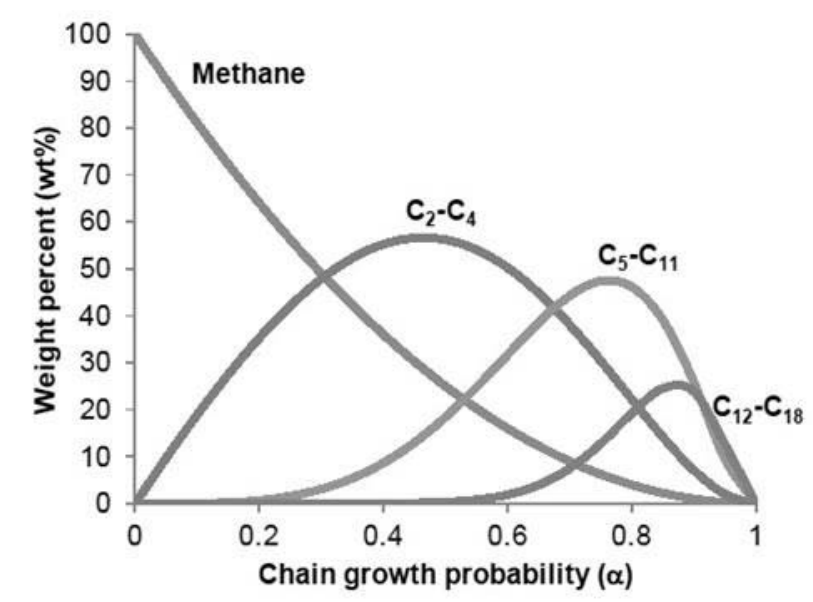

Figure 7.2 Product distribution predicted by the Anderson-Schulz-Flory model [11].

\subsubsection{Direct conversion of syngas to C2-C4 olefins}

As an alternative resource of C2-C4 olefins (typically from fluid catalytic cracking), methanol-to-olefin technology first produces methanol from syngas, then converts methanol into olefins [1]. Since syngas may have the potential for the direct production of olefins, there is still space to simplify the process from syngas to olefins. Recently, de Jong and co-workers reported an effective Fe-based catalyst for this process [11], where they claimed that the maximum selectivity achievable for the C2-C4 fraction is approximately 50 wt.\%, with a chain growth probability ( $\alpha$ ) between 0.4 and 0.5 , as shown in Figure 7.2. In fact, alkali metal promoted $\mathrm{Mo}_{2} \mathrm{C}$ has been studied for selective syngas conversion towards light olefins at ambient pressure [12]. Moreover, with cobalt being added to $\mathrm{Mo}_{2} \mathrm{C}$, the chain growth probability on $\mathrm{Mo}_{2} \mathrm{C}$ in $\mathrm{CO}$ hydrogenation can be increased from about 0.35 to about 0.5 , and the water-gas shift activity can be suppressed too some extent, as described earlier in Chapter 5. Given that cobalt and molybdenum were not optimally incorporated, there is still great potential to optimize the synthesis of bimetallic carbides and the reaction conditions that would lead to better selectivity of C2$\mathrm{C} 4$ olefins and to reduce formation of $\mathrm{C} 1$ products $\left(\mathrm{CH}_{4}\right.$ and $\left.\mathrm{CO}_{2}\right)$ in $\mathrm{CO}$ hydrogenation. 


\section{References of Section 7.2}

[1] M. Stöcker, "Methanol-to-hydrocarbons: catalytic materials and their behavior," Microporous and Mesoporous Materials 29 (1999) 3-48.

[2] A.H. Tullo, "Celanese takes an ethanol plunge," Chemical \& Engineering News 89 (2011) 20-21.

[3] A. Griboval-Constant, J.-M. Giraudon, G. Leclercq, L. Leclercq, "Catalytic behavior of cobalt or ruthenium supported molybdenum carbide catalysts for FT reaction,” Applied Catalysis A: General 260 (2004) 35-45.

[4] N.M. Schweitzer, J.A. Schaidle, O.K. Ezekoye, X. Pan, S. Linic, L.T. Thompson, "High activity carbide supported catalysts for water gas shift," Journal of the American Chemical Society 133 (2011) 2378-2381.

[5] J.A. Schaidle, "Carbide and nitride based catalysts for synthesis gas conversion," Ph.D., University of Michigan, 2011.

[6] X.-H. Wang, M.-H. Zhang, W. Li, K.-Y. Tao, "A simple synthesis route and characterisation of $\mathrm{Co}_{3} \mathrm{Mo}_{3} \mathrm{C}$," Dalton Transactions (2007) 5165-5170.

[7] X.-H. Wang, M.-H. Zhang, W. Li, K.-Y. Tao, "Synthesis and characterization of cobalt-molybdenum bimetallic carbides catalysts,” Catalysis Today 131 (2008) 111-117.

[8] S. Korlann, B. Diaz, M.E. Bussell, "Synthesis of bulk and alumina-supported bimetallic carbide and nitride catalysts," Chemistry of Materials 14 (2002) 40494058.

[9] S. Alconchel, F. Sapiña, E. Martínez, "From nitrides to carbides: topotactic synthesis of the $\eta$-carbides $\mathrm{Fe}_{3} \mathrm{Mo}_{3} \mathrm{C}$ and $\mathrm{Co}_{3} \mathrm{Mo}_{3} \mathrm{C}$," Dalton Transactions (2004) 2463-2468.

[10] C. Liang, W. Ma, Z. Feng, C. Li, "Activated carbon supported bimetallic CoMo carbides synthesized by carbothermal hydrogen reduction,” Carbon 41 (2003) 1833-1839.

[11] H.M. Torres Galvis, J.H. Bitter, C.B. Khare, M. Ruitenbeek, A.I. Dugulan, K.P. de Jong, "Supported iron nanoparticles as catalysts for sustainable production of lower olefins,” Science 335 (2012) 835-838.

[12] K.Y. Park, W.K. Seo, J.S. Lee, "Selective synthesis of light olefins from syngas over potassium-promoted molybdenum carbide catalysts," Catalysis Letters 11 (1991) 349-356. 


\section{Appendix A. Upgrade of steady-state isotopic transient kinetic analysis system for the multi-product purpose}

The information of the construction of multi-product SSITKA is summarized in

Table A.1.

Table A.1 Upgrades of conventional SSITKA for multi-product purposes

\begin{tabular}{|c|c|c|c|}
\hline Part & Quant. & Brand (part number) & Specification \\
\hline 34-port valve & 1 & Valco (EMT2CST16MWE) & N/A \\
\hline Sample loop & 16 & Valco (SL250CSTP) & $250 \mu \mathrm{L}$ \\
\hline Back-up sample loop & 16 & Valco (SL50CSTP) & $50 \mu \mathrm{L}$ \\
\hline Gas chromatography & 1 & SRI (8610C) & $\begin{array}{l}\text { Self-modified sampling valve } \\
\text { Max T: } 220^{\circ} \mathrm{C} \\
\text { FID, TCD }\end{array}$ \\
\hline GC packed column & 1 & HayeSep-D & $3.8 \mathrm{~mm}$ ID, $1.8 \mathrm{~m}$ length \\
\hline GC PLOT column & 2 & Restek (79716-273) & $\begin{array}{l}\text { SS PLOT } \\
\text { 3.5” coil } \\
\text { Max T: } 250^{\circ} \mathrm{C}\end{array}$ \\
\hline Methanizer & 1 & & 3/8” OD \\
\hline Methanation catalyst & $5 \mathrm{~g}$ & Sigma-Aldrich (311324) & $\begin{array}{l}5 \text { wt. } \% \mathrm{Pt} / \mathrm{Al}_{2} \mathrm{O}_{3} \\
40-100 \text { mesh, pelletized }\end{array}$ \\
\hline
\end{tabular}




\section{Appendix B.}

\section{List of Publications at University of Virginia}

[1] H. Shou, R.J. Davis, "Multi-product steady-state isotopic transient kinetic analysis of CO hydrogenation over supported molybdenum carbide," to be submitted to Journal of Catalysis.

[2] H. Shou, L. Li, D. Ferrari, D.S. Sholl, R.J. Davis, "Use of infrared spectroscopy and density functional theory to study the influence of rubidium on alumina-supported molybdenum carbide catalyst for higher alcohol synthesis from syngas," Journal of Catalysis 299 (2013) 150-161.

[3] H. Shou, D. Ferrari, D.G. Barton, C.W. Jones, R.J. Davis, "Influence of passivation on the reactivity of unpromoted and Rb-promoted $\mathrm{Mo}_{2} \mathrm{C}$ nanoparticles for $\mathrm{CO}$ hydrogenation,” ACS Catalysis 2 (2012) 1408-1416.

[4] H. Shou, R.J. Davis, "Reactivity and in situ X-ray absorption spectroscopy of Rbpromoted $\mathrm{Mo}_{2} \mathrm{C} / \mathrm{MgO}$ catalysts for higher alcohol synthesis," Journal of Catalysis 282 (2011) 83-93.

[5] K. Yin ${ }^{[+]}$, H. Shou ${ }^{[+]}$, D. Ferrari, C.W. Jones, R.J. Davis, "Influence of cobalt on rubidium-promoted alumina-supported molybdenum carbide catalysts for higher alcohol synthesis from syngas," Topics in Catalysis (2013), accepted. ${ }^{[+]}$Equal contribution.

[6] M.R. Morrill, N.T. Thao, H. Shou, R.J. Davis, D.G. Barton, D. Ferrari, P.K. Agrawal, C.W. Jones, "Origins of unusual alcohol selectivities over mixed MgAl oxide supported $\mathrm{K} / \mathrm{MoS}_{2}$ catalysts for higher alcohol synthesis from syngas," ACS Catalysis (2013), in review.

[7] L. Li, M.R. Morrill, H. Shou, D.G. Barton, D. Ferrari, R.J. Davis, P.K. Agrawal, C.W. Jones, D.S. Sholl, "On the relationship between Mo K edge energies and DFT computed partial charges," The Journal of Physical Chemistry C 117 (2013) 27692773.

[8] M.R. Morrill, N.T. Thao, P.K. Agrawal, C.W. Jones, R.J. Davis, H. Shou, D.G. Barton, D. Ferrari, "Mixed MgAl oxide supported potassium promoted molybdenum sulfide as a selective catalyst for higher alcohol synthesis from syngas,” Catalysis Letters 142 (2012) 875-881. 